\title{
A ATENÇÃO FARMACÊUTICA NA MELHORIA DO ATENDIMENTO ÀS GESTANTES SOROPOSITIVAS NO MUNICÍPIO DE ITAJAÍ (SC)
}

BENEDITO CARLOS CORDEIRO

Tese apresentada ao Programa de PósGraduação em Saúde Pública da Faculdade de Saúde Pública da Universidade de São Paulo para obtenção do Título de Doutor em Saúde Pública

Área de Concentração: Serviços de Saúde Pública

Orientadora: Profa. Dra. Nicolina Silvana Romano-Lieber

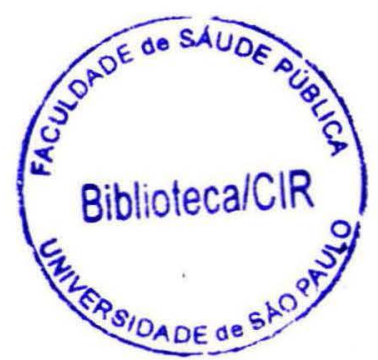

São Paulo 2007 
Autorizo exclusivamente para fins acadêmicos e científicos a reprodução total ou parcial desta tese, por processos fotocopiadores. Ao usá-lo, cite a fonte. Assinatura:

Data:

$$
4967212008 \text { dot }
$$




\section{PASSAGEM DA NOITE}

É noite. Sinto que é noite não porque a sombra descesse (bem me importa a face negra) mas porque dentro de mim, no fundo de mim, o grito se calou, fez-se desânimo. Sinto que nós somos noite, que palpitamos no escuro e em noite nos dissolvemos. Sinto que é noite no vento, noite nas águas, na pedra.

E que adianta uma lâmpada?

E que adianta uma voz?

É noite no meu amigo.

É noite no submarino.

É noite na roça grande. É noite, não é morte, é noite de sono espesso e sem praia. Não é dor, nem paz, é noite, é perfeitamente a noite
Mas salve, olhar de alegria! E salve, dia que surge! Os corpos saltam do sono, o mundo se recompõe. Que gozo na bicicleta! Existir: seja como for. A fraterna entrega do pão. Amar: mesmo nas canções. De novo andar: as distâncias, as cores, posse das ruas. Tudo que a noite perdemos se nos confia outra vez.

Obrigado, coisas fiéis! Saber que ainda há florestas, sinos, palavras; que a terra prossegue seu giro, e o tempo não murchou; não nos diluímos! Chupar o gosto do dia! Clara manhã, obrigado, o essencial é viver!

\section{Carlos Drummond de Andrade} Poeta e farmacêutico 


\section{Dedicatária}

Uma das dúvidas presentes em quase todas as gestantes que aceitavam fazer parte deste estudo era a possibilidade de que seus nomes viessem a ser divulgados. Apesar de todas as explicações e do Termo de Consentimento que elas assinavam, por vezes voltavam a perguntar sobre isso.

Como garantia, em conversa com uma delas, foi dito que, caso houvesse a necessidade de identificação, seria utilizado o nome de personagens em quadrinhos, flores, ou qualquer outro nome fictício. Ao saber disso, ela pediu que, em hipótese alguma, seu nome fictício fosse Rosa: ela achava a rosa perfeita demais, e ela não era assim: ela era apenas uma mulher, como todas as outras.

Em homenagem a esta mulher, e a todas as outras gestantes HIV positivas que participaram da pesquisa ou não, cada gestante foi identificada com o nome de uma flor, omitindo a Rosa. Realmente elas, como todos os seres humanos, não são perfeitas. Mas até por isso mesmo as lições de vida que dão são grandiosas, refletidas na beleza singela de uma flor. 


\section{Agradecimentas}

Lene e Lara, compreensão e motivos para lutar;

Fran, companheira (mesmo à distância - je t'adore);

Nicolina, admiração que só fez crescer com o passar dos anos;

Fernanda (extensivo a todos os funcionários do CEREDI), esperança de um dia poder retribuir a colaboração e o carinho;

A todas as pessoas que colaboraram com esta tese, da Secretaria Municipal de Saúde de Itajaí, 17a . Regional de Saúde e UNIVALI;

E, em especial, às "minhas" gestantes. 


\section{RESUMO}

Introdução. A profilaxia da transmissão materno-infantil do vírus HIV é conseguida com várias medidas, entre elas a terapia anti-retroviral. Necessita-se, porém, de estratégias para reduzir ao mínimo a incidência de novos casos e, entre estas, a Atenção Farmacêutica (seguimento farmacoterapêutico) parece capaz de apresentar resultados promissores aos pacientes aos quais é oferecida. Objetivo. Avaliar os resultados obtidos com o seguimento farmacoterapêutico de gestantes soropositivas. Metodologia. A amostra foi constituída das gestantes com HIV/AIDS atendidas por um Serviço de Atendimento Especializado em Doenças Sexualmente Transmissíveis e AIDS em Itajaí (SC) entre julho de 2006 a julho de 2007. Todas foram convidadas a fazer parte do estudo. Foi utilizado o Método Dáder como instrumento para o Seguimento Farmacoterapêutico e o questionário Simplified Medication Adherence Questionnaire (SMAQ) para a mensuração da adesão à terapia pelas gestantes, em dois momentos. Resultados. Foram acompanhadas 32 gestantes e identificados 38 Problemas Relacionados com Medicamentos (PRM) possíveis de serem solucionados, entre eles a falta de adesão (no momento 1 por $59,4 \%$ das gestantes). Seguidas pelo Método Dáder, foram sugeridas intervenções que resolveram 24 PRM e a adesão mensurada no segundo momento chegou a $75 \%(p<0,05)$. Foi possível ainda observar as características do pré-natal oferecido às gestantes e problemas na inter-relação entre a Atenção Básica e o Programa DST/AIDS. Conclusão. 0 seguimento farmacoterapêutico mostrou-se efetivo para a resolução de problemas advindos com o uso (ou pelo não uso) dos medicamentos quando associado a um trabalho multidisciplinar de atenção integral.

Palavras-chave: Atenção farmacêutica; adesão; HIV; AIDS; transmissão maternoinfantil; anti-retrovirais 


\section{SUMMARY}

Introduction. The prophylaxis of HIV vertical transmission is obtained with several measures, among them the anti-retroviral therapy. It is needed, however, some strategies to reduce to the minimum the incidence of new cases. Pharmaceutical Care (Pharmacotherapeutic Follow-up) seems capable to present promising results with this aim. Objective. To evaluate the outcomes of Pharmacotherapeutic Followup of HIV infected pregnant women. Methodology. The sample was constituted of the women taken care for a Specialized Assistance Service in Sexual Transmitted Diseases and AIDS in Itajaí (SC) during July 2006 to July 2007. All were invited to do part of the study. The Dáder Program was used as instrument for the Pharmacotherapeutic Follow-up and the questionnaire Simplified Medication Adherence Questionnaire (SMAQ) for the measure of the adherence, in two moments. Results. 32 pregnant women were followed-up. 38 Drug Related Problems (DRP) possible of being solved were identified, among them the lack of adherence (in the first moment, $59,4 \%$ of the sample). Followed by the Dáder Program, several interventions were suggested that solved 24 DRP and the adherence measured in the second moment arrived to $75 \%(p<0,05)$. Also, it was observed some characteristics of prenatal care and some problems in the interrelation between Primary Care and STD/AIDS Program. Conclusion. Pharmacoterapeutic Follow-up was shown effective for the resolution of problems with the use (and no use) of the drugs when associated with a multiteam work searching for integral attention.

Key-words: Pharmaceutical care; adherence; HIV; AIDS; mother-to-child transmission; antiretrovirals. 


\section{LISTA DE FIGURAS}

Figura 1. Número de gestantes HIV+ notificadas em Itajaí e na AMFRI no período 2000 - 2005

Figura 2. Número de casos de transmissão vertical ocorridos em Itajaí e AMFRI no período 2000-2004

Figura 3. Utilização de ARV em semanas por crianças nascidas de mães Infectadas pelo HIV no período $2000-2006$

Figura 4. Encerramento de caso em Itajaí e na AMFRI, no período 2000 -2006 .

Figura 5. Fluxograma do processo no Método Dáder 


\section{LISTA DE ABREVIATURAS}

$\mathrm{ABC}$ - Abacavir

ABS - Atenção Básica em Saúde

ACS - Agente Comunitário de Saúde

AIDS - Síndrome da Imunodeficiência Adquirida

AMFRI - Associação dos Municípios da Foz do Rio Itajaí

APV - Amprenavir

ARV - Anti-retrovirais

ATV - Atazanavir

AZT - Zidovudina

CYP 450 - Sistema Citocromo P-450

D4T - Estavudina

ddC - Zalcitabina

ddI - Didanosina

DLV - Delavirdina

DNA - Ácido Desoxi-ribonucléico

EAM - Evento Adverso com Medicamentos

EFZ - Efavirenz

ESF - Estratégia Saúde da Família

EUM - Estudos de Utilização de Medicamentos

HAART - Tratamento Anti-retroviral Altamente Ativo

HIV - Vírus da Imunodeficiência Humana

HIV+ - HIV Positiva

IDV - Indinavir

IF - Inibidor de Fusão

INNTR - Inibidor Não Nucleosídico da Transcriptase Reversa

INTR - Inibidor Nucleosídico da Transcriptase Reversa

IP - Inibidor da Protease

ISOAP (SOAP) - Informação Subjetiva, Objetiva, Avaliação e Plano de Ação

LPVr - Lopinavir/Ritonavir 
MS - Ministério da Saúde

NFV - Nelfinavir

NNT - Número de pacientes que é necessário tratar

NVP - Nevirapina

OMC - Organização Mundial do Comércio

PRM - Problemas Relacionados aos Medicamentos

PSF - Programa Saúde da Família

PWDT - Pharmacist's Workup of Drug Therapy

RAM - Reação Adversa aos Medicamentos

RNA - Ácido Ribonucléico

RNM - Resultados Negativos com Medicamentos

RTV - Ritonavir

SAE - Serviço de Atendimento Especializado

SINANW - Sistema Nacional de Agravos Notificáveis para Windows

SMAQ - Simplified Medication Adherence Questionnaire

SQV - Saquinavir

SUS - Sistema Único de Saúde

TARV - Terapia Anti-retroviral

TDF - Tenofovir

TMI - Transmissão Materno-Infantil

TOM - Therapeutic Outcomes Monitoring

UBS - Unidade Básica de Saúde

UDI - Usuários de Drogas Injetáveis

URM - Uso Racional de Medicamentos

WHO - Organização Mundial da Saúde 


\section{ÍNDICE}

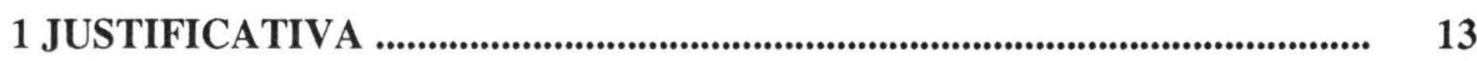

2 INTRODUÇÃO........................................................................................ 15

2.1 A AIDS como problema de saúde pública …………………………………….... 15

2.2 Transmissão Materno-Infantil ............................................................... 16

2.3 Medicamentos Anti-retrovirais...................................................................... 23

2.4 Acesso e custo dos medicamentos anti-retrovirais............................................ 25

2.5 Farmacoepidemiologia dos medicamentos anti-retrovirais............................. $\quad 28$

2.6 Uso Racional de Medicamentos - Adesão, Resistência e Interação

Medicamentosa entre os Anti-retrovirais ................................................... 29

2.7 Integralidade, Promoção da Saúde e o Programa de Saúde da Família -

PSF ...................................................................................................... 34

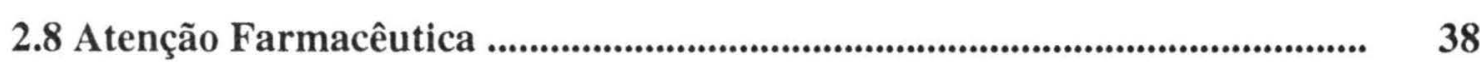

3 OBJETIVOS .......................................................................................... 42

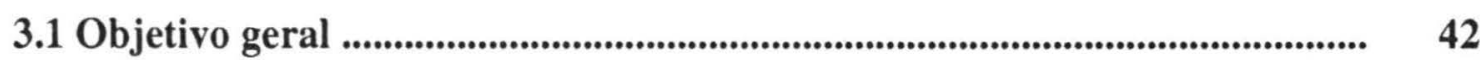

3.2 Objetivos específicos .................................................................................. 42

4 PROCEDIMENTOS METODOLÓGICO _.................................................... 43

4.1 Tipo de estudo ............................................................................................... 43

4.2 População do estudo ..................................................................................... 43

4.3 Método ….................................................................................................................. 44

4.3.1 Seguimento Farmacoterapêutico ………………...................................... 44

4.3.2 Adesão à Terapia ................................................................................................... 49

4.4 Delineamento do estudo ........................................................................... 50

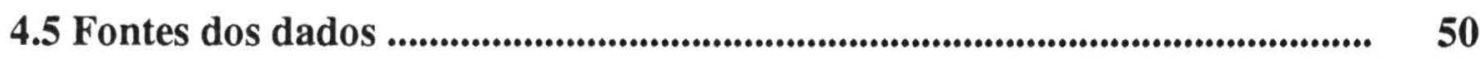

4.6 Análise dos dados e resultados ......................................................................

4.7 Considerações éticas ................................................................................................. 52

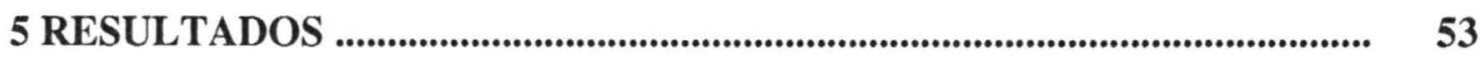

5.1 Descrição Individualizada dos Casos ......................................................... $\quad 54$

5.2 Artigo 1 - Perfil epidemiológico e características do pré-natal e do parto de mulheres com HIV/AIDS do município de Itajaí, SC .............................. $\quad 75$

5.3 Artigo 2 - Adesão ao uso de anti-retrovirais por gestantes HIV positivas 
e a Atenção Farmacêutica ................................................................................... $\quad 100$

5.4 Artigo 3 - Atenção Farmacêutica a gestantes com HIV/AIDS ...................... 123

5.5 Artigo 4 - A verticalidade entre o Programa DST/AIDS e a Estratégia

Saúde da Família em Itajaí (SC): um estudo de caso local ou a realidade brasileira? ............................................................................................................ 149

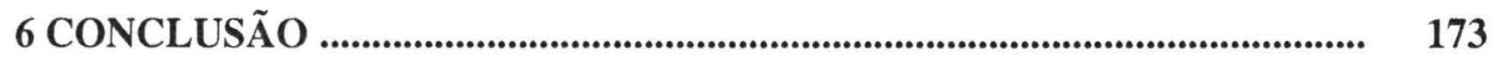

7 REFERÊNCIAS BIBLIOGRÁFICAS ............................................................... 175

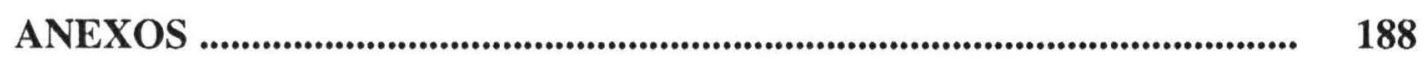

Anexo 1 - Método Dáder ................................................................................. 189

Anexo 2 - Normas para publicação do periódico Revista Brasileira de

Saúde Materno Infantil .................................................................................... 196

Anexo 3 - Normas para publicação do periódico Revista de Saúde

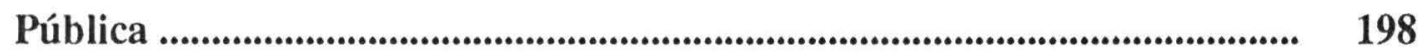

Anexo 4 - Normas para publicação do periódico Cadernos de Saúde

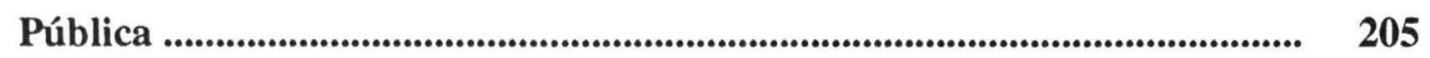

Anexo 5 - Normas para publicação do periódico Saúde e Sociedade ......... 208

Anexo 6 - Termo de Consentimento Livre e Esclarecido ............................. $\quad 210$

Anexo 7 - Cópia do parecer do Comitê de Ética em Pesquisa da FSP ...... $\quad 212$

Anexo 8 - Cópia do trabalho apresentado no II Congresso de Uso

Racional de Medicamentos ................................................................................ 213 


\section{JUSTIFICATIVA}

A AIDS (Síndrome da Imunodeficiência Adquirida) é uma doença que pode ser considerada a primeira pandemia contemporânea. Talvez por isso, sua aparição, em um momento de crença na sociedade moderna, na onipotência da ciência e na tão comentada globalização, trouxe consigo o medo e preconceitos (FONSECA 2005). Entretanto, por mais paradoxal que possa parecer, a resposta da humanidade a este flagelo foi impressionante: em pouquíssimo tempo, seu agente causal foi identificado, os modos de transmissão e a possibilidade de prevenção foram estabelecidos, se descobriram terapias e medicamentos cada vez mais eficazes contra a doença, sem considerar avanços sociais como a resposta governamental, da sociedade organizada e a preocupação com os direitos humanos (CORDEIRO 2001).

Apesar destes avanços, também a doença deu sinais de sua magnitude, em especial atingindo populações que, a princípio, pareciam estar imunes à síndrome. Isto se tornou mais dramático quando as mulheres passaram a ser contaminadas em uma proporção praticamente igual aos homens e, paralelo a isso, o aumento dos casos de transmissão vertical do vírus HIV (Vírus da Imunodeficiência Humana). O grande número de crianças infectadas, principalmente por esta via de contaminação, demonstra bem a vulnerabilidade deste grupo populacional.

Daí vem a primeira motivação para este estudo. Em especial para Itajaí, cidade que durante muito tempo liderou o ranking de incidência nacional, o estudo da infecção HIV/AIDS é não um tópico a mais para pesquisas, mas um compromisso social que a academia deve à sociedade.

A segunda motivação vem do envolvimento da profissão farmacêutica com esta questão. Historicamente, os farmacêuticos pouco se envolveram com o setor público, preferindo a iniciativa privada. Isto causou um viés na profissão, que não percebeu a possibilidade de se fazer saúde pública, mesmo em uma farmácia que tenha por finalidade o lucro. 
Após várias crises, a profissão descobriu, na Atenção Farmacêutica, uma forma de resgatar seu papel e comprometimento não mais com o medicamento, mas agora com o paciente. Como toda novidade, porém, seu início é tímido, havendo a necessidade de documentação das suas práticas e comprovação de sua efetividade.

A junção destas motivações deu origem a este tese. De acordo com Tobar e Yalour (2001, p. 21), tese "significa posição, é uma tomada de partido para solucionar um problema, o problema da pesquisa. Fazer uma tese é sustentar uma posição a respeito de uma determinada questão em uma determinada área do conhecimento". Essa é a presunção desse estudo: sustentar cientificamente uma posição. Uma posição que represente, antes de mais nada, o respeito para com o paciente, beneficiário principal de um novo paradigma para a profissão farmacêutica. 


\section{INTRODUÇÃO}

\subsection{A AIDS como problema de saúde pública}

A AIDS é uma infecção viral responsável por uma imunossupressão nas pessoas infectadas que se manifesta, segundo sua severidade, pelo aparecimento de doenças oportunistas, problemas neurológicos e afecções diversas (RACHID e SCHECHTER 1997).

Esta síndrome surgiu no Brasil em 1982, quando sete pacientes homo/bissexuais foram diagnosticados. A partir daí, sua difusão pode ser descrita em três fases, tanto geográfica quanto demograficamente. Inicialmente (anos 80), concentrada no eixo Rio de Janeiro-São Paulo e outras grandes cidades, estando praticamente restrita a homossexuais, bissexuais e pacientes que necessitaram de sangue e hemoderivados. Na segunda fase, nos primeiros anos da década de 90 , a epidemia atingiu cidades de médio porte, principalmente das regiões Sudeste, Sul e Centro-Oeste, e passou a apresentar um número expressivo de casos entre usuários de drogas injetáveis (UDI) e aumento de casos entre os heterossexuais. A terceira fase, que ainda estamos vivendo, caracteriza-se pela expansão da doença a todos os Estados, atingindo também municípios de pequeno porte, fenômeno conhecido como a "interiorização" da doença e pelo grande número de mulheres infectadas, ou a "feminilização" da doença (MS 1998; SOUZA JÚNIOR et al. 2004).

Outro fato digno de menção é que, nitidamente, percebe-se que a AIDS mudou de padrão neste trajeto, sendo reconhecida inicialmente como uma doença que atingia grupos economicamente mais fortes e conscientes de seus direitos, e apresentando agora um perfil indicativo de pauperização, com a imensa maioria dos infectados não possuindo nível superior de escolaridade.

Todos estes fatores, mas especialmente a "feminilização" da doença, trazem como conseqüência um dos problemas relacionados à AIDS que mais 
preocupam atualmente as autoridades sanitárias do país - a Transmissão MaternoInfantil (TMI) do vírus HIV (MS 2005a).

\subsection{Transmissão Materno-Infantil}

A prevalência do vírus HIV nas mulheres grávidas é um indicador para estimar a possibilidade de transmissão do vírus da mãe para seu filho. Tanto em Itajaí como na região da Associação dos Municípios da Foz do Rio Itajaí - AMFRI (que compreende os municípios de Balneário Camboriú, Bombinhas, Camboriú, Ilhota, Itajaí, Itapema, Luiz Alves, Navegantes, Penha, Piçarras e Porto Belo) observa-se também, em uma série histórica do ano 2000 ao ano 2005, um aumento expressivo no número absoluto de casos, conforme pode ser observado na Figura 1.

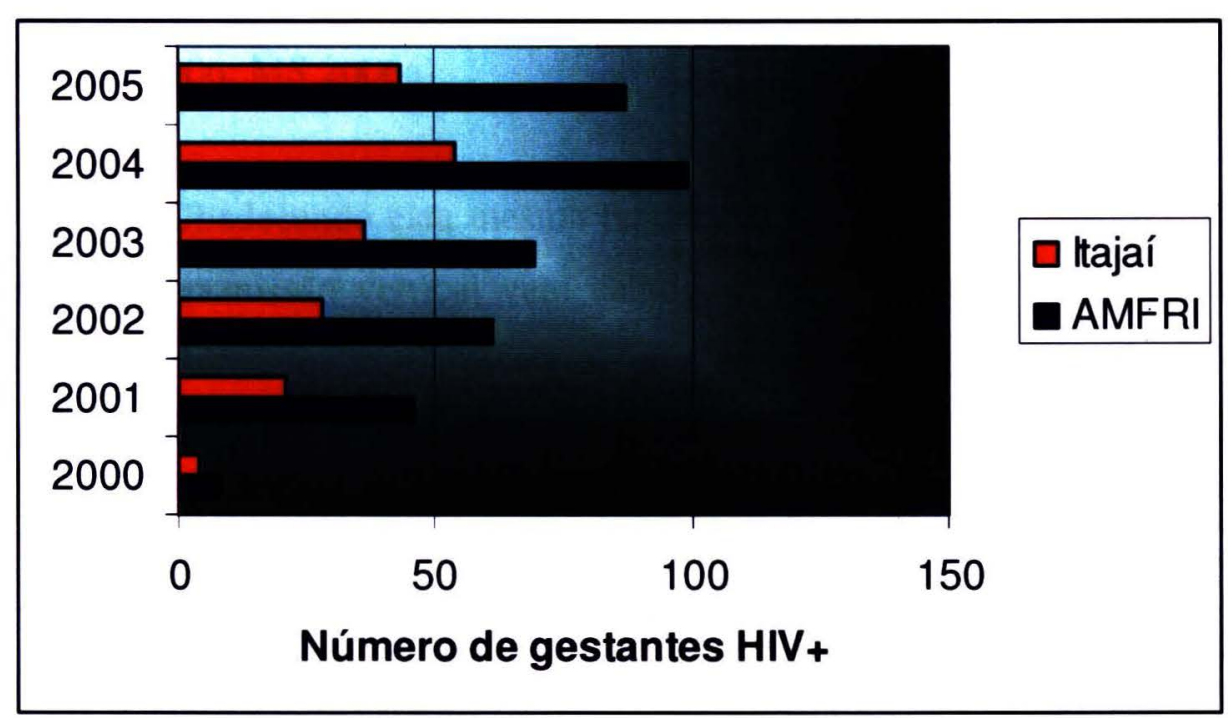

Figura 1. Número de gestantes HIV+ notificadas em Itajaí e na AMFRI no período $2000-2005$

Fonte: SINAN W, Investigação de Gestante HIV+, acessado em 04/09/2007

Estima-se, no Brasil, uma prevalência de $0,41 \%$ de infecção pelo HIV em gestantes, o que representa 12.456 recém-nascidos expostos ao HIV ao ano (MS 2006a). Ainda que o número de gestantes esteja aumentando, o Brasil vem reduzindo progressivamente a incidência de casos de transmissão vertical (BRITO et al. 2006), passando de percentuais próximos aos $90 \%$ da transmissão materno- 
infantil como causa da infecção em menores de 13 anos na década de 90 para 78,1\% em 2006 (MS 2006b).

Estas reduções, entretanto, desenvolvem-se em diferentes proporções no Brasil, sabendo-se as dimensões continentais e as imensas diferenças sócioeconômicas que se expressam entre as diversas cidades e regiões do país. Isto fica demonstrado a partir da informação de que, para o Brasil, 3,5\% das gestantes contaminadas pelo HIV transmitem o vírus para o seu filho, sendo que na região Norte do país este percentual alcança 15\% (MS 2005b). Segundo Matida et al. (2005), em São Paulo, houve um declínio de 389 casos reportados em 1997 para 160 em 2002, com queda na taxa de transmissão vertical de $9 \%$ em 2000 para 2,4\% em 2002, um número próximo ao de Santa Catarina em $2004(1,4 \%)$ e perto das metas do Ministério da Saúde, que seria levar este patamar para abaixo de 1\% (SANTA CATARINA 2006; MS 2006a).

Obedecendo esta mesma tendência, em Itajaí e na AMFRI o número de casos de transmissão vertical vem caindo, como observado na Figura 2. Estes dados devem ser vistos com ressalvas, pois apesar de serem relativos a 2004 e acessados em 2007, sempre existe a possibilidade de serem posteriormente alterados em função do período necessário para a confirmação da infecção. 


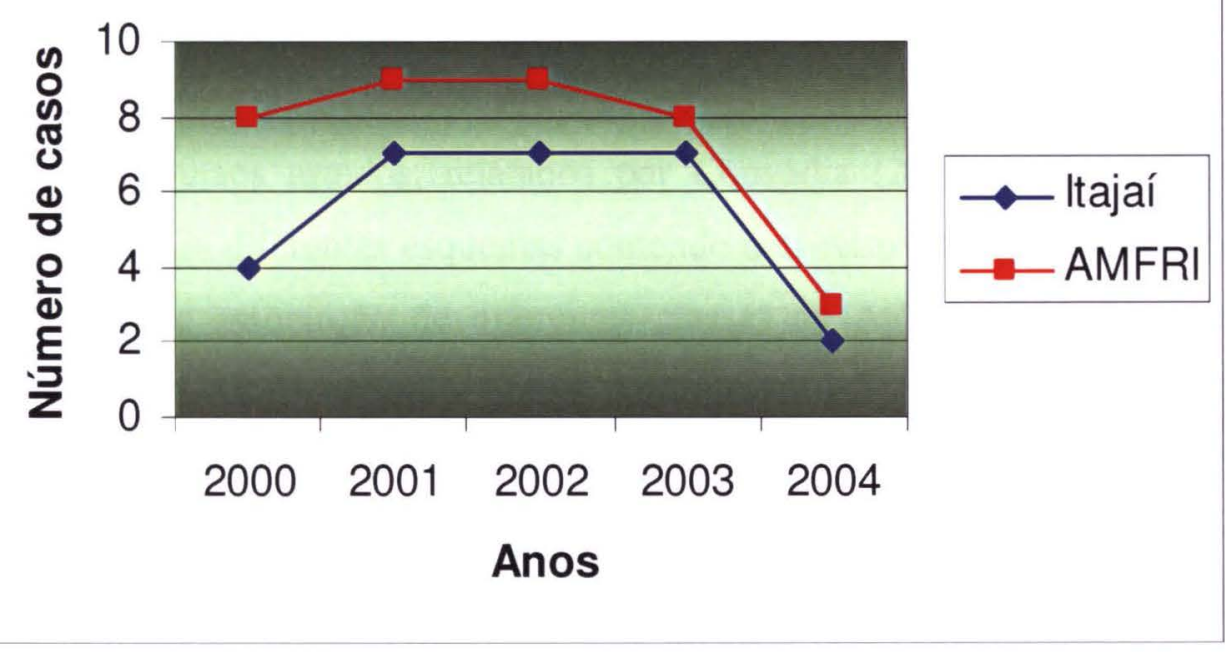

Figura 2. Número de casos de transmissão vertical ocorridos em Itajaí e AMFRI no período 2000-2004

Fonte: SINAN W, Investigação de AIDS em < 13 anos, acessado em $27 / 07 / 2007$

Para esta queda, contribuiu o conhecimento dos diferentes mecanismos de transmissão do vírus da mãe para seu filho. Ela ocorre durante a gestação, o parto e a amamentação. Entre os fatores associados à TMI devem ser destacados: a carga viral materna, a ruptura prolongada das membranas amnióticas, a presença de infecção sexualmente transmissível, o tipo de parto, a prematuridade e o uso de drogas (SOUZA JÚNIOR et al. 2004).

A partir da divulgação do PACTG 076 - Protocolo 076 do Pediatric Aids Clinical Trials Group - em 1994, seguido também pelo Brasil (MS 2006c), conhece-se a importância da utilização da Zidovudina (AZT) pela gestante infectada e pelo recém-nascido, durante as primeiras semanas de vida. Portanto, a utilização da terapia anti-retroviral (TARV) pode causar uma redução da carga viral materna para níveis não detectáveis, reduzindo assim o risco da transmissão a níveis muito baixos.

Isto é o que afirma Kuchenbecker (2004, p. 457), ao dizer que a "eficácia de anti-retrovirais para a prevenção da TMI do HIV tem grande magnitude, 
correspondendo a NNT (Number Needed to Treat) de aproximadamente 5 gestantes tratadas para evitar-se a infecção em um recém-nascido".

Diversos estudos, relatados por Coovadia (2004) e Volmink et al. (2007), compararam diferentes esquemas contendo anti-retrovirais (ARV), chegando à conclusão que a associação de diferentes classes de ARV, com pelo menos 3 medicamentos (HAART - Highly Active Antiretroviral Therapy) é a mais eficaz, apesar de ser dificilmente empregada em países em desenvolvimento. Estes mesmos autores, entretanto, alertam que os medicamentos utilizados para a profilaxia da TMI poderiam ser menos efetivos em uma gravidez subseqüente ou no manejo clínico do tratamento da própria mãe ou do seu filho, que pode se tornar infectado apesar da profilaxia.

Também se desconhece o que representa para a mãe a utilização destes medicamentos. A presença ou não de reações adversas, dificuldades na utilização dos anti-retrovirais, por exemplo, normalmente ou não são estudadas ou são tratadas com certo desdém em função da importância que o uso destes insumos adquire na transmissão materna do vírus (EL BEITUNE et al. 2003).

O aumento da incidência de casos de TMI, resultante da expansão do número de casos de AIDS entre as mulheres, pode ser combatido desde que haja infra-estrutura da Atenção Básica de Saúde (ABS), passando pelo aconselhamento e realização de sorologia para o HIV no pré-natal, a administração do AZT só ou combinado com outros ARV para as gestantes infectadas, a administração do AZT durante o trabalho de parto e no pós-parto para os recém-nascidos e a substituição do aleitamento materno, sendo todos estes procedimentos disponíveis de forma universal e gratuita a toda a população brasileira (MS 2006c).

Ao analisarem-se os dados obtidos através do SINAN W, observa-se que, de um total de 232 gestantes atendidas em Itajaí no período compreendido entre 01/01/2000 até 31/12/2006, somente uma gestante amamentou seu filho, enquanto um outro sofreu amamentação cruzada. Na AMFRI, para este mesmo período, houve 
o acréscimo de apenas mais uma criança amamentada por sua mãe, originando, para um total de 449 gestantes, percentual abaixo de $1 \%$.

Para obter o convencimento da gestante a não amamentar, é importante o oferecimento da fórmula infantil substitutiva do leite materno. Além disso, o serviço de saúde deve procurar ajudar na inibição mecânica ou química da lactação, assim como oferecer suporte para que a mulher não se sinta discriminada por não estar amamentando (MS 2006d).

Outra providência necessária para a profilaxia da transmissão materno-infantil é a utilização, pela criança, da TARV por no mínimo seis semanas após o parto. Para este quesito, pode-se visualizar como Itajaí e a região da AMFRI se comportam, conforme a Figura 3.

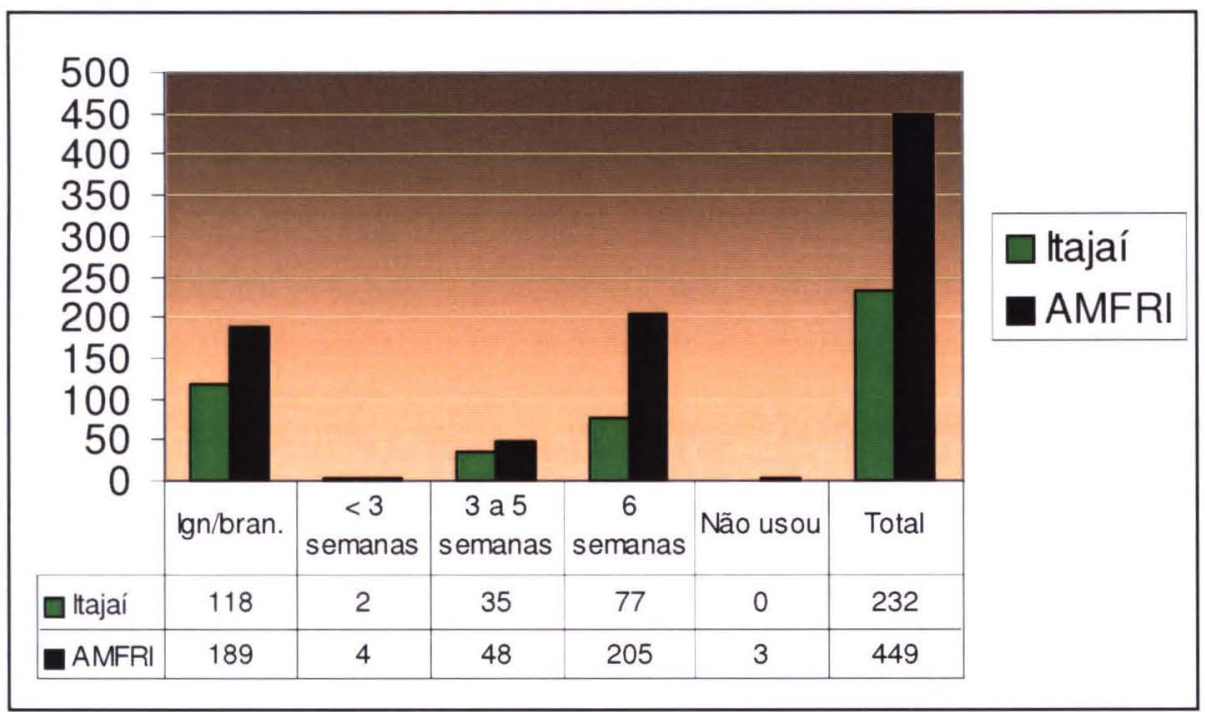

Figura 3. Utilização de ARV em semanas por crianças nascidas de mães Infectadas pelo HIV no período 2000 - 2006

Fonte: SINAN W, Investigação de Gestante $\mathrm{HIV+}$, acessado em 03/09/2007

$\mathrm{O}$ recém nascido de gestante HIV+ (HIV Positiva) necessita receber solução oral nas primeiras 2 horas após o nascimento (ou preferencialmente ainda na sala de parto), devendo ser estendido seu tratamento $-2 \mathrm{mg} / \mathrm{kilo} / \mathrm{dose}$ de seis em seis horas ou $4 \mathrm{mg} / \mathrm{kilo} /$ dose de $12 \mathrm{em} 12$ horas - durante as primeiras seis semanas de 
vida (MS 2006b). Infelizmente os dados obtidos junto ao SINAN apresentam um percentual muito elevado de ignorados/brancos, demonstrando a dificuldade em se trabalhar com estes dados. De qualquer modo, somados os percentuais inferiores às seis semanas e daqueles pacientes que não usaram a medicação $(15,94 \%$ em Itajaí e $12,02 \%$ na AMFRI), observa-se um número elevado de crianças que não estão sendo tratadas conforme o consenso brasileiro, devendo o município e região desenvolver políticas de proteção para o recém-nascido exposto ao HIV.

Para isto, é importante que essa criança seja acompanhada após a alta da maternidade, seja por uma Unidade Básica de Saúde (UBS) ou pelo serviço de referência, observando-se intercorrências devido ao uso dos medicamentos ou sinais e sintomas que possam ser potencialmente atribuídos à infecção pelo HIV, principalmente as alterações de desenvolvimento e crescimento da criança. Para a detecção da transmissão, deve-se solicitar exames de contagem da carga viral entre 1 e 6 meses. Se este primeiro exame apresentar resultado indetectável, colher uma segunda amostra após o quarto mês de vida. Se o primeiro resultado for detectável, deve ser solicitado um segundo exame imediatamente após receber o primeiro resultado (MS 2006a).

Caso a criança tenha as duas cargas indetectáveis, deve ser feita uma sorologia após os 12 meses de idade; se este resultado for negativo, a criança será considerada não infectada. Se a segunda carga viral for detectável, deve-se realizar imediatamente um terceiro exame que, se for positivo, fará com que a criança seja considerada infectada (MS 2006a).

A sorologia Anti-HIV final aponta poucos casos de transmissão vertical em Itajaí e AMFRI. Porém, mais uma vez, é preocupante o expressivo número de ignorados/brancos, que podem mascarar as conclusões a serem tomadas. Já o encerramento do caso, isto é, a notificação da condição sorológica da criança, é fundamental para a vigilância epidemiológica da transmissão vertical do HIV. Os números relativos a Itajaí e à AMFRI são apresentados na Figura 4. 


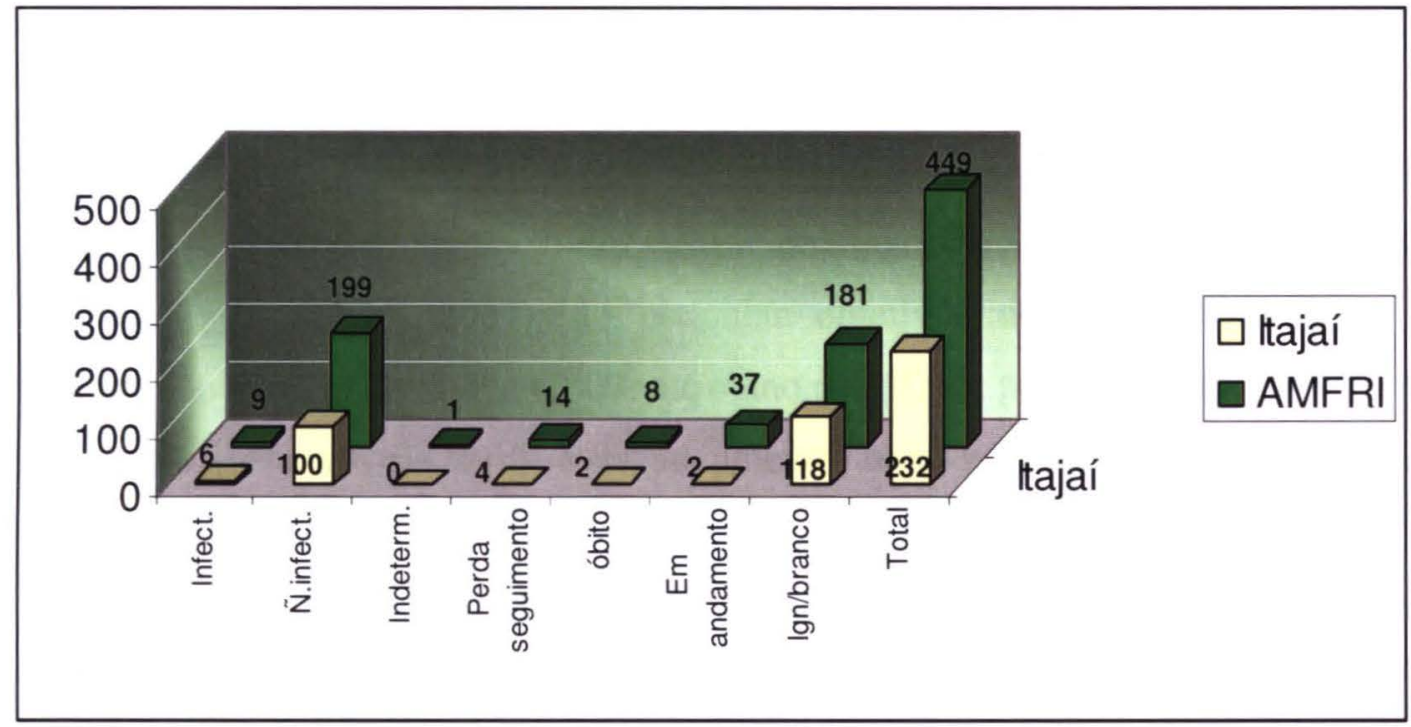

Figura 4. Encerramento de caso em Itajaí e na AMFRI, no período 2000 - 2006 Fonte: SINAN W, Investigação de Gestantes HIV, acessado em 03/09/2007

Por este gráfico, observa-se que, no período 2000 a 2006, 6 crianças foram infectadas pelo HIV através da transmissão vertical. Entretanto, quando se compara este gráfico com o gráfico 2 , observa-se uma discordância quanto a este número de infectados, o que poderia ser explicado pelo fato cada figura ser derivada de uma base de dados diferente.

Seja como for, os resultados encontrados sugerem o acerto da política de prevenção da transmissão vertical do HIV no Brasil. Se for levada em consideração que os ARV são a principal estratégia desta prevenção, e que seus custos representam aproximadamente $5 \%$ dos custos totais da profilaxia (PLUCIENNIK 2003), e se for considerado ainda o que representa um paciente com AIDS, em termos econômicos e em relação à qualidade de vida desta pessoa, muito mais louvável ainda será esta estratégia, de forma complementar a outras atividades a serem oferecidas pelos serviços.

Assim, tanto em função dos altos investimentos feitos pelo Estado brasileiro no fornecimento gratuito da TARV, quanto em função da possibilidade de resistência a estes medicamentos, o entendimento de sua utilização é extremamente importante para uma política que vise enfrentar a epidemia de AIDS em nosso país, 
até como forma de resposta à sociedade pelo investimento no tratamento da AIDS em detrimento de outras patologias mais prevalentes (TEIXEIRA 2003).

Recentemente, todos estes pressupostos foram reafirmados pelo Ministério da Saúde (2007), ao estipular objetivos definidos de redução da transmissão vertical do HIV em 30\% até o ano de 2009 e, posteriormente, novamente mais 30\% até o ano de 2011. Este documento, objetivamente, propõe aumentar a cobertura da testagem para o HIV no pré-natal e ampliar a cobertura das ações de profilaxia da transmissão vertical do HIV em gestantes, parturientes e em crianças expostas, a partir da definição de metas específicas e da definição das responsabilidades entre os três níveis de governo.

\subsection{Medicamentos Anti-retrovirais}

Se no início dos anos 80 a AIDS apresentava altos coeficientes de letalidade e a expectativa de vida de um paciente era estimada em 13 meses (HARDY et al. 1986), ela foi mudando seu comportamento com o passar do tempo e com as novas descobertas científicas. Hoje, há praticamente consenso de que é possível o prolongamento da vida com razoável qualidade por muitos anos. Para isso em muito contribuiu a utilização de uma TARV cada vez mais numerosa que, entretanto, ainda gera controvérsias relacionadas, apenas para citar alguns fatores, com acesso, custos, adesão, resistência e toxicidade (FONSECA 2005).

Existem hoje diversos fármacos ARV, sendo que estes podem ser divididos em classes. Entre estas, as principais são os Inibidores Nucleosídicos da Transcriptase Reversa (INTR); os Inibidores Não Nucleosídicos da Transcriptase Reversa (INNTR); os Inibidores da Protease (IP) e Inibidores da Fusão (IF).

Os INTR interrompem as fases precoces do vírus ao fazer cópias de si mesmo. Estes fármacos podem atrasar a disseminação do vírus pelo corpo e o início das infecções oportunistas. Inibem a replicação do vírus HIV bloqueando a enzima transcriptase reversa que age copiando o RNA viral em DNA. Nesta classe 
encontram-se a Zidovudina (AZT); Didanosina (ddI); Estavudina (d4T); Lamivudina (3TC); Zalcitabina (ddC) e Abacavir (ABC). Há, ainda, o Tenofovir (TDF), na realidade um inibidor nucleotídico da transcriptase reversa, aqui incluído por apresentar praticamente o mesmo mecanismo de inibição enzimática dos outros INTR (BARTLETT e GALLANT 2003).

Os INNTR têm como principal vantagem sobre os nucleosídicos não necessitarem de uma etapa inicial de ativação intracelular, a fosforilação. Os INNTR não interagem com o sítio ativo da transcriptase reversa, mas sim com o sítio de ligação alostérico. Os representantes desta classe são a Delavirdina (DLV), Nevirapina (NVP) e o Efavirenz (EFZ) (BARTLETT e GALLANT 2003).

Os IP interrompem a replicação do vírus numa parte mais avançada do ciclo. São metabolizados pelo sistema citocromo P-450 (CYP 450) sendo por isso susceptíveis à interação não apenas entre os vários fármacos desta classe, mas também com outros fármacos que atuam como inibidores ou indutores deste sistema enzimático. Agem no último estágio de formação do HIV, impedindo a ação da enzima protease, fundamental para a clivagem da cadeia protéica produzida pela célula em proteínas virais e enzimas que formarão o núcleo de cada partícula do HIV. Os IP são o Ritonavir (RTV); Saquinavir (SQV); Indinavir (IDV); Nelfinavir (NFV); Amprenavir (APV) e Lopinavir/Ritonavir (LPV/r) (BARTLETT e GALLANT 2003).

Os IF impedem que a membrana do vírus HIV funda-se com a membrana celular, impedindo que o material genético (RNA) do vírus possa entrar na célula e iniciar a replicação. Atualmente, há somente um IF disponível: o Enfuvirtide (BARTLETT e GALLANT 2003).

Os dados epidemiológicos relacionados à doença a partir da década de 90, mostram uma diminuição na mortalidade e nas internações hospitalares por AIDS comparada aos anos anteriores, provavelmente associada ao uso dos "coquetéis" para 
a doença, ou terapia antiretroviral combinada - em inglês, HAART - Highly Active Antiretroviral Therapy (MS 2006b).

A eficácia da TARV no tratamento da AIDS está bem demonstrada, conforme a literatura específica já demonstrou (PALELLA et al. 1998). Segundo Kuchenbecker (2004), os ARV têm efeito em diversos desfechos primordiais, incluindo entre estes a redução da mortalidade por AIDS (evidência de nível I). Os medicamentos empregados nesta terapia, entretanto, são relativamente caros, e cada vez mais pesquisadores vêm se utilizando de estudos econômicos para avaliar seus custos.

\subsection{Acesso e custo dos medicamentos anti-retrovirais}

Com cada vez mais medicamentos anti-retrovirais tornando-se disponíveis, com inovações a um custo cada vez maior, o que gera inclusive disputas internacionais entre o Brasil e as indústrias multinacionais, faz-se necessário um maior rigor na utilização destes medicamentos (KUCHENBECKER 2004). Deste modo, cada vez mais se justifica a análise e estudo do consumo destes medicamentos, posto que representam importante ferramenta para o combate da infecção, seja pelo óbvio papel no tratamento dos doentes, seja pelo auxílio na prevenção de novos casos, fator por vezes pouco comentado. Em especial, o Brasil é apontado como exemplo no mundo, ao ampliar o acesso e apresentar resultados interessantes na redução dos custos destes medicamentos.

A questão do acesso aos ARV, incluindo sua distribuição de forma gratuita, se torna, portanto, essencial. Isto tem gerado muita discussão, em especial nos países desenvolvidos, que alegavam quatro motivos contrários à distribuição gratuita desses medicamentos nos países em desenvolvimento: 1. a insuficiência dos conhecimentos científicos relacionados à eficácia da terapia no contexto sanitário destes países; 2 . a complexidade dos tratamentos, que devem ser seguidos por toda a vida do paciente, exigindo um acompanhamento médico normalmente não realizado nestes países; 3. a necessidade de um bom nível de desenvolvimento da infra- 
estrutura sanitária para a realização do tratamento; e 4. os custos tornar-se-iam proibitivos. Todos estes aspectos resultariam num risco importante de aparecimento de resistência viral e do deslocamento de recursos necessários à prevenção para um tratamento provavelmente não eficiente (NDOYE et al. 2002).

No Brasil, o fato da AIDS ter atingido grupos privilegiados no início de sua trajetória, associado a outros fatores, o principal deles a implantação do Sistema Único de Saúde (SUS), trouxe consequiências político-econômicas importantes, sendo talvez a maior delas o fornecimento gratuito e universal dos medicamentos para as pessoas infectadas pelo HIV, conforme legislação específica (BRASIL 1996).

Esse compromisso assumido pelo país junto às pessoas que vivem com AIDS vem sendo cumprido, já que relatos demonstram que não faltam ARV em mais de $95 \%$ dos serviços. Esta disponibilização universal dos ARV, contudo, ainda não se refletiu para todos os outros medicamentos, encontrando-se eventuais faltas daqueles necessários ao tratamento ou profilaxia de infecções oportunistas (MELCHIOR et al. 2006), e para grupos de pacientes com outras patologias, que ainda não têm pleno acesso aos medicamentos no Brasil.

Independente desta questão, esta política determinou aos gestores responsáveis pelo sistema de saúde, nos níveis municipal, estadual e federal, novas prioridades na condução do setor. O relatório da Comissão Parlamentar de Inquérito dos Medicamentos (BRASIL 2000) ao descrever a execução orçamentária dos programas que envolviam medicamentos do Ministério da Saúde, para o ano de 1999, revela essas novas prioridades. Assim, do total de 925 milhões de reais despendidos com aqueles programas, cerca de $66 \%$ (610,4 milhões de reais) foram destinados ao Programa de Medicamentos Estratégicos. Detalhando-se estes gastos verifica-se que, daquele total, 486,8 milhões de reais $(79,7 \%)$ foram destinados ao Programa de DST/AIDS enquanto 87 milhões de reais (14,3\%) foram dispensados ao Programa de Hemoderivados e 7,1 milhões $(1,2 \%)$ ao Programa de Hanseníase. Ou 
seja, por estes números, percebe-se que no ano de 1999 mais de $50 \%$ dos valores gastos com medicamentos pelo Ministério da Saúde foram com os anti-retrovirais.

A Tabela 1 apresenta dados atualizados dos gastos com medicamentos pelo Ministério da Saúde, inclusive com a proposta de orçamento para 2008.

Tabela 1. Série histórica dos gastos com medicamentos ${ }^{1}$ pelo Ministério da Saúde e orçamento para 2008 (em milhões de Reais).

\begin{tabular}{|c|c|c|c|c|c|c|c|c|}
\hline Programa & 2003 & 2004 & 2005 & 2006 & 2007 & $\%$ & 2008 & $\%$ \\
\hline \multirow[t]{2}{*}{ Medicamentos } & & & & & & $2003-$ & & 2003 . \\
\hline & & & & & & 2007 & & 2008 \\
\hline Estratégicos* & 231.584 & 790.309 & 681.000 & 690.000 & 721.050 & 211,4 & 153.000 & $-33,9$ \\
\hline Básicos** & 176.800 & 248.542 & 228.020 & 290.000 & 315.000 & 78,2 & 893.000 & 405,1 \\
\hline Excepcionais*** & 516.000 & 813.833 & 1.147 .422 & 1.355 .000 & 1.580 .000 & 206,2 & 1.980 .000 & 283,7 \\
\hline AIDS & 516.000 & 516.000 & 550.000 & 960.000 & 984.000 & 90,7 & 1.013 .000 & 96,3 \\
\hline Imunobiológicos & 250.000 & 480.590 & 550.000 & 750.000 & 783.750 & 213,5 & 882.500 & 253,0 \\
\hline Coagulopatias & 222.000 & 207.840 & 223.000 & 244.000 & 280.000 & 26,1 & 300.000 & 35,1 \\
\hline Total & 1.912 .384 & 3.057 .114 & 3.379 .442 & 4.289 .000 & 4.663 .800 & 143,9 & 5.221 .500 & 173,0 \\
\hline
\end{tabular}

Adaptado de: Departamento de Assistência Farmacêutica/Ministério da Saúde ${ }^{1}$

* Medicamentos Estratégicos: Engloba os medicamentos para endemias, financiados centralizadamente pelo Ministério da Saúde.

**Medicamentos Básicos: Medicamentos destinados a tratar agravos no âmbito da atenção básica.

***Medicamentos Excepcionais: Dependem de pactuação na Comissão Intergestores Tripartite, mediante a regulação fornecida por dados das Autorizações de Procedimentos de Alta Complexidade/Alto Custo (APAC) e critérios técnicos definidos na Portaria 2.577, de outubro de 2006.

Ainda que em termos absolutos a despesa do Ministério da Saúde com os ARV tenha se elevado em mais de $90 \%$ entre os anos 2003 e 2007, percentualmente estes medicamentos passaram a contabilizar pouco mais de $20 \%$ do total investido em medicamentos em 2007. Apesar desta redução, estes números ainda representam elevadas somas monetárias, já que no mesmo período a observação dos gastos do Ministério da Saúde com medicamentos saltou de 5,8\% em 2003 para $12,3 \%$ em $2007^{1}$.

\footnotetext{
${ }^{1}$ Dados fornecidos pela Diretoria de Assistência Farmacêutica (DAF) do Ministério da Saúde
} 
Sabe-se que estes valores representam economia pela não ocorrência de doenças oportunistas e internações, e que o tratamento, considerado exemplar no Brasil, ainda dificulta a disseminação da doença. Porém, dados retirados do site do Programa Nacional DST/AIDS demonstravam que em junho de 2005, havia 161.000 pacientes recebendo os ARV.

Isto posto, a questão da sustentabilidade do Programa coloca-se como crucial e historicamente tem gerado vários enfrentamentos entre o governo brasileiro e as indústrias produtoras dos ARV, tanto no Brasil como em organismo internacionais como a Organização Mundial do Comércio - OMC (PORTELA e LOTROWSKA 2006), chegando inclusive ao licenciamento compulsório do Efavirenz em 2007.

\subsection{Farmacoepidemiologia dos medicamentos anti-retrovirais}

Não se pode ainda esquecer da possibilidade de eventos adversos que estes medicamentos podem produzir. Durante muito tempo, como não havia outras alternativas terapêuticas, convivia-se com os ARV e seus efeitos colaterais, em função de querer-se prolongar a vida das pessoas doentes. Entretanto, a partir da colocação no mercado de uma gama maior destes medicamentos, e da possibilidade de aumento da expectativa de vida daqueles pacientes, passou-se a procurar uma melhor qualidade de vida, o que implica na busca da redução das reações adversas a esses medicamentos.

$\mathrm{O}$ número de reações adversas atribuído aos ARV tem aumentado desde a aprovação de seu uso, entre os quais podem ser citadas a hiperlipidemia, acidose láctica, resistência à insulina, lipodistrofia, hepatotoxicidade e desordens

hematológicas. Algumas destas são potencialmente sérias e podem limitar a capacidade ou mesmo a cooperação dos pacientes para continuar o tratamento. De qualquer modo, relações causais bem definidas em alguns casos e controversas em outros continuam a ser descritas (BARTLETT e GALLANT 2003). 
Considerando, ainda, que em função da urgência, muitos dos ARV não passaram por todos os testes clínicos exigidos normalmente para a comercialização dos medicamentos (FLIEGER 1995; ANGELL 2007), muito mais importante se faz nestes casos o estudo pós-comercialização, ou seja, farmacovigilância.

Portanto, como a prática clínica destes medicamentos ainda está sendo construída, sem que se conheça exatamente como se dá a relação médicos / ARV / pacientes, assim como a interferência do farmacêutico neste processo, estudos como hábitos de prescrição, dispensação e consumo, entre outros (os chamados Estudos de Utilização de Medicamentos - EUM), possibilitariam esclarecimentos quanto aos diversos aspectos relacionados ao seu uso como, por exemplo, a utilização de protocolos terapêuticos nesta área (LAPORTE e TOGNONI 1993).

\subsection{Uso Racional de Medicamentos - Adesão, Resistência e Interações Medicamentosas entre os Anti-retrovirais}

A definição de Uso Racional de Medicamentos (URM), afirma que este é alcançado "quando o paciente recebe o medicamento apropriado a suas necessidades clínicas, por período de tempo e em doses adequadas a ele e com o menor custo possível para ele e sua comunidade" (WHO 1986). A utilização de medicamentos considerada ótima, portanto, envolve considerações clínicas e econômicas, relativizando algumas vezes as questões individuais e enfatizando os reflexos sociais de seu uso (LEITE e CORDEIRO 2007).

Considerando-se que a globalização está ocasionando simplificações na desregulação e desburocratização de registros de novos fármacos em países periféricos, e ainda o crescimento do mercado farmacêutico, com a incorporação e fusão de empresas, a extinção de patentes de muitos fármacos e a consequiente entrada no mercado dos genéricos, torna-se premente a incorporação do conceito acima no uso dos medicamentos (BARROS 2004). 
O Uso Racional de Medicamentos envolve, principalmente, o prescritor e o paciente. É na interação entre estes atores que se dá fundamentalmente a utilização dos medicamentos, sendo ainda de grande importância o dispensador do medicamento, como mais um filtro para eliminar problemas tais como a falta de adesão à terapia (MARIN et al 2003).

Não há um conceito universalmente aceito para a adesão à terapia. Sabaté (2003, p. 3) propôs uma definição a partir de outros autores, que seria "o grau em que o comportamento de uma pessoa - tomar o medicamento, seguir um regime alimentar e executar mudanças em seu modo de vida - corresponde às recomendações acordadas com um prestador de assistência sanitária”.

Mas como a não adesão pode ser considerada universal, outros autores entendem que a adesão aconteceria com a utilização dos medicamentos prescritos ou outros procedimentos em pelo menos $80 \%$ de seu total, observando horários, doses e tempo de tratamento (NEMES 2000). Representa a etapa final do que se sugere como uso racional de medicamentos (LEITE e VASCONCELLOS 2003).

Não há um método considerado gold standard para mensuração da adesão. De um modo geral, pode-se dizer que há métodos diretos e indiretos. Os primeiros são baseados em técnicas analíticas que identificam, através de metabólitos sangüíneos ou de marcadores químicos, a dose e freqüência de utilização de um medicamento (MILSTEIN-MOSCATI et al., 2000).

Os métodos indiretos utilizam principalmente entrevistas ou ainda a contagem de unidades do medicamento em poder do paciente. A entrevista estruturada é a mais utilizada, por apresentar menor custo e ser mais factível, tendo como principal fator negativo a possível superestimativa da adesão (LEITE e VASCONCELLOS 2003).

Pode-se ainda utilizar a entrevista não estruturada. Haaijer-Ruskamp e Hemminki (1993) e Leite e Vasconcellos (2005) citam a pesquisa qualitativa na área 
de medicamentos, ou pesquisa antropológica, como uma possível metodologia. Seu grande mérito é incorporar a perspectiva do usuário, sem desvinculá-lo da sua realidade.

Sabaté (2003) afirma que a adesão é um fator multidimensional, com cinco fatores que a influenciam de modo determinante: fatores sócio-econômicos, fatores relacionados com a equipe de saúde, fatores relacionados com a enfermidade, fatores relacionados com o tratamento e fatores relacionados com o paciente, listando ainda diversas intervenções possíveis, sobre cada um destes fatores, para a melhoria da adesão.

Independente de uma classificação destes fatores, uma primeira causa possível para a não adesão é a inacessibilidade aos medicamentos. Segundo Brand et al. (1977), uma causa para a não-adesão ao tratamento por idosos é o alto custo dos medicamentos, o que pode ser demonstrado, naquele estudo, pelo custo das prescrições dos não aderentes terem, em média, duas vezes o valor das prescrições dos aderentes.

Outra possível causa é o número de medicamentos a ser utilizado pelo paciente. Rutherford et al. (2007), ao fazerem uma revisão sobre diferentes quantidades de ARV prescritos aos pacientes, observam que há melhor adesão com menores quantidades de medicamentos, apesar de alertarem para a possibilidade de maior risco de resistência e falha terapêutica com regimes que contêm menos medicamentos combinados.

Também a percepção dos efeitos adversos causados pela terapia pode dificultar a adesão (MONTESSORI et al. 2004, JOHNSON et al. 2005), o que Milstein-Moscati et al. (2000) chamam em determinadas ocasiões de efeito protetor da não-adesão, ou não-adesão inteligente à terapêutica.

De acordo com Leite (2005), o tipo de doença que o paciente possui também pode ser um dos fatores a influenciar no grau de adesão, já que o modo 
como o paciente compreende seu estado de saúde, se ele é assintomático e como as pessoas ao seu redor vêem a doença pode determinar a aceitação ou não da condição de enfermo.

Outro fator primordial para a adesão é o profissional de saúde. A relação deste com o paciente pode, muitas vezes, ser decisiva para a obtenção da adesão ao tratamento, conforme se constata em diversos estudos publicados (PAULO e ZANINI 1997; JORDAN et al., 2000; PETIT e REDONNET 2002). Em especial, o prescritor possui um poder muito forte sobre o paciente, e suas atitudes podem motivar os pacientes ao cumprimento da terapia (LEITE e VASCONCELLOS 2003).

Por sua vez, a adesão aos ARV tem sido descrita na literatura científica como algo difícil de ser obtido, necessitando de altos percentuais de observância para que tenha eficácia. Deste modo, Paterson et al. (2000) afirmam ser necessário um grau de adesão acima de $95 \%$ para otimizar a redução da carga viral. Em outro estudo, Bangsberg et al. (2001) mostraram que não havia progressão à AIDS entre as pessoas com grau de observância superior a $90 \%$. Devido à inexistência de padrões metodológicos, comparações sempre são difíceis de serem feitas. De qualquer modo, a maioria dos estudos considera como adesão taxas iguais ou maiores a $80 \%$ do total de medicamentos prescritos e, a partir deste corte, Nemes (2000) relatou, em um estudo no Estado de São Paulo, uma prevalência da adesão de $69 \%$ ao tratamento anti-retroviral (IC 95\% $=0.66-0.71)$.

Na explicação da prevalência da não adesão e fatores de risco, neste mesmo estudo, foram apresentados alguns fatores que apresentaram diferença estatisticamente significante para a prevalência (ou não) da adesão: ter história de falta na consulta médica, o tipo de serviço de saúde onde o paciente era tratado, a renda pessoal, o grau de educação e o uso de álcool (NEMES 2000). Já TouretteTurgis e Rebillon (2002) afirmam que têm impacto negativo sobre a adesão a complexidade do tratamento; os efeitos indesejáveis; o pessimismo face à infecção; a depressão; a presença de sintomas debilitantes físicos ou sociais; a falta de renda, moradia e apoio de pessoas próximas; dificuldades ligadas ao acesso aos cuidados de 
saúde; falta de informação e de grupos de apoio e relação ruim com os profissionais de saúde.

Nunes e Slomp (2001), em Itajaí, trabalhando a questão da adesão em gestantes e puérperas soropositivas, demonstraram que os principais fatores interferentes na adesão foram a frequiência às consultas médicas, o regime terapêutico com esquemas posológicos complicados (muitos comprimidos ou várias tomadas ao dia) e o fato da mulher trabalhar fora. Outros pontos normalmente destacados neste tipo de pesquisa, como características sócio-econômicas, suporte familiar e acesso ao atendimento não demonstraram relevância estatística para a adesão ao tratamento naquele estudo.

A adesão, ou melhor, sua falta, torna-se assim um sério problema, em função não apenas do bem estar do paciente infectado, mas também na prevenção do desenvolvimento de mutações de resistência no genoma viral, o que ultrapassa a simples decisão individual de aderir ou não à terapêutica.

Nos Estados Unidos, por exemplo, um estudo demonstrou que $14 \%$ dos casos novos de infecção pelo HIV eram altamente resistentes a pelo menos um medicamento anti-retroviral, e 5,5\% altamente resistentes a duas ou mais drogas. No período entre 1995 e 1998, estes mesmos números correspondiam a 3,5\% e 0,4\% (UNAIDS 2002).

Este assunto está longe de se esgotar, até em função do paradoxo descrito por Bangsberg et al. (2004): dependendo da classe do anti-retroviral, a resistência pode acontecer mais freqüentemente para pacientes com média e alta adesão.

Deve-se lembrar ainda, que tanto os INNTR quanto os IP são metabolizados pelas enzimas da família CYP 450. E o mais interessante é que alguns representantes dessas classes são ao mesmo tempo indutores e inibidores do CYP 450 , o que pode acelerar ou diminuir o metabolismo de outras drogas e dos próprios 
ARV. E a simples diminuição da concentração destes medicamentos na corrente sangüínea pode levar também à resistência (RUDI SOLA 2003).

Além disso, Andrade (2000) afirma que interações entre os ARV e medicamentos naturais, anti-convulsivantes, anticoncepcionais, estatinas, tuberculostáticos e outros medicamentos contra as infecções oportunistas podem resultar em efeitos indesejáveis aos pacientes, ocasionando o abandono da terapia. Isto sem falar na possibilidade de interação com alimentos, que tanto podem interferir na efetividade dos ARV como pode ser uma interessante estratégia para a diminuição de percepções sensoriais negativas, como o gosto, dos ARV (MS 2006e).

\subsection{Integralidade, Promoção da Saúde e o Programa de Saúde da Família - PSF}

A Constituição de 1988 (BRASIL 1988) tem como marca o reconhecimento de muitos direitos de cidadania ou sociais, entre eles a saúde, originando o arcabouço do Sistema Único de Saúde (o SUS). O preconizado pela Constituição ia na contramão da discussão internacional preconizada à época pelo Banco Mundial, que afirmava categoricamente que "a abordagem mais comum para os cuidados de saúde nos países em desenvolvimento tem sido tratá-los como um direito do cidadão e tentar prover serviços gratuitos para todos. Essa abordagem geralmente não funciona" (World Bank, 1987, p. 3).

Não há questionamentos pelo Banco Mundial quanto à equiidade (desde que entendida como focalização), chegando mesmo no documento à sua defesa, junto com outros princípios do SUS, como a descentralização e a participação popular (MATTOS 2002). Eram a universalidade e a integralidade os princípios a serem combatidos. E, como na experiência brasileira a universalidade já está bem encaminhada (se a universalidade for entendida como possibilidade de acesso), falta resolver a integralidade. 
A Integralidade pressupõe ações de saúde combinadas e voltadas, ao mesmo tempo, para a prevenção e a cura. Os serviços de saúde devem ver o indivíduo de forma integral, assim como ele (o serviço) não pode ser fragmentário a ponto de tratar de doenças e não de saúde (ALMEIDA et al. 2001). O princípio da Integralidade deve ser entendido na plenitude do seu termo, como uma recusa ao reducionismo, que compreendia o indivíduo de forma isolada, fragmentada e descontextualizada (SOUZA e COSTA NETO 2000).

Mattos (2002) ainda afirma haver diferentes sentidos do princípio da integralidade, que refletiriam diferentes pontos: o primeiro refere-se a atributos das práticas profissionais de saúde, o segundo refere-se a atributos da organização dos serviços e o terceiro às respostas governamentais aos problemas de saúde. A primeira noção discute a integralidade no cotidiano dos diferentes profissionais de saúde, atuando ou não no âmbito do SUS, e tentando solucionar o conflito entre dicotomias como a fragmentação ou a visão holística, a prevenção ou a assistência. A segunda, decorrente da primeira, tenta superar a organização dos serviços que foram programados de forma vertical para funcionarem como programas horizontais que contemplem a integralidade. A terceira tenta dar conta de problemas específicos que afligem um certo grupo populacional, relativos a políticas governamentais específicas. Neste terceiro sentido pode ser apontada a melhor experiência brasileira de integralidade, que foi a resposta brasileira contra a AIDS:

"No Brasil, talvez seja a resposta governamental à AIDS a que mais se aproxima do princípio da integralidade ... (pois) destoou de uma série de recomendações emanadas de agências internacionais... que defendiam que os governos deveriam se empenhar na oferta das intervenções preventivas... deixando de financiar ou prover algumas intervenções como o uso de anti-retrovirais" (MATTOS 2002, p. 13).

Reafirma-se, assim, a utilização do medicamento como prática integral, como consta no art. $6^{\circ}$, IV d, da Lei Orgânica da Saúde (Lei 8080/90), que afirma ser uma das finalidades do SUS a assistência terapêutica integral, inclusive farmacêutica (BRASIL 1990). Parece claro que a intenção do legislador, ao explicitar estas palavras, foi reconhecer que em muitas situações, não há 
possibilidades terapêuticas sem a utilização dos medicamentos, e garantir o pleno acesso a eles. Do mesmo modo, a integralidade pressupõe um atendimento racional, principalmente seguindo protocolos de tratamentos, sob pena de achar-se que, ao observar-se este princípio, qualquer medicamento prescrito deva ser entregue ao paciente, sem nenhum questionamento sobre a relevância ou eficiência do tratamento.

A Integralidade deve ainda garantir o acesso à saúde e à sua promoção. Não mais a promoção como descrita classicamente por Leavell e Clark (1976), como um apêndice da prevenção de doenças, mas agora entendendo a promoção como algo maior que a prevenção, assim como a saúde é maior que a doença (CZERESNIA e FREITAS 2003).

Há várias definições para a promoção da saúde, a partir de perspectivas conservadoras ou progressistas. Assim, mais importante que um conceito de promoção da saúde, é a idéia que o permeia, relacionada a expressões como políticas públicas saudáveis, intersetorialidade e desenvolvimento sustentável (CZERESNIA e FREITAS 2003).

A promoção da saúde reflete um conceito de saúde positivo e multidimensional, contrário ao negativo - ausência de doença. E seu modelo de intervenção é participativo, ao contrário do utilizado na prevenção da doença, que era centrado no médico (CZERESNIA e FREITAS 2003). Buss (2003) argumenta que a Promoção da Saúde parte de uma concepção ampla do processo saúde-doença e de seus determinantes, refletindo uma reação à crescente medicalização da vida social.

Pode-se discutir o valor dos medicamentos, relativizar suas propriedades farmacológicas, relacioná-los com o efeito placebo, mas é impossível não reconhecer o papel preponderante que representam na saúde (e na percepção de saúde) da população. Portanto, sua utilização passa a ser questão extremamente importante, que até o momento tem sido esquecida em função de outras prioridades no Sistema Único de Saúde. E isto é facilmente comprovável, ao observar-se a não 
utilização da Relação Nacional dos Medicamentos Essenciais (RENAME) em muitos municípios; o ainda inexpressivo número de profissionais de saúde discutindo a Assistência Farmacêutica nas diferentes esferas de governo e o descaso no armazenamento, dispensação e orientação do uso dos medicamentos nas Unidades de Saúde espalhadas pelo Brasil, apenas para citar alguns exemplos (OLIVEIRA et al. 2002).

É justamente o reconhecimento da importância (e também das limitações) dos medicamentos que nos remete à procura da Promoção da Saúde como forma de superação daqueles dilemas. Não cabe aqui uma análise extensa da Promoção da Saúde, mas vale a pena refletir um pouco sobre o enfoque político e técnico oferecido por este novo conceito, como resposta setorial articuladora de recursos técnicos e posições ideológicas norteadoras de políticas públicas. Daí se encontrar associada a valores tais que qualidade de vida, solidariedade, eqüidade, democracia e desenvolvimento.

Neste cenário, necessariamente o medicamento deve ser considerado um bem de saúde, e não uma mera mercadoria (SEVALHO 2003; BÉRAUD 2002; PERINI e ACURCIO 2001). E isto é impossível de acontecer sem um trabalho interdisciplinar, contando com as diferentes profissões de saúde e de outros atores envolvidos como, por exemplo, os agentes comunitários de saúde. A Saúde Pública, a Promoção da Saúde, o Uso Racional de Medicamentos e a Integralidade têm como requisito "sine qua non" a participação de múltiplos saberes, originando múltiplos fazeres (LEITE e CORDEIRO 2007). O medicamento, assim como qualquer outra tecnologia na saúde, não é conhecimento prioritário de um único profissional de saúde. Se o farmacêutico detém um conhecimento mais completo acerca desta matéria, não menos importante é, por exemplo, um Agente Comunitário de Saúde (ACS) que tente fazer com que o paciente em sua residência adira ao tratamento.

É aqui que se encaixa o Programa da Saúde da Família, ou melhor, Estratégia de Saúde da Família (ESF). Esta estratégia, entendida não apenas como mais uma atividade do SUS, deve ser vista como uma forma de substituição do 
modelo vigente, já que baseada em ações de atenção básica à saúde. Não há integralidade sem trabalho interdisciplinar, quer na residência de um paciente atendido por uma equipe do Programa de Saúde da Família (PSF), quer em uma Unidade Hospitalar considerada referência e altamente especializada no Serviço de Saúde (CORBO e MOROSINI 2005).

Em um modelo idealizado, o PSF apresenta, como pré-requisito, a necessidade de um trabalho multiprofissional e a responsabilização desta equipe por uma melhoria da qualidade de vida do paciente. Para isso, mister se faz que o profissional de saúde possa ter o paciente como parceiro nas atitudes que serão desenvolvidas, sem o sentido vertical tão característico das práticas atualmente desenvolvidas pelos profissionais de saúde.

É justamente neste ponto que a equipe multiprofissional pode aprimorar a adesão e outros indicadores de saúde, inclusive com a participação do farmacêutico, conforme se pode observar no item seguinte.

\subsection{Atenção Farmacêutica}

Tradicionalmente o farmacêutico tem em sua formação boa base em técnicas analíticas, pesquisas e desenvolvimento de novos medicamentos e se prepara para ser o profissional que melhor conhece medicamentos. Tradicionalmente, também, os farmacêuticos têm elevada preocupação com a toxicidade dos medicamentos e com os possíveis efeitos colaterais. Deste modo, sua participação na maior parte dos casos acaba trazendo bons resultados, embora se saiba que sua atuação poderia ser muito mais ativa do que a descrita na literatura (ROMANOLIEBER et al. 2002).

Uma forma de modificar este panorama seria a incorporação dos conceitos de Atenção Farmacêutica em sua práxis. Já há algum tempo a Atenção Farmacêutica, definida por Hepler e Strand (1990) como "a provisão responsável da terapia medicamentosa com o propósito de alcançar resultados definidos que 
melhorem a qualidade de vida de um paciente" vem sendo caracterizada como uma nova prática farmacêutica, revolucionária ao redefinir a atuação deste profissional tendo como foco principal o paciente e não mais o medicamento (CORDEIRO e REYNAUD 2005).

Essa prática, no Brasil, está legitimada tanto pela $1^{\mathrm{a}}$. Conferência Nacional de Medicamentos e Assistência Farmacêutica (MS/CNS 2005), que referendou a proposta de consenso brasileiro de Atenção Farmacêutica, quanto pelo Conselho Nacional de Saúde, que aprovou a Política Nacional de Assistência Farmacêutica (BRASIL 2004).

A Política Nacional de Assistência Farmacêutica, por sua vez, ao dispor em seu artigo primeiro, inciso IV, que as ações de Assistência Farmacêutica envolvem aquelas referentes à Atenção Farmacêutica, respalda legalmente esta enquanto política de saúde pública e abre um caminho para que o profissional farmacêutico atue dentro desta nova perspectiva (CASTRO 2004).

Desta forma, e apenas a título de exemplo, a Jointed United Nations Programme on HIV/AIDS (UNAIDS 2002), explicitamente reafirma a importância do farmacêutico na efetividade do tratamento contra a AIDS, em especial nos países que apresentam baixa e média renda per capita. Daqui pode-se depreender que a Atenção Farmacêutica e, em especial, o Seguimento Farmacoterapêutico podem ser importantes ferramentas para lidar com a questão da melhora no uso dos medicamentos, principalmente dos ARV.

O Seguimento Farmacoterapêutico pode ser de extrema valia para este fim, pois segundo Cipolle et al. (1998) realiza-se o Seguimento do Tratamento Farmacológico de um paciente quando se põe em prática uma metodologia que permite buscar, identificar e resolver, de maneira sistemática e documentada, todos os problemas de saúde relacionados com os medicamentos desse paciente, realizando uma avaliação periódica de todo o processo. Isso somente é possível a partir de uma 
parceria com o paciente, visando a melhora dos resultados farmacoterapêuticos que representem uma melhora na sua qualidade de vida.

O Seguimento Farmacoterapêutico é um dos diferentes tipos de exercício da Atenção Farmacêutica, e acontece

"mediante a detecção, prevenção e resolução dos problemas relacionados com os medicamentos (PRM). Este serviço implica num compromisso, e deve existir de forma continuada, sistematizada e documentada, com a colaboração do próprio paciente e com os demais profissionais do sistema de saúde, com a finalidade de alcançar resultados concretos que melhorem a qualidade de vida do paciente" (MINISTERIO DE SANIDAD Y CONSUMO 2001, p.11)

Este serviço visa à obtenção da máxima efetividade dos tratamentos farmacológicos bem como, minimizar os riscos associados ao uso dos medicamentos e, portanto, melhorar a segurança da farmacoterapia, contribuir ao uso racional dos medicamentos e ainda melhorar a qualidade de vida do paciente. O seguimento farmacoterapêutico inova como elemento necessário de assistência sanitária, sem invadir competências de outros membros da equipe de saúde, pois para se proporcionar uma assistência sanitária global e completa é imprescindível uma colaboração multidisciplinar (CORDEIRO e REYNAUD 2005).

Para que ocorra efetivamente o seguimento farmacoterapêutico personalizado, devem-se buscar soluções às necessidades concretas relacionadas com medicamentos do paciente. É essencial que o farmacêutico atenha-se a este ponto, sem tentar resolver outros problemas que não aqueles relacionados com medicamentos.

O farmacêutico, enquanto profissional especialista em medicamentos e membro de uma equipe multiprofissional, poderia utilizar tanto as visitas domésticas do PSF como o atendimento dos pacientes em UBS para o desenvolvimento de atividades capazes de minimizar o uso irracional dos medicamentos, principalmente os medicamentos destinados ao tratamento da AIDS, caros e com esquemas terapêuticos por vezes extremamente complicados. A 
utilização desta técnica em pacientes HIV positivos e sua extrapolação para outras patologias que não a AIDS representariam significativa melhora no atendimento que este paciente recebe atualmente dos Serviços Públicos de Saúde. 


\section{OBJETIVOS}

\subsection{Objetivo geral}

Avaliar a efetividade da atenção farmacêutica em gestantes soropositivas para o vírus HIV atendidas em Serviço de Atendimento Especializado (SAE) de Itajaí (SC).

\subsection{Objetivos específicos}

- Caracterizar as gestantes atendidas pelo SAE;

- Realizar o seguimento farmacoterapêutico;

- Avaliar a adesão das gestantes HIV positivas à terapia anti-retroviral antes e após o Seguimento Farmacoterapêutico;

- Identificar eventos adversos a medicamentos (EAM) ocorridos com o uso de anti-retrovirais.

- Analisar a relação existente entre o Programa DST/AIDS e a Atenção Básica/PSF no cuidado às gestantes soropositivas de Itajaí, SC. 


\section{PROCEDIMENTO METODOLÓGICO}

\subsection{Tipo do estudo}

Trata-se de pesquisa avaliativa. Contandriopoulos et al. (1997, p. 37) definem a pesquisa avaliativa "como o procedimento que consiste em fazer um julgamento ex-post de uma intervenção usando métodos científicos". Dentro desta perspectiva, Hardon et al. (2004) definem este estudo como modelo préintervenção/pós-intervenção.

Segundo estes autores, neste modelo há, inicialmente, a determinação de parâmetros referenciais no começo da intervenção. Com a execução posterior da intervenção, mensura-se a mudança que a intervenção trouxe e se formulam ou confirmam hipóteses para averiguar porque se modificou o comportamento.

\subsection{População do estudo}

A população do estudo foi constituída das gestantes soropositivas atendidas na rede municipal de Itajaí de 01 de julho de 2006 a 31 de janeiro de 2007. Neste período, todas as pacientes HIV+ que procuraram atendimento no SAE de Itajaí foram convidadas a fazer parte do estudo.

Com a ajuda da equipe de profissionais do SAE, foram agendadas as consultas para as gestantes exclusivamente às quartas-feiras, o que possibilitou o seguimento de todas as gestantes unicamente pelo pesquisador. As gestantes foram seguidas, em sua maior parte, no SAE, mas também em outros locais.

Para todas as gestantes que aceitaram participar, foi explanado do que se tratava o estudo, e orientado que o período de seguimento seria até o final da gestação. Assim, do início de fevereiro de 2007 até o dia 13 de julho do mesmo ano (quando a última mulher acompanhada teve seu filho), foi continuado o seguimento das gestantes sem a inclusão de nenhuma outra paciente. 


\subsection{Método}

\subsubsection{Seguimento Farmacoterapêutico}

A principal metodologia empregada foi o Seguimento Farmacoterapêutico que, de acordo com o Consenso Espanhol de Atenção Farmacêutica (MINISTERIO DE SANIDAD Y CONSUMO 2001), necessita respeitar alguns pré-requisitos básicos:

- Para cada uma das atividades que compreendem o seguimento farmacoterapêutico personalizado, devem existir procedimentos operacionais padrão, com a finalidade de garantir a qualidade do serviço;

- O seguimento deve ser oferecido ao paciente que utilize (ou necessite utilizar) medicamentos. Oferece-se o serviço sempre no sentido positivo e não negativo. Como a colaboração do paciente é imprescindível, é necessário informá-lo adequadamente e obter seu consentimento;

- A necessidade de informação detalhada sobre os medicamentos que o paciente utiliza, exige a abertura de uma história farmacoterapêutica, obtida mediante uma entrevista inicial. O seguimento farmacoterapêutico personalizado implica na satisfação das necessidades do paciente em relação a seus medicamentos. Para isto deve avaliar-se a existência de Problemas Relacionados com Medicamentos (PRM), ou a possibilidade de sua aparição. Os PRM são definidos como "problemas de saúde, relacionados ou suspeitos de estarem relacionados à farmacoterapia, e que interferem nos resultados terapêuticos e na qualidade de vida do usuário" (IVAMA et al. 2002).

- Isto exige o estudo do "estado da situação" concreta do paciente e das possíveis intervenções farmacêuticas. Depois do estudo de cada medicamento e/ou problema de saúde, procede-se a classificação das suspeitas de PRM atuais, 
sempre pensando nos conceitos de Necessidade, Efetividade e Segurança (CASTRO 2004). Os PRM podem ser classificados ainda como manifestados ou não manifestados (potenciais). Um PRM potencial é aquele provável de ocorrer - e que o paciente corre o risco de sofrer - caso não seja feita uma intervenção. Enquanto para os PRM manifestados procura-se um "tratamento", para os PRM potenciais trabalha-se com a prevenção (ROVERS et al 1998).

Após detectarem-se os possíveis PRM, priorizam-se as atuações para conseguir resolver os PRM identificados, sendo preferível começar com apenas um, o qual não é necessariamente o mais importante nem o mais urgente, e sim, aquele que mais preocupa o paciente.

Existem diferentes metodologias possíveis para a prática do Seguimento Farmacoterapêutico. Peretta e Ciccia (2002) detalham a técnica conhecida como SOAP, por eles denominada ISOAP (Informação Subjetiva, Objetiva, Avaliação e Plano de Ação). Castro (2004), além de descrever esta última, pormenoriza ainda as técnicas PWDT (Pharmacist's Workup of Drug Therapy), TOM (Therapeutic Outcomes Monitoring) e o Método Dáder.

Não existe um método que apresente vantagens definitivas sobre outro. Os métodos PWDT e Dáder produzem uma documentação mais estruturada, tendo como ponto negativo o aumento do tempo dos encontros e como ponto positivo o fato de proporcionar um tempo adequado para a análise da literatura e o delineamento de um plano terapêutico. O método ISOAP (ou SOAP) não tem um formulário específico como guia a ser seguido, o que simplifica os registros, mas pode fazer com que dados importantes sejam perdidos por um profissional inexperiente com esta técnica. O método TOM está direcionado para enfermidades específicas, o que facilita a análise dos problemas decorrentes desta patologia, mas que pode desconsiderar o paciente como um ser integral (CASTRO 2004).

A metodologia proposta neste estudo para o Seguimento Farmacoterapêutico personalizado foi baseada no Método DADER (Anexo 1), 
desenvolvido pela Grupo de Investigación en Atención Farmacêutica, da Universidad de Granada, Espanha (Machuca et al. 2004), que apresenta vantagens como sua simplicidade sem a necessidade de equipamentos. Provavelmente, é o método de seguimento mais empregado no Brasil hoje, o que permite possíveis comparações e já apresenta um bom volume de experiências publicadas, tendo inclusive um guia para sua utilização em pacientes com HIV/AIDS (AMARILES MUÑOZ et al. 2006).

O Método Dáder foi revisto em 2007 (SABATER HERNÁNDEZ et al. 2007) e, dinamicamente, foram propostas algumas mudanças metodológicas, inclusive com a introdução do termo RNM (Resultado Negativo com a Medicação), já que uma revisão encontrou muita inexatidão quanto ao significado de PRM na literatura (FERNÁNDEZ-LLIMÓS et al. 2005). Foi proposto, assim, que o termo PRM estaria mais relacionado com causa, deixando-se o termo RNM para resultado e para a classificação quanto à necessidade, efetividade e segurança. Neste trabalho foi empregada a classificação dos PRM preconizada antes desta recente revisão: quanto à necessidade, efetividade e segurança, sem a utilização da subdivisão qualitativo/quantitativo.

Após a seleção do paciente, marca-se um encontro (primeira entrevista). A primeira entrevista consiste basicamente de 3 fases:

a) Preocupações de saúde: esta fase consiste em perguntas abertas. Pede-se para o paciente falar sobre o que o preocupa quanto à sua saúde e aos seus medicamentos. Não se deve interromper, o que não quer dizer que não se deva reconduzir, se necessário em determinado momento, para os problemas de saúde e para os medicamentos. Portanto não se deve perguntar nada, pois se poderia distrair a atenção do paciente das verdadeiras preocupações em relação à sua saúde. Se for necessário aprofundar algum aspecto concreto, utiliza-se a terceira fase da entrevista - a Revisão;

b) Sacola de medicamentos: ao convidar o paciente para participar deste serviço, deve-se solicitar que para sua primeira visita, traga numa "sacola" 
todos os medicamentos que utiliza. O objetivo é obter toda a informação possível sobre cada um dos medicamentos, e em especial averiguar o conhecimento do paciente a respeito do medicamento e se existe ou não adesão ao tratamento. Este objetivo se alcança através de dez perguntas abertas para cada um dos medicamentos presentes na sacola, quais sejam: 1. Utiliza ainda o medicamento? 2. Quem prescreveu? 3. Para quê é utilizado? 4. Como é o resultado? 5. Desde quando? 6. Quanto usa? 7. Como usa? 8. Até quando? 9. Alguma dificuldade com seu uso? e 10. Algo estranho é observado com seu uso? Aproveita-se ainda a oportunidade para falar ao paciente sobre a importância do descarte dos medicamentos vencidos;

c) Revisão: nesta fase explica-se ao paciente que será feita uma rápida revisão para garantir que não foi esquecido nenhum dado importante. Pergunta-se: "Você toma algum medicamento para...?". Esta fase visa obter informações sobre outros medicamentos que o paciente esteja utilizando e que tenha esquecido de trazer na "sacola", ou ainda obter informações sobre outros problemas de saúde que tenha esquecido de referir-se na primeira fase.

Obtidos os dados através desta entrevista, procede-se a uma fase de estudo do estado de situação do paciente, com uma avaliação global e levantamento das suspeitas de PRM. Em entrevistas posteriores, o paciente é informado dos problemas detectados e da possível solução sob a ótica do farmacêutico (intervenção farmacêutica), tudo sempre devidamente documentado, além de busca por novos PRM.

Todos estes passos podem ser visualizados em seu conjunto a partir da figura seguinte. 


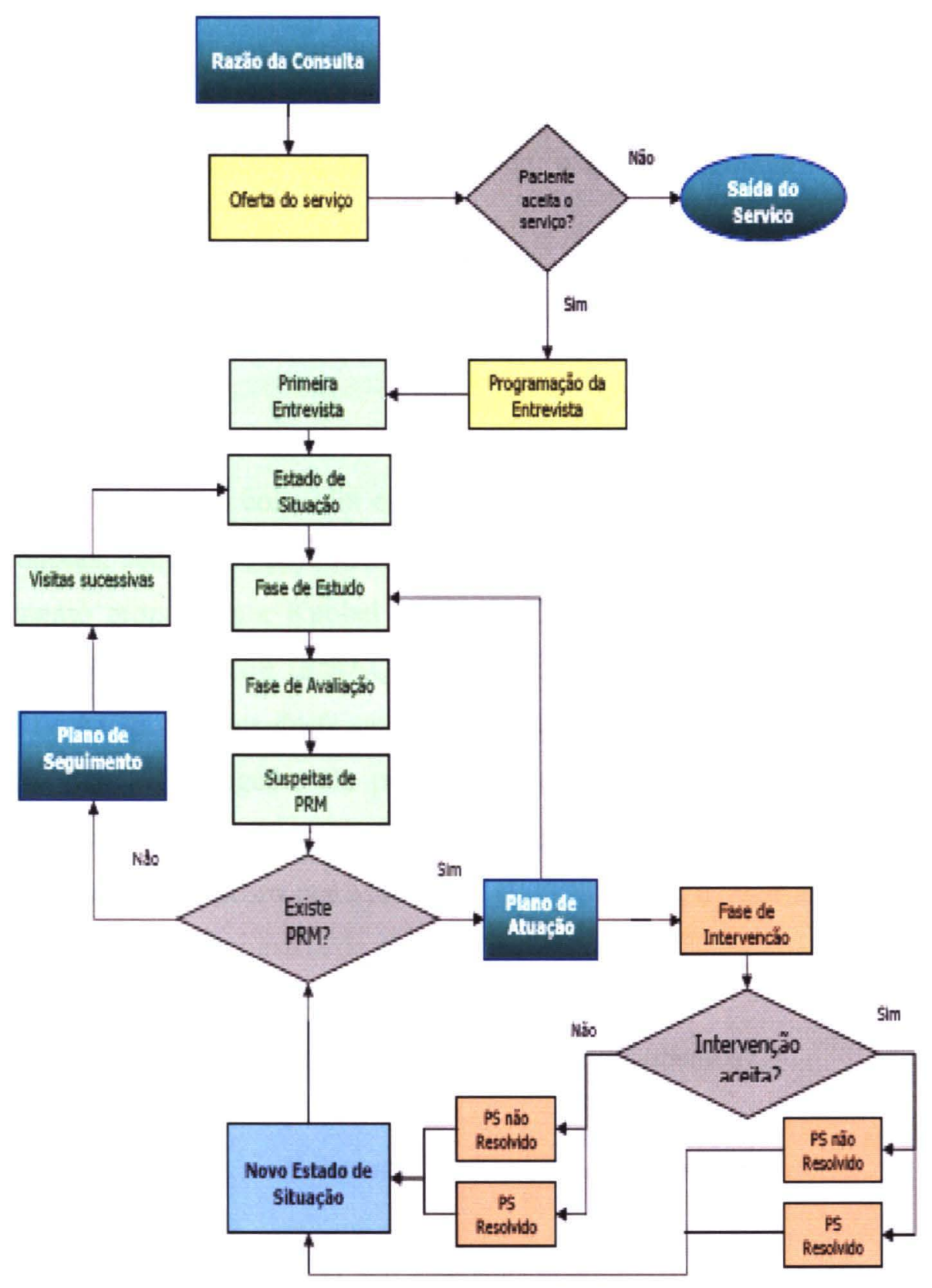

Figura 5. Fluxograma do processo no Método Dáder

Fonte: Machuca et al (2004), p. 8

Outro objetivo que se busca obter com o Método Dáder é a identificação dos eventos adversos observados com os ARV. Eventos adversos aos medicamentos podem ser definidos, de acordo com o Uppsala Monitoring Center (UMC 2004, p. 54) como "qualquer ocorrência clínica desfavorável que ocorra 
durante o uso de uma terapia medicamentosa, sem que possua, necessariamente, relação causal com o medicamento”. Preferiu-se a pesquisa destes eventos adversos ao invés das Reações Adversas aos Medicamentos (RAM) porque estas pressupõem uma relação causal difícil de ser investigada, o que extrapolava os objetivos deste trabalho.

\subsubsection{Adesão à Terapia}

Já a adesão ao tratamento foi mensurada em dois momentos, um inicial (SMAQ 1) que coincidia com o início do Seguimento Farmacoterapêutico e outro depois, decorridos pelo menos um mês do seu início (SMAQ 2), por meio do instrumento proposto por Knobel et al. (2002), denominado Simplified Medication Adherence Questionnaire (SMAQ) e desenvolvido especificamente para pacientes com HIV/AIDS. Apesar deste questionário ainda não ter sido nem traduzido nem validado para o português, ele permite a mensuração quantitativa do número de comprimidos tomados em um determinado período de tempo. Este instrumento é derivado daquele proposto por Moriski et al. (1986) para avaliar adesão à terapia de hipertensão arterial, e consiste de seis perguntas:

1. Você, às vezes, se esquece de tomar seus medicamentos?

( ) $\operatorname{Sim}$ ( ) Não

2. Você, toma seus medicamentos no horário indicado?

( ) $\operatorname{Sim}$ ( ) Não

3. Se às vezes você se sente mal com seus medicamentos, deixa de toma-los?

( ) $\operatorname{Sim~(~)~Não~}$

4. Durante a última semana, quantas vezes você não tomou seu medicamento?

5. Você ficou sem tomar algum medicamento no último final de semana?

6. Nos últimos 3 meses, quantos dias você não tomou seus medicamentos corretamente?

O SMAQ foi considerado "positivo" quando uma paciente não aderente foi detectada, isto é, quando havia uma resposta positiva para qualquer uma 
das 3 primeiras questões, ou mais de duas doses perdidas na última semana, ou mais de 2 dias sem medicamentos nos últimos 3 meses (neste trabalho, este resultado foi denominado qualitativo). Além disso, a partir da resposta dada na pergunta 4 calculava-se o percentual de adesão da paciente à TARV (denominado quantitativo).

Para a primeira entrevista, foi utilizado como critério estar utilizando os ARV por pelo menos 4 semanas. Passadas aproximadamente outras 4 semanas, quando as pacientes retornavam para uma nova consulta ou para buscar seus medicamentos mensais, era novamente aplicado o mesmo questionário.

\subsection{Delineamento do Estudo}

Trata-se de um estudo de série de casos. Nele são descritas características dos pacientes, de forma abrangente, sistemática e em profundidade. Ainda que não permita a confiabilidade que os ensaios clínicos randomizados trazem, a série de casos permite a descrição dos pacientes e de sua situação de forma contextualizada e holística (TOBAR e YALOUR 2003; FUCHS e FUCHS 2004).

\subsection{Fontes dos dados}

Além dos dados obtidos com o Método Dáder e com o instrumento SMAQ, outra fonte importante de informações sobre as pacientes foram seus prontuários. Apesar das reconhecidas falhas que existem no preenchimento destes documentos, muitas informações obtidas pelo Método Dáder puderam ser confirmadas ou não nesses documentos, assim como a história terapêutica anterior ao Seguimento Farmacoterapêutico.

Outras fontes de dados foram a Secretaria Municipal de Saúde e a $17^{\mathrm{a}}$. Regional de Saúde; a primeira forneceu as Fichas de Investigação de Gestantes HIV+ e Crianças Expostas e a Declaração de Nascidos Vivos de todas as gestantes pesquisadas e de seus filhos. Por sua vez, a segunda forneceu os dados condensados destas mesmas fichas para Itajaí e a Região da AMFRI (Associação dos Municípios 
da Foz do Rio Itajaí), através do programa SINANW - Sistema de Informações de Agravos de Notificação.

\subsection{Análise dos dados e resultados}

A análise dos dados foi feita a partir da planilha eletrônica Excel® para Windows.

Os resultados estão apresentados na forma de 4 artigos científicos e um pequeno relato com observações pessoais de cada um dos casos acompanhados.

$O$ primeiro artigo, intitulado "PERFIL EPIDEMIOLÓGICO E CARACTERÍSTICAS DO PRÉ-NATAL E DO PARTO DE MULHERES COM HIV/AIDS DO MUNICÍPIO DE ITAJAÍ, SC”, apresenta uma caracterização da amostra e tece considerações sobre a qualidade dos serviços oferecidos às gestantes. $\mathrm{O}$ artigo foi redigido conforme as determinações metodológicas da Revista Brasileira de Saúde Materno-Infantil (Anexo 2).

O segundo, intitulado "ADESÃO AO USO DE ANTIRETROVIRAIS POR GESTANTES HIV POSITIVAS E A ATENÇÃO FARMACÊUTICA" analisa de forma mais detalhada os resultados referentes à adesão obtidos na pesquisa e será submetido ao periódico Revista de Saúde Pública, observando as normas necessárias para sua publicação (Anexo 3).

O terceiro artigo, "ATENÇÃO FARMACÊUTICA A GESTANTES COM HIV/AIDS" descreve de forma pormenorizada como aconteceu o Seguimento Farmacoterapêutico e seus principais resultados. Está redigido segundo as normas do Cadernos de Saúde Pública (Anexo 4).

O quarto, intitulado "A VERTICALIDADE ENTRE O PROGRAMA DST/AIDS E A ESTRATÉGIA SAÚDE DA FAMÍlLIA (ESF) EM ITAJAÍ (SC): UM ESTUDO DE CASO LOCAL OU A REALIDADE BRASILEIRA?", apresenta 
uma reflexão sobre a difícil inter-relação entre aqueles dois programas e será submetido à revista Saúde e Sociedade, obedecendo aos requisitos necessários para que seja aceito (Anexo 5).

\subsection{Considerações éticas}

O presente estudo, atendendo a resolução 196/96 do Conselho Nacional de Saúde, foi aprovado pelo Comitê de Ética em Pesquisa da Faculdade de Saúde Pública - USP, de acordo com o Ofício COEP/55/06, em anexo (Anexo 6).

Vale ressaltar aqui, como particularidades, que além do consentimento formal tanto das gestantes (Anexo 7) quanto da Secretaria Municipal de Saúde de Itajaí (Anexo 8), observou-se o sigilo absoluto dos nomes das pacientes, dando-se a cada uma delas o nome de uma flor para sua identificação.

Os resultados deste trabalho serão divulgados tanto internamente, através de palestras para os profissionais de saúde participantes das equipes do PSF, da Secretaria Municipal de Saúde de Itajaí e gestantes HIV positivas quanto externamente, através da publicação e apresentação em eventos das conclusões obtidas com este estudo. 


\section{RESUltados}

Entre julho de 2006 ao final de janeiro de 2007, 37 gestantes procuraram o SAE, sendo que 32 aceitaram participar do estudo (3 se recusaram e outras duas não puderam ser contatadas). Entre fevereiro e julho de 2007, foi continuado o seguimento daquelas gestantes que ainda não haviam parido seus filhos, sem a inclusão de novas gestantes.

Os contatos com as gestantes aconteceram unicamente no SAE para 23 gestantes. Três mulheres, além do contato no SAE, receberam o pesquisador em suas residências na única vez em que foram entrevistadas. Duas mulheres tiveram um contato no SAE e outro no Presídio de Itajaí. Duas tiveram seus únicos contatos em Unidades de Saúde do município e uma outra foi acompanhada no consultório particular de sua ginecologista. Uma gestante teve um primeiro contato no ambulatório de Universidade e depois foi seguida no SAE. Além disso, podem ser relatadas várias visitas às residências, tanto com equipes do PSF como com a equipe do próprio $\mathrm{SAE}$, que resultaram infrutíferas pela negativa em receber o pesquisador.

Das 32 gestantes, uma descobriu-se mais tarde não estar grávida e outra veio a óbito. Tanto para estas mulheres, quanto para outras 4 em que foi possível apenas um único encontro, o seguimento ficou prejudicado, já que houve a identificação de PRM sem a sugestão de intervenção para a resolução dos problemas.

O instrumento SMAQ foi utilizado, no primeiro momento, em todas as 32 gestantes que aceitaram participar do estudo. Já a segunda aplicação ficou restrita a apenas 24 destas mulheres, em função principalmente de terem procurado o SAE já muito próximas do término da gestação.

Os resultados da aplicação tanto do seguimento quanto do questionário SMAQ estão descritos nos artigos subseqüentes. A fim de trazer subsídios para a compreensão de todo o trabalho, que não poderia ser resumido para 
estar presente em um artigo, segue uma pequena descrição de cada um dos casos seguidos pelo Método Dáder.

\subsection{Descrição Individualizada dos Casos}

\section{Gestante 1 - Acácia}

Acácia tem 20 anos, 8 a 11 anos de escolaridade. É muito expansiva, e foi uma das participantes do grupo de adesão que fazia trabalhos artesanais.

Utilizou durante toda a gestação o esquema AZT/3TC 2 + NVP 2, um total de 4 comprimidos diários. Utilizou também os medicamentos Escopolamina e Compostos com Ferro paralelo aos ARV. Não há interações significativas clinicamente entre estes medicamentos. Não relata nem reações adversas nem dificuldades com o esquema.

Apesar de esquecer de tomar os medicamentos e se descuidar quanto ao horário de tomá-los, tem bom conhecimento sobre seus medicamentos. Considerada não aderente pelo SMAQ 1 no primeiro momento ( 2 respostas sim e $85 \%$ de adesão), passa a ser aderente pelo SMAQ 2 (100\% de adesão).

É assídua nas consultas, e com o passar do seguimento passa a não ter problemas de adesão. Foi orientada a tomar o Composto com Ferro longe das refeições, com suco de laranja, mas já fazia isso. Suas consultas correm normalmente e tem seu filho no final de 2006.

PRM quanto à efetividade (potencial) por falta de adesão (SMAQ 1)

Estratégia e Intervenção proposta: Trabalhado junto à gestante a importância do tratamento correto. Esclarecidas dúvidas sobre HIV, AIDS, TARV e parto.

Via de comunicação: Verbal, junto à própria gestante.

Resultado: Intervenção aceita, Problema resolvido (Melhora da adesão - SMAQ 2)

No. de contatos: 7

\section{Gestante 2 - Açucena}

Açucena tem 31 anos, 8 a 11 anos de escolaridade. Costuma vir às consultas com seu marido e não aparenta ter problemas com a adesão à terapia. Iniciou a tomar os ARV com AZT 6. Paralelo a este medicamento, utilizou Paracetamol, Polivitamínicos, Ácido Fólico e Passiflora. Em função do uso 
moderado de Paracetamol, não há interações clinicamente significantes. Apresentou náuseas como evento adverso com este esquema, e foi orientada que muitos ARV apresentam efeitos que desaparecem com o uso em poucos dias ou semanas.

Depois da monoterapia, passou a utilizar AZT/3TC 2+ NFV 10 (12 comprimidos) e os demais medicamentos que já usava, sem interações clinicamente significantes. Em função de um evento adverso - anemia severa (além de náuseas e diarréia), substituiu este esquema por D4T(40) $2+3 \mathrm{TC} 2+\mathrm{NFV} 10$ (14 comprimidos). Com este esquema, passa a tomar somente um Composto com Ferro, sem interações clinicamente significantes. Não relata eventos adversos com o terceiro esquema.

Não apresentou problemas de adesão (SMAQ 1 e 2); todas as respostas negativas com $100 \%$, apesar de relatar dificuldades para engolir o NFV. Estas melhoram com a orientação de tomá-lo com alimentos (que inclusive aumentam os níveis séricos do NFV), de preferência de fácil digestão e consistência branda (mais cozidos). Sua gravidez corre normalmente e tem seu filho no primeiro semestre de 2007.

PRM quanto à segurança (esquema 1 - náuseas)

PRM quanto à segurança (esquema 2 - náuseas, diarréia, anemia)

Estratégia e Intervenção proposta: Paciente orientada sobre importância do tratamento. Esclarecidas dúvidas sobre HIV, AIDS, TARV e parto. Trabalhado junto à gestante a possibilidade de RAM diminuir com o tempo no primeiro esquema e orientada a conversar com seus médicos sobre possibilidade de troca de medicação no segundo esquema.

Via de comunicação: Verbal, junto à própria gestante

Resultado: Intervenções aceitas, Problemas resolvidos

No. de contatos: 4

\section{Gestante 3 - Angélica}

Angélica tem 23 anos, 8 a 11 anos de escolaridade. Muito retraída, não gosta de falar de si. É paciente AIDS e já esteve internada por infecção oportunista. Utiliza o esquema D4T(30) $2+3$ TC $2+$ LPVr 6 (10 comprimidos). Tem dificuldades com a adesão (duas respostas sim, 28\% de adesão pelo SMAQ 1), alegando que esquece de tomar os medicamentos e se descuida quanto aos horários de tomá-los. Utiliza com os ARV Espiramicina, Ácido Fólico, Metoclopramida, 
Paracetamol, Diclofenaco, Metronidazol (gel vaginal) e Compostos com Ferro, sem interações clinicamente significantes. Apresenta o evento adverso anemia e relata náuseas para deglutir os comprimidos de Lopinavir/Ritonavir.

É orientada a tomar este medicamento com alimentos, de preferência de fácil digestão e consistência branda (mais cozidos). Ao retornar, alega melhora, mas continua com baixa adesão (SMAQ $2-21 \%$ ). Segue com poucas melhoras na adesão até ter seu filho, no primeiro semestre de 2007.

PRM: Quanto à efetividade (potencial) por falta de adesão - SMAQ 1

PRM: Quanto à segurança: anemia, náuseas com LPVr

Estratégia e Intervenção proposta: Trabalhado junto à gestante a importância do tratamento correto, esclarecidas dúvidas sobre HIV, AIDS, TARV e parto. Orientada para tomar LPVr com alimentos para diminuir náuseas e cuidar com o uso do ferro para a anemia

Via de comunicação: Verbal, junto à própria gestante

Resultado: Intervenção não aceita quanto à adesão. Problema não resolvido. Intervenção aceita quanto ao modo de tomar Compostos com Ferro e LPVr - Alega melhora, mas PRM ainda não resolvido

No. de contatos: 4

\section{Gestante 4 - Antúrio}

Antúrio tem 22 anos, 4 a 7 anos de escolaridade. É caso de AIDS, utilizando o esquema EFZ $1+$ AZT/3TC 2 (3 comprimidos). Paralelo a estes medicamentos, utilizava Sulfadiazina, Ácido folínico, Pirimetamina e Miconazol (creme vaginal). Tão logo ficou confirmada a gravidez, este esquema foi abandonado, passando para AZT/3TC 2 + NFV 10. Com este esquema, utilizou os medicamentos Sulfadiazina, Ácido folínico, Pirimetamina e Clindamicina, sem interações clinicamente significantes. Possui histórico de faltas de consultas e no prénatal. Em função disso, são feitas visitas à sua residência, porém sempre sem sucesso. Possui baixa adesão (SMAQ 1 - três respostas positivas, nível de adesão $0 \%$ ) e relata náuseas e anemia com este esquema. É orientada a utilizar o NFV com alimentos. 
A segunda mensuração do SMAQ mostra $14 \%$ de tomada dos medicamentos ARV. Como esta é a terceira gravidez e nas outras duas seus filhos negativaram, acredita que os medicamentos não são necessários. Sofre internação no início de 2007 e chega a ir para a UTI por infecção oportunista. Logo em seguida tem seu filho, que tem Apgar 02 no primeiro minuto. Mais tarde seu filho é transferido para hospital em Florianópolis, com suspeita de perfuração da alça intestinal (já apresentava ascite fetal intra-útero).

PRM: Quanto à efetividade (potencial) por falta de adesão - SMAQ 1

PRM: Quanto à segurança: náuseas e anemia

Estratégia e Intervenção proposta: Trabalhado junto à gestante a importância do tratamento correto, esclarecidas dúvidas sobre HIV, AIDS, TARV e parto. Orientada a observar evento adverso (náuseas), que pode ser resolvido se tomar NFV com alimentos. Orientada acompanhar com médico a anemia.

Via de comunicação: Verbal, junto à própria gestante.

Resultado: Intervenção não aceita. Problema não resolvido quanto à adesão. Intervenção não aceita sobre tomar com alimentos com NFV, problema não resolvido.

No. de contatos: 3

\section{Gestante 5 - Amor-perfeito}

Amor-perfeito tem 41 anos e nível superior de escolaridade. Tem seu tratamento realizado em consultório privado, utilizando o esquema AZT/3TC $2+$ NVP 2 (4 comprimidos). Utilizou, em paralelo aos ARV, Paracetamol, Compostos com Ferro e Ampicilina, sem interações clinicamente significantes. Não aparenta problemas com adesão (SMAQ 1 e 2 com respostas negativas e 100\% de adesão) nem eventos adversos com a terapia. Segue a gravidez normalmente, sem problemas, e tem seu filho no início de 2007.

É orientada a tomar compostos com ferro longe das refeições, com suco de laranja.

PRM: Quanto à efetividade (potencial): compostos com ferro devem ser tomados longe das refeições, com suco de laranja. 
Estratégia e Intervenção proposta: Trabalhado junto à gestante a importância do tratamento correto. Esclarecidas dúvidas sobre HIV, AIDS, TARV e parto e uso de medicamentos com alimentos.

Via de comunicação: Verbal, junto à própria gestante.

Resultado: Intervenção aceita, problema resolvido.

No. de contatos: 3

\section{Gestante 6 - Azaléia}

Azaléia tem 21 anos e 8 a 11 anos de escolaridade. É uma das pacientes mais assíduas e também freqüentava o grupo de adesão para trabalhos artesanais. Inicia com o esquema AZT 6, utilizando também os medicamentos Sulfato ferroso, Escopolamina, Benzoato de Benzila, Óleo Mineral, Dimeticona e Polivitamínico, sem interações clinicamente significantes. Com este esquema relata como evento adverso "fraqueza" e tem uma resposta positiva pelo SMAQ1 (se descuida quanto ao horário de tomar os medicamentos, apesar de apresentar $100 \%$ de adesão). Passa depois ao esquema AZT/3TC 2 + NFV 10, utilizando em paralelo os medicamentos Escopolamina, Dipirona e Polivitamínico, sem interações clinicamente significativas. Sofre com um evento adverso - diarréia intensa. Orientada a conversar com seu médico sobre isso, este prefere manter o esquema, o que faz com a diarréia persista até o final da gestação. Tem seu filho no início de 2007.

PRM: Quanto à efetividade (potencial) por falta de adesão - SMAQ 1

PRM: Quanto à segurança: Diarréia intensa

Estratégia e Intervenção proposta: Trabalhada junto à gestante a importância do tratamento correto e a necessidade de determinar um horário de fácil lembrança para tomar ARV. Orientada a conversar com médicos sobre possível troca de medicação pela diarréia. Esclarecidas dúvidas sobre HIV, AIDS, TARV e parto.

Via de comunicação: Verbal, junto à própria gestante.

Resultado: Intervenção aceita e problema resolvido (Melhora da adesão - SMAQ 2, $100 \%)$. Conversa com médicos que preferem manter o esquema apesar dos efeitos adversos: Intervenção não aceita e problema não resolvido.

No. de contatos: 7 


\section{Gestante 7 - Begônia}

Begônia tem 25 anos, 4 a 7 anos de escolaridade. É das poucas gestantes que permitiu a visita em sua casa, apesar de ter se mudado antes da visita. Inicia com esquema AZT 6, utilizando também Compostos com Ferro, sem interações significativas clinicamente. Aparenta ter boa adesão (SMAQ 1 e 2 com respostas negativas e $100 \%$ de adesão), apresentando anemia quando do uso do AZT. Passa depois a utilizar o esquema AZT/3TC 2 + NFV 10, com náuseas e vômitos e utilizando em paralelo Compostos com Ferro e Metoclopramida sem interações significativas clinicamente. Segue uma gravidez tranqüila, tendo seu filho no segundo semestre de 2006.

PRM: Quanto à segurança: Anemia.

PRM: Quanto à segurança: Náuseas e vômitos.

Estratégia e Intervenção proposta: Trabalhada junto à gestante a importância do tratamento correto e orientada a conversar com médicos sobre efeitos adversos estarem ou não relacionados aos medicamentos. Esclarecidas dúvidas sobre HIV, AIDS, TARV e parto. Orientada a usar corretamente sulfato ferroso e a metoclopramida, medicamentos prescritos.

Via de comunicação: Verbal, junto à própria gestante

Resultado: Intervenções aceitas, Problemas resolvidos (Anemia controlada com sulfato ferroso, náuseas controladas com metoclopramida).

No. de contatos: 7

\section{Gestante 8 - Bouganville}

Bouganville tem 24 anos, 4 a 7 anos de escolaridade. Faz uso de esquema AZT/3TC 2 + NVP 2 (4 comprimidos) e utilizou também Azitromicina, Compostos com Ferro, Amoxicilina e Paracetamol, sem interações clinicamente significantes. Às vezes esquece de tomar os medicamentos e descuida-se quanto ao horário de tomá-los (2 respostas positivas e adesão de $85 \%$ pelo SMAQ 1). Possui boa frequiência às consultas. Diarréia e sonolência são eventos adversos que acompanham seu tratamento. É orientada quanto ao uso correto de Compostos de Ferro. Pelo SMAQ 2, a questão da adesão é bem resolvida (sem respostas positivas e 
$100 \%$ de adesão) e os eventos adversos desaparecem com o tempo. Seu maior questionamento é sobre a possibilidade de realizar uma ligadura de trompas quando da cesárea. Sofre preconceito com um médico (consulta particular) que diz que, como ela tem o vírus, deve ser prostituta. Segue a gestação normalmente e tem seu filho no início de 2007.

PRM: Quanto à efetividade (potencial) por falta de adesão - SMAQ 1.

PRM: Quanto à segurança: Diarréia e sonolência.

Estratégia e Intervenção proposta: Trabalhada junto à gestante a importância do tratamento correto e orientada a conversar com médicos sobre possibilidade de troca de medicamentos. Esclarecidas dúvidas sobre HIV, AIDS, TARV e parto.

Via de comunicação: Verbal, junto à própria gestante.

Resultado: Intervenção aceita e problema resolvido (Melhora da adesão - SMAQ 2). Conversa com médicos que preferem manter o esquema, pois efeitos adversos são bem tolerados. Intervenção não aceita e PRM não resolvido (problemas persistem).

No. de contatos: 5

\section{Gestante 9 - Bromélia}

Bromélia tem 22 anos, 4 a 7 anos de escolaridade. Inicia com esquema AZT 6, sem relatar o uso de nenhum outro medicamento. Queixa-se que o AZT causa sonolência. Todas as respostas pelo SMAQ são positivas e tem adesão de $0 \%$. É usuária de drogas inalatórias e abandona o tratamento ainda no seu início, apesar de todas as iniciativas da equipe de saúde do SAE e da Unidade Básica de Saúde que freqüenta. Segue com uma gravidez tranquiila mas é denunciada ao Conselho Tutelar, que lhe retira a criança logo após o nascimento, no final de 2006.

PRM: Quanto à necessidade

PRM: Quanto à efetividade (potencial) por falta de adesão - SMAQ 1

PRM: Quanto à segurança: sonolência.

Estratégia e Intervenção proposta: Não foi possível trabalhar com a gestante, pois apresentou várias faltas às consultas.

Resultado: Paciente não fez uso do medicamento, nenhum PRM resolvido.

No. de contatos: 1 


\section{Gestante 10 - Camélia}

Camélia tem 34 anos, 8 a 11 anos de escolaridade. É caso de AIDS e utiliza o esquema AZT 6 + 3TC 2 + EFZ 1 (9 comprimidos), juntamente com Ácido fólico. Este esquema foi substituído, tão logo foi confirmada a gestação, por AZT/3TC 2 + NFV 10, utilizado juntamente com Compostos de Ferro e Paracetamol, sem interações clinicamente significantes. Com SMAQ 1, utilizando o primeiro esquema, todas as respostas são negativas e a adesão é de 100\%. Com SMAQ 2, passa a alegar que esquece de tomar os medicamentos e que, se sente-se mal (relata diarréia, náuseas, tonturas), para de tomá-los, apesar da adesão continuar em $100 \%$. Orientada a tomar o NFV com alimentos. Apesar de relatar que o problema foi resolvido com o tempo, não há registros da retirada dos $\mathrm{ARV}$ em seu prontuário. Segue uma gravidez normal e tem seu filho no início de 2007.

PRM: Quanto à efetividade (potencial): Falta de adesão (SMAQ 2)

PRM: Quanto à segurança: Diarréia, náuseas e tonturas.

Estratégia e intervenção proposta: Trabalhada junto à gestante a importância do tratamento correto e orientada a conversar com médicos sobre possibilidade de alteração de esquema, pois provavelmente este fez com que a paciente deixasse de ser aderente (pelos efeitos adversos). Esclarecidas dúvidas sobre HIV, AIDS, TARV e parto.

Via de comunicação: Verbal, junto à própria gestante.

Resultado: Intervenção não aceita, problema não resolvido quanto à adesão. A paciente relata que os médicos preferiram manter o esquema para evitar resistência, apesar dos efeitos adversos. Intervenção não aceita, problema não resolvido.

No. de contatos: 4

\section{Gestante 11 - Camomila}

Camomila tem 27 anos, 8 a 11 anos de escolaridade. É caso de AIDS. Começa utilizando o esquema AZT/3TC 2 + NFV 10, juntamente com Compostos com ferro, Paracetamol, Cefalexina, Miconazol (creme vaginal), Levofloxacino e Ceftriaxona sem interações clinicamente significantes. Levofloxacino e Compostos de ferro não foram utilizados ao mesmo tempo. É assídua, cuida-se bastante, tendo 
boa adesão à terapia (SMAQ 1 e 2 sem respostas positivas, adesão de 100\%). No último trimestre passa a apresentar diarréia severa. Tem seu filho no final de 2006.

PRM: Quanto à segurança: Diarréia

Estratégia e Intervenção proposta: Trabalhada junto à gestante a importância do tratamento correto e orientada a conversar com médicos sobre possibilidade de trocar esquema devido aos efeitos adversos severos. Esclarecidas dúvidas sobre HIV, AIDS, TARV e parto. Orientada a utilizar NFV com alimentos.

Via de comunicação: Verbal, junto à própria gestante.

Resultado: Intervenção não aceita, problema não resolvido (médicos preferem manter esquema para evitar resistência).

No. de contatos: 5

\section{Gestante 12 - Copo de leite}

Copo de leite tem 32 anos, 8 a 11 anos de escolaridade. É caso de AIDS. Utiliza o esquema D4T(40) $2+3$ TC $2+\operatorname{LPVr} 6$ (10 comprimidos), juntamente com Ácido Fólico, Amoxicilina e Óleo mineral, sem interações clínicas significantes. Já teve vários problemas com infecções oportunistas, hoje parece se cuidar bastante. Tem boa adesão (SMAQ 1 e 2 sem respostas positivas, adesão de $100 \%$ ), tendo dúvidas apenas na associação entre os ARV e os alimentos. Segue uma gestação tranqüila tendo seu filho no final de 2006.

PRM: Quanto à efetividade (potencial) por utilização incorreta de LPVr

Estratégia e Intervenção proposta: Trabalhada junto à gestante a importância do tratamento correto. Esclarecidas dúvidas sobre HIV, AIDS, TARV e parto. Esclarecido que LPVr deve ser tomado com alimentos para melhor efeito.

Via de comunicação: Verbal, junto à própria gestante.

Resultado: Intervenção aceita, problema resolvido.

No. de contatos: 2

\section{Gestante 13 - Cravo}

Cravo tem 33 anos, nenhuma escolaridade. Pelo prontuário, sabe-se que começou a utilizar ARV pelo esquema AZT 6 juntamente com Compostos com Ferro, Amoxicilina, Penicilina (injetável) e Azitromicina, sem interações clínicas 
significantes e sem relato de eventos adversos. Depois passou a utilizar AZT/3TC 2 + NFV 10 (12 comprimidos), relatando o aparecimento de diarréia. Mensurada a adesão pelo SMAQ 1, obtém-se 3 respostas positivas e um percentual de $85 \%$ de adesão.

É usuária de drogas inalatórias. Mora em casa com único cômodo, de chão batido. Tem seu filho no segundo semestre de 2006 .

PRM: Quanto à efetividade: Falta de adesão (SMAQ 1)

PRM: Quanto à segurança: Diarréia

Estratégia e Intervenção proposta: Primeiro e único contato poucos dias antes do parto sendo trabalhada junto à gestante a importância do tratamento correto.

Via de comunicação: Verbal, junto à própria gestante.

Resultado: Não pode ser verificado se houve mudança de comportamento No. de contatos: 1

\section{Gestante 14 - Crisântemo}

Crisântemo tem 30 anos, 4 a 7 anos de escolaridade, paciente AIDS. Já utiliza o esquema AZT/3TC 2 + NVP 2 (4 comprimidos), em conjunto com Amoxicilina, Compostos com Ferro e Paracetamol, sem interações clínicas significantes. Relata anemia com este esquema. Pelo SMAQ 1, duas respostas positivas e percentual de adesão de $71 \%$. Em visita à sua residência, alega não estar sentindo movimentos fetais. Posteriormente, descobre-se não estar grávida (diagnosticado cisto).

PRM: Quanto à necessidade: Paciente AIDS que possui histórico de não usar ARV PRM: Quanto à efetividade: Uso incorreto de Compostos com Ferro.

PRM: Quanto à segurança: Anemia.

Estratégia e Intervenção proposta: Trabalhada junto à gestante a importância do tratamento correto e orientação sobre uso de Compostos com ferro.

Via de comunicação: Verbal, junto à própria gestante.

Resultado: Não foi possível mensurar nenhum resultado, pois não houve $o$ seguimento da paciente.

No. de contatos: 1 


\section{Gestante 15 - Dália}

Dália tem 27 anos, 4 a 7 anos de escolaridade, paciente AIDS. Inicia profilaxia com AZT/3TC $2+$ NFV 10 (12 comprimidos), juntamente com Paracetamol, Ranitidina e Prometazina sem interações clínicas significantes e sem relato de eventos adversos. SMAQ 1 oferece duas respostas positivas, apesar de percentual indicar $100 \%$ de adesão. Não é muito assídua no SAE. Alega ter dificuldades para tomar NFV. SMAQ 2 continua oferecendo 2 respostas positivas e $100 \%$ de adesão. Segue sua gravidez normalmente e tem seu filho no início de 2007.

PRM: Quanto à efetividade: Falta de adesão (SMAQ 1)

Estratégia e Intervenção proposta: Trabalhada junto à gestante a importância do tratamento correto e tomada junto com alimentos do NFV para melhorar tolerância a este medicamento. Esclarecidas dúvidas sobre HIV, AIDS, TARV e parto.

Via de comunicação: Verbal, junto à própria gestante.

Resultado: Intervenção não aceita, problema não resolvido (SMAQ 2)

No. de contatos: 2

\section{Gestante 16 - Dente de leão}

Dente de leão tem 35 anos, 8 a 11 anos de escolaridade, paciente AIDS. Utiliza o esquema D4T (40) $2+3$ TC $2+$ RTV $1+$ ATV 2 (7 comprimidos), juntamente com Escopolamina, Ciprofloxacino e Metoclopramida, sem interações clínicas significativas. Alega que os ARV causam náuseas. Adesão pelo SMAQ 1 e 2 sem respostas positivas, adesão de 100\%. Orientada a utilizá-los com alimentos, o que é importante quando associado ATV + RTV. Segue com sua gravidez, até seu término no segundo semestre de 2007.

PRM: Quanto à segurança: Náuseas.

Estratégia e Intervenção proposta: Trabalhada junto à gestante a importância do tratamento correto. Sugerido à gestante tomar medicamento com alimentos e que o medicamento prescrito (Metoclopramida) pode resolver problema de náuseas. Esclarecidas dúvidas sobre HIV, AIDS, TARV e parto.

Via de comunicação: Verbal, junto à própria gestante

Resultado: Intervenção aceita, resolvido problema com metoclopramida, PRM resolvido. 
No. de contatos: 5

\section{Gestante 17 - Gérbera}

Gérbera tem 17 anos, escolaridade de 4 a 7 anos. Utilizando AZT 6 juntamente com Compostos de Ferro, sem interações clínicas significativas. Bastante insegura, recusa-se no início a utilizar os ARV, pois não "sabe para que servem" e a receber uma visita em sua casa. Quando aceita participar do estudo, seu SMAQ apresenta duas respostas positivas e adesão de $71 \%$. Passa depois a utilizar o esquema ATC 2 + NFV 10 (12 comprimidos), sem relatar o uso de nenhum outro medicamento e sem eventos adversos. Com o passar do Seguimento, relata para a médica que as informações transmitidas por este método são importantes para ela. Mensurada a adesão pelo SMAQ 2, nenhuma resposta positiva e adesão de $100 \%$. Segue com gravidez tranqüila e tem seu filho no início de 2007.

PRM: Quanto à efetividade: Falta de adesão (SMAQ 1)

Estratégia e Intervenção proposta: Trabalhada junto à gestante a importância do tratamento correto. Esclarecidas dúvidas sobre HIV, AIDS, TARV e parto.

Via de comunicação: Verbal, junto à própria gestante

Resultado: Intervenção aceita, problema resolvido (melhora de adesão SMAQ 2)

No. de contatos: 5

\section{Gestante 18 - Girassol}

Girassol tem 34 anos, escolaridade de 4 a 7 anos. Inicia utilizando o esquema AZT 6, juntamente com Paracetamol, Diclofenaco e Escopolamina, sem interações clínicas significantes e diarréia como evento adverso. É orientada a observar se o evento adverso não passa após alguns dias ou semanas. Pelo SMAQ 1, apresenta duas respostas positivas e $43 \%$ de adesão. É usuária de drogas inalatórias. Passa depois ao esquema ATC 2 + NFV 10 (12 comprimidos) utilizando, ainda, Metronidazol (creme vaginal) sem interações clínicas significativas, sem eventos adversos ou dificuldades para utilizar ARV. Adesão mensurada pelo SMAQ 2 posteriormente demonstra ainda duas respostas positivas e $57 \%$ de adesão. Tem parto prematuro no final de 2006.

PRM: Quanto à efetividade: Falta de adesão (SMAQ 1) 
Quanto à segurança: Diarréia (Esquema 1)

Estratégia e Intervenção proposta: Trabalhada junto à gestante a importância do tratamento correto. Esclareceu-se, também, que várias vezes alguns eventos adversos (diarréia) desaparecem com o passar do tempo. Esclarecidas dúvidas sobre HIV, AIDS, TARV e parto.

Via de comunicação: Verbal, junto à própria gestante.

Resultado: Intervenção não aceita, problema não resolvido (Falta de adesão SMAQ 2). Intervenção aceita, problema de segurança resolvido.

No. de contatos: 3

\section{Gestante 19 - Hortência}

Hortência tem 31 anos, 4 a 7 anos como grau de escolaridade, paciente AIDS. Utiliza o esquema AZT 6 + EFZ 1 (7 comprimidos), juntamente com Etambutol e Isoniazida para tuberculose. É usuária de drogas inalatórias. Este esquema é abandonado logo que se confirma sua gravidez e passa a utilizar AZT/3TC $2+$ NFV 10 (12 comprimidos), juntamente com Metoclopramida, Dimeticona, Etambutol, Isoniazida, Ácido Fólico, Paracetamol, Escopolamina, Ceftriaxona, e Polivitamínico. Observada interação potencial de severidade moderada entre Isoniazida e Paracetamol. Relata diarréia e náuseas com este esquema. SMAQ 1 apresenta 3 respostas positivas e 0\% de adesão. Antes do segundo contato, vem a notícia que está internada no Hospital em estado grave, vindo a óbito alguns dias depois.

PRM: Quanto à efetividade: Falta de adesão (SMAQ 1).

PRM: Quanto à segurança: Diarréia, náuseas.

Estratégia e Intervenção proposta: Trabalhada junto à gestante a importância do tratamento correto e para observar intensidade dos eventos adversos.

Via de comunicação: Verbal, junto à própria gestante.

Resultado: Não foi possível mensurar nenhum resultado, pois não houve o seguimento da paciente.

No. de contatos: 1 


\section{Gestante 20- Hibisco}

Hibisco tem 23 anos, nenhuma escolaridade. Inicia a profilaxia com AZT 6, utilizando ainda Compostos com Ferro e Paracetamol, sem interações clínicas importantes e relatando azia com este esquema. Depois acontece a troca por esquema AZT/3TC $2+\mathrm{NFV} 10$ (12 comprimidos), sem o relato de outros medicamentos e de eventos adversos. Adesão mensurada por SMAQ 1 e 2 não apresenta respostas positivas, adesão de $100 \%$. Segue com gravidez tranquiila tendo seu filho no final de 2006.

PRM: Quanto à segurança: Azia (Esquema 1).

Estratégia e Intervenção proposta: Trabalhada junto à gestante a importância do tratamento correto. Esclarecido também que várias vezes alguns eventos adversos desaparecem com o passar do tempo. Esclarecidas dúvidas sobre HIV, AIDS, TARV e parto.

Via de comunicação: Verbal, junto à própria gestante.

Resultado: Intervenção aceita, problema resolvido.

No. de contatos: 3

\section{Gestante 21 - Jacinto}

Jacinto tem 31 anos, escolaridade de 8 a 11 anos. Começa utilizando o esquema AZT/3TC 2 + NFV 10 (12 comprimidos), associado com polivitamínicos, sem interações clínicas significativas. Não relata dificuldades ou eventos adversos, mas seu SMAQ 1 mostra uma resposta positiva, ainda que o nível de adesão seja de $100 \%$. Posteriormente, no SMAQ 2, não aparece nenhuma resposta positiva e adesão de $100 \%$. Tem gravidez tranquiila e filho nasce no início de 2007.

PRM: Quanto à efetividade: Falta de adesão (SMAQ 1)

Estratégia e Intervenção proposta: Trabalhada junto à gestante a importância do tratamento correto. Esclarecidas dúvidas sobre HIV, AIDS, TARV e parto.

Orientada quanto à tomada de NFV com alimentos.

Via de comunicação: Verbal, junto à própria gestante.

Resultado: Intervenção aceita, problema resolvido (Melhora de adesão - SMAQ 2). No. de contatos: 4 


\section{Gestante 22 - Jasmim}

Jasmim tem 27 anos, escolaridade de 8 a 11 anos. Inicia com esquema AZT 6, junto com Compostos com Ferro e Paracetamol, sem interações clínicas significativas, relatando anemia como evento adverso. Troca posteriormente para esquema AZT/3TC 2 + NFV 10 (12 comprimidos), tomado junto com Amoxicilina, sem interação clínica significativa. Apresenta náuseas como evento adverso neste esquema. Apesar de relatos de faltas às consultas, SMAQ 1 e 2 apresentam respostas negativas e $100 \%$ de adesão. Tem seu filho no início de 2007, sem outros problemas na gestação.

PRM: Quanto à segurança: Anemia (Esquema 1).

PRM: Quanto à segurança: Náuseas (Esquema 2).

Estratégia e Intervenção proposta: Trabalhada junto à gestante a importância do tratamento correto. Esclarecido também que várias vezes alguns eventos adversos desaparecem com o passar do tempo. Orientada a usar Compostos com Ferro longe de alimentos, com suco de laranja, e NFV com alimentos. Esclarecidas dúvidas sobre HIV, AIDS, TARV e parto.

Via de comunicação: Verbal, junto à própria gestante

Resultado: Intervenções aceitas, problemas resolvidos.

No. de contatos: 2

\section{Caso 23 - Lírio}

Lírio tem 26 anos, escolaridade de 4 a 7 anos. É paciente com AIDS utilizando o esquema AZT/3TC 2 + NVP 2 (4 comprimidos), paralelo ao Paracetamol, Diazepam, Sulfametoxazol + trimetoprim, Polivitamínicos e Compostos com Ferro. A associação AZT/3TC com Sulfametoxazol + trimetoprim deve ser utilizada com cuidado. Os eventos adversos relatados são anemia, náuseas, fraqueza, sonolência, inapetência. Usuária de drogas inalatórias. Apresenta uma resposta positiva tanto no SMAQ 1 quanto no SMAQ 2, apesar de em ambos o nível de adesão estar em $100 \%$ e de histórico de faltas ao SAE. Tem gestação tranqüila, com filho nascendo no primeiro semestre de 2007.

PRM: Quanto à efetividade: Falta de adesão (SMAQ 1)

PRM: Quanto à segurança: Anemia, náuseas, fraqueza, sonolência, inapetência. 
Estratégia e Intervenção proposta: Trabalhada junto à gestante a importância do tratamento correto. Esclarecido também que várias vezes alguns eventos adversos desaparecem com o passar do tempo. Orientada sobre as interações de NFV e Compostos com Ferro com alimentos.

Via de comunicação: Verbal, junto à própria gestante.

Resultado: Intervenções não aceitas, problemas não resolvidos (Falta de adesão SMAQ 2), eventos adversos persistem.

No. de contatos: 2

\section{Gestante 24 - Magnólia}

Magnólia tem 40 anos, nenhuma escolaridade. Angustiada por ter descoberto recentemente sua condição de portadora do vírus, durante o pré-natal. Começa utilizando o esquema AZT/3TC 2 + NFV 10, juntamente com Compostos com Ferro, sem interações clínicas importantes. Relata anemia com este esquema. Tanto o SMAQ 1 quanto o SMAQ 2 apresentam somente respostas negativas e o grau de adesão é estimado em $100 \%$. Sua gravidez corre tranqüila. Apesar de poder fazer uma cesárea antes, esta é feita praticamente no período previsto para o parto normal, já que queria fazer a cirurgia com a sua obstetra. Tem seu filho no primeiro semestre de 2007.

PRM: Quanto à segurança: Anemia

Estratégia e Intervenção proposta: Trabalhada junto à gestante a importância do tratamento correto. Esclarecido como usar sulfato ferroso para combater anemia. Orientada a utilizar NFV com alimentos. Esclarecidas dúvidas sobre HIV, AIDS, TARV e parto.

Via de comunicação: Verbal, junto à própria gestante.

Resultado: Intervenção aceita, problema resolvido.

No. de contatos: 5

\section{Gestante 25 - Margarida}

Margarida tem 17 anos, 4 a 7 anos de escolaridade. Descobre sua condição de soropositiva somente ao final de sua gestação, começando a tomar ARV com o esquema AZT/3TC 2 + NFV 10 (12 comprimidos) junto com Metronidazol, 
sem interações clínicas significantes. Não relata eventos adversos, nem dificuldades com esquema. Suas respostas são todas negativas no SMAQ 1 e o nível de adesão é estimado em 100\%. Sua gestação termina sem problemas, no final de 2006.

PRM: Não identificados PRM.

Estratégia e Intervenção proposta: Trabalhada junto à gestante a importância do tratamento correto. Esclarecidas dúvidas sobre HIV, AIDS e parto. Orientada quanto à necessidade de NFV ser tomado com alimentos.

Via de comunicação: Verbal, junto à própria gestante.

Resultado: Não foi proposta intervenção pois a paciente começou a tomar o medicamento muito próximo ao parto, não foi achado nenhum PRM.

No. de contatos: 1

\section{Gestante 26 - Miosótis}

Miosótis tem 27 anos, 4 a 7 anos de escolaridade. Está presa, e soube somente ao final da gestação que era portadora do vírus HIV. Começa utilizando o esquema AZT/3TC $2+\mathrm{NFV}$ 10. Usa em paralelo aos ARV os medicamentos Metronidazol (creme vaginal) e azitromicina, sem interações importantes. Não relata eventos adversos nem dificuldades com o uso dos ARV. Seu único SMAQ não apresenta respostas positivas e o nível de adesão é estimado em $100 \%$. Tem seu filho no início de 2007.

PRM: Não identificados PRM.

Estratégia e Intervenção proposta: Trabalhada junto à gestante a importância do tratamento correto. Esclarecidas dúvidas sobre HIV, AIDS e parto. Orientada a tomar NFV com alimentos.

Via de comunicação: Verbal, junto à própria gestante.

Resultado: Não foi proposta intervenção pois a paciente começou a tomar o medicamento muito próximo ao parto.

No. de contatos: 2

\section{Gestante 27 - Narciso}

Narciso tem 19 anos, 8 a 11 anos de escolaridade, e também está presa, descobrindo sua condição de soropositiva somente ao final da gestação. 
Começa utilizando o esquema AZT/3TC 2 + NFV 10 (12 comprimidos), paralelo ao uso de Paracetamol, sem interações importantes. Relata diarréia como evento adverso. Tem seu filho no início de 2007.

PRM: Quanto à segurança: diarréia.

Estratégia e Intervenção proposta: Trabalhada junto à gestante a importância do tratamento correto. Esclarecidas dúvidas sobre HIV, AIDS e parto. Orientada a observar evento adverso, que pode ser auto resolutivo.

Via de comunicação: Verbal, junto à própria gestante.

Resultado: Intervenção aceita, PRM resolvido.

No. de contatos: 2

\section{Gestante 28 - Orquídea}

Orquídea tem 32 anos, 4 a 7 anos de escolaridade. Inicia utilizando o esquema AZT/3TC $2+$ NFV 10 (12 comprimidos), sem relato de outros medicamentos. Relata como eventos adversos fraqueza e desânimo. Pelo SMAQ 1, nenhuma resposta positiva mas apenas $85 \%$ de adesão. No SMAQ 2, sem respostas positivas e $100 \%$ de adesão. Gravidez corre sem problemas, tem seu filho no primeiro semestre de 2007.

PRM: Quanto à segurança: Fraqueza, desânimo.

PRM: Quanto à efetividade: Falta de adesão (SMAQ 1).

Estratégia e Intervenção proposta: Trabalhada junto à gestante a importância do tratamento correto. Esclarecidas dúvidas sobre HIV, AIDS e parto. Orientada a observar se os sintomas não desaparecem com o tempo. Orientada a utilizar NFV com alimentos.

Via de comunicação: Verbal, junto à própria gestante.

Resultado: Intervenções aceitas, PRM resolvidos.

No. de contatos: 4

\section{Gestante 29 - Papoula}

Papoula tem 17 anos, 4 a 7 anos de escolaridade. Inicia o uso de ARV com AZT 6 , juntamente com Compostos com Ferro, sem interações importantes. Relata anemia como evento adverso. Nesse momento, seu SMAQ 1 apresenta duas 
respostas positivas e $85 \%$ de adesão. Passa depois ao esquema AZT/3TC $2+$ NFV 10 (12 comprimidos), continuando a usar Compostos com Ferro, ainda sem interações importantes, mas continuando com anemia, que só melhora no último trimestre da gravidez. SMAQ 2 não apresenta respostas positivas e nível de adesão é estimado em $100 \%$. Segue sem problemas, tendo seu filho no primeiro semestre de 2007.

PRM: Quanto à efetividade: (falta de adesão - SMAQ 1).

PRM: Quanto à segurança: Anemia.

Estratégia e intervenção proposta: Trabalhada junto à gestante a importância do tratamento correto. Esclarecidas dúvidas sobre HIV, AIDS e parto. Orientada a tomar sulfato ferroso longe das refeições e com suco de laranja, para melhorar de anemia. Observar junto com a médica a necessidade de monitoração mais freqüente ou não do grau de anemia, que pode ser tanto da gravidez quanto do uso do ARV. Orientada a usar NFV com alimentos.

Via de comunicação: Verbal, junto à própria gestante.

Resultado: Intervenção aceita, PRM resolvido (melhora de adesão - SMAQ 2). Intervenção aceita, melhora da anemia, PRM resolvido.

No. de contatos: 5

\section{Gestante 30 - Peônia}

Pêonia tem 33 anos, 4 a 7 anos de escolaridade. Inicia uso de ARV por AZT 6, juntamente com Paracetamol e Compostos com Ferro, sem interações significativas e sem relato de eventos adversos. Com SMAQ 1, apresenta uma resposta positiva, apesar de nível de adesão ser estimado em 100\%. Passa depois a utilizar AZT/3TC 2 + NFV 10 (12 comprimidos), continuando a utilizar também Paracetamol e Compostos com Ferro, sem interações importantes. Relata agora diarréia como evento adverso e dificuldade para engolir o NFV. SMAQ 2 não apresenta resposta positivas, com a adesão estimada em 100\%. Gravidez continua sem maiores problemas, tendo seu filho no primeiro semestre de 2007.

PRM: Quanto à efetividade: (falta de adesão - SMAQ 1)

PRM: Quanto à segurança: Diarréia

Estratégia e intervenção proposta: Trabalhada junto à gestante a importância do tratamento correto. Esclarecidas dúvidas sobre HIV, AIDS e parto. Orientada a 
observar se os sintomas não desaparecem com o tempo. Orientada a tomar o NFV com alimentos.

Via de comunicação: Verbal, junto à própria gestante.

Resultado: Intervenção aceita, PRM resolvido (melhora de adesão - SMAQ 2). Intervenção aceita, melhora da diarréia, melhora na tomada do NFV. PRM resolvido. No. de contatos: 4

\section{Gestante 31 - Tulipa}

Tulipa tem 23 anos, 4 a 7 anos de escolaridade. Usuária de drogas inalatórias. Prefere fazer pré-natal na Unidade Básica de Saúde, apesar de faltar muito às consultas. Iniciou com AZT 6, junto com Metronidazol (creme vaginal), Albendazol, Cefalexina e Compostos com Ferro, sem interações importantes. Relatou anemia com este esquema. Passou depois ao uso de AZT/3TC 2 + NFV 10 (12 comprimidos), associado somente com Compostos com Ferro, relatando náuseas com o uso do NFV. Somente ao final da gestação parece se preocupar mais e procura o SAE, aceitando participar do estudo. SMAQ 1 apresentou 3 respostas positivas e $28 \%$ de adesão. Logo em seguida tem seu filho, no final do primeiro semestre de 2007.

PRM: Quanto à efetividade: Falta de adesão (SMAQ 1).

PRM: Quanto à segurança: Náuseas.

Estratégia e Intervenção proposta: Trabalhada junto à gestante a importância do tratamento correto. Esclarecidas dúvidas sobre HIV, AIDS e parto. Orientada a observar se os sintomas não desaparecem com o tempo, pois começou a tomar os medicamentos muito próximo ao parto. Orientada a tomar NFV com alimentos e uso correto de Compostos com Ferro.

Via de comunicação: Verbal, junto à própria gestante.

Resultado: Não foi possível observar resultado, pois o primeiro contato ocorreu muito próximo ao término da gestação.

No. de contatos: 1

\section{Gestante 32 - Violeta}

Violeta tem 24 anos, 4 a 7 anos de escolaridade. Já é paciente com AIDS, fazendo uso do esquema AZT/3TC 2 + NVP 2 (4 comprimidos), juntamente 
com Compostos com Ferro e Paracetamol, sem interações clínicas importantes. Relata como eventos adversos anemia, fraqueza, desânimo. SMAQ 1 apresenta 3 respostas positivas, com nível de adesão em 100\%, sem relatos de dificuldades em tomar os ARV. Orientada sobre a utilização Compostos com Ferro associados com alimentos. Feito SMAQ 2, sem respostas positivas e adesão novamente de $100 \%$. Gestação sem problemas, tem seu filho já no início do segundo semestre de 2007.

PRM: Quanto à efetividade: Falta de adesão (SMAQ 1).

PRM: Quanto à segurança: Anemia, fraqueza, desânimo.

Estratégia e Intervenção proposta: Trabalhada junto à gestante a importância do tratamento correto. Esclarecidas dúvidas sobre HIV, AIDS e parto. Orientada a observar se os sintomas não desaparecem com o tempo. Orientada a tomar compostos com ferro longe de alimentos, com suco de laranja.

Via de comunicação: Verbal, junto à própria gestante.

Resultado: Intervenção aceita, PRM resolvido (melhora da adesão - SMAQ 2). Intervenção aceita, melhora dos sintomas, PRM resolvido.

No. de contatos: 4 
ARTIGO 1 (Título Provisório)

PERFIL EPIDEMIOLÓGICO E CARACTERÍSTICAS DO PRÉ-NATAL E DO PARTO DE MULHERES COM HIV/AIDS DO MUNICÍPIO DE ITAJAÍ, $\mathrm{SC}$ 
PERFIL EPIDEMIOLÓGICO E CARACTERÍSTICAS DO PRÉ-NATAL E DO PARTO DE MULHERES COM HIV/AIDS DO MUNICÍPIO DE ITAJAÍ, SC

EPIDEMIOLOGIC PROFILE AND PRENATAL CARE AND DELIVERY CHARACTERISTICS OF HIV INFECTED PREGNANT WOMEN IN ITAJAÍ, SC

Benedito Carlos Cordeiro ${ }^{1}$, Nicolina Silvana Romano-Lieber ${ }^{2}$

${ }^{1}$ Professor do Curso de Farmácia da Universidade do Vale do Itajaí - UNIVALI. R.

Uruguai 458 - Centro. Itajaí, SC, Brasil. CEP 88302-202

${ }^{2}$ Professora do Departamento de Prática em Saúde Pública, Faculdade de Saúde Pública da Universidade de São Paulo - FSP/USP. Av. Dr. Arnaldo, 715 - São Paulo, SP, Brasil. CEP: 01246-904

Correspondência para:

Benedito Carlos Cordeiro

Curso de Farmácia / UNIVALI

R. Uruguai, 458 - Centro

Itajaí, SC, Brasil

Telefone: 554733417540

E-mail: bcordeiro@terra.com.br 


\section{RESUMO}

Introdução. $\mathrm{O}$ aumento do número de casos de AIDS entre as mulheres ocasionou um acréscimo na transmissão vertical do HIV. Entretanto, hoje há várias intervenções que evidenciam a redução dos riscos dessa transmissão, sendo a principal delas a utilização dos anti-retrovirais (ARV) no pré-natal, durante o parto e também para a criança recém-nascida. Conhecer este uso é essencial para traçar estratégias de combate a essa forma de transmissão. Objetivo. Analisar o perfil epidemiológico de gestantes HIV+ atendidas em Serviço de Atendimento Especializado em DST/AIDS (SAE) em Itajaí, Santa Catarina, bem como as características do seu pré-natal e parto. Material e métodos. A amostra foi obtida de modo consecutivo, não aleatório, após convite a todas as gestantes que realizaram pré-natal no SAE. Os dados foram obtidos em seguimento prospectivo e também em prontuários e fichas de notificações, no período de julho de 2006 a julho de 2007. Resultados. Foram seguidas 32 gestantes, com idade média de 27,1 anos (IC 95\% 24,9 - 29,3). Mais de $90 \%$ delas tiveram 4 ou mais consultas de pré-natal, $81 \%$ iniciaram a profilaxia com ARV antes da $28^{\mathrm{a}}$. semana ou já estavam em tratamento com esses medicamentos. $86 \%$ dos partos foram via cirurgia cesárea e $15 \%$ das crianças podem ser classificadas como de baixo peso ao nascer. Conclusão. Embora tenham sido identificadas falhas no pré-natal, o serviço pode ser considerado satisfatório e de acordo com os protocolos e diretrizes do Ministério da Saúde.

Palavras-chave: Pré-natal; HIV; AIDS; transmissão vertical; anti-retrovirais. 


\section{ABSTRACT}

Introduction. The increased number of AIDS cases among women caused an augmentation in mother-to-child HIV transmission (TMTC). Today, several interventions present evidences of risks reduction of transmission, the main of them the use of antiretrovirals in prenatal care, during the delivery and also for the newly born baby. To know this use is essential to plan fight strategies to this form of transmission. Objective. To analyze the epidemiologic profile of the HIV infected pregnant women assisted in a Specialized Assistance Service (SAS) in STD/AIDS in Itajaí, Santa Catarina, besides the characterization of prenatal carte and delivery. Material and methods. The sample was obtained in a not random consecutive way, after invitation to all pregnant women that accomplished prenatal care in the SAS. The data were obtained prospectively in medical records and notifications' formularies, in the period from July 2006 to July 2007. Results. 32 women were followed-up, which had median age 27,1 years. More than $90 \%$ had 4 or more medical consultations of prenatal care, $81 \%$ initiated prophylaxis before 28th week or were already in treatment with anti-retroviral, $86 \%$ of the deliveries were through cesarean surgery and $15 \%$ of the children can be classified as low weight at birth. Conclusion. In spite of some problems detected, the facility can be considered satisfactory in agreement with protocols and guidelines of the Ministry of Health.

Key-words: Prenatal care; HIV; AIDS; antiretrovirals; mother-to-child transmission. 


\section{INTRODUÇÃO}

Com o aumento do número de casos de AIDS entre as mulheres, a transmissão vertical do HIV passou a ser cada vez mais freqüente, sendo responsável pela quase totalidade de casos de infecção HIV/AIDS em crianças. Em função desta realidade, estudos foram feitos para evitar a passagem do vírus entre mãe e filho, sendo que, em 1994, um estudo multicêntrico (Pediatric Aids Clinical Trials Group - PACTG 076), chegou à conclusão de que a administração de Zidovudina (AZT) na gestação, no parto e para o recém-nascido reduziriam a taxa de transmissão de aproximadamente $25 \%$ para $8,3 \%^{1}$.

Entretanto, se forem observadas outras intervenções preventivas, este percentual reduz-se ainda mais, situando-se entre 0 e $2 \%$. Entre estas intervenções, podem ser citadas: o uso de anti-retrovirais combinados; o parto por cirurgia cesariana eletiva para mulheres com cargas virais elevadas ou desconhecidas e com a quimioprofilaxia de AZT injetável durante o trabalho de parto; a administração de AZT oral para o recém-nascido exposto, do nascimento até 42 dias de vida; e a não-amamentação, associada ao fornecimento de fórmula infantil até os seis meses de idade $\mathrm{e}^{1,2}$.

Há evidências que mostram que a maior parte dos casos de transmissão vertical do HIV (em torno de 65\%) ocorre no trabalho de parto e no parto propriamente dito, e os $35 \%$ restantes ocorrem intra-útero especialmente no último trimestre da gestação. Há ainda o risco adicional de transmissão pela lactação, renovável a cada exposição da criança ao peito (mamada), estimada em 7 a $22 \%$, podendo este percentual chegar a $30 \%$ se a infecção da lactante ocorrer durante o período da amamentação ${ }^{2}$.

Outros fatores de risco para a transmissão são, ainda, a via de parto e o parto prolongado, em função da carga viral nas secreções cérvico-vaginais; a ruptura de 
bolsa amniótica por mais de quatro horas e a presença de hemorragia intra-parto; a carga viral (em especial na hora do parto), o genótipo e o fenótipo viral; o estado clínico e imunológico e nutricional das mulheres, presença de Doenças Sexualmente Transmissíveis e outras co-infecções; o tempo de uso dos anti-retrovirais na gestação; fatores comportamentais da mulher como o uso de drogas e relações sexuais desprotegidas; prematuridade e baixo peso da criança e o aleitamento materno ${ }^{2}$. Todavia, após análise multivariada ficou evidenciado que o mais importante preditor da transmissão é a carga viral no momento do parto ${ }^{3}$.

A caracterização destes fatores reveste-se de importância para estipular estratégias mais eficazes da profilaxia da transmissão vertical do vírus HIV. Assim, o objetivo deste trabalho foi analisar o perfil epidemiológico de gestantes HIV+ atendidas em Serviço de Atendimento Especializado em Itajaí, Santa Catarina bem como as características do pré-natal e do parto a que foram submetidas.

\section{MATERIAL E MÉTODOS}

Foi realizado um estudo descritivo, prospectivo, a partir do seguimento de gestantes HIV positivas no Serviço de Atendimento Especializado (SAE) em Doenças Sexualmente Transmissíveis e HIV/AIDS do município de Itajaí, instituição pública que funciona como o único Centro de Referência para HIV/AIDS no município.

A amostra estudada foi consecutiva, não probabilística, com período de coleta de dados entre julho de 2006 a julho de 2007. Foi oferecida a possibilidade de participar do estudo a todas as gestantes HIV+ que tiveram essa condição confirmada e que fossem ao SAE em busca de atendimento para ali realizarem seu pré-natal ou mesmo para conseguirem os medicamentos anti-retrovirais. 
Para a coleta de dados, utilizou-se uma metodologia de seguimento farmacoterapêutico - Método Dáder ${ }^{4}$, técnica que enfatiza os problemas advindos com a utilização de medicamentos e tenta solucioná-los, além de dados obtidos de prontuários e das Fichas de Investigação de Agravo Gestante HIV+ e Crianças Expostas e da Declaração de Nascidos Vivos, ambas fornecidas pela Secretaria Municipal de Saúde de Itajaí.

Foram explicados a todas as gestantes que oficializaram sua participação através de Termo de Consentimento Livre e Esclarecido os aspectos éticos da pesquisa, como anonimato e sigilo e que o seguimento aconteceria enquanto a mulher estivesse grávida. Obteve-se o consentimento formal da Secretaria Municipal de Saúde de Itajaí e aprovação pelo Comitê de Ética em Pesquisa da Faculdade de Saúde Pública da Universidade de São Paulo.

Para elaborar a distribuição de frequiência dos dados e outras análises estatísticas, foi empregada a planilha eletrônica Excel® para Windows, versão 2003.

\section{RESULTADOS}

No período compreendido entre 01/07/2006 a 31/01/2007, foram atendidas 37 gestantes HIV positivas no Serviço de Atendimento Especializado de Itajaí (SAE), das quais, depois de convidadas a fazer parte do estudo, 32 aceitaram, 3 recusaram e outras duas não puderam ser contatadas.

As 32 gestantes que aceitaram foram acompanhadas no período compreendido entre 05/07/2006 a 13/07/2007, quando a última teve seu filho.

Das 32, uma descobriu-se não ser gestante, pois estava com um cisto que, a princípio, sugeria tratar-se de um embrião, o que foi descartado depois. Os dados 
iniciais tomados desta mulher foram mantidos, pois independiam do fato dela ser ou não gestante, era mais importante sua percepção como tal. Uma outra gestante foi a óbito antes de terminar sua gestação.

As pacientes que fizeram o pré-natal no SAE eram procedentes, em sua maioria, da própria cidade de Itajaí (27 gestantes) e de Florianópolis, Balneário Camboriú e Ilhota (uma gestante de cada cidade). Duas gestantes eram do presídio municipal de Itajaí.

As características sócio-demográficas das gestantes estão apresentadas na tabela 1.

Na tabela 2, são apresentados dados referentes ao exame de pré-natal das gestantes pesquisadas.

A utilização dos ARV pode ser melhor visualizada pela tabela 3, junto a outras informações tais como número de casos já notificados como AIDS, idade gestacional do início do uso de anti-retrovirais e tempo total de utilização destes medicamentos. Apenas 8 gestantes sabiam a sua carga viral após a $34^{\mathrm{a}}$. semana de gestação, o que interferiu na escolha da via de parto e demonstra mais uma vez que os exames laboratoriais são um "nó" crítico para a profilaxia da TMI (o aparelho para a realização dos exames permaneceu quebrado por quase todo o período da coleta de dados). Isto interferiu nas características dos partos que ocorreram, conforme descrito na tabela 4.

As crianças nascidas destas gestantes apresentaram as características descritas na tabela 5. As variáveis são o peso ao nascer, em gramas, e o Apgar tomado no primeiro minuto de vida e decorridos 5 minutos do nascimento.

\section{DISCUSSÃO}


A maioria $(84,4 \%)$ das gestantes é do próprio município de Itajaí, como seria de se esperar em função da elevada incidência de pessoas infectadas no município e da feminização da doença. As pacientes provenientes de Florianópolis e Balneário Camboriú provavelmente fizeram seu pré-natal no serviço ou por reconhecerem sua qualidade ou por preferirem fazê-lo fora de seus municípios, garantindo algum sigilo sobre sua condição. A paciente de Ilhota foi encaminhada por aquele município em função do mesmo não oferecer atendimento especializado na área, sendo Itajaí a referência neste serviço. Separaram-se as gestantes que estavam no presídio municipal, pois para as mesmas não havia escolha quanto ao local de realização do pré-natal. Mulheres detentas apresentam maior risco de infecção pelo HIV, além de uma maior prevalência que a população em geral, e sua vulnerabilidade deveria ser constante preocupação para uma estratégia de controle da $\operatorname{AIDS}^{5}$.

O predomínio da faixa etária de 20 a 34 anos é previsível, já que este estrato compreende grande parte da vida fértil da mulher. O segundo estrato etário com maior frequiência de casos é o que vai de 15 a 19 anos. O número de gestantes adolescentes reforça a necessidade de políticas de informação para o controle de natalidade, inexistindo ações sistemáticas de aconselhamento quanto ao planejamento familiar na maioria dos programas de $\mathrm{AIDS}^{6}$.

A maioria das mulheres $(87,5 \%)$ apresentava escolaridade intermediária. É de ressaltar, entretanto, a presença de mulheres com nenhuma escolaridade na amostra. A epidemia, em especial nas mulheres, vem crescendo entre aquelas com menor grau de escolaridade e, se este for considerado um indicativo de renda, é mais um indício demonstrativo da gradativa "pauperização" da doença? . 
Em relação à distribuição dos casos segundo raça, percebe-se o predomínio de mulheres da raça branca, refletindo a composição étnica majoritária em Santa Catarina.

O comportamento de risco apontado por $100 \%$ das gestantes infectadas foi a relação sexual desprotegida, o que demonstra a vulnerabilidade da mulher. Chamou a atenção, porém, o uso de drogas lícitas ou ilícitas, relatado por mais de $20 \%$ da amostra. O consumo de crack está fortemente ligado à prostituição, pois quando os usuários esgotam seus recursos pode acontecer o comércio do próprio corpo. Em uma situação de desespero, há possibilidade da dispensa do preservativo ou o pagamento de um preço irrisório pela relação sexual, com um consequiente aumento do número de parceiros para alcançar a quantia necessária para a compra da droga ${ }^{8}$. Desta amostra, quando perguntadas qual a profissão que exerciam, 18 mulheres afirmaram ser "do lar". Quando comparadas estas respostas com seus prontuários, em 3 desses constava tratarem-se de profissionais do sexo.

Outros problemas relacionados ao crack são microinfartos placentários que permitem a passagem transplacentária do vírus, predisposição ao descolamento prematuro de placenta ou, ainda, estar relacionado a disfunções metabólicas ${ }^{9,10}$.

A maconha não está associada a efeitos gestacionais adversos podendo, entretanto, aumentar a taxa de partos prematuros. Além disso, sua associação com o álcool ocasiona maior frequiência de crianças com síndrome alcólica fetal do que em mães que usaram isoladamente o álcool, este risco aumentando quando as mulheres forem consideradas bebedoras contumazes, isto é, usuárias de mais de seis drinques, copos de vinho ou cerveja por dia ${ }^{11}$. Some-se a isso o fato de possíveis interações medicamentosas com os medicamentos utilizados contra o HIV. 
Há relatos na literatura de associação entre o fumo e alterações placentárias, crescimento intra-uterino restrito, corioamniorrexe prematura, resultando em trabalho de parto pré-termo. Todas estas complicações estão ligadas ao aumento da taxa de transmissão perinatal do HIV, além da possibilidade de aborto espontâneo, mortalidade perinatal e malformações congênitas ${ }^{9,11}$.

O pré-natal tem como características cruciais a qualidade e a humanização. Isso implica no estabelecimento de vínculos sólidos entre o profissional de saúde e a gestante, garantido também pela provisão dos recursos necessários para que, ao final da gravidez, nasça uma criança saudável e se garanta o bem-estar materno e neonatal. A capacidade de dialogar, sensibilidade e capacidade de percepção, sem julgamentos, preconceitos e com garantia de sigilo, dão à gestante segurança para falar de sua intimidade, em um dos momentos mais importantes de sua vida ${ }^{12}$.

Graças a estas peculiaridades, o pré-natal é também um momento essencial para uma abordagem de redução de riscos e de educação em saúde, passando pelo aconselhamento quanto à realização do teste anti-HIV.

Em que pese a elevada cobertura do pré-natal no Brasil, cerca de $85 \%^{1}$, várias deficiências podem ser apontadas quando de sua realização: o início tardio, a falta de qualidade da consulta em si, a escassez de práticas educativas e de aconselhamento, o difícil acesso aos exames diagnósticos laboratoriais e a falta de um sistema articulado com hierarquização.

Deste modo, denota-se que os problemas no pré-natal não são quantitativos, mas sim qualitativos. Vários relatos na literatura apontam para os problemas da qualidade no pré-natal $^{13,14,15}$, que representam a perda de oportunidades de prevenção quanto ao HIV e outros agravos. Uma dessas perdas se refere ao início tardio do pré-natal e ao 
número de consultas, já que há relatos que a primeira consulta antes da $12^{\text {a }}$. semana e o aumento de visitas pré-natais impactou significativamente na redução de taxas de nascimento pré-termo e de fetos de baixo peso e muito baixo peso ${ }^{16}$.

O Ministério da Saúde ${ }^{1}$ estipulou como parâmetros a serem seguidos por estados e municípios a captação precoce das gestantes, com realização da primeira consulta de pré-natal antes de 16 semanas e a realização de no mínimo seis consultas de prénatal, valores superiores aos do Pacto pela Vida ${ }^{17}$, que definiu como indicador de saúde da mulher o percentual de gestantes com 4 ou mais consultas de pré-natal. Isto se deve a enorme desigualdade no oferecimento do pré-natal, tanto entre as diferentes regiões do Brasil como em relação às diferentes raças que compõem o espectro populacional brasileiro ${ }^{18}$.

Dentro destas recomendações, a amostra apresentou resultados que podem ser considerados satisfatórios. Quase $72 \%$ das gestantes tiveram 7 ou mais consultas; destas, as duas mulheres negras e duas pardas fizeram 7 consultas ou mais, uma fez de 4 a 6 consultas e a outra de 1 a 3 consultas. Contudo, quando se investiga a idade de início do pré-natal, observa-se que, destas seis gestantes, apenas uma começou antes da $14^{\mathrm{a}}$ semana.

Das gestantes acompanhadas, 17 (53,13\%) sabiam de sua condição de soropositivas para o vírus HIV antes do pré-natal e $15(46,88 \%)$ ficaram sabendo durante o prénatal. Isto mostra, ao menos neste quesito, a qualidade deste serviço na cidade, contribuindo para a diminuição de situações de vulnerabilidade das gestantes, além de garantir precocidade à profilaxia da transmissão materno-fetal do vírus HIV. $\mathrm{Na}$ amostra estudada, 11 gestantes (aproximadamente 1/3) já haviam sido notificadas como casos de AIDS. Existe uma associação entre as mulheres notificadas como 
AIDS e as que estavam fazendo uso de ARV quando da notificação da gestante como HIV+. É primordial que, para a definição da terapêutica da gestante, esteja claro se a estratégia será somente a prevenção da transmissão vertical - profilaxia com TARV - ou também o tratamento para a mulher que necessitar dessa terapia por haver indicação, em função de estado clínico ou imunológico comprometido.

Tanto a carga viral elevada quando associada à monoterapia com AZT, quanto o tratamento anti-retroviral com esquema duplo induzem o aparecimento de resistência aos anti-retrovirais, prejudicando o tratamento posterior. Isso, somado à ampla comprovação da eficácia da terapia anti-retroviral combinada, tornaram a HAART (Highly Active Antiretroviral Therapy) a melhor opção para o tratamento profilático das gestantes infectadas pelo $\mathrm{HIV}^{1}$.

O Ministério da Saúde ${ }^{1}$ estipula 3 cenários possíveis para a profilaxia baseando-se justamente no uso prévio ou não da TARV. Assim, os dois primeiros referem-se às pacientes que ainda não fazem uso destes medicamentos, o último é aplicado para as que já fazem uso. Para estas gestantes, devem ser informados os potenciais riscos e benefícios da manutenção, modificação ou suspensão do tratamento, tanto para a evolução de sua própria doença quanto a possíveis efeitos teratogênicos para a criança.

Um dos principais critérios definidores dos cenários 1 e 2 dizem respeito à idade gestacional de início da profilaxia ARV. Idealmente, esta deve ser iniciada a partir da $14^{\mathrm{a}}$. semana de gestação. $\mathrm{Na}$ amostra, $43,7 \%$ das mulheres iniciou a profilaxia dentro deste período.

Ainda que não haja estudos conclusivos, acredita-se que a transmissão intra-útero ocorra predominantemente no último trimestre, sugerindo que, em gestantes que não 
apresentam outros fatores associados (tais como toxoplasmose, citomegalovirose, sífilis e uso de drogas ilícitas), a terapia pode ser iniciada com 28 semanas de gestação sem aumento do risco de transmissão intra-útero ${ }^{3}$. Assim, preocupa o percentual de gestantes, $15,6 \%$, que iniciou a profilaxia depois desse período e que, consequentemente, está mais sujeita ao risco de transmissão do vírus aos fetos.

É de se destacar, ainda, que apesar de amplamente comprovado que o uso de ARV é capaz de reduzir significativamente a carga viral plasmática do HIV para níveis indetectáveis, uma das mulheres acompanhadas não fez uso, por se recusar a usar estes medicamentos. A recusa em tomar os medicamentos é a causa mais freqüente da não utilização dos $\mathrm{ARV}^{19}$. E, se a recusa em tomar os $\mathrm{ARV}$, como direito pessoal, já é polêmica, esta aumenta quando há outro indivíduo envolvido sem chance de realizar escolhas.

Recente revisão sistemática ${ }^{20}$ afirma que o tratamento de longo prazo com AZT tem expressivos resultados na diminuição dos riscos da transmissão vertical, embora importantes benefícios, porém menos pronunciados, também tenham sido encontrados no uso deste medicamento por curto período de tempo. Embora não haja uma clara definição do que seja um tratamento de longo e um de curto prazo, parece claro que a utilização dos anti-retrovirais por um período de tempo maior que seis semanas seja mais efetiva do que por períodos inferiores. $\mathrm{Na}$ amostra estudada, o percentual de mulheres que usaram a TARV por menos de seis semanas foi de quase $10 \%$.

Percebe-se um número substancial de partos pela via cesárea (acima de 80\%). Tal resultado está de acordo com o esperado, em função das recomendações do Ministério da Saúde ${ }^{1}$, que preconiza, para mulheres com carga viral desconhecida ou 
acima de 1000 cópias/ml, o parto por operação cesariana eletiva. Estas são as mesmas recomendações encontradas nos Estados Unidos ${ }^{21}$ que, entretanto, levantam dúvidas quanto à necessidade de mulheres com carga viral menor que 1000 cópias/ml também fazerem a cirurgia cesariana ${ }^{22}$.

Levando-se em consideração que a cesariana, apesar de recomendada, pode também estar associada ao aumento de morbidades e do risco de infecções decorrentes do processo invasivo, torna-se essencial que a paciente e seus familiares sejam alertados sobre os benefícios e riscos da escolha da via de parto, considerando-se, além da avaliação obstétrica, o desejo da mãe quando possível ${ }^{23}$.

Considerando-se que para muitas gestantes a cesárea eletiva será a via de parto escolhida, a idade gestacional das gestantes torna-se essencial, evitando-se a prematuridade. Esta cirurgia estaria recomendada entre a $38^{\text {a }}$. e $39^{\text {a }}$. semana, antes do rompimento das membranas. No caso destas romperem-se antes da $34^{\mathrm{a}}$. semana, a conduta deve ser particularizada, em função da falta de evidências clínicas nesta situação ${ }^{1}$.

O tempo de ruptura da bolsa amniótica apresenta números preocupantes em relação às mulheres estudadas, pois em $15 \%$ dos partos houve um tempo superior a 4 horas, percentual mais elevado que o verificado em outros estudos ${ }^{10,23}$. Este fator de risco para a transmissão vertical do HIV mostra informações discordantes na literatura: se há estudos dizendo que a transmissão vertical aumenta significativamente após cada hora passadas aquelas quatro horas ${ }^{1}$, há outros contradizendo a afirmação ${ }^{9}$.

As gestantes que compuseram a amostra fizeram uso da TARV durante o parto em percentuais muito semelhantes aos descritos na literatura ${ }^{10,23,24}$, o que demonstra que o consenso brasileiro para a profilaxia da transmissão materno-infantil do HIV está 
sendo seguido pelos hospitais de Itajaí, ainda que tal resultado encontre-se longe dos $100 \%$ desejados.

Mais de $80 \%$ das crianças nascidas das parturientes HIV+ fizeram uso do AZT ou outro anti-retroviral antes das primeiras 24 horas de vida, percentual também observado em outro estudo ${ }^{24}$. O consenso brasileiro, assim como o protocolo para a prevenção da transmissão vertical, recomendam que a criança receba a primeira dose de medicamento imediatamente após o parto ou nas primeiras duas horas de vida, podendo-se ainda esperar pelas primeiras 8 horas caso a mãe tenha recebido o ARV durante o parto. Este prazo, entretanto, não poderá ultrapassar as 48 horas iniciais, pois não há comprovação de benefício da profilaxia passado este período de tempo ${ }^{1,2}$. Embora a infecção pelo HIV não seja fator de risco para o baixo peso ou Apgar baixo, diversos autore ${ }^{23,24,25}$ concordam que o baixo peso da criança e maior risco da transmissão do vírus estão associados.

Observa-se que mais de $15 \%$ das crianças nasceu com peso inferior a $2500 \mathrm{~g}$, característico de baixo peso. Em relação ao Apgar, uma única criança apresentou Apgar índice 2,0 no primeiro minuto e 7,0 na segunda medida, característico de asfixia leve, representando um percentual de 3\% das crianças, próximo aos $4 \%$ verificados em estudo que avaliou hospitais de quatro regiões do Brasil ${ }^{25}$. E, apesar de todas as crianças terem nascido sem registro de anomalias, no caso específico daquela criança ficou comprovado posteriormente, durante internamento hospitalar próximo ao parto, ascite fetal intra-útero, sugestivo de mal-formação congênita. Apesar da limitação causada pelo baixo número de gestantes participantes do estudo, ainda que representassem praticamente toda população de gestantes com HIV/AIDS do município, naquele período, pelos dados apresentados, percebe-se que não há 
grande discordância do que é preconizado pelo Ministério da Saúde em suas diretrizes e protocolos ou do verificado em estudos semelhantes. Se, de um lado, percebe-se que ainda há muito a ser feito para atingir a condição que seria desejável para o serviço de pré-natal, a começar por políticas de informação e comunicação, por outro se nota que os principais parâmetros deste estudo (características da assistência ao pré-natal, parto e às crianças nascidas daquelas gestantes) demonstram a efetividade das medidas adotadas para minimizar a possibilidade da transmissão vertical no município.

\section{REFERÊNCIAS}

1. Ministério da Saúde. Protocolo para a prevenção de transmissão vertical de HIV e sífilis. Brasília: SVS/PN-DST/AIDS; 2006.

2. Ministério da Saúde. Recomendações para profilaxia da transmissão vertical do HIV e terapia anti-retroviral em gestantes. Brasília: SVS/PN-DST/AIDS; 2007.

3. Senise J. Evitando a transmissão vertical. Adesão em foco 1. Bristol-Myers Squibb; sd. Disponível em: http://www.infoaids.com.br/encontre/ Biblioteca3/ADESÃO EM FOCO 1.pdf

4. Grupo de Investigación en Atención Farmacéutica. Universidad de Granada. Seguimiento farmacoterapéutico: Método Dáder (3a. Revisión: 2005). Pharmacy Practice 2006; 4(1): 44-53.

5. Strazza L, Massad E, Azevedo Raymundo S, Carvalho Heráclito B. Estudo de comportamento associado à infecção pelo HIV e HCV em detentas de um presídio de São Paulo, Brasil. Cad. Saúde Pública 2007; 23(1): 197-205. 
6. Santos NJS, Buchalla CM, Fillipe EV, Bugamelli L, Garcia S, Paiva V. Mulheres HIV positivas, reprodução e sexualidade. Rev. Saúde Pública 2002; 36(4 Supl): 12-23.

7. Bastos FI \& SZWARCWALD CL. AIDS e pauperização: principais conceitos e evidências empíricas. Cad Saúde Pública 2000; 16(Sup.1): 65-76.

8. Nappo $\mathrm{S}$ (pesquisadora principal). Comportamento de risco de mulheres usuárias de crack em relação às DST/AIDS. São Paulo: CEBRID; 2004.

9. Duarte G, Quintana SM, El Beitune P. Fatores que influenciam a transmissão vertical do vírus da imunodeficiência humana tipo 1. RBGO 2005; 27(11): 698705.

10. Gianvecchio RP \& Goldberg TBL. Fatores protetores e de risco envolvidos na transmissão vertical do HIV-1. Cad. Saúde Pública 2005; 21(2): 581-588.

11. Peres RM \& Spritzer DT. Álcool, fumo e outras drogas. In: Sanseverino MTV, Spritzer DT, Schüler-Faccini L (org.). Manual de Teratogênese. Porto Alegre: Editora da Universidade/UFRGS; 2001. p. 451-467.

12. Ministério da Saúde. Pré-natal e Puerpério: atenção qualificada e humanizada manual técnico. Brasília: SAS/Departamento de Ações Programáticas Estratégicas; 2006.

13. Feliciano KVO \& Kovacs MH. Vulnerabilidade programática na prevenção da transmissão materno-fetal da AIDS. Rev. bras. saúde matern. infant. 2002; 2(2): $157-165$.

14. Souza Jr PRB, Szwarcwald CL, Barbosa Jr A, Carvalho MF, Castilho EA. Infecção pelo HIV durante a gestação: Estudo-Sentinela Parturiente, Brasil, 2002. Rev Saúde Pública 2004; 38(6): 764-772. 
15. Araújo MAL, Vieira NFC, Bucher JSN. Aconselhamento pré e pós-teste antiHIV como estratégia da melhoria da cobertura de testagem em gestantes e prevenção da transmissão vertical do HIV. Boletim epidemiológico AIDS/DST 2006; Ano III (1):16-22.

16. Morais EN, Alflen TL, Spara P, El Beitune P. Momento e freqüência da visitas de pré-natal: repercussões sobre os nascimentos pré-termo. RBGO 1998; 20(1): 25-32.

17. Ministério da Saúde. Anexo A - Portaria 399/GM, de 22 de fevereiro de 2006. Divulga o Pacto pela Saúde 2006 - Consolidação do SUS e aprova as Diretrizes Orçamentárias do Referido Pacto. Brasília: Editora MS; 2006.

18. Ministério da Saúde. Painel de Indicadores do SUS 2. Temático Saúde da Mulher. Brasília: MS; 2007.

19. Brito AM, Szwarcwald CL, Castilho EA. Fatores associados à interrupção de tratamento anti-retroviral em adultos com AIDS, Rio Grande do Norte, Brasil, 1999 - 2002. Rev. Assoc. Med. Bras. 2006; 52(2):86-92.

20. Volmink J, Siegfried NL, Merwe L, Brocklehurst P. Antiretrovirals for reducing the risk of mother-to-child transmission of HIV infection (Cochrane Review). In: The Cochrane Library, Issue 2, 2007. Oxford: Update Software. Available from: http://www.update-software.com

21. Public Health Service Task Force. Recommendations for Use of Antiretroviral Drugs in Pregnant HIV-1 Infected Women for Maternal Health and Interventions to Reduce Perinatal HIV-1 Transmission in the United States 2006; $65 \mathrm{p}$. Available from http://aidsinfo.nih.gov/ContentFiles/PerinatalGL.pdf. 
22. European Collaborative Study. Mother-to-Child Transmission of HIV Infection in the Era of Highly Active Antiretroviral Therapy. Clinical Infectious Diseases 2005; 40: 458-465.

23. Maturana AP, Rizzo CV, Vasquez DF, Cavalheiro N, Holzer S, Morais VS. Avaliação da assistência ao parto em gestantes infectadas pelo HIV. Arq. Méd. ABC 2007; 32(1): 11-16.

24. Nishimoto TMI, Eluf Neto E, Rozman MA. Transmissão materno-infantil do vírus da imunodeficiência humana: avaliação de medidas de controle no município de Santos. Rev. Assoc. Med. Bras. 2005; 51(1): 54-60.

25. Vasconcelos ALR \& Hamann EM. Por que o Brasil ainda registra elevados coeficientes de transmissão vertical do HIV? Uma avaliação da qualidade da assistência prestada a gestantes/parturientes infectadas pelo HIV e seus recémnascidos. Rev. Bras. Saúde Matern. Infant. 2005; 5(4): 483-492. 
Tabela 1. Características sócio-demográficas de gestantes HIV positivas acompanhadas no Serviço de Atendimento Especializado de Itajaí, SC, no período de julho de 2006 a janeiro de 2007

\begin{tabular}{cccc}
\hline Variáveis & Classes & $n$ & $\%$ \\
\hline Faixa etária & 15 a 19 anos & 4 & 12,50 \\
& 20 a 34 anos & 24 & 75,00 \\
& 35 a 49 anos & 4 & 12,50 \\
& Total & 32 & 100,00 \\
Escolaridade & Nenhuma & 3 & \\
& 4 a 7 anos & 17 & 9,37 \\
& 8 a 11 anos & 11 & 53,13 \\
& 12 ou mais & 1 & 34,38 \\
& Total & 32 & 3,12 \\
Raça & Branca & 26 & 100,00 \\
& Negra & 2 & 81,25 \\
& Parda & 4 & 6,25 \\
& Total & 32 & 12,50 \\
\hline
\end{tabular}


Tabela 2. Características da assistência pré-natal em gestantes com HIV/AIDS atendidas pelo Serviço de Atendimento Especializado do Município de Itajaí, SC, no período de julho de 2006 a janeiro de 2007

\begin{tabular}{clcc}
\hline Variável & Classes & $n$ & $\%$ \\
\hline Idade gestacional da primeira consulta de pré-natal & s14 semanas & 16 & 50,00 \\
& 15 a 24 semanas & 10 & 31,25 \\
& 25 a 34 semanas & 4 & 12,50 \\
& $\geq 35$ semanas & 2 & 6,25 \\
No. consultas realizadas no pré-natal & & 32 & 100,00 \\
& & & \\
& 0 a 3 & 3 & 9,38 \\
& 4 a 6 & 6 & 18,75 \\
\hline
\end{tabular}


Tabela 3. Características do uso da terapia anti-retroviral por gestantes com HIV/AIDS atendidas pelo Serviço de Atendimento Especializado do Município de Itajaí, SC, no período de julho de 2006 a janeiro de 2007

\begin{tabular}{|c|c|c|c|}
\hline Variáveis & Classes & n & $\%$ \\
\hline \multirow[t]{3}{*}{ Estado sorológico da gestante } & $\mathrm{HIV+}$ & 21 & 65,63 \\
\hline & AIDS & 11 & 34,38 \\
\hline & Total & 32 & 100,00 \\
\hline \multirow[t]{3}{*}{ Realizando tratamento ARV } & Sim & 9 & 28,13 \\
\hline & Não & 23 & 71,88 \\
\hline & Total & 32 & 100,00 \\
\hline \multirow[t]{7}{*}{ Idade gestacional em semanas de início da profilaxia ARV } & $<14$ semanas & 0 & 0,00 \\
\hline & 14 a 20 semanas & 14 & 43,75 \\
\hline & 21 a 28 semanas & 3 & 9,38 \\
\hline & $>28$ semanas & 5 & 15,63 \\
\hline & Já faz uso & 9 & 28,13 \\
\hline & Não fez uso & 1 & 3,13 \\
\hline & Total & 32 & 100,00 \\
\hline \multirow[t]{6}{*}{ Tempo total de uso da profilaxia ARV em semanas } & $\leq 6$ semanas & 3 & 9,38 \\
\hline & 7 a 21 semanas & 13 & 40,63 \\
\hline & $\geq 22$ semanas & 13 & 40,63 \\
\hline & Não usou & 1 & 3,13 \\
\hline & Ignorado/branco & 2 & 6,25 \\
\hline & Total & 32 & 100,00 \\
\hline
\end{tabular}


Tabela 4. Características do parto das gestantes com HIV/AIDS atendidas pelo Serviço de Atendimento Especializado do Município de Itajaí, SC, no período de julho de 2006 a janeiro de 2007

\begin{tabular}{|c|c|c|c|}
\hline Variáves & Classes & $n$ & $\%$ \\
\hline \multirow[t]{3}{*}{ Tipo de parto } & Cesárea & 26 & 86,66 \\
\hline & Vaginal & 4 & 13,33 \\
\hline & Total & 30 & 100,00 \\
\hline Idade gestacional do Parto em & $\leq 35$ semanas & 2 & 6,66 \\
\hline \multirow[t]{2}{*}{ semanas } & 36 a 41 semanas & 28 & 93,33 \\
\hline & Total & 30 & 100,00 \\
\hline Tempo de ruptura das & $<4$ horas & 5 & 16,66 \\
\hline \multirow[t]{4}{*}{ membranas em horas } & $>4$ horas & 5 & 16,66 \\
\hline & Ignorado/branco & 4 & 13,33 \\
\hline & Não se aplica & 16 & 53,33 \\
\hline & Total & 30 & 100,00 \\
\hline Fez uso ARV durante o & Sim & 27 & 90,00 \\
\hline \multirow[t]{3}{*}{ Parto } & Não & 0 & 0,00 \\
\hline & Ignorado/branco & 3 & 10,00 \\
\hline & Total & 30 & 100,00 \\
\hline \multirow[t]{5}{*}{ Início profilaxia ARV na criança } & Primeiras $24 \mathrm{~h}$ & 27 & 90,00 \\
\hline & Após $24 \mathrm{~h}$ & 0 & 0,00 \\
\hline & Não realizado & 0 & 0,00 \\
\hline & Ignorado/branco & 3 & 10,00 \\
\hline & Total & 30 & 100,00 \\
\hline
\end{tabular}


Tabela 5. Características dos recém-nascidos de gestantes com HIV/AIDS atendidas pelo Serviço de Atendimento Especializado do Município de Itajaí, SC, no período de julho de 2006 a janeiro de 2007

\begin{tabular}{|c|c|c|c|}
\hline Variáveis & Classes & $n$ & $\%$ \\
\hline \multirow[t]{3}{*}{ Peso ao nascer $(\mathrm{g})$} & Entre 1500 a 2499 & 5 & 16,67 \\
\hline & $\geq 2500$ & 25 & 83,33 \\
\hline & Total & 30 & 100,00 \\
\hline \multicolumn{4}{|l|}{ Média aritmética $=2915,67 \mathrm{~g}$} \\
\hline Desvio padrão da amostra: & 469,68 & & \\
\hline Intervalo de confiança (95\%) para & média: $2.740,29-3.091,05$ & & \\
\hline \multirow[t]{3}{*}{ Apgar $1^{\natural} \cdot$ medida } & $\leq 7$ & 4 & 13,33 \\
\hline & 8 a 10 & 26 & 86,67 \\
\hline & Total & 30 & 100,00 \\
\hline \multirow[t]{3}{*}{ Apgar $2^{a}$. medida } & $\leq 7$ & 1 & 3,33 \\
\hline & 8 a 10 & 29 & 96,67 \\
\hline & Total & 30 & 100,00 \\
\hline
\end{tabular}


ARTIGO 2 (Título Provisório)

ADESÃO AO USO DE ANTI-RETROVIRAIS POR GESTANTES HIV POSITIVAS E A ATENÇÃO FARMACÊUTICA 
ADESÃO AO USO DE ANTI-RETROVIRAIS POR GESTANTES HIV POSITIVAS E A ATENÇÃO FARMACÊUTICA

\section{ADHERENCE TO ANTIRETROVIRALS FOR HIV INFECTED PREGNANT WOMEN AND PHARMACEUTICAL CARE}

Benedito Carlos CORDEIROa, Nicolina Silvana ROMANO-LIEBER ${ }^{\mathrm{b}}$

${ }^{a}$ Curso de Farmácia da Universidade do Vale do Itajaí - UNIVALI. Itajaí, SC, Brasil. ${ }^{b}$ Departamento de Prática de Saúde Pública da Faculdade de Saúde Pública da Universidade de São Paulo - FSP/USP. São Paulo, SP, Brasil

Correspondência para: Benedito Carlos Cordeiro

R. Uruguai, 458 - Centro

88302-202 Itajaí, SC, Brasil

E-mail: bcordeiro@terra.com.br

Artigo baseado na tese de doutorado "A Atenção Farmacêutica na melhoria do atendimento às gestantes soropositivas no município de Itajaí, SC" apresentada na Faculdade de Saúde Pública da Universidade de São Paulo - FSP/USP em 2008 


\section{ADESÃO AO USO DE ANTI-RETROVIRAIS POR GESTANTES HIV POSITIVAS E A ATENÇÃO FARMACÊUTICA}

\section{Resumo}

Introdução. A adesão à terapêutica é um tema com controvérsias quanto à definições, mas há consenso quanto à sua importância para a eficácia de um tratamento. Para as gestantes soropositivas, é importante ainda considerarse que a adesão à profilaxia anti-retroviral é essencial tanto para as mulheres quanto para seus filhos. Objetivo. Verificar a alteração dos níveis de adesão em gestantes HIV+ após seguimento farmacoterapêutico acompanhadas por um Serviço de Atendimento Especializado em DST/AIDS (SAE) de Itajaí, Santa Catarina. Metodologia. No período de julho de 2006 a julho de 2007, foram convidadas a participar do estudo as gestantes que faziam seu pré-natal no SAE. Foi utilizado o instrumento SMAQ, para verificação da adesão em dois momentos: antes e depois do seguimento farmacoterapêutico (Método Dáder). Resultados. 32 gestantes foram seguidas no período. O SMAQ mensurou como baseline $40,6 \%$ de adesão (qualitativo) e $59,4 \%$ considerando um corte de $95 \%$ (quantitativo). Observou-se melhora na adesão tanto no SMAQ qualitativo quanto no quantitativo (75 e $87,5 \%$ respectivamente), o que foi estatisticamente significativo $(p<0,05)$. Foi encontrado como preditor de não adesão 0 grau de escolaridade e uso de álcool, mas após o seguimento farmacoterapêutico

não se observou diferença quanto a estas variáveis. $O$ seguimento foi especialmente eficaz junto às gestantes que não eram notificadas como 
casos AIDS e com maior número de consultas no pré-natal. Conclusão. Quando realizado concomitantemente com outros serviços de saúde em uma equipe multidisciplinar, a atenção farmacêutica mostrou-se efetiva para a melhoria dos níveis de adesão aos anti-retrovirais.

Palavras-chave: adesão; HIV; AIDS; atenção farmacêutica; gestantes; transmissão materno-infantil.

\section{Abstract}

Introduction. The adherence to therapy is a controversial theme with regards to definitions, but there is consensus as for its importance for the effectiveness of a treatment. For the HIV infected pregnant women, still is important to consider that adherence to the antiretroviral prophylaxis is essential as for the women as for their children. Objective. To verify the change of adherence levels in HIV infected pregnant women accompanied by a Specialized Assistance Service in STD / AIDS (SAE) of Itajaí, Santa Catarina, after pharmacotherapeutic follow-up. Methodology. In the period of July 2006 to July 2007, the HIV infected pregnant women that had prenatal care in SAE were invited to participate in the study. The tool used for verification of adherence was SMAQ in two moments: before and after the pharmacotherapeutic follow-up (Dáder Program). Results. 32 pregnant women were followed in the period. SMAQ measured as baseline $40,6 \%$ of adherence (qualitative) and $59,4 \%$ considering a cut of $95 \%$ (quantitative). It was observed improvement in the adherence as in qualitative as in the quantitative SMAQ (75 and $87,5 \%$ respectively), what was statistically 
significant $(p<005)$. It was found as predictor of no adherence the education degree and alcohol use, but after the pharmacotherapeutic follow-up no difference was observed for these variables. The follow-up was especially effective for the pregnant women that were not notified as AIDS cases and with larger consultations number in the prenatal care. Conclusion. When accomplished concomitantly with other health services of a multidisciplinary team, the pharmaceutical care was shown effective in the improvement of antiretrovirals adherence levels.

Key-words: adherence; HIV; AIDS; pharmaceutical care; pregnant; motherto-child transmission. 
Introdução. A adesão à terapêutica é um tema que apresenta vasta relação de estudos científicos, pela relevância que assume nos dias atuais. Porém, até mesmo a definição do termo e a precisão de até que ponto a falta de adesão pode comprometer um plano terapêutico são pontos controversos, que diferem entre diferentes patologias e autores.

De um modo geral, a adesão é ainda mais problemática quando se estudam enfermidades consideradas crônicas. Para ter-se uma idéia da magnitude deste problema, estima-se que nos países desenvolvidos a adesão aos tratamentos de longo prazo, pela população em geral, seja de $50 \%$, sendo ainda menor nos países em desenvolvimento ${ }^{24}$.

No caso da infecção HIV/AIDS, estes números tornam-se ainda mais dramáticos, pois a falta de adesão não apenas prejudica os próprios pacientes como acarreta um grave problema de saúde pública, ao possibilitar a oportunidade de criação de vírus mutantes resistentes aos antiretrovirais (ARV). Assim, estima-se que a adesão à terapia anti-retroviral (TARV) deve estar situada entre 90 a $95 \%$ da dose prescrita para que se consiga a diminuição da carga viral, recuperação do número de linfócitos TCD4 e evitar a progressão da infecção até a doença ${ }^{2,22}$.

Entretanto, atingir tais patamares para o tratamento anti-retroviral é desafiante para os pacientes e para a equipe de saúde, pois sua complexidade apresenta vários fatores que dificultam a adesão: mais de um fármaco, várias doses por dia, presença de muitas reações adversas e pacientes assintomáticos, além de representar importante questão econômica, pelo investimento sanitário nestes medicamentos. 
Este desafio é potencializado quando se trata de evitar a transmissão materno-infantil do vírus HIV. Um estudo de caso ${ }^{9}$ descreveu que a adesão variável de uma mãe foi responsável pela transmissão de um vírus multiresistente a seu filho, o que poderia ter sido evitado com o uso dos antiretrovirais de forma consistente, conforme resultados amplamente comprovado, ${ }^{6,25}$. Além disso, a busca de metodologias que consigam melhorar os níveis de adesão nestas situações torna-se imperativo a ser buscado, com diversas formas relatadas na literatura, entre elas a Atenção Farmacêutica ${ }^{13}$.

Em vista destas considerações, e pelo fato da adesão tratar-se de uma variável dinâmica, o objetivo deste estudo é demonstrar o nível de melhora de adesão à TARV obtido por meio da Atenção Farmacêutica às gestantes HIV+ atendidas em um Serviço de Atendimento Especializado (SAE) em DST/AIDS em Itajaí, Santa Catarina.

Metodologia. Foram convidadas a participar do estudo todas as gestantes HIV+ que procuravam atendimento no SAE de Itajaí/SC, no período de 01/07/2006 a 31/12/2007. Para o Seguimento Farmacoterapêutico utilizou-se - Método Dáder ${ }^{15}$. A última gestante acompanhada teve seu filho no dia 13/07/2007, quando se encerrou o período de coleta de dados. Alguns dados foram obtidos a partir dos prontuários das gestantes.

Foram pesquisadas variáveis sócio-demográficas e outras de interesse para caracterizar a população estudada como uso de álcool e drogas, estado sorológico da paciente e número de consultas ao serviço para acompanhamento do pré-natal. 
Para a mensuração da adesão à terapêutica, foi utilizado o método $S M A Q^{14}$, que foi adaptado do método proposto por Moriski et al. ${ }^{19}$ (1986). O SMAQ é constituído de 6 questões: 1. Você, às vezes, se esquece de tomar seus medicamentos? 2, Você, toma seus medicamentos no horário indicado? 3. Se às vezes você se sente mal com seus medicamentos, deixa de tomá-los? 4. Durante a última semana, quantas vezes você não tomou seu medicamento? 5. Você ficou sem tomar algum medicamento no último final de semana? 6. Nos últimos 3 meses, quantos dias você não tomou seus medicamentos corretamente?

O SMAQ foi considerado "positivo" quando uma paciente não aderente foi detectada, isto é, quando havia uma resposta positiva para qualquer uma das 3 primeiras questões, ou mais de duas doses perdidas na última semana, ou mais de 2 dias sem medicamentos nos últimos 3 meses. Este resultado, neste estudo, passou a ser denominado qualitativo.

Além disso, a partir da resposta dada na pergunta 4 calculava-se 0 percentual de adesão da paciente à TARV, considerando-se como aderentes aquelas gestantes que utilizassem $\geq 95 \%$ das doses dos antiretrovirais prescritos (neste caso, foi utilizada a denominação quantitativo). Para a primeira entrevista, foi utilizado como critério estar utilizando os ARV por pelo menos 4 semanas. Passadas aproximadamente outras 4 semanas, quando as pacientes retornavam para uma nova consulta ou para buscar seus medicamentos, era novamente aplicado o mesmo questionário.

A análise dos dados foi feita a partir da planilha eletrônica Excel® para Windows 2003, calculando-se o teste de diferença entre duas proporções 
para dados associados ou pareados de $\mathrm{McNemar}^{3}$ e aplicando-se o teste exato de Fisher. Um valor de $p<0,05$ foi considerado estatisticamente significante.

A todas as gestantes foi explicado o objetivo do trabalho e solicitado o consentimento informado, sendo explicitado que este seguimento seria feito até o término da gestação. O projeto foi aprovado pelo Comitê de Ética em Pesquisa da Faculdade de Saúde Pública - USP.

Resultados. Neste período, 37 mulheres foram acompanhadas pelo SAE, das quais 32 aceitaram participar do estudo (três gestantes se negaram e outras duas não puderam ser contatadas).

A caracterização sociodemográfica destas gestantes pode ser visualizada na Tabela 1, em que se observa a predominância da faixa etária de 20 a 34 anos, da escolaridade de 4 a 7 anos e da raça branca.

As demais variáveis pesquisadas são apresentadas na Tabela 2. Apesar de ser uma população constituída exclusivamente por gestantes, observou-se um percentual alto de usuárias ou ex-usuárias de drogas ilícitas ou álcool. Mais de $65 \%$ da amostra era portadora do HIV e, de um modo geral, o número de consultas no pré-natal pode ser considerado alto, devendo ser destacado que, para este item, têm-se os dados de apenas 30 mulheres, já que uma veio a óbito antes de terminar sua gestação e uma outra, que havia sido identificada como gestante, foi depois diagnosticada como portadora de um cisto.

Os ARV utilizados pelas gestantes, distribuídos por esquemas, podem ser vistos na Tabela 3. Observa-se que 13 gestantes começaram com um 
esquema, o qual foi trocado decorrido algum tempo. Isto aconteceu com 11 das 12 gestantes que iniciaram a profilaxia com AZT (uma abandonou o tratamento) e com 3 gestantes que utilizavam o ARV Efavirenz no esquema 1.

Somente para uma mulher que utilizava o esquema 2 aconteceu a troca por um novo esquema (esquema 3). Estas trocas significaram, em todos os casos, um aumento no número de comprimidos necessários.

A adesão aos ARV foi mensurada pelo instrumento SMAQ em dois momentos (SMAQ 1 e 2), conforme Tabela 4. Todas as gestantes responderam ao questionário na primeira entrevista; na segunda vez foi aplicado a 24 mulheres, porque as outras procuraram o SAE muito próximo do término da gestação. Para o cálculo da significância estatística, foram considerados os dados oriundos apenas das mulheres que responderam o instrumento nos dois momentos.

Por estes resultados, observa-se uma inversão: enquanto no SMAQ qualitativo a maioria das gestantes era não aderente no SMAQ 1, utilizandose o corte de $95 \%$ a maior parte das gestantes foi considerada aderente.

Tanto para o SMAQ qualitativo quanto para o quantitativo a melhora da adesão foi estatisticamente significante no segundo momento $(p<0,05)$.

A variável adesão foi associada a outras variáveis: idade, grau de escolaridade, raça, uso de drogas, uso de álcool, caso HIV ou AIDS, numero de consultas do pré-natal e número de comprimidos, sendo que as associações consideradas estatisticamente significantes $(p<0,05)$ no teste exato de Fisher encontram-se na Tabela 5. 
Verifica-se que as variáveis Grau de Escolaridade e Uso de álcool apresentaram significância estatística para não adesão (SMAQ qualitativo) antes de serem seguidas pelo Método Dáder, enquanto as variáveis Caso HIV/AIDS (qualitativo) e número de consultas no pré-natal (quantitativo) não eram estatisticamente significantes no primeiro teste passando a sê-lo no segundo.

Discussão. Uma limitação deste estudo encontra-se no tamanho da amostra, que é pequeno para possibilitar sua validade para outras populações. Independente desse fato, para a população estudada, observou-se um predomínio de mulheres entre 20-34 anos, escolaridade de 4 a 7 anos e de raça branca. Esta faixa de idade está dentro do esperado, pois como se tratam de gestantes, este largo espaço de anos está, mais do que as outras faixas de idade, compreende grande parte do período fértil das mulheres e a raça branca é preponderante em larga escala em Santa Catarina. Já a maior freqüência de escolaridade entre 4 a 7 anos demonstra um fato que vem se apresentando gradualmente na infecção pelo HIV, ou seja, o aumento da freqüência entre as pessoas com menor escolaridade ${ }^{10}$. Quando se analisa a associação entre os dados sócio-demográficos com a adesão, observa-se que o grau de escolaridade apresenta-se estatisticamente significante, concordando com vários estudos publicados ${ }^{1,5,7,20,21}$. Este fato pode estar relacionado com a capacidade de entendimento de toda a complexidade envolvida com o tratamento antiretroviral. 
Quanto às variáveis apresentadas na tabela 2, preocupa o uso de drogas, tanto ilícitas (foram relatados o uso de drogas inalatórias - maconha e crack) como lícitas (álcool), pelo efeito teratogênico que estes compostos possuem $^{23}$ e pela possível interação com os anti-retrovirais. 0 estado sorológico (infecção pelo HIV ou caso notificado AIDS) é uma informação importante, que inclusive poderá determinar que, ao final da gestação, a mulher possa parar com o uso dos $A R V^{18}$. Já o número de consultas de prénatal demonstra a adequação deste parâmetro com as recomendações oficiais (o Ministério da Saúde considera ideal um número de 7 ou mais, sendo aceitável pelo menos 4 consultas $)^{17}$.

Quando analisadas a associação destas variáveis com a adesão, percebese que o uso de álcool demonstrou ser um fator preditivo de não adesão para esta amostra, da mesma forma como relatado por outros estudos ${ }^{4,20}$, embora em outro trabalho ${ }^{7}$ esta associação não tenha sido encontrada.

Ser gestante HIV+ ou um caso já notificado de AIDS também não é fator preditivo de adesão, o que concorda com a literatura ${ }^{5}$, que afirma que 0 estágio da doença não está associado à adesão.

Um dos fatores mais presentes na literatura como fator preditivo da adesão, de forma diretamente proporcional, é a freqüência às consultas médicas $^{5,20,21}$. Neste estudo, provavelmente em função do número elevado de consultas realizadas no pré-natal, tal associação não foi encontrada, o que demonstra que, talvez mais importante que a freqüência às consultas, seja a orientação repassada pelos profissionais de saúde nestes momentos $^{7,8,16}$. 
Em relação aos esquemas anti-retrovirais (e as trocas de esquemas) e número de comprimidos, há amplo consenso que estes são fatores impactantes na adesão à TARV 5,16,20,21. Para este trabalho, esta variável não foi estatisticamente significante, provavelmente porque 0 número máximo de comprimidos tomados (14) fosse muito menor do que o utilizado no final dos anos $90^{20}$, embora aquela tendência tenha se mantido mesmo em estudos mais atuais ${ }^{16,21}$.

De um modo geral, o nível de adesão observado tanto com o SMAQ qualitativo quanto com o corte de $95 \%$ está dentro do encontrado em outros estudos $^{5}$. Os percentuais diferentes encontrados são esperáveis, já que a mensuração da adesão se dá por parâmetros distintos. De qualquer forma, o simples fato de apresentar duas medidas, quando comparado com outros instrumentos que apresentam apenas uma, já é um bom indício de sua confiabilidade ${ }^{14}$, já que, independentemente de sua sensibilidade ou especificidade, tanto os resultados qualitativos como os quantitativos constataram a melhora da adesão.

É importante perceber ainda que o instrumento SMAQ apontou mudanças quando utilizado em dois momentos distintos, um antes e outro depois da intervenção originada pelo Seguimento Farmacoterapêutico. Deste modo, as variáveis que foram preditoras da não adesão (escolaridade e uso de bebidas alcoólicas) deixaram de sê-lo após a intervenção, sugerindo que o seguimento foi eficaz na melhoria da adesão das pacientes que apresentavam aquelas características. 
Observou-se ainda que a intervenção alterou de forma significativa duas variáveis, caso HIV/AIDS e número de consultas no pré-natal. A maioria das mulheres que já havia sido notificada como caso de AIDS já utilizava o tratamento, tendo maior conhecimento das suas conseqüências, benefícios e riscos, o que pode fazer com que o seguimento não seja tão importante para elas. Para as gestantes não AIDS, que iniciavam o tratamento e se sentiam inseguras quanto aos diversos aspectos relacionados com a profilaxia, o seguimento mostrou-se uma importante ferramenta para melhora da adesão.

O seguimento também se mostrou mais efetivo para aquelas mulheres que tiveram maior número de consultas, o que é esperado, pois quanto mais as gestantes vinham às consultas, maior era $\circ$ número de contatos e a possibilidade de intervenção. E, como este maior número de consultas ocasionava um aumento do contato com a equipe de enfermagem e com os médicos (além de maior contato no seguimento), os resultados permitem sugerir que, mais importante do que o seguimento propriamente dito, é o trabalho multidisciplinar.

Mais que mensurar o nível de adesão, este trabalho demonstrou a necessidade de estratégias para a melhoria deste parâmetro. Esta estratégia passa pela necessidade de parceria e comprometimento entre a equipe multiprofissional e o paciente, através da informação e motivação para uma mudança comportamental ${ }^{11}$. Isto pode ser conseguido, entre tantas formas possíveis, com o seguimento farmacoterapêutico, que pareceu capaz, neste estudo, de colaborar para a melhoria da adesão das pacientes. Quando esta 
prática puder ser incorporada de forma sistemática aos serviços de saúde e, em especial, na estratégia de saúde da família, que tem por pressuposto ir até o paciente, haverá maior possibilidade de aumento do nível de adesão do paciente à terapia anti-retroviral, como já verificado anteriormente ${ }^{12}$.

\section{AGRADECIMENTOS}

Renato César Dittrich colaborou na análise estatística dos dados.

\section{Referências bibliográficas}

1. Albrecht S, Semrau K, Kasonde P, Sinkala M, Kankasa C, Vwalika C et al. Predictors of nonadherence to single-dose nevirapine therapy for the prevention of mother-to-child HIV transmission. J Acquir Immune Defic Syndr. 2006; 41(1): 114-118.

2. Bangsberg DR, Perry S, Charlebois ED, Clark RA, Robertson M, Zolopa AR et al. Non-adherence to highly active antiretroviral therapy predicts progression to AIDS. AIDS 2001; 15(9): 1181-1183.

3. Berquó ES, Souza JMP, Gotlieb SLD. Bioestatística. 2ª ed. São Paulo: EPU; 1981. Teste de hipóteses em tabelas $2 \times 2$ e de $r \times s ; p$. 281-297.

4. Bonolo PF, César CC, Acúrcio FA, Ceccato MGB, Pádua CAM, Álvares $\mathrm{J}$ et al. Non-adherence among patients initiating antiretroviral therapy: a challenge for health professionals in Brazil. AIDS 2005; 19(suppl 4): S5-S13. 
5. Bonolo PF, Gomes RRFM, Guimarães MDC. Adesão à terapia antiretroviral (HIV/AIDS): fatores associados e medidas de adesão. Epidemiol. Serv. Saúde 2007; 16(4): 261-278.

6. Brocklehurst P. Interventions for reducing the risk of mother-to-child transmission of HIV infection (Cochrane Review). In: The Cochrane Library, Issue 2, 2007. Oxford: Update Software. Available from: http://www.update-software.com

7. Carvalho CV, Duarte DB, Merchán-Hamann E, Bicudo E, Languardia J. Determinantes da aderência à terapia anti-retroviral combinada em Brasília, Distrito Federal, Brasil, 1999-2000. Cad. Saúde Pública 2003; 19(2): 593-604.

8. Ceccato MGB, Acúrcio FA, Bonolo PF, Rocha GM, Guimarães MDC. Compreensão de informações relativas ao tratamento anti-retroviral entre indivíduos infectados pelo HIV. Cad. Saúde Pública 2004; 20(5): 1388-1397.

9. Desai N, Mathur M. Selective transmission of multidrug resistant HIV to a newborn related to poor maternal adherence. Sex. Transm. Inf. 2003; 79: 419-421.

10. Fonseca MG, Bastos Fl, Derrico M, Andrade CLT, Travassos C, Szwarcwald CL. AIDS e grau de escolaridade no Brasil: evolução temporal de 1986 a 1996. Cad. Saúde Pública 2000; 16(Supl 1): $77-$ 87.

11. Garcia R, Schooley RT, Badaró R. An adherence trilogy is essential for long-term HAART success. BJID 2003; 7(5): 307-314. 
12. Gupta N, Silva ACS, Passos LN. The role of integrated home-based care in patient adherence to antiretroviral therapy. Revista da Sociedade Brasileira de Medicina Tropical 2005; 38(3): 241-245.

13. Haynes RB, Yao X, Degani A, Kripalani S, Garg A, McDonald HP. Intervenciones para mejorar el cumplimiento con la medicación (Revisión Cochrane traducida). En: La Biblioteca Cochrane Plus, 2007, Número 2. Oxford: Update Software. Disponible en: http://www.update-software.com

14. Knobel H, Alonso J, Casado JL, Collazos J, González J, Ruiz I et al. Validation of a simplified medication adherence questionnaire in a large cohort of HIV-infected patients: the GEEMA Study. AIDS 2002; 16: 605-613.

15. Machuca M, Fernández--Llimós F, Faus Dáder MJ. Método Dáder. Manual de Acompanhamento Farmacoterapêutico. Universidad de Granada. Trad. de JCQP Frade; 2004. Disponível em: http://www.pharmanet.com.br/atencao/metododader.pdf

16. Malta M, Petersen ML, Clair S, Freitas F, Bastos Fl. Adherence to antiretroviral therapy: a qualitative study with physicians from Rio de Janeiro, Brazil. Cad. Saúde Pública 2005; 21(5): 1424-1432.

17. Ministério da Saúde. Painel de Indicadores do SUS. Brasília: MS/OPAS; 2006.

18. Ministério da Saúde. Recomendações para profilaxia da transmissão vertical do HIV e terapia anti-retroviral em gestantes. Brasília: MS; 2007. 
19. Moriski DE, Green LW, Levine DM. Concurrent and predictive validity of a self-reported measure of medication adherence. Medical Care 1986; 24(1): 67-74.

20. Nemes MIB (pesquisadora principal). Aderência ao tratamento por anti-retrovirais em serviços públicos de saúde no Estado de São Paulo. Brasília: Ministério da Saúde; 2000.

21. Nemes MIB, Carvalho HB, Souza MFM. Antiretroviral therapy adherence in Brazil. AIDS 2004; 18(suppl 3): S15-S20.

22. Paterson DL, Swindells S, Mohr J, Brester M, Vergis EN, Squier C, et al. Adherence to protease inhibitor therapy and outcomes in patients with HIV infection. Ann Intern Med 2000; 133: 21-30.

23. Peres RM, Spritzer DT. Álcool, fumo e outras drogas. In: Sanseverino MTV, Spritzer DT, Schüler-Faccini L. Manual de Teratogênese. Porto Alegre: Editora da UFRGS; 2001. p. 451-467.

24. Sabaté $E(e d)$. Adherence to long term therapies: evidence for action. Geneva: World Health Organization; 2003.

25. Volmink J, Siegfried NL, Merwe L, Brocklehurst P. Antiretrovirals for reducing the risk of mother-to-child transmission of HIV infection (Cochrane Review). In: The Cochrane Library, Issue 2, 2007. Oxford: Update Software. Available from: http://www.update-software.com 
Tabela 1. Características sócio-demográficas de gestantes acompanhadas no Serviço de Atendimento Especializado em DST/AIDS de Itajaí no período de julho de 2006 a janeiro de 2007

\begin{tabular}{|c|c|c|c|}
\hline Variáveis & Classes & $\mathrm{n}$ & $\%$ \\
\hline \multirow[t]{4}{*}{ Faixa etária } & 15 a 19 anos & 4 & 12,50 \\
\hline & 20 a 34 anos & 24 & 75,00 \\
\hline & 35 a 49 anos & 4 & 12,50 \\
\hline & Total & 32 & 100,00 \\
\hline \multirow[t]{5}{*}{ Escolaridade } & Nenhuma & 3 & 9,37 \\
\hline & 4 a 7 anos & 17 & 53,13 \\
\hline & 8 a 11 anos & 11 & 34,38 \\
\hline & 12 ou mais & 1 & 3,12 \\
\hline & Total & 32 & 100,00 \\
\hline \multirow[t]{4}{*}{ Raça } & Branca & 26 & 81,25 \\
\hline & Negra & 2 & 6,25 \\
\hline & Parda & 4 & 12,50 \\
\hline & Total & 32 & 100,00 \\
\hline
\end{tabular}


Tabela 2. Características relativas a uso de drogas, estado sorológico e número de consultas de pré-natal de gestantes acompanhadas no Serviço de Atendimento Especializado de Itajaí, SC, no período de julho de 2006 a janeiro de 2007

\begin{tabular}{|c|c|c|c|}
\hline Variáveis & Classes & $\mathrm{N}$ & $\%$ \\
\hline Uso de drogas & $\begin{array}{l}\text { Sim } \\
\text { Não }\end{array}$ & $\begin{array}{l}7 \\
25\end{array}$ & $\begin{array}{l}21,9 \\
78,1\end{array}$ \\
\hline Uso de álcool & $\begin{array}{l}\text { Sim } \\
\text { Não }\end{array}$ & $\begin{array}{l}6 \\
26\end{array}$ & $\begin{array}{l}18,8 \\
81,3\end{array}$ \\
\hline $\begin{array}{l}\text { Estado sorológico } \\
\text { da gestante }\end{array}$ & $\begin{array}{l}\text { HIV } \\
\text { AIDS }\end{array}$ & $\begin{array}{l}21 \\
11\end{array}$ & $\begin{array}{l}65,6 \\
34,4\end{array}$ \\
\hline $\begin{array}{l}N \text { de consultas no } \\
\text { Pré-natal }\end{array}$ & $\begin{array}{l}\leq 6 \\
7 \text { ou mais }\end{array}$ & $\begin{array}{l}7 \\
23\end{array}$ & $\begin{array}{l}23,3 \\
76,7\end{array}$ \\
\hline
\end{tabular}


Tabela 3. Análise de freqüência simples para diferentes esquemas de uso de antiretrovirais (Esq. ARV1, Esq. ARV 2 e Esq. ARV 3) de uma população de gestantes (32) acompanhadas no Serviço de Atendimento Especializado de Itajaí, SC, no período de julho de 2006 a janeiro de 2007 e número de comprimidos utilizados em cada esquema

\begin{tabular}{l|c|c|c}
\hline Variável Esq.ARV 1 & Frequência & $\%$ & N compr. \\
\hline AZT 6 & 12 & 37,500 & 6 \\
3TC/AZT 2 + NFV 10 & 8 & 25,000 & 12 \\
3TC/AZT 2 + NVP 2 & 6 & 18,750 & 4 \\
AZT 6 + 3TC 2 + EFZ 1 & 1 & 3,125 & 9 \\
AZT 6 + EFZ 1 & 1 & 3,125 & 7 \\
D4T(30) 2 + 3TC 2 + LPVr 6 & 1 & 3,125 & 10 \\
D4T(40) 2 + 3TC 2 + LPVr 6 & 1 & 3,125 & 7 \\
D4T(40) 2 + 3TC 2 + RTV 1 + ATV 2 & 1 & 3,125 & 3 \\
EFZ 1 + 3TC/AZT 2 & & & \\
& & & \\
Variável Esq.ARV 2 & 13 & 40,625 & 12 \\
3TC/AZT 2 + NFV 10 & & \\
Variável Esq.ARV 3 & & \\
D4T(40)2 + 3TC 2 + NFV 10 & & \\
\hline
\end{tabular}


Tabela 4. Adesão ao uso de anti-retrovirais por gestantes acompanhadas no Serviço de Atendimento Especializado de Itajaí, SC, no período de julho de 2006 a janeiro de 2007, mensurada pelo Simplified Medication Adherence Questionnaire (SMAQ), em dois momentos distintos (SMAQ 1 e SMAQ 2)

\begin{tabular}{lllll}
\hline & Variável & SMAQ 1 & SMAQ 1 & SMAQ 2 \\
& & 32 gestantes & 24 gestantes & 24 gestantes \\
\hline Qualitativo & Adesão & 40,6 & 41,7 & 75 \\
& Não adesão & 59,4 & 58,3 & 25 \\
Corte de 95\% & Adesão & 59,4 & 66,7 & 87,5 \\
(quantitativo) & Não adesão & 40,6 & 33,3 & 12,5 \\
\hline
\end{tabular}


Tabela 5. Variáveis que mostraram resultados estatisticamente significativos com a adesão ao uso de anti-retrovirais por gestantes acompanhadas no Serviço de Atendimento Especializado de Itajaí, SC, no período de julho de 2006 a janeiro de 2007, mensurada pelo Simplified Medication Adherence Questionnaire (SMAQ), em dois momentos distintos (SMAQ 1 e SMAQ 2) de acordo com o teste exato de Fisher.

\begin{tabular}{lll}
\hline Variável & Teste SMAQ 1 & Teste SMAQ 2
\end{tabular}

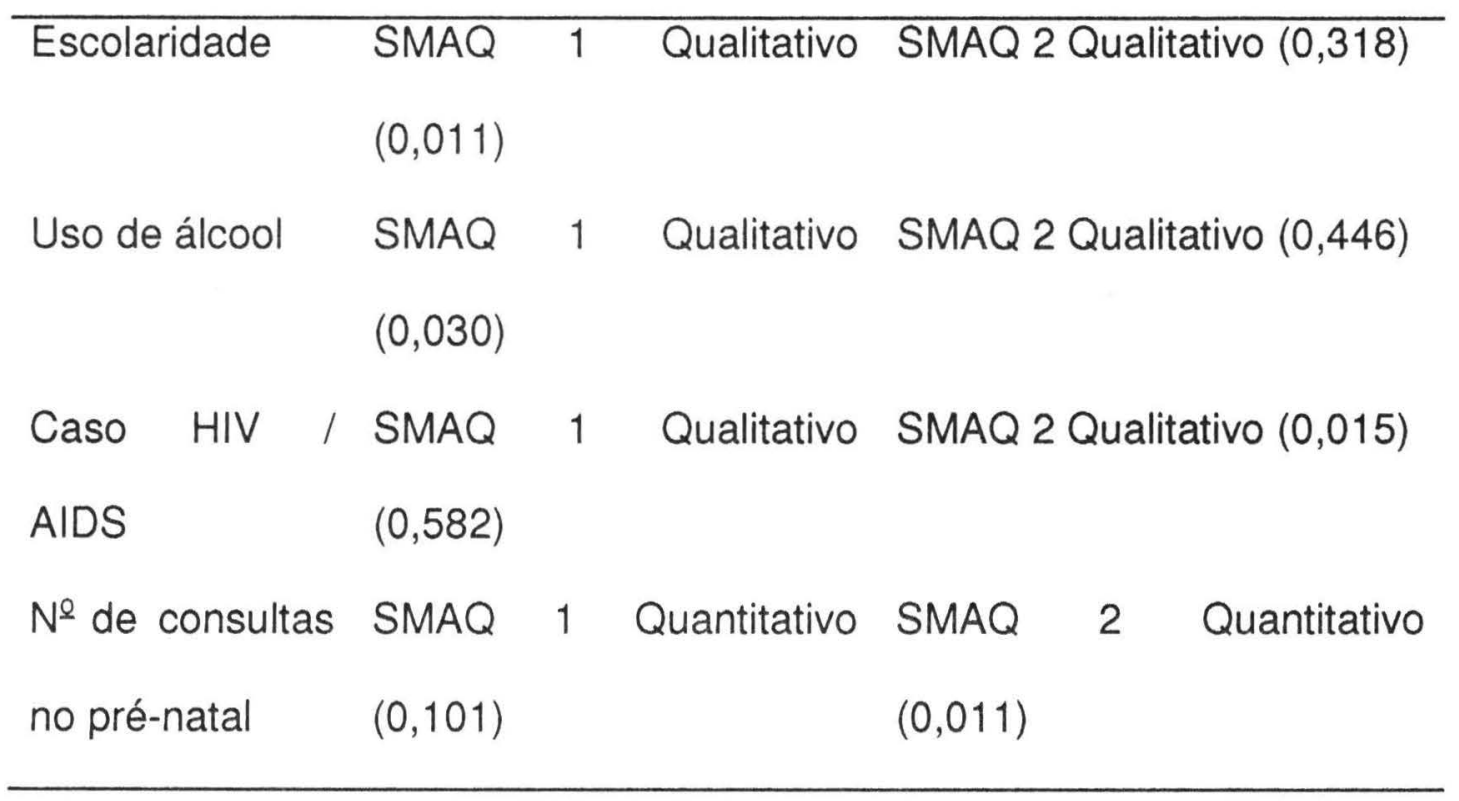


ARTIGO 3 (Título provisório)

ATENÇÃO FARMACÊUTICA A GESTANTES COM HIV/AIDS 


\section{ATENÇÃO FARMACÊUTICA A GESTANTES COM HIV/AIDS}

\section{PHARMACEUTICAL CARE TO HIV-INFECTED PREGNANT WOMEN}

${ }^{1}$ Benedito Carlos Cordeiro, ${ }^{2}$ Nicolina Silvana Romano-Lieber

${ }^{1}$ Curso de Farmácia, Universidade do Vale do Itajaí - UNIVALI, ${ }^{2}$ Departamento de Prática de Saúde Pública, Faculdade de Saúde Pública da Universidade de São Paulo - FSP/USP

Correspondência para:

Benedito Carlos Cordeiro

Curso de Farmácia / UNIVALI

R. Uruguai, 458 - Centro

Itajaí, SC, Brasil

Telefone: 554733417540

E-mail: bcordeiro@terra.com.br 


\section{ATENÇÃO FARMACÊUTICA A GESTANTES COM HIV/AIDS}

\section{Resumo}

Introdução: A estratégia terapêutica utilizada contra a infecção HIV/AIDS baseia-se na utilização de medicamentos anti-retrovirais. Estes possuem características que dificultam sua efetividade, o que é importante na transmissão vertical do vírus HIV. Uma das estratégias para modificar este panorama é a atenção farmacêutica, especialmente o seguimento farmacoterapêtico, ainda pouco documentada como prática dentro dos serviços de saúde. Objetivo: avaliar os resultados obtidos com o seguimento farmacoterapêutico em um grupo de gestantes HIV positivas, atendidas em um Serviço de Atendimento Especializado (SAE) em Itajaí, SC. Metodologia: Foram seguidas 32 gestantes HIV+ no período de julho de 2006 a julho de 2007, utilizando o Método Dáder de Seguimento Farmacoterapêutico e o instrumento Simplified Medication Adherence Questionnaire para mensuração do nível de adesão. Resultados: A adesão aos anti-retrovirais apresentou melhora (considerando $\mathrm{p}<0,05)$ e o seguimento farmacoterapêutico foi eficaz em propor soluções para 38 Problemas Relacionados com Medicamentos, dos quais 24 foram resolvidos após uma proposta de intervenção farmacêutica. Conclusão: o estudo demonstrou a importância desta estratégia quando considerada em conjunto com outras atividades desenvolvidas por uma equipe multiprofissional no atendimento a pacientes HIV/AIDS.

\footnotetext{
Abstract

Introduction: The therapeutic strategy against the infection HIV / AIDS is based on the use of antiretrovirals. These drugs possess characteristics that make difficult their
} 
effectiveness, what is important in the HIV transmission mother-to-child. One kind of possibility to modify this panorama is pharmaceutical care, especially the pharmacotherapeutic follow-up, which is still little documented as a practice inside of health services. Objective: to evaluate the results obtained with the pharmacotherapeutic follow-up in a group of HIV positive pregnant women, assisted in a Specialized Assistance Service (SAS) in Itajaí, SC. Methodology: 32 HIV+ pregnant women were followed in the period from July 2006 to July 2007, using the pharmacoterapeutic follow-up Dáder Program and the instrument Simplified Medication Adherence Questionnaire to measure the adherence level. Results: The adherence level to the antiretroviral improved (whereas $\mathrm{p}<0,05$ ) and the pharmacoterapeutic follow-up was effective in proposing solutions for 38 Drug Related Problems, of which 24 were resolved after a proposal of pharmaceutical intervention. Conclusion: It was demonstrated the importance of pharmacoterapeutic follow-up when considered together with other activities developed by a multiprofessional team to the patient HIV / AIDS.

Introdução. O pressuposto na estratégia terapêutica a ser seguida atualmente na infecção HIV/AIDS é que se trata de uma doença de longo curso, sob tratamento. Desde sua introdução, a terapia anti-retroviral (TARV), em especial com a associação de diferentes classes de anti-retrovirais (ARV), pode ser considerada o fator decisivo para a mudança do perfil desta doença, cujo período de sobrevida anterior era muito curto ${ }^{1}$. Entretanto, diferentemente de outras enfermidades consideradas crônicas, a rápida velocidade de replicação e mutação do vírus HIV requer graus elevados de adesão ao tratamento, superiores mesmo a $95 \%^{2}$. Além 
disso, a ocorrência de várias reações adversas aos ARV, somadas ao relativo desconhecimento do exato perfil de ação destes medicamentos, em função da rapidez na obtenção de autorização para sua comercialização pelo Food and Drug Administration (FDA), agência reguladora de medicamentos dos Estados Unidos, tornam os estudos sobre seu uso cada vez mais necessários.

Deste modo, a utilização da TARV reveste-se de vários problemas, caso se queira oferecer ao paciente a melhor conduta em busca da segurança e efetividade essenciais a esta terapêutica. O uso racional dos ARV impõe-se como um imperativo para obterem-se resultados definidos, que resultem em uma melhoria da qualidade de vida dos pacientes HIV positivos. Isto é ainda mais importante quando se trata de gestantes, pois a segurança dos medicamentos durante a gravidez humana costuma derivar do empirismo ${ }^{3}$.

Em recente revisão sistemática ${ }^{4}$ denota-se que é muito freqüente a baixa adesão às terapias medicamentosas em geral, com taxas estimadas em torno de $50 \%$ dos medicamentos prescritos. Uma das várias formas de modificar esta situação é o desenvolvimento de práticas de atenção farmacêutica, que apresentam alguns resultados contraditórios na literatura, ora sem resultados estatisticamente significantes de melhora de adesão ${ }^{5,6}$, ora com resultados relevantes relacionados ao cumprimento da prescrição ${ }^{7}$.

Atenção farmacêutica é um termo amplo, que congrega várias ações possíveis a serem efetuadas por um farmacêutico: atendimento farmacêutico, dispensação, orientação; educação e seguimento farmacoterapêutico. Entre estas, o seguimento farmacoterapêutico é reconhecido como a atividade mais complexa, na qual o profissional assume o compromisso de detectar, prevenir e resolver problemas 
relacionados com medicamentos (PRM) junto com o paciente e demais profissionais do sistema de saúde, para alcançar resultados concretos que melhorem a qualidade de vida do paciente ${ }^{8}$.

As divergências nos resultados apresentados justificam o desenvolvimento de mais estudos para verificação da real validade da atenção farmacêutica em resolver PRM e melhorar as taxas de adesão. Assim, o objetivo do presente estudo é observar os resultados obtidos com o seguimento farmacoterapêutico em um grupo de gestantes HIV positivas, atendidas em um Serviço de Atendimento Especializado (SAE).

Metodologia. Todas as gestantes HIV positivas que procuravam atendimento no SAE de Itajaí/SC, entre julho de 2006 a janeiro de/2007 foram convidadas a fazer parte do estudo. Nesse período, 37 gestantes foram acompanhadas pelo SAE, das quais 32 aceitaram participar do estudo (três gestantes se negaram e outras duas não puderam ser contatadas).

Para o seguimento farmacoterapêutico utilizou-se o Método Dáder ${ }^{9}$ e o número de entrevistas com as mulheres variou de uma a sete. Este método propõe, entre outras estratégias, a resolução de PRM, manifestados ou não, além de oferecer oportunidade para a orientação farmacêutica e a educação em saúde para os pacientes. A última gestante seguida teve seu filho no dia 13/07/2007, quando se encerrou o período de coleta de dados.

Para a mensuração da adesão à terapêutica, foi utilizado o método SMAQ Simplified Medication Adherence Questionnaire ${ }^{10}$, que é uma modificação do método proposto por Moriski et al. ${ }^{11}$ para avaliar a adesão à terapêutica para hipertensão arterial. O questionário é composto de 6 questões:1) Você, às vezes, se esquece de tomar seus medicamentos? 2) Toma seus medicamentos no horário 
indicado? 3) Se às vezes você se sente mal com seus medicamentos, deixa de tomálos? 4) Durante a última semana, quantas vezes você não tomou seu medicamento? 5. Você ficou sem tomar algum medicamento no último final de semana? 6. Nos últimos 3 meses, quantos dias você não tomou seus medicamentos corretamente? O SMAQ foi considerado "positivo" quando uma paciente não aderente foi detectada, isto é, quando havia uma resposta positiva para qualquer uma das 3 primeiras questões, ou mais de duas doses perdidas na última semana, ou mais de 2 dias sem medicamentos nos últimos 3 meses. As gestantes respondiam ao questionário na primeira entrevista do seguimento farmacoterapêutico e uma segunda vez, após cerca de 4 semanas, quando retornavam para nova consulta ou para buscar seus medicamentos mensais. Todas as gestantes responderam ao questionário na primeira entrevista; na segunda vez foi aplicado a 24 mulheres, principalmente por terem procurado o SAE muito próximo do término da gestação.

Foram pesquisados também os outros medicamentos utilizados, além dos ARV. Todos foram classificados utilizando-se o Anatomical Therapeutic Chemical Classification Index (ATC), desenvolvido pelo WHO Collaborating Centre for Drug Statistics Methodology ${ }^{12}$.

Os medicamentos também foram classificados quanto à teratogenicidade utilizandose a classificação do Food and Drug Administration (FDA) ${ }^{13,14}$ quanto ao potencial de risco para o feto. Estas informações, juntamente com as possíveis interações dos medicamentos, foram pesquisadas na base de dados eletrônica Drugdex ${ }^{\circledR}{ }^{15}$, da empresa Thomson Micromedex.

Também foram pesquisados possíveis eventos adversos observados pelo uso dos medicamentos. 
Classificaram-se os PRM encontrados quanto à necessidade, efetividade e segurança e buscaram-se soluções que eram repassadas às gestantes em encontros posteriores à detecção dos problemas. Todas as intervenções foram sugeridas diretamente às gestantes, algumas com orientação de discutir o problema com seus médicos. Assim, as intervenções foram aceitas ou não aceitas, tanto pelas pacientes como por seus médicos.

Atendendo a resolução 196/96 do Conselho Nacional de Saúde, o projeto foi aprovado pelo Comitê de Ética em Pesquisa da Faculdade de Saúde Pública - USP.

Resultados. A média de idade das 32 gestantes acompanhadas foi de 27,1 anos (IC $95 \% 24,9-29,3)$ e $62,5 \%$ tinham menos de 8 anos de estudo. Dessas gestantes, 11 foram diagnosticadas como casos de AIDS, as demais eram portadoras do vírus HIV. Entre os 11 casos de AIDS, 9 já estavam em tratamento quando foram confirmadas como gestantes.

É primordial que, para a definição da terapêutica da gestante, esteja claro se a estratégia será somente a prevenção da transmissão vertical - profilaxia com TARV - ou também o tratamento para a mulher que dele necessitar, em função de estado clínico ou imunológico comprometido. As que apenas fazem profilaxia poderão, dependendo dos resultados de seus exames, suspender o uso dos medicamentos ao final da gestação.

Para estas gestantes, devem ser informados os potenciais riscos e benefícios da manutenção, modificação ou suspensão do tratamento, tanto para a evolução de sua doença quanto a possíveis efeitos teratogênicos para a criança. Tanto a carga viral elevada, quando associada à monoterapia com Zidovudina (AZT), quanto o 
tratamento anti-retroviral com esquema duplo (AZT + Lamivudina (3TC) ou AZT + Nevirapina (NVP)) induzem o aparecimento de resistência aos anti-retrovirais, prejudicando o tratamento posterior. Isso, somado à ampla comprovação da eficácia da terapia anti-retroviral combinada, tornaram a HAART (Highly Active Antiretroviral Therapy), ou seja, a combinação de vários ARV (tipicamente três ou quatro), a melhor opção para o tratamento profilático das gestantes infectadas pelo HIV ${ }^{16}$.

$\mathrm{Na}$ Tabela 1, observam-se os esquemas de tratamento que foram utilizados pelas gestantes para a profilaxia da transmissão materno-infantil do vírus ou como tratamento (para as mulheres identificadas como casos AIDS). O esquema inicial para 12 gestantes HIV + foi 6 comprimidos de AZT (destas, uma gestante abandonou o tratamento). Este esquema foi substituído depois por 2 comprimidos da associação Zidovudina e Lamivudina (AZT/3TC) e 10 comprimidos de Nelfinavir (NFV). Para uma destas gestantes, foi posteriormente prescrito um novo esquema, com dois comprimidos de Estavudina (D4T 40), 2 de Lamivudina (3TC) e 10 de Nelfinavir.

Oito gestantes HIV + começaram a profilaxia diretamente com o esquema que associa 2 comprimidos de AZT/3TC mais 10 comprimidos de NFV, pois iniciaram seu prénatal no SAE depois da $28^{\mathrm{a}}$ semana de gestação, enquanto outras 6 gestantes utilizaram como esquema a associação de 2 comprimidos de AZT/3TC adicionados de outros 2 comprimidos de Nevirapina (NVP).

Outros esquemas empregavam ainda os ARV LPVr (associação entre Lopinavir e Ritonavir), RTV (Ritonavir), ATV (Atazanavir) e EFZ (Efavirenz).

Tabela 1. Esquema da terapia antitetroviral (TARV) em gestantes com HIV/Aids no Município de Itajaí, SC - 07/2006 a 07/2007 


\begin{tabular}{lcc}
\hline Medicamento e n $^{\mathbf{0}}$ comprimidos diários & N & $\%$ \\
\hline AZT 6 / (AZT/3TC) 2 + NFV 10 & 10 & 31,20 \\
(AZT/3TC) 2 + NFV 10 & 8 & 25,00 \\
(AZT/3TC) 2 + NVP 2 & 6 & 18,75 \\
AZT 6 & 1 & 3,13 \\
AZT 6 / (AZT/3TC) 2 + NFV 10 / D4T(40) 2 + 3TC 2 + NFV 10 & 1 & 3,13 \\
D4T(30) 2 + 3TC 2 + LPVr 6 & 1 & 3,13 \\
D4T(40) 2 3TC 2 + LPVr 6 & 1 & 3,13 \\
D4T(40) 2 + 3TC 2 + RTV 6 + ATV 2 & 1 & 3,13 \\
(AZT/3TC) 2 + EFZ 1 / AZT/3TC) 2 + NFV 10 & 1 & 3,13 \\
AZT 6 + 3TC 2 + EFZ 1 / (AZT/3TC) 2 + NFV 10 & 1 & 3,13 \\
AZT 6 + EFZ 1 / (AZT/3TC) 2 + NFV 10 & 1 & 3,13 \\
\hline TOTAL & 32 & 100,0 \\
\hline
\end{tabular}

AZT: Zidovudina; 3TC: Lamivudina; NFV: Nelfinavir; D4T: Estavudina; NVP: Nevirapina; LPVr: Lopinavir/Ritonavir; RTV: Ritonavir; ATV: Atazanavir; EFZ: Efavirenz.

Além dos anti-retrovirais, houve o relato de utilização de outros 35 medicamentos, classificados pelo Sistema ATC (Anatomical Chemical Therapeutic) conforme a tabela abaixo (em negrito, aparecem os antiretrovirais, todos classificados na letra J):

Tabela 2. Classificação ATC dos medicamentos utilizados pelas gestantes com HIV/Aids no Município de Itajaí, SC - 07/2006 a 07/2007

\begin{tabular}{|c|c|}
\hline Classificação ATC & Medicamentos ( $\mathrm{n}^{\circ}$ de usuárias) \\
\hline $\begin{array}{l}\text { A - Trato alimentar e } \\
\text { metabolismo }\end{array}$ & $\begin{array}{l}\text { Metoclopramida (4), Multivitaminas (4), Óleo mineral } \\
\text { (2), Ranitidina (1), Dimeticona (2) }\end{array}$ \\
\hline $\begin{array}{l}\text { B- Sangue e órgãos } \\
\text { hematopoiéticos }\end{array}$ & Compostos com ferro (19), Ácido fólico (5) \\
\hline $\begin{array}{l}\text { G - Sistema geniturinário } \\
\text { e hormônios sexuais }\end{array}$ & $\begin{array}{l}\text { Metronidazol (creme vaginal) (4), Miconazol (creme } \\
\text { vaginal) (2) }\end{array}$ \\
\hline $\begin{array}{l}\mathrm{J} \text { - Antiinfecciosos gerais } \\
\text { para uso sistêmico }\end{array}$ & $\begin{array}{l}\text { Amoxicilina (5), Ampicilina (1), Atazanavir (1); } \\
\text { Azitromicina (3), Benzilpenicilina (1), Cefalexina (2), } \\
\text { Ceftriaxona (1), Ciprofloxacino (1), Clindamicina (1), }\end{array}$ \\
\hline & Efavirenz (3); Espiramicina (1), Estavudina (4); \\
\hline & Etambutol (1), Isoniazida (1), Lamivudina (31); \\
\hline & 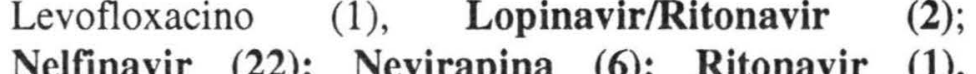 \\
\hline & $\begin{array}{l}\text { Sulfadiazina (1), Sulfametoxazol + trimetoprim(1), } \\
\text { Zidovudina (29) }\end{array}$ \\
\hline $\begin{array}{l}\text { M - Sistema músculo } \\
\text { esquelético }\end{array}$ & Diclofenaco (2) \\
\hline $\begin{array}{l}\mathrm{N} \text { - Sistema nervoso } \\
\text { central }\end{array}$ & $\begin{array}{l}\text { Escopolamina (6), Paracetamol (15), Diazepam (1), } \\
\text { Dipirona (1) }\end{array}$ \\
\hline P - Antiparasit & o de benzila (1), I \\
\hline
\end{tabular}


(1), Pirimetamina (1)

$\mathrm{R}$ - Sistema respiratório Prometazina (1)

Não foi encontrado Ácido folínico (1)

Herbal ATC Index - Passiflora (1)

Hipnótico e sedativo

A classificação dos medicamentos utilizados pelas gestantes, quanto a seu poder teratogênico, conforme critério do FDA é apresentada na Tabela 3 (os ARV estão em negrito).

Tabela 3. Medicamentos utilizados por gestantes com HIV/AIDS do Município de Itajaí, SC, no período de 07/2006 a 07/2007, segundo classificação de risco para o feto, do Food and Drug Administration (FDA)

\begin{tabular}{|c|c|}
\hline Medicamentos & Classificação FDA \\
\hline $\begin{array}{l}\text { Ac. fólico; Compostos com ferro; } \\
\text { Isoniazida; } \\
\text { Multivitamínicos; }\end{array}$ & $\begin{array}{l}\text { A - Os estudos em mulheres não } \\
\text { demonstraram nenhum risco }\end{array}$ \\
\hline $\begin{array}{l}\text { Amoxicilina; Ampicilina; Atazanavir; } \\
\text { Azitromicina; Benzilpenicilina; Cefalexina; } \\
\text { Ceftriaxona; Clindamicina; Etambutol; } \\
\text { Metoclopramida; } \\
\text { Nevirapina, Nelfinavir, Petronidazol; } \\
\text { Ranitidina; Ritonavir }\end{array}$ & $\begin{array}{l}\text { B - Pesquisas com animais não } \\
\text { demonstraram risco fetal, mas não } \\
\text { existem estudos controlados em } \\
\text { mulheres grávidas }\end{array}$ \\
\hline $\begin{array}{l}\text { Ac. Folínico; Albendazol; Ciprofloxacino; } \\
\text { Diazepam; Diclofenaco; Dipirona } \\
\text { Escopolamina; Espiramicina; Estavudina; } \\
\text { Lamivudina; Levofloxacino; } \\
\text { Lopinvavir/ritonavir; Pirimetamina; } \\
\text { Prometazina; Sulfadiazina; Sulfametoxazol } \\
\text { + trimetoprim; Zidovudina }\end{array}$ & $\begin{array}{l}\text { C - Estudos em animais revelaram } \\
\text { efeitos adversos no feto, mas não } \\
\text { existem estudos disponíveis realizados } \\
\text { em seres humanos }\end{array}$ \\
\hline $\begin{array}{l}\text { Benzoato de benzila; Dimeticona; } \\
\text { Metronidazol (gel vaginal); Miconazol } \\
\text { (creme vaginal); Óleo mineral; Passiflora }\end{array}$ & $\begin{array}{l}\text { D - Os estudos em seres humanos } \\
\text { revelaram riscos, mas o uso pode ser } \\
\text { justificado em alguns casos } \\
\text { Indeterminada }\end{array}$ \\
\hline
\end{tabular}

Foram encontradas 11 interações medicamentosas, todas classificadas, pela litaratura, como potenciais ou não clinicamente relevantes. Estas interações bem como seus efeitos, pesquisados na literatura, estão descritas no quadro 1. 


\begin{tabular}{|c|c|}
\hline Interações & Manejo clínico \\
\hline $\begin{array}{l}\mathrm{AZT}+3 \mathrm{TC} \\
3 \mathrm{TC}+\mathrm{AZT}\end{array}$ & $\begin{array}{l}\text { Embora usualmente não haja interação clínica } \\
\text { significante, há relatos de pacientes que reportaram } \\
\text { severa anemia com esta associação }\end{array}$ \\
\hline $\begin{array}{l}\mathrm{AZT}+\mathrm{NVP} \\
\mathrm{NVP}+\mathrm{AZT}\end{array}$ & $\begin{array}{l}\text { Diminui os níveis séricos e a eficácia do AZT, por } \\
\text { possível alteração no metabolismo do CYP } 450 \text {. Não é } \\
\text { recomendado ajuste de dose. }\end{array}$ \\
\hline $\begin{array}{l}\mathrm{AZT}+\mathrm{NFV} \\
\mathrm{NFV}+\mathrm{AZT}\end{array}$ & $\begin{array}{l}\text { Diminuição da concentração do AZT. Severidade } \\
\text { moderada. Monitorar a eficácia do AZT em pacientes } \\
\text { com esta combinação e ajustar sua dose }\end{array}$ \\
\hline $\begin{array}{l}\text { AZT + Paracetamol } \\
\text { Paracetamol + AZT }\end{array}$ & $\begin{array}{l}\text { Neutropenia, aumento da hepatotoxicidade do } \\
\text { paracetamol, severidade moderada. Estes efeitos não } \\
\text { estão consistentemente relatados. Evitar múltiplas } \\
\text { doses ou uso crônico do paracetamol. Aumento de } \\
\text { depressão medular. Pancreatite. Alternativamente, } \\
\text { ibuprofeno poderia ser considerado. }\end{array}$ \\
\hline $\begin{array}{l}\text { AZT + Pirimetamina } \\
\text { Pirimetamina + AZT }\end{array}$ & $\begin{array}{l}\text { Aumento no risco de supressão da medula óssea. } \\
\text { Severidade maior. Se há o desenvolvimento de sinais } \\
\text { de deficiência de folato, pirimetamina deve ser } \\
\text { interrompida. Ácido folínico deve ser administrado até } \\
\text { que a hematopoiese normal seja restabelecida. }\end{array}$ \\
\hline $\begin{array}{l}\text { AZT + Azitromicina } \\
\text { Azitromicina + AZT }\end{array}$ & $\begin{array}{l}\text { Pode aumentar os níveis séricos do AZT. Não é } \\
\text { recomendado ajuste da dose }\end{array}$ \\
\hline $\begin{array}{l}\text { AZT + Sulfametoxazol/ } \\
\text { trimetoprim } \\
\text { Sulfametoxazol/trimetoprim } \\
+ \text { AZT }\end{array}$ & $\begin{array}{l}\text { Aumenta os níveis séricos do AZT. Pode reduzir o } \\
\text { número de eritrócitos e neutrófilos, aumentando os } \\
\text { riscos de anemia. Administrar com precaução. }\end{array}$ \\
\hline $\begin{array}{l}3 \mathrm{TC}+\mathrm{NFV} \\
\mathrm{NFV}+3 \mathrm{TC} \\
\end{array}$ & $\begin{array}{l}\text { Aumento dos níveis séricos do } 3 \mathrm{TC} \text { em } 10 \% \text {. Não é } \\
\text { recomendado ajuste de dose. }\end{array}$ \\
\hline $\begin{array}{l}\text { 3TC + Sulfametoxazol/ } \\
\text { Trimetoprim } \\
\text { Sulfametoxazol/trimetoprim } \\
+3 \mathrm{TC}\end{array}$ & $\begin{array}{l}\text { Aumento do risco de eventos adversos do } 3 \text { TC por } \\
\text { aumento da concentração deste fármaco (não foi } \\
\text { explorado o significado clínico deste achado); } \\
\text { severidade menor. }\end{array}$ \\
\hline $\begin{array}{l}\text { RTV + ATV } \\
\text { ATV + RTV }\end{array}$ & $\begin{array}{l}\text { Aumento da concentração plasmática do ATV. } \\
\text { Severidade moderada. Se forem co-administrados, é } \\
\text { recomendável que o ATV seja dado com alimentos. }\end{array}$ \\
\hline $\begin{array}{l}\text { Isoniazida + Paracetamol } \\
\text { Paracetamol + Isoniazida }\end{array}$ & $\begin{array}{l}\text { Aumento do risco de hepatotoxicidade. Severidade } \\
\text { moderada. O uso do paracetamol deve ser limitado } \\
\text { entre os pacientes que usam Isoniazida. }\end{array}$ \\
\hline
\end{tabular}

Quadro 1. Interações encontradas entre os medicamentos utilizados pelas gestantes

Fez parte da orientação dada às gestantes a interação dos fármacos com alimentos.

Para as que utilizavam ATV, NFV, LPVr e RTV foi informada a necessidade de 
tomar estes medicamentos com alimentos; para os outros ARV, havia a possibilidade de escolha entre tomar com alimentos ou em jejum. Também foi explicado que os compostos com ferro são melhor absorvidos quando utilizados preferencialmente longe das refeições, com suco de laranja ou outro suco cítrico.

Os eventos adversos com o os esquemas terapêuticos utilizados pelas gestantes podem ser visualizados na Tabela 4.

Tabela 4. Eventos adversos e freqüência com que apareceram associados ao uso de esquemas terapêuticos utilizados por gestantes com HIV/AIDS no Município de Itajaí, SC - 07/2006 a 07/2007

\begin{tabular}{|c|c|}
\hline Esquema & Evento adverso ( $n^{\circ}$ de usuárias) \\
\hline AZT 6 & $\begin{array}{l}\text { Anemia (4), fraqueza/sonolência (2), } \\
\text { náuseas (1), diarréia (1), azia (1), não relata } \\
(3)\end{array}$ \\
\hline ATC $2+$ NFV 10 & $\begin{array}{l}\text { Diarréia (8), náuseas (7), anemia }(4) \text {, } \\
\text { tontura (1), fraqueza/sonolência (1), não } \\
\text { relata (7) }\end{array}$ \\
\hline D4T(40) $2+3 \mathrm{TC} 2+\mathrm{NFV} 10$ & Não relata (1) \\
\hline ATC $2+$ NVP 2 & $\begin{array}{l}\text { Anemia (3), fraqueza/sonolência } \\
\text { diarréia (1), náuseas (1), não relata (2), }\end{array}$ \\
\hline $\mathrm{D} 4 \mathrm{~T}(30) 2+3 \mathrm{TC} 2+\mathrm{LPVr} 6$ & Anemia (1) \\
\hline $\mathrm{D} 4 \mathrm{~T}(40) 2+3 \mathrm{TC} 2+\mathrm{LPVr} 6$ & Não relata (1) \\
\hline D4T(40) $2+3$ TC $2+$ RTV $6+$ ATV 2 & Náuseas (1) \\
\hline ATC $2+$ EFZ 1 & Não relata (1) \\
\hline AZT $6+3$ TC $2+$ EFZ 1 & Não relata (1) \\
\hline AZT $6+$ EFZ 1 & Não relata (1) \\
\hline
\end{tabular}

Foram relatadas dificuldades, como náuseas, para a ingestão da associação Lopinavir/Ritonavir, citada uma vez, e para a ingestão do Nelfinavir, citada por 6 pacientes.

De acordo com os resultados encontrados com o instrumento SMAQ, após a primeira entrevista, verificou-se que 19 mulheres $(59,4 \%)$ eram não aderentes à TARV. No segundo momento, das 24 gestantes entrevistadas, 18 (75\%) mostraram-se aderentes, o que se mostrou estatisticamente significante (considerando $\mathrm{p}<0,05$ ). 
Para duas gestantes, não foram observados PRM. Para as demais, foram encontrados 51 PRM: 2 PRM quanto à necessidade, 22 quanto à efetividade, (destes, 20 PRM não manifestados - potenciais - por falta de adesão) e 27 quanto à segurança, com uma média de 1,7 PRM por gestante.

Quanto ao Seguimento Farmacoterapêutico, variou entre 1 encontro (6 mulheres), 2 a 3 encontros (10 mulheres) e 4 a 7 encontros (16 mulheres). Portanto, para algumas mulheres, apesar de serem observados PRM, não houve seguimento farmacoterapêutico propriamente dito, pois como tiveram um único encontro, não houve a possibilidade de apresentar uma proposta de intervenção para resolução de PRM.

Das 26 gestantes acompanhadas, uma não apresentou PRM enquanto para as demais foram encontrados 17 PRM quanto à efetividade e 21 quanto à segurança. Para estes PRM, foram propostas intervenções, que poderiam ou não ser aceitas. Por sua vez, independente da proposta de intervenção ser aceita, estes PRM poderiam ou não ser resolvidos. A Tabela 5 resume essas ações.

Tabela 5. Resultados da resolução de Problemas Relacionados a Medicamentos (PRM) encontrados em gestantes com HIV/AIDS no Município de Itajaí, SC 07/2006 a 07/2007

\begin{tabular}{lccc}
\hline \multicolumn{2}{c}{ Efetividade } \\
\hline Intervenção & PRM resolvido & $\begin{array}{c}\text { PRM não } \\
\text { resolvido }\end{array}$ & Total \\
Aceita & \multicolumn{4}{c}{$\begin{array}{c} \\
\text { Não aceita }\end{array}$} & 0 & 6 & 11 \\
Total & 11 & 6 & 6 \\
& \multicolumn{4}{c}{ Segurança } \\
Intervenção & PRM resolvido & PRM não & 17 \\
& \multicolumn{4}{c}{ resolvido } & Total \\
Aceita & 13 & 1 & 14 \\
Não aceita & 1 & 6 & 7 \\
Total & 14 & 7 & 21 \\
\hline
\end{tabular}


Discussão. Observa-se que o Consenso brasileiro para a profilaxia da transmissão vertical do HIV e terapia anti-retroviral em gestantes ${ }^{16}$ está sendo seguido pelos médicos prescritores em Itajaí. Os esquemas mais utilizados são os preconizados, enquanto outros que incluíam Estavudina e Efavirenz, por exemplo, não são utilizados para a profilaxia da transmissão materno-infantil do vírus (estavam sendo utilizados pelas gestantes diagnosticadas como casos de AIDS). Assim, há uma predominância do esquema AZT/3TC + NFV, seja ele iniciado após a monoterapia com AZT, com outro esquema ou diretamente (foi utilizado por 22 gestantes). O segundo esquema mais utilizado é AZT/3TC + NVP, que apresenta maior possibilidade de resistência cruzada ocasionada pela NVP em relação aos outros Inibidores da Transcriptase Reversa Não Nucleosídicos (NNRTI). Mesmo a troca do esquema AZT/3TC + NFV por D4T(40) + 3TC + NFV ocorrida com uma gestante também é recomendada pelo consenso, já que neste caso foi diagnosticada anemia grave, que poderia ser causada ou agravada com o uso do AZT.

Deve ser ressaltado, entretanto, que quando do diagnóstico da gestação, 3 mulheres faziam uso do anti-retroviral Efavirenz (EFZ), considerado teratogênico. Principalmente no primeiro trimestre da gestação, período da organogênese, este medicamento não deveria ser utilizado ${ }^{17}$. Isso demonstra que há uma falha de comunicação entre o Programa DST/AIDS e as mulheres que fazem uso do EFZ, seja pela ausência de informações ou pela não compreensão da sua importância. De qualquer modo, houve a imediata troca de esquema a partir do conhecimento do estado gestacional destas mulheres por seus médicos.

Em conjunto com os ARV, foi relatado o uso de outros 35 medicamentos, sendo $37 \%$ deles classificados como anti-infecciosos gerais para uso sistêmico, que foram 
utilizados por 13 mulheres (40,62\%). Porém, os fármacos mais utilizados pelas gestantes foram os compostos com ferro $(59,4 \%)$ e o paracetamol $(46,9 \%)$, medicamentos corriqueiramente utilizados em gestações, ainda que com controvérsias quanto às reais necessidades ${ }^{13,14,18}$.

A maioria dos fármacos utilizados pelas gestantes $(38,6 \%)$ foi classificada na letra C segundo o critério do FDA para teratogenicidade, em que a segurança não está estabelecida. Este percentual é semelhante ao encontrado por Fonseca et al. ${ }^{19} \mathrm{e}$ Andrade et al. ${ }^{20}$, embora neste último estudo, uma coorte nos Estados Unidos, a maior parte dos medicamentos utilizados tenha sido classificada como B.

De todos os fármacos, o único a apresentar riscos maiores de causar teratogenicidade, segundo a literatura, foi o Efavirenz ${ }^{17}$ enquanto outros 6 fármacos $(13,63 \%)$ foram classificados como indeterminados. Estes resultados diferem dos encontrados por Lacroix et al. ${ }^{21}$, que afirmam que, em uma região do sudeste da França, 59,3\% das gestantes usaram medicamentos classificados como D e 78,9\% foram expostas a medicamentos de categoria indeterminada.

Em relação às interações encontradas, a maior parte delas não é clinicamente significante ou é potencial. Várias das interações descritas são comumente utilizadas nos esquemas anti-retrovirais $(\mathrm{AZT}+3 \mathrm{TC} ; \mathrm{AZT}+\mathrm{NVP} ; \mathrm{AZT}+\mathrm{NFV} ; 3 \mathrm{TC}+\mathrm{NFV}$; RTV + ATV), com resultados positivos que suplantam os possíveis riscos. O Paracetamol, apesar de poder causar hepatoxicidade, é o analgésico antitérmico mais recomendado na gestação. Assim, desde que seja utilizado da forma recomendada pelos profissionais de saúde, representa a melhor opção para estas mulheres. A associação entre AZT e Pirimetamina exigia a utilização concomitante de Ácido folínico, como estava acontecendo com a única gestante sob esta prescrição, 
enquanto a associação AZT + Azitromicina não necessita reajustes de doses. Sulfametoxazol/Trimetoprim é muito utilizado para o tratamento e profilaxia de algumas infecções oportunistas, sendo comum seu uso conjunto com ARV. Apesar dessa associação apresentar riscos moderados, a monitoração do tratamento seria a postura adequada para esta interação.

Mur Lalaguna et al. ${ }^{22}$ classificam as interações em 1) contraindicada ou não recomendada; 2) potencial interação que pode justificar uma mudança na dose ou monitoração; e 3) Interação sem relevância clínica. Estes autores encontraram um percentual muito baixo de interações contraindicadas ou não recomendadas na Espanha (1,7\%), enquanto neste estudo não se encontrou nenhuma. Mesmo assim, quaisquer interações devem ser acompanhadas, pois boa parte dos anti-retrovirais, em especial os Inibidores da Protease, podem ser indutores, inibidores ou simples substratos do sistema citocromo $\mathrm{P} 450$, o que lhes confere a capacidade de alterar e terem seus metabolismos alterados por outros fármacos.

Quanto ao seguimento farmacoterapêutico, foram feitas intervenções relativas à interação dos ARV com alimentos. Este tipo de interação é responsável por impor problemas farmacocinéticos relativos à absorção daqueles medicamentos, com implicações na sua biodisponibilidade, além de poderem dificultar a sua tomada. Estas informações, que a maior parte das gestantes desconhecia, e outras relacionadas à alimentação e nutrição ${ }^{23}$ não só podem ocasionar uma melhora da absorção dos ARV como foram importantes para algumas mulheres que tinham dificuldades na utilização de Nelfinavir (de 6 casos que relataram dificuldades, 3 resolveram o problema com a ingestão correta com alimentos). 
Em relação aos eventos adversos encontrados com a utilização dos diferentes esquemas, observa-se que, de 12 mulheres que utilizaram o AZT monoterapia, 4 apresentaram anemia e duas fraqueza/sonolência. De fato, a literatura aponta a anemia e astenia como dois sintomas frequientemente associados ao uso da Zidovudina. Provavelmente, também foi o AZT o responsável por estes mesmos sintomas quando utilizado o esquema AZT/3TC + NVP, enquanto a presença do NFV no esquema AZT/3TC + NFV pode ser responsabilizada pela diarréia e náuseas ${ }^{24}$. Contudo, estes sintomas, em geral, são comuns em gestantes podendo não ter sido observados devido ao uso dos medicamentos, razão pela qual foram denominados eventos e não reações adversas.

Destaca-se, no estudo, a adesão ao uso dos anti-retrovirais. Quando entrevistadas no primeiro momento, apenas 13 das 32 gestantes se mostraram aderentes à terapia. Para 24 delas, foi possível realizar uma nova entrevista. Destas, 18 mostraram-se aderentes quando entrevistadas pela segunda vez, o que se mostrou estatisticamente significante, considerando $p<0,05$. O Seguimento demonstrou que, das 13 consideradas aderentes, apenas uma deixou de sê-lo em função dos eventos adversos relacionados à TARV, o que já havia sido observado por outros autores ${ }^{25,26}$ e, das 19 não aderentes, 9 mudaram sua condição.

Entre as limitações deste estudo, devem ser ressaltados o pequeno número de participantes e a falta de um grupo controle. É importante observar também que o maior número de encontros aconteceu quando as mulheres foram ao SAE, ou seja, sua freqüência ao serviço fez com que participassem mais do estudo. Nemes ${ }^{27}$ já demonstrava que um dos itens que melhora a adesão dos pacientes à TARV é o histórico de comparecimento à consulta médica. Ou seja, quanto mais a gestante 
tinha contato com o seguimento farmacoterapêutico, mais também ela tinha consultas médicas e com a equipe da enfermagem, o que impossibilita a afirmação de que o Seguimento Farmacoterapêutico tenha sido o único fator para a mudança de comportamento em relação à adesão.

De qualquer maneira, pode-se supor que a resolução dos PRM contribuiu para o aumento da adesão à TARV, uma vez que, de 38 PRM possíveis de resolução pelo seguimento farmacoterapêutico, 25 foram resolvidos. Há vários relatos na literatura mostrando que a intervenção farmacêutica pode colaborar com o êxito da farmacoterapia. Assim, Castro ${ }^{28}$, em um ensaio clínico utilizando a Atenção Farmacêutica, relata que se observou no grupo de pacientes hipertensos que recebeu a intervenção a redução da pressão arterial de forma significativa.

Mais especificamente em relação à AIDS/HIV, Gal ${ }^{29}$ (2004), em uma revisão, relata uma série de atividades feitas por farmacêuticos, desde a participação em programas de redução de danos até a Atenção Farmacêutica, que resultaram melhores cuidados na prevenção e tratamento de pacientes com AIDS. Também Cociña Abella ${ }^{30} \mathrm{e}$ Codina Jané et al. ${ }^{31}$ publicaram estudos demonstrando como a Atenção Farmacêutica melhorou a adesão ao tratamento anti-retroviral, enquanto Calderón Hernanz et al. ${ }^{32}$ publicaram trabalho demonstrando que a Atenção Farmacêutica conseguiu detectar erros na administração de ARV. Ventura Cerdá et al ${ }^{33}$, por sua vez, demonstraram a satisfação dos pacientes HIV atendidos em uma unidade que oferecia serviços de Atenção Farmacêutica.

Há algum tempo documentos relatam a necessidade da presença do farmacêutico na luta contra a epidemia HIV/AIDS ${ }^{34}$. Embora nem sempre se saiba qual a melhor alternativa de ação nesse sentido, existem diversos relatos mostrando estratégias e 
métodos possíveis de atuação nessa área ${ }^{35,36,37}$. Entre estes, destaca-se o seguimento farmacoterapêutico que, não obstante seu potencial, apresenta deficiências quanto à demonstração efetiva de que seja útil de uma perspectiva de evidência científica, em função da falta de estudos que demonstram sua efetividade ${ }^{38}$.

O seguimento farmacoterapêutico não tem como única finalidade a identificação de resultados negativos da farmacoterapia nem uma mera intervenção nestes casos, mas sim a resolução de uma ocorrência clínica negativa. Ainda que não haja evidências definitivas relacionando os tratamentos multidisciplinares com o oferecimento de serviços mais efetivos aos pacientes HIV/AIDS ${ }^{39}$, os resultados apresentados aqui demonstram que o trabalho multidisciplinar, com a equipe que atendia as gestantes no SAE de Itajaí, proporcionou uma atenção integral à saúde condizente com os princípios dos SUS.

Conclusão: Os prescritores de Itajaí observam as recomendações do Consenso brasileiro para a profilaxia da transmissão vertical do HIV e terapia anti-retroviral em gestantes. Os medicamentos utilizados pelas gestantes com HIV/AIDS de Itajaí, além dos ARV, são os mesmos observados em estudos similares. Com o seguimento farmacoterapêutico foi possível identificar PRM e fazer intervenções. Os resultados sugerem que o seguimento colaborou com a melhora da adesão à TARV das pacientes com HIV/AIDS e que o trabalho multiprofissional pode trazer bons resultados quanto à farmacoterapia nesse grupo de pacientes, em particular.

\section{Colaboradores}


B.C. Cordeiro contribuiu na revisão da literatura, elaboração da metodologia, trabalho de campo e redação do artigo final. N. S. Romano-Lieber colaborou na elaboração da metodologia e revisão do artigo final.

\section{Referências bibliográficas}

1. Zdanowicz MM. The pharmacology of HIV drug resistance. American Journal of Pharmaceutical Education 2006; 70(5): Article 100.

2. Paterson DL, Swindells S, Mohr J, Brester M, Vergis EN, Squier C, et al. Adherente to protease inhibitor therapy and outcomes in patients with HIV infection. Annals of Internal Medicine 2000; 133(1): 21-30.

3. Osório-de-Castro CGS, Paumgartten FJR, Silver LD. O uso de medicamentos na gravidez. Ciência \& Saúde Coletiva 2004; 9(4):987-996.

4. Haynes RB, Yao X, Degani A, Kripalani S, Garg A, McDonald HP. Intervenciones para mejorar el cumplimiento con la medicación (Revisión Cochrane traducida). En: La Biblioteca Cochrane Plus 2007; Numero 2. Oxford: Update Software Ltd. http://www.update-software.com (acessado em 23/Ago/2007)

5. Volume CI, Garris KB, Kassam R, Cox CE, Cave A. Pharmaceutical care research and education project: patient outcomes. J Am Pharm Assoc 2001; 41(3): 411-420.

6. Weinberger M, Murray MD, Marrero DG, Brewer N, Lykens M, Harris LE et al. Effectiveness of pharmacist care for patients with reactive airways disease: a randomized controlled trial. JAMA 2002; 288(13): 1594-1602. 
7. Sandi $\mathbf{J}$ e Arias L. Impacto de la inducción farmacéutica sobre la adherencia de pacientes VIH/SIDA com tratamiento antirretroviral en el Hospital San Juan de Dios (Costa Rica). Seguim Farmacoter 2003; 1(2): 43-48.

8. Cordeiro BC e Reynaud F. Atenção farmacêutica: evolução ou revolução? In: Cordeiro BC e Leite SN. O Farmacêutico na Atenção à Saúde. Itajaí: UNIVALI; 2005. p. 51-70.

9. Grupo de Investigación en Atención Farmacéutica. Universidad de Granada. Seguimiento farmacoterapéutico: Método Dáder (3 ${ }^{\mathrm{a}}$. Revisión: 2005). Pharmacy Practice 2006; 4(1): 44-53.

10. Knobel H, Alonso J, Casado JL, Collazos J, González J, Ruiz I, et al. Validation of a simplified medication adherence questionnaire in a large cohort of HIV-infected patients: the GEEMA Study. AIDS 2002; 16: 605613.

11. Moriski DE, Green LW, Levine DM. Concurrent and predictive validity of a self-reported measure of medication adherence. Medical Care 1986; 24(1): $67-74$.

12. World Health Organization. WHO Collaborating Centre for Drug Statistics Methodology. Anatomical therapeutic chemical (ATC) index with defined daily doses (DDs). Geneva; [s.d.]. http://www.whocc.no/atcddd (acessado em 26/9/2007).

13. Mengue SS, Schenkel EP, Duncan BB, Schmidt MI. Uso de medicamentos por gestantes em seis cidades brasileiras. Rev. Saúde Pública 2001; 35(5): $415-420$. 
14. Carmo TA \& Nitrini SMOO. Pescrições de medicamentos para gestantes: um estudo farmacoepidemiológico. Cad Saúde Pública 2004; 20(4): 1004-1013.

15. Drugdex®. Thomson hicromedex. http://www.thomsonhc.com/hcs/librarian (acessado em 29/09/2007)

16. Ministério da Saúde (MS). Recomendações para a profilaxia da transmissão vertical do HIV e terapia anti-retroviral em gestantes. Brasília; 2006 a. http://www.aids.gov.br (acessado em 10/08/2006)

17. Public Health Service Task Force. Recommendations for use of antiretroviral drugs in pregnant women for maternal health and Interventions to reduce perinatal HIV-1 transmission in the United States; 2006. http://www.aidsinfo.nih.gov (Acessado em 05/10/2007)

18. Gomes KRO, Moron AF, Silva RS, Siqueira AAF. Prevalência do uso de medicamentos na gravideze relações com as características maternas. Rev Saúde Pública; 1999 33(3): 246-254.

19. Fonseca MRCC, Fonseca E, Bergsten-Mendes G. Prevalência do uso de medicamentos na gravidez: uma aobrdagem epidemiológica. Rev Saúde Pública 2002; 36(2): 205-212.

20. Andrade SE, Gurwitz JH, Davis RL, Chan KA, Finkelstein JA, Fortman K, et al. Prescription drug use in pregnancy. American Journal of Obstetrics and Gynecology 2004; 191: 398-407.

21. Lacroix I, Damase-Michel C, Lapeyre-Mestre M, Montastruc JL. Prescription of drugs during pregnancy in France. Lancet 2000; 356: 1735-1736. 
22. Mur Lalaguna MA, Cobos Campos R, Hurtado Gómez MF, Martinez Tutor MJ. Estúdio de lãs interacciones entre fármacos antirretrovirales y tratamiento concomitante. Farmácia Hospitalaria 2003; 27(2): 84-92.

23. Ministério da Saúde (MS). Alimentação e nutrição para pessoas que vivem com HIV e AIDS. Brasília; 2006b. http://www.aids.gov.br (Acessado em 05/02/2007)

24. Kuchenbecker RS. Antivirais. In: Fuchs FD, Wannmacher L, Ferreira MBC, editores. Farmacologia Clínica: Fundamentos da Terapêutica Racional. 3a. ed. Rio de Janeiro: Guanabara Koogan; 2004. p. 450-472.

25. Johnson MO, Charlebois E, Morin SF, Catz SL, Goldstein RB, Remien RH, et al. Perceived Adverse Effects of Antiretroviral Therapy. Journal of Pain and Symptom Management 2005; 29(2): 193-205.

26. Montessori V, Press N, Harris M, Akagi L, Montaner JSG. Adverse effects of antiretroviral therapy for HIV infection. CMAJ 2004; 170(2): 229-238.

27. Nemes MIB, pesquisadora principal. Aderência ao Tratamento por Antiretrovirais em Serviços Públicos de Saúde no Estado de São Paulo. Brasília: Ministério da Saúde; 2000. 171 p.

28. Castro MS. Atenção Farmacêutica: efetividade do seguimento farmacoterapêutico de pacientes hipertensos não controlados [Tese de Doutorado]. Porto Alegre: Faculdade de Medicina, UFRGS; 2004.

29. Gal DL. Improving the prevention and treatment of HIV/AIDS throug pharmacist interventions. The International Network for Pharmacists on HIV/AIDS. http://www.fip.org/hivaids (Acessado em 23/09/07) 
30. Cociña Abella C, Aranda Gallardo D, Magro Horcajada C. Atención farmacéutica en pacientes con Síndrome de Inmunodeficiencia Adquirida. Pharm Care Esp 2003; 5: 146-150.

31. Codina Jané C, Tuset Creus M, Ibarra Barrueta O, Delgado Sánchez O, Morancho Echevarría O, García Díaz B. Evaluación de un programa de atención farmacéutica dirigido a mejorar la adherencia al tratamiento antirretroviral. Farmacia Hospitalaria 2004; 28(Supl. 1): 19-26.

32. Calderón Hernanz B, Santolaya Perrín R, Pérez Sanz C, Gómez Castillo JJ, Luque Infantes R. Detección de errores en la administración del tratamiento antirretroviral en pacientes externos. Farmacia Hospitalaria 2004; 28(3): 201 204.

33. Ventura Cerdá CERDÁ JM, Sanfélix Gimeno G, Monte Boquet E, Fernández Villalba EM, Alós Almiñana. Satisfacción percibida por pacientes infectados por el VIH com la unidad de atención farmacéutica a pacientes externos (UFPE). Farmacia Hospitalaria 2005; 29(2): 134-139.

34. OMS/FIP. Organisation Mondiale de la Santé, Fédération Internationale Pharmaceutique. Le Role du Pharmacien dans la lutte contre la pandémie VIH-SIDA; 1997. http://hivaids.fip.org/website/fr (Acessado em 15/06/00)

35. Ventura Cerdá CERDÁ JM \& Alós Albiñana M. Programa de atención farmacéutica a pacientes VIH con tratamiento antirretroviral: metodologia y documentación. Farmacia Hospitalaria 2004; 28 (Supl. 1): 72-79.

36. Barrueco N, Castillo I, Ais A, Martínez C, Sanjurjo M. Programa de atención farmacéutica a pacientes pediátricos en tratamiento antirretroviral. Farmacia Hospitalaria 2005; 29(6):367-374. 
37. Valín LO. Atención farmacéutica al paciente con VIH: papel del grupo VIHSEFH. Farmacia Hospitalaria 2004; 28(Supl. 1): 80-84.

38. Baena MI, Martínez-Olmos J, Faus MJ, Fajardo P, Martínez-Martínez F. El seguimiento farmacoterapéutico: un componente de la calidad en la atención al paciente. Ars Pharm 2005; 46(3): 213-232.

39. Handford CD, Tynam AM, Rackal JM, Glazier RH. Ámbito y organización de la atención de personas que conviven con VIH/SIDA (Revisión Cochrane traducida). En: La Biblioteca Cochrane Plus 2007; Numero 2. Oxford: Update Software Ltd. http://www.update-software.com (Acessado em $13 / 08 / 2007)$ 
ARTIGO 4 (Título Provisório)

A VERTICALIDADE ENTRE O PROGRAMA DST/AIDS E A ESTRATÉGIA SAÚDE DA FAMÍLIA EM ITAJAÍ (SC): UM ESTUDO DE CASO LOCAL OU A REALIDADE BRASILEIRA? 


\section{A verticalidade entre o Programa DST/AIDS e a Estratégia Saúde da Família}

(ESF) em Itajaí (SC): Um estudo de caso local ou a realidade brasileira?

Verticality between STD/AIDS Program and Family Health Program (FHP) in Itajaí (SC): a local case study or the Brazilian reality?

${ }^{a}$ Benedito Carlos Cordeiro, ${ }^{b}$ Nicolina Silvana Romano-Lieber

${ }^{a}$ Mestre em Saúde Pública. Professor do Curso de Farmácia da Universidade do Vale do Itajaí - UNIVALI. R. Uruguai, 458 - Centro. Itajaí, Santa Catarina, Brasil. 88302202.E-mail: bcordeiro@terra.com.br

${ }^{\mathrm{b}}$ Doutora em Saúde Pública. Professora do Departamento de Prática de Saúde Pública da Faculdade de Saúde Pública da Universidade de São Paulo - FSP/USP. Av. Dr. Arnaldo, 715. São Paulo, São Paulo, Brasil. 01246-904. E-mail: nicolina@usp.br

\section{Resumo}

Introdução. A Estratégia de Saúde da Família (ESF) foi considerada a estratégia reorganizadora da Atenção Básica do Brasil. Entretanto, muitas vezes suas ações ou são superpostas a outros programas ou caem em um vácuo, que pode perigosamente desresponsabilizar os dois programas pela execução de determinadas atividades. Objetivo. Avaliar a articulação entre o PSF e o Programa DST/AIDS no município de Itajaí/SC em um item específico: o pré-natal de gestantes HIV+, gerando uma reflexão que possa ser generalizada para outros municípios do Brasil. Metodologia. A partir da realidade vivenciada no Serviço de Atendimento Especializado (SAE) em DST/AIDS do município, fez-se pesquisa bibliográfica, utilizando textos oficiais e a literatura científica. Resultados e discussão. As gestantes HIV+ do município realizam seu pré-natal no SAE, o que interfere, por exemplo, no estabelecimento de vínculo entre a equipe e a gestante. Tal fato pode indicar a não responsabilização da Atenção Básica para com estas mulheres, existindo uma verticalização entre o Programa DST/AIDS e a Atenção Básica. Conclusão. Há necessidade de se rediscutir a horizontalidade entre os programas instituídos pelo Ministério da Saúde, com a Atenção Básica assumindo suas responsabilidades e utilizando o SAE como referência, a partir da verificação de uma gestação de alto risco, redefinindo-se que a gestante HIV+ nem sempre pode ser classificada nesta categoria. 
Palavras-chave: PSF; AIDS; Pré-natal, HIV, .Gestantes

\begin{abstract}
Introduction: Family Health Program (FHP) is considered the best strategy to reorganize the primary health care (PHC) of Brazil. However, many times its actions are superposed to other programs or fall in a vacuum. This may dangerously become irresponsibles the programs for the execution of determined activities. Objective. To evaluate the articulation between FHP and the STD/AIDS Program in the city of Itajaí / SC in a specific item: prenatal care of HIV+ pregnant women, generating a reflection that could be generalized for other cities in Brazil. Methodology. From the reality lived in a Specialized Assistance Service (SSA) in STD/AIDS of the city, it was done bibliographical researches, using official texts and the scientific literature. Results and discussion. The HIV+ pregnant women of the city achieve their prenatal in SSA, with interference in principles of FHP as, for example, the establishment of bonds between the health team and the pregnant woman. Such fact can indicate a verticality among the STD / AIDS Program and the PHC. Conclusion. It is necessary to rediscuss the horizontality among the programs offered by Ministry of Health, with the PHC assuming its responsibility and using the SSA as reference, starting from assuming what is a high risk pregnancy, being redefined that the HIV+ pregnant woman not always could be classified in this category.

Key-words: Family Health Program, AIDS, Prenatal care, HIV, Pregnant women
\end{abstract}

\title{
Introdução
}

O Programa Saúde da Família (PSF), criado em 1994, é definido como uma estratégia de reforma da assistência do Sistema Único de Saúde (SUS) desde 1997 (MS, 1997). Por causa dessa compreensão, aliada à noção de transitoriedade que permeia um programa, a superação "programa versus estratégia" se impôs, sendo a Estratégia Saúde da Família (ESF) hoje considerada a estratégia prioritária para a reorganização da atenção básica no Brasil, conforme a Portaria 648/06 (MS, 2006a). Entretanto, muitas vezes suas ações são superpostas a outros programas ou caem num vácuo que pode tirar a responsabilidade desses programas pela execução de determinadas atividades. 
No período de julho de 2006 a 2007 foi realizado um acompanhamento de todas as gestantes HIV positivas do município de Itajaí, SC (Cordeiro, 2008). Dentre outros resultados do seguimento dessas mulheres observou-se que todas procuravam o serviço especializado em DST/AIDS do município para realizarem seu pré-natal, mesmo já tendo iniciado o acompanhamento na atenção básica. Como o desenho inicial do projeto pressupunha o seguimento das mesmas dentro do PSF, o fato gerou novo problema de pesquisa.

Buscando melhor entendimento desta forma particular de uso dos serviços, este trabalho faz um exame dos preceitos gerais do PSF e do programa DST/AIDS, suas formas de articulação, bem como das principais diretrizes oficiais disponíveis para condução desse tipo de problema. Na medida do possível, os achados foram contextualizados para as condições particulares vividas por aquelas gestantes HIV positivas, ao realizarem seus exames de pré-natal no município de Itajaí, SC.

\section{Estratégia Saúde da Família (ESF) e seus Princípios - o PSF Ideal}

Segundo Baldani e col. (2005), o PSF deve ter como lógica o rompimento da organização disciplinar tradicional, fragmentada e prioritariamente voltada para a dimensão biológica do processo saúde-doença, passando a atuar em ações centradas na família, percebida a partir de seu ambiente sócio-cultural. Ainda, de acordo com Corbo e Morosini (2005), o PSF, considerando os princípios do SUS e as concepções da atenção primária à saúde, incorpora como seus também os princípios da integralidade e universalidade da assistência, eqüidade, resolutividade e humanização do atendimento e estímulo à participação comunitária.

Além destes princípios, "tomados" do SUS, outro documento vai apresentar ainda como princípios (MS, 2005):

a) Caráter substitutivo: uma vez que o PSF não propõe estruturas novas, mas o aproveitamento das estruturas já existentes que passariam a trabalhar em outra lógica, substituindo as práticas tradicionalmente focadas na doença por outras comprometidas com promoção da saúde e melhoria da qualidade de vida da população (MS, 2005; Marques; Mendes, 2002); 
b) Integralidade e Intersetorialidade: as equipes do PSF devem procurar, junto aos outros setores da sociedade, a complementaridade necessária para a promoção da saúde e prevenção das doenças, pela própria impossibilidade do setor saúde em responsabilizar-se por todos os condicionantes da saúde;

c) Territorialização: Cada equipe tem uma área de abrangência definida e população adscrita (podendo variar entre 2400 a 4500 pessoas). Seu trabalho leva em consideração as informações epidemiológicas e sociais da população para definição inclusive de micro-áreas, identificando eventuais desigualdades e oferecendo uma atenção diferenciada aos grupos e famílias mais vulneráveis;

d) Equipe Multiprofissional: A composição básica de uma equipe apresenta minimamente um médico, um enfermeiro, um ou dois auxiliares de enfermagem e de quatro a seis agentes comunitários de saúde (ACS). Continuam indefinidos o incentivo e a participação de outros profissionais no PSF, ainda que haja iniciativas isoladas em vários pontos do país da inclusão de outros profissionais;

e) Responsabilização e vínculo: As equipes assumem como sua a responsabilidade pela melhoria da qualidade de vida e saúde daquela população, a partir do oferecimento de uma atenção humanizada e da valorização da dimensão subjetiva e social nas suas práticas; e

f) Estímulo à participação da comunidade e ao controle social: Compete ao PSF ser indutor da participação da comunidade no planejamento, na gestão e avaliação da saúde local, assim como no estabelecimento de projetos conjuntos para a melhoria da qualidade de vida da população, democratizando a execução das políticas públicas, e valorizando a participação nas instâncias previstas em lei - conselhos e conferências - além de outras formas de mobilização e organização, como associações de bairros e outras (Corbo; Morosini, 2005; MS, 2006a).

Especificamente em Itajaí, e consoante ao que acontece em outros municípios brasileiros, uma das prioridades apontadas pelo Plano Municipal de Saúde 20052008 é a reorientação do modelo assistencial, através da incorporação da saúde da família como estratégia de atenção primária. Para isso, entre outras atividades propostas, está a implantação de equipe ampliada de acordo com análise de risco epidemiológico e implementação de núcleos de apoio matricial (Itajaí, 2005). 
Constam ainda do documento, a implementação dos princípios de humanização e acolhimento, a consolidação do planejamento estratégico em saúde, a definição das áreas de abrangência das Unidades de Saúde com adscrição da clientela e a redefinição dos níveis hierárquicos de complexidade na rede municipal. A humanização vai tratar do estabelecimento de vínculo entre a comunidade e a equipe do PSF, e de como apoiar a população no caso de referência a outros níveis de atenção. Trata-se do "acolhimento do outro, do respeito à alteridade expressa em um sujeito doente, com história e trajetória particulares, emergidas de um processo coletivo de vida" (Corbo; Morosini, 2005, p. 171).

\section{Desempenho da Estratégia Saúde da Família (ESF) - o PSF real}

Hoje, o modelo de atenção à saúde no país, baseado na ESF, é referência internacional, destaque e modelo para outros países. Está consolidada nos municípios brasileiros e há um aumento da satisfação dos usuários quanto ao atendimento recebido (MS, 2007a).

A análise da evolução da cobertura populacional, no período 1998-2007, demonstra o crescimento e a importância da ESF na política de Atenção Básica brasileira. Em 1998, a população coberta, que era de 6,55\%, passou para 46,5\% em julho de 2007 , sendo realizada por 27500 equipes do PSF (MS, 2007a).

Em avaliação normativa realizada no período de junho de 2001 a agosto de 2002, pelo Departamento de Atenção Básica do Ministério da Saúde, 38\% das 13501 equipes do PSF avaliadas à época contavam com menos de um ano de funcionamento e 40\% tinham entre um e dois anos (MS, 2004). Observa-se, assim, que a Estratégia ainda continua em fase de implantação, não estando totalmente consolidada.

Também o número de municípios a oferecer a Estratégia sofreu significativo aumento no período de implantação das equipes já que, em 1998, estavam instaladas em 20,4\% dos municípios brasileiros, encontrando-se hoje em 92,2\% dos municípios, chegando em vários estados, como Santa Catarina, a 100\% dos municípios. 
A adesão destes municípios representa não só a legitimação institucional da estratégia, como também a aceitação dos incentivos monetários capazes de dar sustentabilidade financeira para a Atenção Básica (UFBA, 2002; Marques; Mendes, 2002).

Em estudo que avaliou o andamento da ESF quanto a indicadores selecionados da Saúde da criança, Saúde da mulher e Controle da hipertensão arterial sistêmica, mostrou-se que, no período 1998-2004, no Brasil, os indicadores relacionados à morbi-mortalidade declinaram e os que refletem a cobertura dos serviços cresceram significativamente. A magnitude da variação mostrou-se mais intensa onde o PSF esteve mais presente, chegando-se à conclusão de que este está contribuindo de forma decisiva na redução dos diferenciais no acesso e na prestação dos serviços de saúde no Brasil (MS, 2006b).

\section{As contradições e desafios da ESF - ainda o PSF real}

A despeito de todos os inegáveis resultados positivos demonstrados pela ESF, a literatura científica vem demonstrando, como seria de se esperar para algo ainda em implantação, alguns problemas relacionados ao seu funcionamento.

Crevelim (2005), por exemplo, em pesquisa qualitativa com membros de uma equipe do PSF e conselheiros de um Conselho Local de Saúde, chega à conclusão de que os trabalhadores reconhecem seu trabalho como de equipe, mas não incluem os usuários na dinâmica do grupo de trabalho e no planejamento das ações, o que impede a construção de um projeto assistencial comum.

Já Tesser (2006a; 2006b) preocupa-se com os perigos da medicalização da sociedade e sua implicação na prática do PSF, que corre o risco de crescer sem inovar na clínica e assim aumentar o consumo abusivo e contraprodutivo dos serviços biomédicos. Por sua vez, Baldani e col. (2005) afirmam que há várias dificuldades no trabalho em equipe no PSF, até mesmo em função da formação tecnicista e "hospitalocêntrica" dos profissionais, o que gera um pequeno relacionamento interno da equipe e inexistência de responsabilidade coletiva pelos resultados do trabalho, além da desmotivação causada pela precarização do vínculo empregatício, como também observado por Corbo e Morosini (2005). 
Nesta mesma linha de pensamento, Assis e col. (2002) e Leite e Cordeiro (2007) tecem várias considerações sobre a necessidade de uma equipe multiprofissional e interdisciplinar para que a Integralidade possa ser alcançada, em decorrência das limitações técnicas e físicas da equipe atual e das múltiplas dimensões do conhecimento.

Para Silva e Trad (2005), apesar de ocorrer a partilha das decisões no trabalho em equipe, o planejamento das ações concentra-se nos profissionais de nível superior. Deste modo, alguns profissionais podem sentir-se preteridos na busca dos acordos e consensos acerca dos problemas de saúde da comunidade, gerando um descompromisso com as metas da equipe. É o mesmo pensamento de Corbo e Morosini (2005), que comentam que a hierarquização do saber-poder reproduz-se na saúde da família: médicos mandam, enfermeiros obedecem e agentes comunitários cumprem.

Também Ferraz e Aerts (2005), neste sentido, mostram que o trabalho dos Agentes Comunitários de Saúde poderia ser potencializado com poucas medidas, entre elas a capacitação e educação permanente no programa, enquanto Facchini et al. (2006) acreditam que o trabalho burocrático ocupa parte importante do tempo de trabalho das equipes, em detrimento de suas atividades fins.

Já Moura e Souza (2002) e Alves (2005) afirmam que a educação em saúde é fundamental para a concretização da integralidade. As primeiras discutem a baixa frequiência das atividades educativas desenvolvidas pelo PSF e que, quando realizadas, de maneira vertical, não permitem integração com a clientela, enquanto para a segunda autora, o modelo dialógico seria responsável pela reformulação dos discursos e das racionalidades subjacentes ao PSF, garantindo, mediante o desenvolvimento de práticas educativas no âmbito do PSF, a expressão e assimilação do princípio da integralidade pelas equipes de saúde da família. A integralidade aqui deve ser considerada de modo amplo, caracterizada pela assimilação de práticas preventivas e assistenciais pelo mesmo serviço, estreitando a relação entre os serviços básicos e os demais níveis de atenção à saúde, como também pela visão do ser humano como um todo e não como “... partes de um organismo vivo, dilacerado e objetivizado pelo olhar reducionista da biomedicina, e reconhecer nele um sujeito, um semelhante a mim mesmo" (Alves, 2005, p. 43). 
Conill (2002) também se preocupa com a Integralidade, em função do dimensionamento inadequado entre equipe e população, fazendo com que o tempo seja um impedimento para a realização do menos complexo. E, como a referência também apresenta problemas, o mais complexo torna-se igualmente difícil.

Ainda na discussão da Integralidade, Marques e Mendes (2003) alegam que o financiamento da Atenção Básica como prioridade no país pode sucatear a rede existente de média e alta complexidade. $O$ que estes autores sugerem, implicitamente, é que a escolha pelo princípio da Universalidade poderia tornar inalcançável a Integralidade.

Enquanto Viana e Dal Poz (2005) e Facchini e col. (2006) defendem que focalização e universalização não são excludentes, ou seja, que a formulação do PSF representou um esforço bem sucedido graças a uma presença maior em regiões mais pobres e com população mais vulnerável, Weber (2006) faz uma crítica contundente ao programa. O autor inicia seu raciocínio a partir da documentação oficial do PSF desde sua implantação, em 1994, até 2004, além de analisar relatórios e um projeto do Banco Mundial. Por esses documentos, e consoante à globalização e ao neoliberalismo hegemônicos na década de 90, os organismos internacionais financiariam um pacote clínico básico, destinado a melhorar a saúde das famílias mais pobres, ao mesmo tempo em que se estimularia a diversidade e a competição no setor privado para a prestação de serviços mais complexos (ou para pessoas que não necessitassem dos serviços públicos). Em outras palavras, o Banco Mundial pressupõe que "os direitos de cidadania não funcionam em países em desenvolvimento por conta da ineficiência do Estado, em contraposição à eficiência das organizações privadas" (p. 96).

Ainda segundo esse autor, o PSF é uma intervenção na saúde das populações pobres. E, quando o Estado utiliza-se de políticas públicas focadas na pobreza, desloca o direito à saúde de todos para alguns, através de uma ação compensatória para os cidadãos pobres, a focalização contrapondo-se à universalização.

Paradoxalmente, ao se fazer uma opção pelos pobres, estes são excluídos de serviços de qualidade, pela impossibilidade de comparação e baixa capacidade organizacional desta parcela da população para reivindicar seus direitos. Tal exclusão gera um círculo vicioso, que afasta aqueles socialmente mais organizados e mobilizados para 
a iniciativa privada e mantém os menos favorecidos à mercê dos serviços oferecidos cada vez com menos qualidade.

Assim, Weber (2006) utiliza a filosofia foucaultiana para colocar o Agente Comunitário de Saúde como a materialização microfísica do poder e o PSF como um dispositivo da biopolítica de governamento (sic), já que "o Estado, entre outros instrumentos de governamentalidade (sic), utiliza a Medicina Social para vigiar, controlar e normalizar a população, obtendo como efeito a dominação/captura desta" (p.80).

Por último, mas não menos importante, vale ressaltar que o PSF foi idealizado para não ser apenas mais um programa vertical do Ministério da Saúde, mas sim, como já foi dito, um instrumento de reorganização do modelo de saúde. Para isso, seria necessária sua integração com toda a estrutura que já existe na saúde e com os demais programas, o que parece não ter sido alcançado até o momento (Viana; Dal Poz, 2005).

\section{O Programa DST/AIDS}

Uma das características essenciais dos programas oficiais DST/AIDS foi a não dissociação entre as ações de previdência e assistência, o que redundou na distribuição gratuita dos anti-retrovirais (ARV). Vale frisar que esta distribuição foi feita contra recomendações e advertências do Banco Mundial, que desde o início da década de 90 financiava projetos na área de doenças sexualmente transmissíveis no Brasil (Mattos e col. 2001).

Ao longo dos anos, o Programa Nacional DST/AIDS passou a acumular sucessos, detendo a epidemia e sendo reconhecido como referência mundial a partir da $13^{\mathrm{a}}$. Conferência Internacional de AIDS, em 2000. Com o reconhecimento internacional e o apoio popular, o país passa ainda a negociar preços dos ARV baseando sua política na oferta de transferência de tecnologia, na produção local de genéricos e na possibilidade de quebra de patentes, tantas vezes ameaçada e realizada, em 2007, com o medicamento Efavirenz, em função da sustentabilidade do programa - seu maior desafio (Fonseca, 2005).

Muito do sucesso do programa está na concretização e incorporação dos princípios do SUS, já que a história do PN-DST/AIDS está baseada na integração entre 
prevenção e assistência, na universalidade de acesso, na incorporação dos direitos civis e luta contra discriminações e na incorporação da sociedade civil organizada, que refletem a evolução da sociedade brasileira frente ao desafio que a epidemia trouxe. (Galvão, 2000).

Também a história do Programa Municipal DST/AIDS de Itajaí é singular. Segundo Chiaradia (1998), em 1987, são notificados os primeiros casos no município e, em 1990, acontece a inauguração do ambulatório para o tratamento e diagnóstico das DST e AIDS.

Em 1991 é criado o Programa Municipal DST/AIDS e, no ano seguinte, o hospital local inaugura uma ala específica para o tratamento dos pacientes da síndrome, contando com 14 leitos. Em 1995 é inaugurado, graças a um convênio com o Ministério da Saúde, o Centro de Orientação e Apoio Sorológico (COAS), para diagnóstico e aconselhamento dos pacientes portadores e doentes pelo HIV. Em meados deste mesmo ano, a cidade passa a ocupar o primeiro lugar no ranking da incidência acumulada proporcional no país, com a revista VEJA trazendo uma reportagem que lhe conferia o indesejável título de "capital brasileira da AIDS". Esta reportagem causou forte impacto no município, fazendo com que este negasse o problema ao invés de enfrentá-lo (Chiaradia, 1998). Somente em 1997 a equipe do programa DST/AIDS foi reestruturada e então se iniciou o enfrentamento da situação epidemiológica do município.

Em 1998, é fundado o principal serviço de assistência aos portadores e doentes de HIV/AIDS no município, o Hospital Dia (atualmente rebatizado como CEREDI Centro de Referência em Doenças Infecciosas), com equipe multiprofissional e atendimento ambulatorial (também para DST) e serviço de atendimento domiciliar terapêutico.

Hoje o município tem ainda um CTA (Centro de Testagem e Aconselhamento), que sucedeu o COAS; laboratório de análises clínicas que realiza contagem de linfócitos CD4 e carga viral; Programa de Redução de Danos e o Programa Bem-me-quer, para trabalhar a prevenção com profissionais do sexo no município. Toda essa estrutura, conquistada no decorrer desses anos, garantiu um padrão de qualidade que faz, 
inclusive, com que pessoas de outras cidades (e até de outros estados) realizem seu tratamento em Itajaí.

\section{Recomendações e diretrizes na atenção básica a gestantes soropositivas}

Muito embora os programas disponham de estudos e análises dos seus problemas e de suas formas de desempenho, as formas de atendimento da população em muito dependem da interpretação das recomendações do Ministério da saúde, das diretrizes oficiais relativas à Atenção Básica e ao Programa Municipal de DST/AIDS, além de razões pessoais das pacientes, que convém serem examinadas.

As recomendações do Ministério da Saúde permitem diferentes interpretações sobre o assunto. Assim, há textos que recomendam que o acompanhamento de gestantes soropositivas para o vírus HIV deve ser feito por serviços especializados, por exemplo:

“(...) evidente que o manejo das gestantes portadoras do HIV ...exige... referência constituída por equipe multidisciplinar. Assim, faz-se necessário que as Unidades Básicas de Saúde (UBS) tenham estabelecidas as referências: os SAE (Serviços de Assistência Especializados para portadoras do HIV)... para o encaminhamento dos casos" (MS 2006c, p. 101).

"Ao ser feito o diagnóstico de infecção pelo HIV durante a gestação, a paciente, preferencialmente, deverá ser encaminhada para o Serviço de Assistência Especializado (SAE) que fará o seu acompanhamento clínico (...) $O$ acompanhamento pré-natal também deverá ser feito em serviço de referência durante toda a gestação (...)" (MS, 2007b, p. 5).

Entretanto, outros documentos recomendam o encaminhamento aos serviços especializados apenas em casos excepcionais:

"Unidades Básicas de Saúde (UBS)... podem monitorar a gestante até que seja necessário iniciar a TARV (Terapia anti retroviral). É importante manter o acompanhamento conjunto entre UBS e a Unidade de Referência para apoio social, acesso a insumos de prevenção, melhora de adesão, reconhecimento precoce de eventos adversos à TARV, acesso aos anti-retrovirais facilitado $e$ 
acompanhamento clínico-obstétrico, formando uma rede integral de atenção à saúde" (grifo original do texto) (MS 2006d, p. 44).

“(...) entre as situações em que deve ser considerado o encaminhamento ao pré-natal de alto risco ou avaliação com especialista estão: ...portadoras de doenças infecciosas (hepatites, toxoplasmose, infeç̧ão pelo HIV, sífilis e outras DST); (...) Identificando-se um ou mais desses fatores, a gestante deverá ser tratada na UBS, conforme orientam os protocolos de Ministério da Saúde. Os casos não previstos para tratamento na UBS deverão ser encaminhados para a atenção especializada que, após avaliação, deverá devolver a gestante para a atenção básica com as recomendações para o seguimento da gravidez ou deverá manter o acompanhamento pré-natal nos serviços de referência para gestação de alto risco. Nesse caso, a equipe da atenção básica deverá manter o acompanhamento da gestante, observando a realização das orientações prescritas pelo serviço de referência (MS 2006e, p. 22-24).

Diante do exposto, surgem dúvidas sobre qual orientação seguir: Quando a paciente é referenciada para o SAE, isso significa que ali ela terá consultas com um infectologista ou deve fazer seu pré-natal? As UBS devem continuar o acompanhamento da gestante ou não? Quando o serviço especializado não estiver acessível ou for de difícil acesso, como devem agir as UBS? A gestação HIV positiva é considerada de alto risco? Por quê? Seria esta uma forma de discriminação contra estas gestantes ou trata-se apenas de garantir a elas um melhor cuidado?

A interpretação dos diferentes documentos ministeriais também pode explicar o fato da Atenção Básica, no Município de Itajaí, dificilmente realizar o exame pré-natal daquelas gestantes. É possível que se compreenda que todo o pré-natal seja feito pelo serviço de referência. Também é possível que devido ao excesso de atendimentos nas Unidades Básicas e também ao número de famílias cada vez maior ao preconizado pelo Ministério da Saúde para o PSF, os profisssionais que são responsáveis pelo pré-natal prefiram encaminhá-las a outro serviço, com uma conseqüente diminuição na sobrecarga de tarefas. Também se pode supor que, por parte dos profissionais da Atenção Básica, persista preconceito em relação à AIDS 
ou exista desconhecimento quanto aos cuidados gerais, incluindo a terapêutica, destas gestantes.

Com relação às razões do Programa Municipal DST/AIDS preferir fazer ele próprio o pré-natal destas gestantes é possível supor que esta seja a sua interpretação dos documentos ministeriais, que estipulam ser aquela uma das suas funções. Segundo, porque é sua a responsabilidade pela notificação dos casos de transmissão vertical do HIV, e esta vigilância torna-se mais fácil quando o serviço é oferecido por seus funcionários, mais experientes e comprometidos com as metas de redução de casos.

Quanto às razões pessoais das gestantes para realizar o pré-natal em serviço especializado, sabe-se que em Itajaí o serviço especializado possui reconhecida qualidade e é exclusivo, enquanto que nas Unidades Básicas há constantes filas. $\mathrm{O}$ deslocamento até o CEREDI - Centro de Referência em Doenças Infecciosas, denominação para o SAE local - é necessário, seja para consultas com os infectologistas seja para busca dos medicamentos, fazendo com que seja natural a ida a esse serviço. Algumas destas mulheres, que faziam o pré-natal na Atenção Básica, começaram a realizá-lo também no CEREDI. Mas a oferta de um duplo serviço, além de não ser racional e custo-efetiva, tomava tempo em demasia e em pouco tempo a gestante escolhia um dos serviços, com clara opção pelo pré-natal oferecido pelo CEREDI.

A questão do sigilo também é importante e contraditória. Algumas gestantes podem ter preferido fazer seu pré-natal no CEREDI por estarem afastadas da UBS e das equipes do PSF, temendo que sua condição de soropositivas pudesse ser revelada a outras pessoas de sua comunidade. Outras prefeririam fazer o pré-natal em outro local que não o CEREDI, pois como este local é reconhecido pela população local como específico para pacientes com AIDS, o simples fato de entrarem em suas dependências poderia denunciar sua condição de portadoras do vírus.

\section{Integração entre o PSF e o Programa DST/AIDS}

Machado (2006) aponta que o Ministério da Saúde, ao implementar sua agenda de políticas de saúde entre os anos de 1990 a 2002, priorizou três políticas ao longo de várias gestões: a descentralização, o Programa de Saúde da Família e a política de 
combate à AIDS. Os principais motivos para a entrada e continuidade dessas políticas foram "a confluência de diferentes agendas reformistas, a constituição de uma base social de apoio, a formação de grupos técnicos sólidos no Ministério da Saúde e o caráter atrativo como marca de governo ou de gestão ministerial” (p. 45).

Ainda segundo Machado (2006), a característica marcante destas três políticas, mas em especial do PSF e do combate à AIDS, foi a forte indução federal, sem que houvesse articulação entre si e com outras políticas públicas na esfera econômica e social. Isto criou políticas prioritárias isoladas, que podem, em uma conjuntura desfavorável, ser descontinuadas e impedirem a construção de um projeto nacional abrangente e sólido para a saúde.

Talvez o fato do PSF e do Programa Nacional DST/AIDS terem sido considerados prioridades tenha feito com que sofressem menos a escassez de recursos, característica dos anos 90. O primeiro por ser estratégico inclusive para a descentralização, que em última análise praticamente se tornou sinônimo de municipalização da saúde. O segundo, em função dos convênios com o Banco Mundial, os quais sempre lhe garantiram os recursos necessários para sua estratégia.

De qualquer modo, parece claro que os dois programas têm dificuldades para se relacionar (entre si ou com outros programas). Neste sentido, Viana e Dal Poz (2005, p. 257) ao analisarem os modelos de implantação do PSF em algumas cidades do nordeste, sudeste e sul do Brasil, concluem que o "programa não possui um bom grau de integração com os demais programas operados pelas secretarias municipais de saúde e com as unidades de saúde".

Exemplificando, ao se falar em pré-natal, enquanto Moura e col. (2003) e Ribeiro e col. (2004) comentam que ainda há várias falhas que comprometem sua realização (apesar de que, comparativamente, ele é mais bem executado no PSF que na forma tradicional), Souza Jr e col. (2004) apontam que deveriam ser estabelecidas estratégias conjuntas do PN-DST/AIDS com os programas de saúde da mulher e o PSF, em busca da melhoria de cobertura, acesso e qualidade do pré-natal.

Arilha (2002), entretanto, afirma que desde 1996 já se percebia a necessidade de trabalho conjunto entre as duas áreas que, efetivamente, iniciou-se com a produção de alguns textos neste sentido (MS, 1998a; MS, 1998b; MS, 2003; MS, 2006c, MS, 
2007c). Do último documento, pode-se dizer que é extremamente oportuno, já que ao apontar metas e responsabilidades específicas por cada nível de governo, conduz para um cenário que ultrapasse a simples retórica.

Por outro lado, se houve a produção de textos e intenção de aproximação entre as duas áreas, parece não ter havido uma política consistente de integração, conforme a literatura registra até o momento, Exemplificando, Bravo e col. (2006) e Camargo Júnior (2003) criticam os Programas DST/AIDS por agirem de forma verticalizada e desarticulada, tanto em relação ao PSF quanto com outros programas estratégicos para a questão da AIDS, como o Programa de Saúde da Mulher e o Programa de Tuberculose.

Se a necessidade de descentralizar decisões para as Unidades Básicas é cada vez mais urgente, deve-se questionar até que ponto estas Unidades estão preparadas para atividades como a educação em saúde, triagem para o HIV e aconselhamento, por exemplo. Há dúvidas se as atividades que hoje são desenvolvidas em serviços especializados poderiam ser realizadas em Unidades Básicas, ou pelas equipes do PSF - o que pressupõe deixar de trabalhar casos individuais para trabalhar dentro de uma comunidade. Ou, ainda, se as Unidades Básicas estão preparadas para lidar com os pacientes HIV positivos sem preconceitos e estigmas, como os serviços especializados estão atuando após anos convivendo com essa realidade. Deve ser também sopesado se o aumento de cobertura não trará a perda da qualidade, conseguida em anos de trabalho árduo ou se o aumento do acesso (universalidade) implica necessariamente em uma diminuição da integralidade.

Se estes questionamentos dizem respeito à Atenção Básica, deve-se entender que ela funciona quando tem o suporte do serviço especializado (Silva, 2007). E, em municípios de pequeno e médio porte, que representam a grande maioria no Brasil, há sérias dificuldades com a atenção especializada, internações, exames diagnósticos e referência/contra-referência, começando pela falta de profissionais. Considerando esta realidade, não seria lógica a criação sem critérios de novos serviços. O enfrentamento da epidemia passa por um pacto entre os municípios de cada região, com a consolidação e ampliação dos bons serviços e abertura apenas daqueles que se fizerem estritamente necessários. 
Criteriosamente, de acordo com os questionamentos levantados, um estudo no Rio de Janeiro com coordenadores de Programas de AIDS e Secretarias Municipais, Estadual e Ministério da Saúde revelou que estes atores reconhecem a grande dificuldade de interface dos Programas DST/AIDS com outras áreas, em decorrência de diferenças técnicas e políticas. Mesmo entre os programas de AIDS das três esferas de gestão há tensões, apesar de que, nesse caso, não parecem interferir de forma relevante no relacionamento entre os gestores (Ferla e col., 2006).

Se há problemas na gestão dos programas, isto está refletido também na ponta dos serviços. Feliciano e Kovacs (2002) alertam para a vulnerabilidade institucional das ações de controle da transmissão vertical da AIDS tanto em UBS com modelo assistencial tradicional, ou seja, baseado na demanda espontânea, quanto naquelas em que é oferecido o PSF. Para estas autoras, intervenções isoladas são insuficientes para produzir modificações importantes na saúde dos grupos populacionais, devendo ser construída uma abordagem a partir da noção de vulnerabilidade para fortalecer o "processo de trabalho fundado na complexa integração de ações individuais e coletivas, curativas e preventivas, articulados em um sistema de cuidados em níveis progressivos de atuação" (p. 164).

É a mesma linha de raciocínio de Araújo e col. (2006), que comentam que, além da capacitação sobre temas específicos, falta conhecimento aos profissionais que atuam no PSF das peculiaridades relacionadas ao HIV/AIDS. Para Silva e col. (2005), este desconhecimento é mútuo: tanto os profissionais do PSF desconhecem as formas de acesso e rotina dos serviços especializados em DST/AIDS quanto os profissionais destes serviços desconhecem a rotina e a dinâmica de atendimento em HIV/AIDS do PSF. Segundo estes autores, uma sugestão de superação desse impasse na procura da integração dos programas passa por um processo de referência e contra-referência, articulado nos distintos níveis de complexidade do SUS, com fluxos e percursos definidos, ordenados e compatíveis com a demanda.

\section{A título de conclusão}

Pelo exposto, as políticas públicas em relação à AIDS deveriam ser repensadas. Considerando que a síndrome vem se interiorizando no país, e que a descentralização 
é um dos princípios do SUS (e uma das prioridades do Ministério, como observado anteriormente), o PN-DST/AIDS, como mentor da estratégia de combate à doença, precisa refletir sobre suas limitações e as possibilidades da Atenção Básica de atuar de forma articulada.

Voltando às gestantes atendidas em Itajaí e, por consequiência, aos Programas Saúde da Família e DST/AIDS no município, observa-se que há um grande distanciamento entre a prática e as proposições oficiais.

O Programa DST/AIDS, por exemplo, sofre por sua auto-suficiência. Ao assumir o pré-natal das gestantes HIV positivas, aceita implicitamente a discriminação que estas mulheres sofrem da Atenção Básica. Mais, como interfere em uma área para a qual não está preparado, solicita a ajuda do PSF para resgatar pacientes faltosas e "devolver" aquelas que não aderiram ao serviço. Desse modo, pode-se dizer que trabalha com as "boas" gestantes, ficando as "más" para a Atenção Básica.

Como resultado prático dos conflitos da legislação, articulação e gestão dos programas surgem problemas que se refletem na prestação dos serviços e no não cumprimento dos princípios estabelecidos. Assim, foi possível concluir que: a) o caráter substitutivo não estava sendo observado, pois, certamente, não se referia à substituição do pré-natal realizado pela Atenção Básica pelo do Serviço de referência; b) integralidade e intersetorialidade não estavam sendo respeitadas porque não se pode falar em cuidados integrais quando se troca a Atenção Básica pela especializada, onde a pessoa novamente volta a ser "compartimentalizada"; c) não existe territorialização se as gestantes são encaminhadas a serviço especializado, independente da área em que moram; d) não se observou responsabilização e vínculo do PSF com as gestantes já que, uma vez que estas abandonam o pré-natal na Unidade Básica de Saúde (UBS), a Atenção Básica se isenta da responsabilidade de seu pré-natal; e) não se verificou estímulo à participação da comunidade no caso estudado.

O não cumprimento desses princípios, com um grupo específico de usuários, coloca em questão a própria ESF, uma vez que não há como se abrir mão de princípios em determinado momento para retomá-los mais tarde. 
Conclui-se, então, que a maioria dos problemas observados no caso de Itajaí ocorre em função da verticalização dos programas, devendo-se pensar em como torná-los horizontais. Para melhoria dos serviços e real aplicação de princípios tão caros ao sistema de saúde, sugere-se que Atenção Básica deveria fazer o pré-natal de todas as gestantes, deixando o seguimento em serviço especializado apenas para aquelas consideradas de alto risco ou que a responsabilidade do pré-natal seja apenas das UBS deixando para os SAE apenas acompanhamentos periódicos. Com este objetivo, todos os profissionais envolvidos com o pré-natal deveriam ser capacitados continuadamente para entender as peculiaridades envolvidas com o HIV/AIDS. Também é fundamental que os pacientes passem a ser considerados em toda sua plenitude dentro de um contexto sócio cultural. Se uma gravidez já traz consigo inquietações e ansiedades, estas angústias podem estar exponencialmente presentes, em particular, nas gestantes HIV positivas.

\section{Referências Bibliográficas}

1. ALVES, V.S. Um modelo de educação em saúde para o Programa Saúde da Família: pela integralidade da atenção e reorientação do modelo assistencial. Interface - Comunic, Saúde, Educ. 2005; 9(16):39-52.

2. ARAÚJO, M.A.L.; VIEIRA, N.F.C.; BUCHER, J.S.N. Aconselhamento pré e pós-teste anti-HIV como estratégia da melhoria da cobertura de testagem em gestantes e prevenção da transmissão vertical do HIV. Boletim epidemiológico AIDS/DST 2006; Ano III (1):16-22.

3. ARILHA, M. Políticas públicas de saúde, mulheres e DSTs/AIDS: reajustando o olhar. Coleção ABIA - Saúde Sexual e Reprodutiva, no. 4. Rio de Janeiro; 2002.

4. ASSIS, A.M.O.; SANTOS, S.M.C.; FREITAS, M.C.S.; SANTOS, J.M.; SILVA, M.C.M. O Programa Saúde da Família: contribuições para uma reflexão sobre a inserção do nutricionista na equipe multidisciplinar. Rev. Nutr. 2002; 15(3): 255266.

5. BALDANI, M.H; FADEL, C.B.; POSSAMAI, T.; QUEIROZ, M.G.S. A inclusão da odontologia no Programa Saúde da Família no Estado do Paraná, Brasil. Cad. Saúde Pública 2005; 21(4):1026-1035. 
6. BRAVO, M.I.; ROCHA, F., MAKSUD, I.; KAMEL, L. Políticas públicas de DST/AIDS e controle social no estado do Rio de Janeiro. Coleção ABIA políticas públicas e AIDS, no. 5. Rio de Janeiro; 2006.

7. CAMARGO JÚNIOR, K.R. Prevenções de HIV/AIDS: desafios múltiplos. Divulgação em Saúde para Debate 2003; 27:70-80.

8. CHIARADIA, C.F. Uma história social da AIDS: estudo de caso sobre a incidência da AIDS em Itajaí/SC. Florianópolis, 1998. Dissertação (Mestrado em Educação) - Centro de Ciências da Educação, Universidade Federal de Santa Catarina, 1998.

9. CONILL, E.M. Políticas de atenção primária e reformas sanitárias: discutindo a avaliação a partir da análise do Projeto Saúde da Família em Florianópolis, Santa Catarina, Brasil, 1994-2000. Cad. Saúde Pública 2002; 18(Suplemento):191-202.

10. CORBO, A.A.; MOROSINI, M.V.G.C. Saúde da Família: História Recente da Reorganização da Atenção à Saúde. In: ESCOLA POLITÉCNICA DE SAÚDE JOAQUIM VENÂNCIO (Org.). Textos de apoio em políticas de saúde. Rio de Janeiro: Editora Fiocruz; 2005. p. 157-182.

11. CORDEIRO, B.C. A Atenção Farmacêutica na melhoria do atendimento às gestantes soropositivas no município de Itajaí. São Paulo, 2008. Tese (Doutorado em Saúde Pública) - Faculdade de Saúde Pública, Universidade de São Paulo, 2008.

12. CREVELIM, M.A. Participação da comunidade na equipe de saúde da família: é possível estabelecer um projeto comum entre trabalhadores e usuários? Ciência \& Saúde Coletiva 2005; 10(2): 323-331.

13. FACCHINI, L.A.; PICCINI, R.X.; TOMASI, E.; THUMÉ, E.; SILVEIRA, D.S.; SIQUEIRA, F.V.; et al. Desempenho do PSF no Sul e no Nordeste do Brasil: avaliação institucional e epidemiológica da Atenção Básica à Saúde. Ciência \& Saúde Coletiva 2006; 11(3): 669-681.

14. FELICIANO, K.V.O.; KOVACS, M.H. Vulnerabilidade programática na prevenção da transmissão materno-fetal da AIDS. Rev. bras. saúde matern. infant. 2002; 2(2):157-165.

15. FERLA, A.A.; POSSA, L.B.; LEAL, M.B.; VALÉRIO, A.G.; CLAUSS, S.M. Descentralização e políticas públicas para DST/AIDS: Estudo do sistema de 
saúde no Estado do Rio de Janeiro. Coleção ABIA - políticas públicas e AIDS, no. 7. Rio de Janeiro; 2006.

16. FERRAZ, L.; AERTS, D.R.G.C. O cotidiano de trabalho do agente comunitário de saúde no PSF em Porto Alegre. Ciência \& Saúde Coletiva 2005; 10(2): 347355.

17. FONSECA, A.F. Políticas de HIV/AIDS no Sistema Único de Saúde: uma busca pela integralidade da atenção. In: ESCOLA POLITÉCNICA DE SAÚDE JOAQUIM VENÂNCIO (Org.). Textos de apoio em políticas de saúde. Rio de Janeiro: Editora Fiocruz; 2005. p. 183-205.

18. GALVÃO, J. AIDS no Brasil - a agenda de construção de uma epidemia. Rio de Janeiro: ABIA, São Paulo: 34; 2000.

19. ITAJAÍ. Plano Municipal de Saúde 2005-2008. Secretaria Municipal de Saúde; 2005.

20. LEITE, S.N.; CORDEIRO, B.C. Promoção do Uso Racional de Medicamentos: a Interdisciplinaridade Necessária. In: SAUPE, R.; WENDHAUSEN, A.L.P. (Org.). Interdisciplinaridade e Saúde. Itajaí: UNIVALI; 2007. p. 157-172.

21. MACHADO, C.V. Prioridades de saúde no Brasil nos anos 1990: três políticas, muitas lições. Rev Panam Salud Publica 2006; 20(1): 44-49.

22. MARQUES, R.M.; MENDES, A. A política de incentivos do Ministério da Saúde para a atenção básica: uma ameaça à autonomia dos gestores municipais e ao princípio da integralidade? Cad. Saúde Pública 2002; 18(Suplemento): 163171.

23. MARQUES, R.M.; MENDES, A. Atenção Básica e Programa de Saúde da Família (PSF): novos rumos para a política de saúde e seu financiamento? Ciência \& Saúde Coletiva 2003; 8(2): 403-415.

24. MATTOS, R.A.; TERTO JÚNIOR, V.; PARKER, R. As estratégias do Banco Mundial e a resposta à AIDS no Brasil. Coleção ABIA - políticas públicas e AIDS, no. 1. Rio de Janeiro; 2001.

25. MINISTÉRIO DA SAÚDE (MS). ABC do SUS: Doutrinas e princípios. Brasília: Secretaria Nacional de Assistência à Saúde; 1990. Disponível em: http://www.ccs.ufsc.br/geosc/babcsus.pdf Acesso em 15/08/2006 
26. MINISTÉRIO DA SAÚDE (MS). Saúde da Família: uma estratégia de organização dos serviços de saúde. Brasília: Secretaria de Assistência à Saúde; 1997.

27. MINISTÉRIO DA SAÚDE (MS). Aprendendo sobre AIDS e DST. Brasília: Coordenação Nacional DST/AIDS; 1998a.

28. MINISTÉRIO DA SAÚDE (MS). Prevenção e Controle das DST/AIDS na Comunidade. Brasília: Coordenação Nacional DST/AIDS; 1998b.

29. MINISTÉRIO DA SAÚDE (MS). Aconselhamento em DST/HIV/AIDS para a Atenção Básica. Brasília: Coordenação Nacional DST/AIDS; 2003.

30. MINISTÉRIO DA SAÚDE (MS). Avaliação Normativa do Programa Saúde da Família no Brasil - Monitoramento da Implantação e Funcionamento das Equipes de Saúde da Família - 2001/2002. Brasília: SAS/DAB; 2004.

31. MINISTÉRIO DA SAÚDE (MS). Avaliação para Melhoria da Qualidade da Estratégia Saúde da Família. Brasília: SAS/DAB; 2005. Disponível em: http://dtr2004.saude.gov.br/dab/caadab/documentos/doc tec amq_portugues.pdf Acesso em 26/08/2007

32. MINISTÉRIO DA SAÚdE (MS). Portaria No. 648, de 28 de março de 2006 (a). Aprova a Política Nacional de Atenção Básica, estabelecendo a revisão de diretrizes e normas para a organização da Atenção Básica para o Programa Saúde da Família (PSF) e o Programa Agentes Comunitários de Saúde (PACS). Disponível em: http://dtr2001.saude.gov.br/sas/PORTARIAS/Port2006/GM/GM648.htm Acesso em 15/08/2007

33. MINISTÉRIO DA SAÚDE (MS). Saúde da Família no Brasil: uma análise de indicadores selecionados: 1998-2004. Brasília: SAS/DAB; 2006b. Disponível em: http://dtr2004.saude.gov.br/dab/caadab/documentos/saude_familia_brasil.pdf Acesso em 20/07/2007

34. MINISTÉRIO DA SAÚDE (MS). Cadernos de atenção básica - HIV/AIDS, hepatites e outras DST. Brasília: SAS/DAB; $2006 \mathrm{c}$.

35. MINISTÉRIO DA SAÚDE (MS). Protocolo para a prevenção de transmissão vertical de HIV e sifilis. Brasília: SVS/Programa Nacional de DST e AIDS; 2006d. 
36. MINISTÉRIO DA SAÚDE (MS). Pré-natal e Puerpério: atenção qualificada e humanizada - manual técnico. Brasília: SAS/Departamento de Ações Programáticas Estratégicas; 2006e.

37. MINISTÉRIO DA SAÚDE (MS). Atenção Básica e a Saúde da Família. 2007a. Página disponível em: http://dtr2004.saude.gov.br/dab/abnumeros.php\#numeros Acesso em 15/07/2007

38. MINISTÉRIO DA SAÚDE (MS). Recomendações para a Profilaxia da Transmissão Vertical do HIV e Terapia Anti-Retroviral em Gestantes. Brasília: SVS/Programa Nacional de DST e AIDS; $2007 \mathrm{~b}$.

39. MINISTÉRIO DA SAÚDE (MS). Plano Operacional-Redução da Transmissão Vertical do HIV e da Sifilis. Disponível em: http://www.aids.gov.br Acesso em $12 / 10 / 2007$

40. MOURA, E.R.F.; SOUZA, R.A. Educação em saúde reprodutiva: proposta ou realidade do Programa Saúde da Família? Cad. Saúde Pública 2002; 18(6): 1809 1811.

41. MOURA, E.R.F.; HOLANDA, J.R.F.; RODRIGUES, M.S.P. Avaliação da assistência pré-natal oferecida em uma microrregião de saúde do Ceará, Brasil. Cad. Saúde Pública 2003; 19(6): 1791-1799.

42. RIBEIRO, J.M.; COSTA, N.R.; PINTO, L.F.S.; SILVA, P.L.B. Atenção ao prénatal na percepção das usuárias do Sistema Único de Saúde: um estudo comparativo. Cad. Saúde Pública 2004; 20(2): 534-545.

43. SILVA, C.G.S. Serviço de Assistência Especializada (SAE): Uma Experiência Profissional. Psicologia Ciência e profissão 2007; 27(1): 156-163.

44. SILVA, I.Z.Q.J.; TRAD, L.A.B. O trabalho em equipe no PSF: investigando a articulação técnica e a interação entre os profissionais. Interface - Comunic, Saúde, Educ. 2005; 9(16): 25-38.

45. SILVA, L.M.S.; GUIMARÃES, T.A.; PEREIRA, M.L.D.; MIRANDA, K.C.L.; OLIVEIRA, E.N. Integralidade em saúde: avaliando a articulação e a coresponsabilidade entre o Programa Saúde da Família e um serviço de referência em HIV/AIDS. Epidemiologia e Serviços de Saúde 2005; 14(2): 97-104.

46. SOUZA JÚNIOR, P.R.B.; SZWARCWALD, C.L.; BARBOSA, J.R.A.; CARVALHO, M.F.; CASTILHO, E.A. Infecção pelo HIV durante a gestação: 
Estudo-Sentinela Parturiente, Brasil, 2002. Rev Saúde Pública 2004; 38(6): 764772.

47. TEIXEIRA, P.R. Acesso universal a medicamentos para AIDS: a experiência do Brasil. Divulgação em Saúde para Debate 2003; 27: 50-57.

48. TESSER, C.D. Medicalização social (I): o excessivo sucesso do epistemicídio moderno na saúde. Interface - Comunic, Saúde, Educ. 2006a; 9(18): 64-76.

49. TESSER, C.D. Medicalização social (II): limites biomédicos e propostas para a clínica na atenção básica. Interface - Comunic, Saúde, Educ. 2006b; 10(20): 34762.

50. UNIVERSIDADE FEDERAL DA BAHIA (UFBA). O Programa de Saúde da Família: evolução de sua implantação no Brasil. Salvador: ISC; 2002.

51. VIANA, A.L.A.; DAL POZ, M.R. A Reforma do Sistema de Saúde no Brasil. PHYSIS: Rev. Saúde Coletiva 2005; 15(Suplemento):225-264.

52. WEBER, C.A.T. Programa de Saúde da Família: educação e controle da população. Porto Alegre: AGE; 2006. 


\section{CONCLUSÃO}

Este trabalho procurou averiguar as melhorias que a atenção farmacêutica poderia trazer para um grupo constituído por gestantes soropositivas de um Serviço de Atendimento Especializado em DST/AIDS em Itajaí, Santa Catarina. Os resultados encontrados possibilitam as seguintes conclusões:

A caracterização da amostra demonstrou que a faixa etária predominante foi a compreendida entre 20 a 34 anos, com média de idade 27,1 anos (IC $95-24,9-29,3) ; 62,5 \%$ das gestantes possuíam escolaridade menor que 8 anos e $81,2 \%$ eram da raça branca;

As características do pré-natal, entre elas o número total de consultas (71,9 \% tiveram 7 ou mais consultas), da utilização dos ARV (apenas 5 gestantes começaram a profilaxia após a $28^{\mathrm{a}}$. semana e uma recusou-se a utilizar os ARV), do parto (não há registros da não utilização de ARV durante o parto ou de que o início da profilaxia na criança não tenha ocorrido nas primeiras 24 horas) e do nascimento (peso médio das crianças ao nascer foi de 2915,7 (IC 95\% - 2740,29 - 3091,05) demonstram que, apesar da existência de falhas, o serviço oferece qualidade dentro dos padrões do Ministério da Saúde;

O seguimento farmacoterapêutico foi aplicado a 32 gestantes, utilizando o Método Dáder, e encontrou interações medicamentosas e com alimentos, além do relato de 40 eventos adversos observados em paralelo ao uso dos ARV;

O Método Dáder foi eficaz em resolver problemas manifestados ou não quanto à necessidade, efetividade e segurança já que foram detectados 38 PRM, dos quais 25 foram resolvidos (destes, 24 após uma proposta de intervenção sugerindo o modo de resolução do PRM);

A adesão mensurada em um primeiro momento (baseline) foi de $40,6 \%$ para o SMAQ qualitativo e $59,4 \%$ para o SMAQ quantitativo. Este mesmo 
instrumento, utilizado após um período em que as gestantes foram seguidas pelo Método Dáder, demonstrou melhora na adesão das gestantes que passou para $75 \%$ (qualitativo) e $87,5 \%$ (quantitativo), o que foi estatisticamente significante considerando $\mathrm{p}=0.05$ para o SMAQ qualitativo;

A relação existente entre o Programa DST/AIDS e o Programa de Saúde da Família no município é vertical, ocasionando a realização do pré-natal no serviço especializado e desvinculando as gestantes das Unidades Básicas perto de suas residências, o que se opõe aos princípios que nortearam a criação do PSF e o redefiniram como a estratégia principal da Atenção Básica;

Em suma, a Atenção Farmacêutica e, em especial, o seguimento farmacoterapêutico demonstrou ser uma ferramenta poderosa a ser utilizado por um farmacêutico na melhoria do atendimento às gestantes soropositivas, desde que integrado em uma estratégia que envolva o atendimento multidisciplinar e vise a atenção integral daquelas pacientes. 


\section{REFERÊNCIAS BIBLIOGRÁFICAS}

1. ALMEIDA ES, CHIORO A, ZIONI F. Políticas Públicas e Organização do Sistema de Saúde: Antecedentes, Reforma Sanitária e o SUS. In: WESTPHAL MF, ALMEIDA ES (org). Gestão de Serviços de Saúde. São Paulo: EDUSP; 2001. p. 13-50.

2. AMARILES MUÑOZ P, GIRALDO ALZATE NA, HENAO ORTEGA ES. Guía de actuación farmacéutica en pacientes con VIH/SIDA. Medellín: Humax Pharmaceutical; 2006. Disponible en: http://www.ugr.es/ cts131/esp/guias/GUIAS.HTM

3. ANDRADE A. Terapia Anti-retroviral: Farmacologia e Interações Medicamentosas. IV Brazil Johns Hopkins University Conference on HIV/AIDS; 2000. Available from: http://www.hopkins-aids.edu/brazil

4. ANGELL M. A verdade sobre os laboratórios farmacêuticos. Rio de Janeiro: Record; 2007.

5. BANGSBERG DR, PERRY S, CHARLEBOIS ED, CLARK RA, ROBERTSON M, ZOLOPA AR et al. Non-adherence to highly active antiretroviral therapy predicts progressions to AIDS. AIDS 2001; 15(9): 1181-1183.

6. BANGSBERG DR, MOSS AR, DEEKS SG. Paradoxes of adherence and drug resistance to HIV antiretroviral therapy. J. Antimicrob. Chemoter. 2004; 53(5): 696-699.

7. BARROS JAC. Políticas Farmacêuticas: a serviço dos interesses da saúde? Brasília: UNESCO; 2004. 
8. BARTLETT JG, GALLANT JE. Medical Management of HIV Infection. Baltimore: Johns Hopkins University; 2003.

9. BÉRAUD C. Petite Encyclopédie critique du médicament. Paris: Les Éditions de l'Atelier/Les Éditions Ouvrières; 2002.

10. BRAND FN, SMITH RT, BRAND PA. Effect of economic barriers to medical care on patient's noncompliance. Public Health Reports 1977; 92:72-78.

11. BRASIL. Constituição da República Federativa do Brasil. Brasília: Gráfica do Senado; 1988.

12. BRASIL. Lei Orgânica da Saúde - número 8080, de 19 set. 1990. Diário Oficial da União, n. 182, pp. 18055-18059.

13. BRASIL. Lei 3913/96, de 13 de novembro de 1996. Dispõe sobre a distribuição gratuita de medicamentos aos portadores do HIV e doentes de AIDS. LEX, São Paulo, v.60, p.2605.

14. BRASIL. Relatório da CPI-Medicamentos. Brasília: Senado Federal; 2000.

15. BRASIL. Conselho Nacional de Saúde. Resolução 338. Política Nacional de Assistência Farmacêutica. Diário Oficial da República Federativa do Brasil. Brasília, 20 de maio de 2004.

16. BRITO AM, SOUZA JL, LUNA CF, DOURADO I. Tendência da transmissão vertical de AIDS após terapia anti-retroviral no Brasil. Rev. Saúde Pública 2006; 40(Supl): 18-22. 
17. BUSS PM. Uma Introdução ao Conceito de Promoção da Saúde. In: CZERESNIA D \& FREITAS CM (orgs). Promoção da Saúde: Conceitos, Reflexões, Tendências. Rio de Janeiro: FIOCRUZ; 2003. pp. 15-38

18. CASTRO MS. Atenção Farmacêutica: efetividade do seguimento farmacoterapêutico de pacientes hipertensos não controlados. Porto Alegre; 2004. [tese de doutorado - Faculdade de Medicina da UFRGS].

19. CIPOLLE RJ, STRAND LM, MORLEY PC. Pharmaceutical Care Practice. New York: McGraw-Hill; 1998.

20. CONTANDRIOPOULOS AP, CHAMPAGNE F, DENIS JL, PINEAULT R. A avaliação na área da saúde: conceitos e métodos. In: HARTZ ZMA. Avaliação em Saúde: dos modelos conceituais à prática na análise da implantação de programas. Rio de Janeiro: FIOCRUZ; 1997. p. 29-47.

21. CORBO AA, MOROSINI MVGC. Saúde da Família: História recente da reorganização da atenção à saúde. In: ESCOLA POLITÉCNICA DE SAÚDE JOAQUim VEnÂNCIO (org). Textos de Apoio em Políticas de Saúde. Rio de Janeiro: FIOCRUZ; 2005. p.157-181.

22. CORDEIRO BC. Custos diretos envolvidos na terapia anti-retroviral no município de Itajaí (SC), no período 1996-1998. São Paulo; 2001. [dissertação de mestrado - Faculdade de Saúde Pública da USP].

23. CORDEIRO BC, REYNAUD F. Atenção Farmacêutica: Evolução ou Revolução? In: CORDEIRO BC \& LEITE SN (orgs). O Farmacêutico na Atenção à Saúde. Itajaí: UNIVALI; 2005.

24. COOVADIA H. Antiretroviral Agents - how best to protect infants from HIV and save their mothers from AIDS. N Engl J Med 2004; 351(3): 289292 
25. CZERESNIA D, FREITAS CM. Promoção da Saúde: Conceitos, Reflexões, Tendências. Rio de Janeiro: FIOCRUZ; 2003.

26. EL BEITUNE P, DUARTE G, SANTOS JE, QUINTANA SM, FIGUEIRÓFILHO EA, MARCOLIN AC. O uso de anti-retrovirais em gestantes modifica o perfil lipídico? RBGO 2003; 25(8): 593-598.

27. FERNÁNDEZ-LLIMÓS F, FAUS DÁDER MJ, GASTELURRUTIA MA, BAENA MI, MARTÍNEZ-MARTÍNEZ F. Evolución del concepto de problemas relacionados con los medicamentos: resultados como el centro de un nuevo paradigma. Seguim Farmacoter 2005; 3(4): 167-188.

28. FLIEGER K. FDA finds new ways to speed treatments to patients. FDA Consumer Special Report. January 1995. Available from: http://www.fda.gov/fdac/special/newdrug/speeding.html

29. FONSECA AF. Políticas de HIV/AIDS no Sistema Único de Saúde: uma busca pela integralidade da atenção. In: ESCOLA POLITÉCNICA DE SAÚDE JOAQUIM VENÂNCIO (org). Textos de Apoio em Políticas de Saúde. Rio de Janeiro: FIOCRUZ; 2005. p. 183-205.

30. FUCHS SC, FUCHS FD. Métodos de Investigação Farmacológico-Clínica. In: FUCHS FD, WANNMACHER L, FERREIRA MBC. Farmacologia Clínica: Fundamentos da Terapêutica Racional. 3a. ed. Rio de Janeiro: Guanabara Koogan; 2004. p. 8-21.

31. HAAIJER-RUSKAMP FM, HEMMININKI E. The social aspects of drug use. In: DUKES MNG, HAAIJER-RUSKAMP FM. Drug utilization studies - methods and uses. Copenhagen: WHO; 1993. 
39. KUCHENBECKER RS. Antivirais. In: FUCHS FD, WANNMACHER L, FERREIRA MBC. Farmacologia Clínica: Fundamentos da Terapêutica Racional. 3a. ed. Rio de Janeiro: Guanabara Koogan; 2004. p. 450-472.

40. LAPORTE JR, TOGNONI G (ed). Principios de epidemiología del medicamento. $2^{\mathrm{a}}$ ed. Barcelona : Masson-Salvat; 1993. Estudios de utilización de medicamentos y de farmacovigilancia; p. 1-24.

41. LEAVEll S, ClARCK EG. Medicina Preventiva. São Paulo: McGrawHill; 1976.

42. LEITE SN, CORDEIRO BC. Promoção do Uso de Medicamentos: a Interdisciplinaridade Necessária. In: SAUPE R, WENDHAUSEN ALP (orgs). Interdisciplinaridade e Saúde. Itajaí: UNIVALI; 2007. p. 157-172.

43. LEITE SN, VASCONCELLOS MPC. Adesão à terapia medicamentosa: elementos para discussão de conceitos e pressupostos adotados na literatura. Ciência \& Saúde Coletiva 2003; 8(3): 775-782.

44. LEITE SN. Adesão à Terapêutica Medicamentosa: o que o Farmacêutico Tem a Ver com Isso? In: CORDEIRO BC, LEITE SN (orgs). O Farmacêutico na Atenção à Saúde. Itajaí: UNIVALI; 2005.

45. LEITE SN, VASCONCELLOS MPC. Compreendendo a relação saúde/doença/tratamento: estudos qualitativos em farmácia. In: CORDEIRO BC, LEITE SN (orgs). O Farmacêutico na Atenção à Saúde. Itajaí: UNIVALI; 2005.

46. MACHUCA M, FERNÁNDEZ-LLIMÓS F, FAUS DÁDER MJ. Método Dáder. Manual de Acompanhamento Farmacoterapêutico. Universidad de Granada. Trad. de JCQP Frade; 2004. Disponível em: http://www.pharmanet.com.br/atencao/metododader.pdf 
47. MARIN N, LUIZA VL, OSÓRIO-DE-CASTRO CGS, MACHADO-DOSSANTOS (orgs). Assistência Farmacêutica para Gerentes Municipais. Rio de Janeiro: OPAS/OMS; 2003.

48. MATIDA LH, SILVA MH, TAYRA A, SUCCI RCM, GIANNA MC, GONÇALVES A et al. Prevention of mother-to-child transmission of HIV in São Paulo State, Brazil: an update. AIDS 2005; 19(supl 4): 37-41.

49. MATTOS RA. Os Sentidos da Integralidade: Algumas Reflexões Acerca de Valores que Merecem Ser Definidos. In: PINHEIRO R, MATTOS RA (orgs). Os Sentidos da Integralidade na Atenção e no Cuidado à Saúde. 2002. 1-16. p. Disponível em: www.lappis.org.br/cgi/cgilua.exe/sys/start.htm?sid=3

50. MELCHIOR R, NEMES MIB, BASSO CR, CASTANHEIRA ERL, BRITTO E ALVES MTS, BUCHALLA CM et al. Avaliação da estrutura organizacional da assistência ambulatorial em HIV/AIDS no Brasil. Rev. Saúde Pública 2006; 40(1): 143-151.

51. MILSTEIN-MOSCATI I, PERSANO S, CASTRO LLC. Aspectos metodológicos e comportamentais da adesão à terapêutica, pp. 171-179. In CASTRO LLC (org.). Fundamentos de farmacoepidemiologia. AG Editora, [s.1.]; 2000.

52. MINISTÉRIO DA SAÚDE (MS). A AIDS no Brasil: um esforço conjunto governo-sociedade. Brasília: 1998.

53. MINISTÉRIO DA SAÚDE (MS). XIV Seminário Brasil-França. 2005a. Disponível em: http://www.aids.gov.br 
54. MINISTÉRIO DA SAÚDE (MS). Boletim Epidemiológico AIDS/DST. 2005b. Disponível em: http://www.aids.gov.br

55. MINISTÉRIO DA SAÚDE/CONSELHO NACIONAL DE SAÚdE. $\mathbf{1}^{\text {a }}$. Conferência Nacional de Medicamentos e Assistência Farmacêutica. Relatório Final. Brasília: Ministério da Saúde; 2005.

56. MINISTÉRIO DA SAÚDE (MS). Protocolo para a prevenção da transmissão vertical de HIV e sífilis. Brasília: SVS/PN-DST/AIDS; 2006a.

57. MINISTÉRIO DA SAÚDE (MS). Boletim Epidemiológico AIDS/DST. 2006b. Disponível em: http://www.aids.gov.br

58. MINISTÉRIO DA SAÚDE (MS). Recomendações para Profilaxia da Transmissão Vertical do HIV e Terapia Anti-Retroviral em Gestantes. Brasília; 2006c. Disponível em: http://www.aids.gov.br

59. MINISTÉRIO DA SAÚDE (MS). Cadernos de Atenção Básica 18: HIV/AIDS, hepatites e outras DST. Brasília: SAS/DAB; 2006d.

60. MINISTÉRIO DA SAÚDE (MS). Alimentação e nutrição para pessoas que vivem com HIV e AIDS. Brasília: SVS/SAS; 2006e. Disponível em: http://www.aids.gov.br

61. MINISTÉRIO DA SAÚDE (MS). Plano operacional - Redução da Transmissão Vertical do HIV e da Sífilis Congênita. Brasília; 2007. Disponível em: http://www.aids.gov.br

62. MINISTERIO DE SANIDAD Y CONSUMO. Consenso sobre Atención Farmacéutica. Ars Pharmaceutica 2001; 42(3-4): 221-241. Disponible en: http://farmacia.ugr.es/ars/pdf/228.pdf 
63. MONTESSORI V, PRESS N, HARRIS M, AKAGI L, MONTANER JSG. Adverse effects of antiretroviral therapy for HIV infection. CMAJ 2004; 170(2): 229-238.

64. MORISKI DE, GREEN LW, LEVINE DM. Concurrent and Predictive Validity of a Self-reported Measure of Medication Adherence. Medical Care 1986; 24(1): 67-74.

65. NDOYE I, TAVERNE B, DESCLAUX A, LANIÈCE I, EGROT M, DELAPORTE E et al. Présentation de l'initiative sénégalaise d'accés aux antirétroviraux. In: L'initiative Sénégalaise d'Accés aux Antirétroviraux. Paris: ANRS; 2002. p. 5-22.

66. NEMES MIB (pesquisadora principal). Aderência ao tratamento por antiretrovirais em serviços públicos no Estado de São Paulo. Brasília: Ministério da Saúde; 2000.

67. NUNES E, SLOMP M. Adesão à Terapia Anti-retroviral em Gestantes e Pós-Gestantes Soropositivas Atendidas no Hospital-Dia do Município de Itajaí (SC). Itajaí; 2001. [Monografia de Conclusão do Curso de Farmácia Centro de Ciências da Saúde da UNIVALI].

68. OLIVEIRA MA, ESHER AFSC, SANTOS EM, COSENDEY MAE, LUIZA VL, BERMUDEZ JAZ. Avaliação da assistência farmacêutica às pessoas com HIV/AIDS no Município do Rio de Janeiro. Cad. Saúde Pública 2002; 18(5): 1429-1439.

69. PALELlA FJ, DELANEY KM, MOORMAN AC, LOVELESS MO, FUHRER J, SATTEN GA et al. Declining Morbidity and Mortality Among Patients with Advanced Human Immunodeficiency Virus Infection. The New England Journal of Medicine 1998; 338(13):853-60. 
70. PATERSON DL, SWINDELLS S, MOHR J, BRESTER M, VERGIS EN, SQUIER $C$ et al. Adherence to protease inhibitor therapy and outcomes in patient with HIV infection. Ann Intern Med 2000, 133: 21-30.

71. PAULO LG, ZANINI AC. Compliance: sobre o encontro paciente/médico. São Roque: IPEX Editora; 1997.

72. PERETTA M, CICCIA G. Reengenharia Farmacêutica. Brasília: Ethosfarma; 2000.

73. PERINI E, ACURCIO FA. Farmacoepidemiologia. In: GOMES MJVM, REIS AMM. Ciências Farmacêuticas: um abordagem em Farmácia Hospitalar. São Paulo: Atheneu; 2001. p. 85-107.

74. PETIT F, REDONNET C. Éducation Thérapeutique \& Conseil à l'Officine. Paris: Maloine; 2002.

75. PLUCIENNIK AMA. Prevenção da transmissão materno-infantil do HIV: é mais caro identificar do que tratar a gestante soropositiva. Rev. Assoc. Med. Bras. 2003; 49(1): 12.

76. PORTELA MC, LOTROWSKA M. Assistência aos pacientes com HIV/AIDS no Brasil. Rev. Saúde Pública 2006; 40(Supl): 70-79.

77. RACHID M, SCHECHTER M. Manual de HIV/AIDS. $2^{\star}$ ed. Rio de Janeiro: REVINTER; 1997.

78. ROMANO-LIEBER NS, TEIXEIRA JJV, FARHAT FCLG, RIBEIRO E, CROZATTI MTL, OLIVEIRA GSA. Revisão dos estudos de intervenção do farmacêutico no uso de medicamentos por pacientes idosos. Cadernos de Saúde Pública 2002; 18(6): 1499-1507. 
79. ROVERS JP, CURRIE JD, HAGEL HP, McDONOUGH RP, SOBOTKA JL. A practical guide to pharmaceutical care. Washington: American Pharmaceutical Association; 1998.

80. RUDI SOLA N. Interacciones farmacológicas de los medicamentos antirretrovirales. Barcelona; 2003. Disponible en: http://www.fundacionpromedic.org/es/activitats/curso2/libro1/cap1-4.pdf

81. RUTHERFORD GW, SANGANI PR, KENNEDY GE. Régimen de mantenimiento con tres o cuatro medicamentos antirretrovirales versus régimen de mantenimiento con dos medicamentos antirretrovirales para la infección por VIH (Revisión Cochrane traducida). En: La Biblioteca Cochrane Plus 2007; Numero 2. Oxford: Update Software Ltd. Disponible en http://www.update-software.com

82. SABATÉ E (ed). Adherence to long term therapies: evidence for action. Geneva: World Health Organization; 2003.

83. SABATER HERNÁNDEZ D, SILVA-CASTRO MM, FAUS DÁDER MJ. Método Dáder. Guia de Seguimiento Farmacoterapéutico. $3^{\mathrm{a}}$. ed. Granada; 2007.2 Disponible em: http://www.ugr.es/ cts131/esp/guias/GULAS.HTM

84. SANTA CATARINA. O perfil epidemiológico da AIDS. Florianópolis: Secretaria de Estado da Saúde/Diretoria de Vigilância Epidemiológica; 2006.

85. SEVALHO G. O medicamento percebido como objeto híbrido: uma visão crítica do uso racional. In: ACURCIO FA (org). Medicamentos e Assistência Farmacêutica. Belo Horizonte: COOPMED; 2003. p. 1-8.

86. SOUZA HM, COSTA NETO MM. Caderno de Atenção Básica - PSF. Brasília: Ministério da Saúde 2000; n. 1. p.9. 
87. SOUZA JÚNIOR PRB, SZWARCWALD CL, BARBOSA JÚNIOR A, CARVALHO MF, CASTILHO EA. Infecção pelo HIV Durante a Gestação: Estudo-Sentinela Parturiente, Brasil, 2002. Rev. Saúde Pública 2004; 38(6):764-72.

88. TEIXEIRA PR. Acesso universal a medicamentos para AIDS: a experiência do Brasil. Divulgação em Saúde para Debate 2003; 27:50-57.

89. TOBAR F, YALOUR MR. Como fazer teses em saúde pública conselhos e idéias para formular projetos e redigir teses e informes de pesquisas. Rio de Janeiro: FIOCRUZ; 2001.

90. TOURETTE-TURGiS C, REBILLON M. Mettre en place une consultation d'observance aux traitements contre le VIH/Sida. De la théorie à la pratique. Paris: Comment Dire; 2002.

91. UNAIDS. Report on the Global HIV/AIDS epidemic. Geneva: UNAIDS; 2002.

92. UPPSALA MONITORING CENTER (UMC). Viewpoint - Part 22004. Available from: http://www.who-umc.org

93. VOLMINK J, SIEGFRIED NL, VAN DER MERWE L, BROCKLEHURST P. Antirretrovirales para la reducción del riesgo de transmisión maternoinfantil de la infección por VIH (Revisión Cochrane traducida). En: La Biblioteca Cochrane Plus 2007; Numero 2. Oxford: Update Software Ltd. Disponible en http://www.update-software.com.

94. WORLD BANK. Financing Health Services in Developing Countries: an Agenda for Reform. Washington: World Bank; 1987. 
95. WHO. Uso Racional de los Medicamentos. Informe de la Conferencia de Expertos - Nairobi, 1985. Genebra: WHO; 1986. 
ANEXOS 
Anexo 1. Método Dáder

\section{HISTÓRIA FARMACOTERAPÊUTICA}

PACIENTE $\mathrm{n}^{\circ}$ :

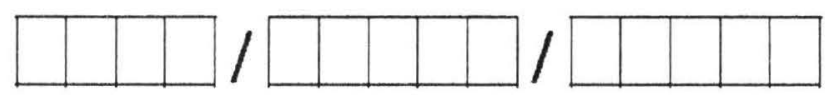

NOME:

DATA:

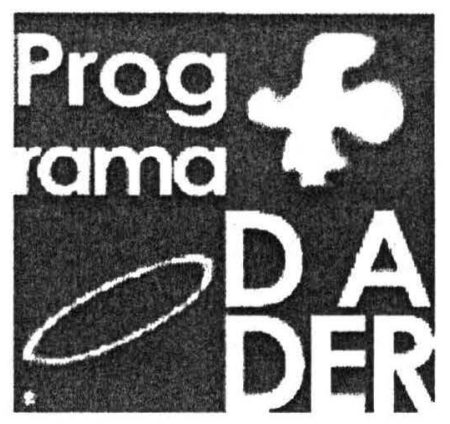


PRIMERA VISITA

PACIENTE $n^{\circ}$ :

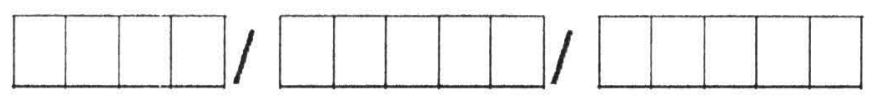

PROBLEMAS / PREOCUPAÇÕES DE SAÚdE

Controlado Início

1.

2.

3.

4.

5.

6.

7.

8.

9.

10.

SACOLA COM MEDICAMENTOS

\begin{tabular}{|l|l|}
\hline Nome 1: & ADERE: $M, R, P$ \\
\hline 1. Utiliza? & 6. quanto usa? \\
2. quem prescreveu? & 7. como usa? \\
3. para que? & 8. ate quando? \\
4. esta melhor? & 9. dificuldade? \\
5. desde quando? & 10.algo estranho? \\
\hline
\end{tabular}




\begin{tabular}{|c|c|c|}
\hline Nome 2: & ADERE: $M, R, P$ & CONHECE: $M, R, P$ \\
\hline $\begin{array}{l}\text { 1. Utiliza? } \\
\text { 2. quem prescreveu? } \\
\text { 3. para qué? } \\
\text { 4. está melhor? } \\
\text { 5. desde quando? } \\
\end{array}$ & $\begin{array}{l}\text { 6. quanto usa? } \\
\text { 7. cono usa? } \\
\text { 8. atè quando? } \\
\text { 9. dificuldade? } \\
\text { 10.algo estranho? }\end{array}$ & \\
\hline Nome 4: & ADERE: $M, R, P$ & CONHECE: $M, R, P$ \\
\hline $\begin{array}{l}\text { 1. Utillza? } \\
\text { 2. quem prescreveu? } \\
\text { 3. para quê? } \\
\text { 4. está melhor? } \\
\text { 5. desde quando? }\end{array}$ & $\begin{array}{l}\text { 6. quanto usa? } \\
\text { 7. como usa? } \\
\text { 8. até quando? } \\
\text { 9. dificuldade? } \\
\text { 10.algo estranho? }\end{array}$ & \\
\hline
\end{tabular}

\begin{tabular}{l} 
Nome 5: \\
1. Utiliza? \\
2. quem prescreveu? \\
3. para quê? \\
4. está melhor? \\
5. desde quando? \\
\hline
\end{tabular}

ADERE: $M, R, P$ CONHECE: $M, R, P$
6. quanto usa?
7. como usa?
8. até quando?
9. dificuldade?
10.algo estranho?

\begin{tabular}{|c|c|c|}
\hline Nome 6: & ADERE: $M, R, P$ & CONHECE: $M, R, P$ \\
\hline $\begin{array}{l}\text { 1. Utiliza? } \\
\text { 2. quem prescreveu? } \\
\text { 3. para quê? } \\
\text { 4. esta melhor? } \\
\text { 5. desde quando? }\end{array}$ & $\begin{array}{l}\text { 6. quanto usa? } \\
\text { 7. como usa? } \\
\text { 8. até quando? } \\
\text { 9. dificuldade? } \\
\text { 10.algo estranho? }\end{array}$ & \\
\hline
\end{tabular}

\begin{tabular}{|l|l|}
\hline Nome 7: & ADERE: $M, R, P$ \\
\hline 1. Utiliza? & 6. quanto usa? \\
2. quem prescreveu? & 7. como ussa? \\
3. para quê? & 8. até quando? \\
4. está melhor? & 9. dificuldade? \\
5. desde quando? & 10.algo estranho? \\
\hline
\end{tabular}

\begin{tabular}{|l|l|}
\hline Nome 8: & ADERE: $M, R, P$ \\
\hline 1. Utiliza? & 6. quanto usa? \\
2. quem prescreveu? & 7. como usa? \\
3. para quê? & 8. até quando? \\
4. está melhor? & 9. dificuldade? \\
5. desde quando? & 10.algo estranho? \\
\hline
\end{tabular}

\begin{tabular}{|c|c|c|}
\hline Nome 9: & ADERE: $M, R, P$ & CONHECE: $M, R, P$ \\
\hline $\begin{array}{l}\text { 1. Utiliza? } \\
\text { 2. quem prescreveu? } \\
\text { 3. para quê? } \\
\text { 4. está melhor? } \\
\text { 5. desde quando? }\end{array}$ & $\begin{array}{l}\text { 6. quanto usa? } \\
\text { 7. como usa? } \\
\text { 8. até quando? } \\
\text { 9. dificuldade? } \\
\text { 10.algo estranho? }\end{array}$ & \\
\hline
\end{tabular}

\begin{tabular}{|l|l|}
\hline Nome 10: & ADERE: $M, R, P$ \\
\hline 1. Utiliza? & 6. quanto usa? \\
2. quem prescreveu? & 7. como usa? \\
3. para quê? & 8. até quando? \\
4. está melhor? & 9. dificuldade? \\
5. desde quando? & 10.algo estranho? \\
\hline
\end{tabular}




\begin{tabular}{|c|c|c|}
\hline Nome 11: & ADERE: $M, R, P$ & CONHECE: $M, R, P$ \\
\hline $\begin{array}{l}\text { 1. Utiliza? } \\
\text { 2. quem prescreveu? } \\
\text { 3. para quê? } \\
\text { 4. está melhor? } \\
\text { 5. desde quando? }\end{array}$ & $\begin{array}{l}\text { 6. quanto usa? } \\
\text { 7. como usa? } \\
\text { 8. até quando? } \\
\text { 9. dificuldade? } \\
\text { 10.algo estranho? }\end{array}$ & \\
\hline Nome 12: & ADERE: $M, R, P$ & CONHECE: $M, R, P$ \\
\hline $\begin{array}{l}\text { 1. Utiliza? } \\
\text { 2. quem prescreveu? } \\
\text { 3. para quê? } \\
\text { 4. esta melhor? } \\
\text { 5. desde quando? }\end{array}$ & $\begin{array}{l}\text { 6. quanto usa? } \\
\text { 7. como ussa? } \\
\text { 8. até quando? } \\
\text { 9. dificuldade? } \\
\text { 10.algo estranho? }\end{array}$ & \\
\hline Nome 13: & ADERE: $M, R, P$ & CONHECE: $M, R, P$ \\
\hline $\begin{array}{l}\text { 1. Utiliza? } \\
\text { 2. quem prescreveu? } \\
\text { 3. para quê? } \\
\text { 4. esta melhor? } \\
\text { 5. desde quando? }\end{array}$ & $\begin{array}{l}\text { 6. quanto usa? } \\
\text { 7. como ussa? } \\
\text { 8. até quando? } \\
\text { 9. dificuldade? } \\
\text { 10.algo estranho? }\end{array}$ & \\
\hline
\end{tabular}

$\mathrm{M}=$ Muito bom $\mathrm{R}=$ Regular $\mathrm{P}=$ Pouco

\section{Medicamentos usados anteriormente}

\begin{tabular}{|l|l|}
\hline Nome 1: & \\
\hline 1. Utiliza? & 4.Está melhor? \\
3. para quê? & 10. algo estranho? \\
\hline
\end{tabular}

\begin{tabular}{|l|l|}
\hline Nome 2: & \\
\hline $\begin{array}{l}\text { 1. Utiliza? } \\
\text { 3. para quê? }\end{array}$ & $\begin{array}{l}\text { 4.Está melhor? } \\
\text { 10. algo estranho? }\end{array}$ \\
\hline
\end{tabular}

\begin{tabular}{|l|l|}
\hline Nome 3: & \\
\hline $\begin{array}{l}\text { 1. Utiliza? } \\
\text { 3. para quê? }\end{array}$ & $\begin{array}{l}\text { 4.Está melhor? } \\
\text { 10. algo estranho? }\end{array}$ \\
\hline
\end{tabular}

\begin{tabular}{|l|l|}
\hline Nome 4: & \\
\hline 1. Utiliza? & $\begin{array}{l}\text { 4.Está melhor? } \\
\text { 3. para quê? }\end{array}$ \\
\hline
\end{tabular}

\begin{tabular}{|l|l|}
\hline Nome 5: & \\
\hline 1. Utiliza? & $\begin{array}{l}\text { 4.Está melhor? } \\
\text { 3. para quê? }\end{array}$ \\
\hline
\end{tabular}




\section{REVISÃo}

- CABELO:

- CABECA:

- OLHOS, OUVIDOS, NARIZ, GARGANTA:

- BOCA (ferida, seca):

- PESCOÇO:

- MÃOS (dedos, unhas):

- BRAÇOS E MÚSCULOS:

- CORAC̄̃O:

- PULMAO:

- APARELHO DIGESTIVO:

- RINS (urina):

- FÍGADO:

- APARELHO GENITAL:

- PERNAS:

- PÉS (dedos, unhas,..):

- MÚSCULOS ESQUELÉTICOS (gota, dor nas costas, tendinitis ....):

- PELE (seca, erupções,....):

- PSICOLÓGICO (depressão,...):

- NEUROLÓGICO (epilepsia,...):

- IMC

- PARÂMETROS ANORMAIS: (temperatura, PA, colesterol, glicose...):

- CIGARRO:

- ALCOOL:

- CAFÉ:

- CHÁS:

- OUTRAS DROGAS:

- OUTROS HÁBITOS ANORMAIS (atividade física, dieta...):

- VITAMINAS E SAIS MINERAIS:

- VACINAS:

- ALeRgias A MEdicamentos e/OU RAM

- SITUAÇÕES FISIOLÓGICAS (e data):

- OBSERVAÇÕES:

OUTROS DADOS DO PACTENTE
- Telefone:
- Endereço:
- Profissão:
- Médico principal:
- Médicos especialistas: $\frac{}{\text { - Data de nascimento: }}-\frac{}{\text { MINUTOS: }}$ - Cuidador:
Assinatura do Farmacêutico:


ESTADO DE STTUAÇÃO

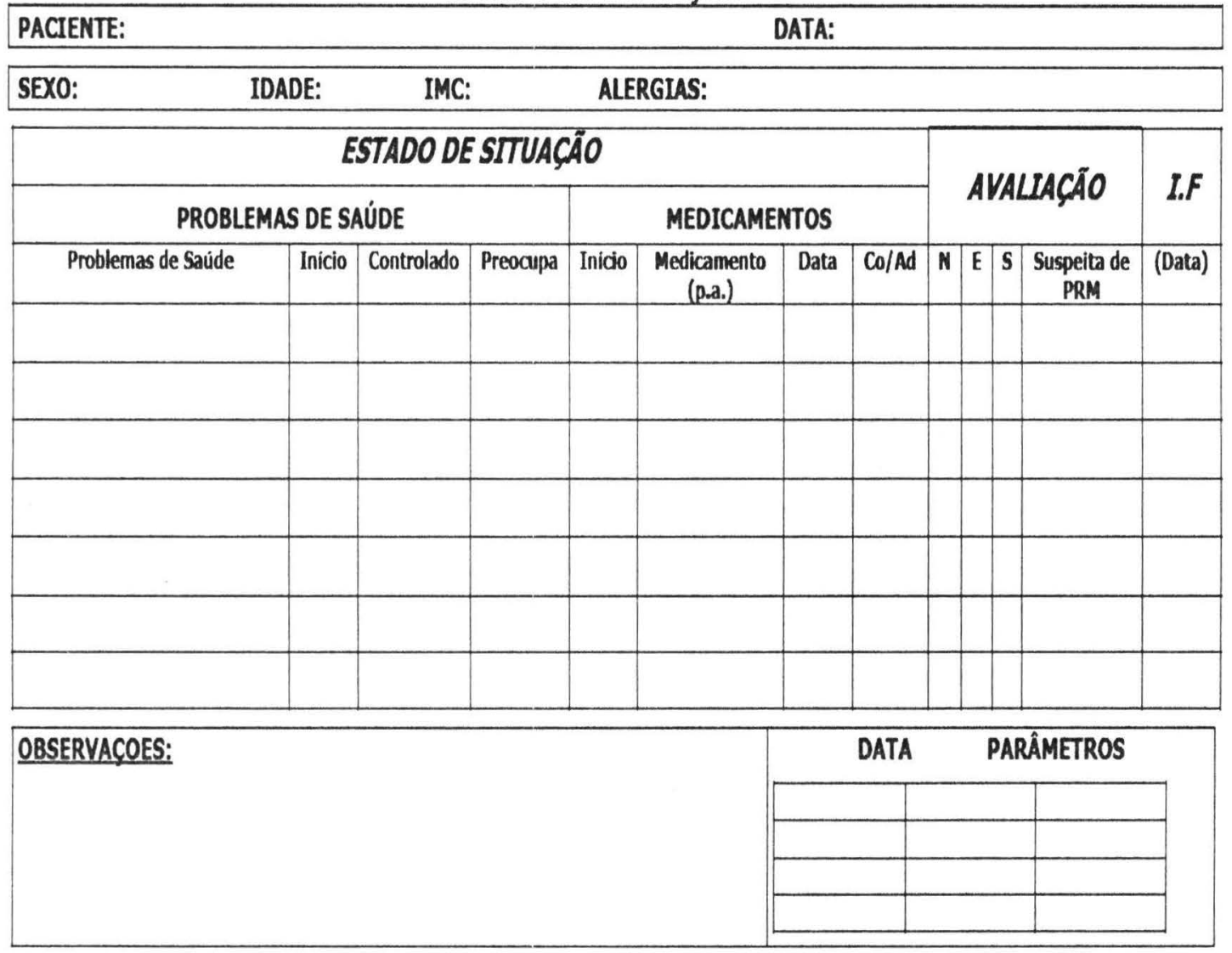

Gupo de Investigaçâo em Atençâo Famnacêutica. Universidade de Granada 


\section{INTERVENÇÃO FARMACÊUTICA}

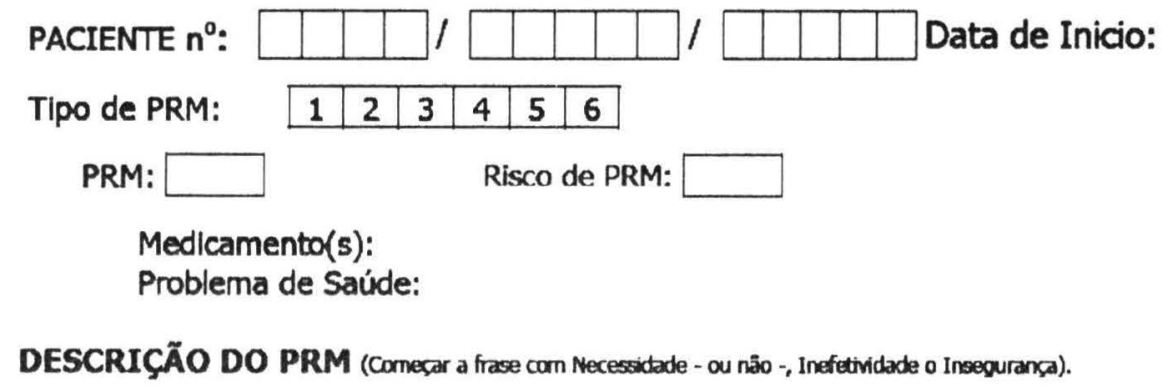

\section{CAUSA:}

1. Interação

2. Não adesão

3. Duplicidade

4. Nenhuma das anteriores

Descrever

O QUE SE PRETENDE FAZER PARA RESOLVER O PRM:

\section{VIA DE COMUNICAÇĀO:}

1. Verbal farmacêutico - paciente

2. Escrita farmacêutico - paciente

3. Verbal farmacêutico - paciente - médico

4. Escrita farmacêutico - paciente - médico

RESULTADO:

\begin{tabular}{|l|l|l|}
\cline { 2 - 3 } \multicolumn{1}{c|}{} & $\begin{array}{l}\text { P. Saúde } \\
\text { Resolvido }\end{array}$ & $\begin{array}{l}\text { P. Saúde não } \\
\text { Resolvido }\end{array}$ \\
\hline $\begin{array}{l}\text { Intervenção } \\
\text { Aceita }\end{array}$ & & \\
\hline $\begin{array}{l}\text { Intervención } \\
\text { Nõo aceita }\end{array}$ & & \\
\hline
\end{tabular}

\section{O QUE OCORREU?}

No MEDICAMENTOS QUE ESTAVA UTIUIZANDO (na data da intervenção): No VISITAS ANTERIORES A RESOLUÇÃO:

Data final da Intervenção: 
Anexo 2. Normas para publicação do periódico Revista Brasileira de Saúde Materno Infantil

Instruções aos Autores

\section{Escopo e política}

A Revista Brasileira de Saúde Materno Infantil é uma publicação trimestral (março, junho, setembro e dezembro) cuja missão é a divulgação de artigos científicos englobando o campo da saúde materno infantil. As contribuições devem abordar os diferentes aspectos da saúde materna, saúde da mulher e saúde da criança, contemplando seus múltiplos determinantes biomédicos, socioculturais e epidemiológicos. São aceitos trabalhos nas seguintes línguas: português, espanhol e inglês. A seleção baseia-se no princípio da avaliação pelos pares (peer review) $\square$ especialistas nas diferentes áreas da saúde da mulher e da criança.

\section{DIREITOS AUTORAIS}

Os trabalhos publicados são propriedade da Revista, vedada a reprodução total ou parcial e a tradução para outros idiomas, sem a autorização da mesma. Os trabalhos deverão ser acompanhados da Declaração de Transferência dos Direitos Autorais, assinada pelos autores. Os conceitos emitidos nos trabalhos são de responsabilidade exclusiva dos autores.

\section{COMITÊ DE ÉTICA}

Também serão exigidos para os artigos nacionais a Declaração de Aprovação do Comitê de Ética conforme as diretrizes da Comissão Nacional de Ética em Pesquisa (CONEP) e, para os artigos do exterior a Declaração de Aprovação do Comitê de Ética do local onde a pesquisa foi realizada.

\section{SEÇÕES DA REVISTA \\ Editorial}

Revisão apresentação do histórico da evolução científica e avaliação crítica de um tema, tendo como suporte para a investigação a literatura considerada relevante.

Artigos Originais divulgam os resultados de pesquisas inéditas permitindo a reprodução destes resultados dentro das condições citadas no mesmo. Para os artigos originais recomenda-se seguir a estrutura convencional conforme as seguintes secções: Introdução: onde se apresenta a relevância do tema, as hipóteses iniciais, a justificativa para a pesquisa e o objetivo, que deve ser claro e breve; Métodos: descreve a população estudada, os critérios de seleção e exclusão da amostra, define as variáveis utilizadas e informa a maneira que permite a reprodutividade do estudo, em relação a procedimentos técnicos e instrumentos utilizados, além da análise estatística; Resultados: são apresentados de forma concisa, clara e objetiva, em seqüência lógica e apoiados nas ilustrações: tabelas e figuras - gráficos, desenhos, fotografias; Discussão: interpreta os resultados obtidos e verifica a compatibilidade entre estes resultados e os citados na literatura, ressaltando aspectos novos e importantes, vinculando as conclusões aos objetivos do estudo. Aceitam-se outros formatos, quando pertinente, de acordo com a natureza do trabalho. Os trabalhos deverão ter no máximo 25 páginas e recomenda-se citar até 30 referências bibliográficas.

Notas de Pesquisa relatos concisos sobre um tema original (máximo de cinco páginas).

Informes Técnicos Institucionais deverão ter estrutura similar a uma Revisão, mas sem o resumo/abstract. Por outro lado podem ser feitas, a critério do autor, citações no texto e suas respectivas referências ao final. 
Ponto de Vista opinião qualificadas sobre saúde materno-infantil (a convite dos editores).

Resenhas crítica de livros publicados nos últimos dois anos ou em redes de comunicação on line (máximo de cinco páginas).

Teses resumos de teses ou dissertações que abordem os aspectos da saúde da mulher e da criança conforme o escopo da Revista, apresentada até no máximo de dois anos. As monografias correspondentes devem acompanhar os resumos pois serão incorporadas ao acervo da biblioteca do Instituto Materno Infantil de Pernambuco, IMIP.

Cartas crítica a trabalhos publicados recentemente na Revista (máximo de três páginas).

\section{Forma e preparação de manuscritos}

\section{APRESENTAÇÃO DOS MANUSCRITOS}

Os manuscritos encaminhados à Revista deverão ser digitados no programa Microsoft Word for Windows, em fonte Times New Roman, tamanho 12, em espaço duplo, impresso em duas vias, acompanhados por um disquete; podem também, ser enviados via e-mail.

\section{Estrutura do manuscrito}

Página de identificação título do trabalho: em português ou no idioma do texto e em inglês, nome e endereço completo dos autores e respectivas instituições; indicação do autor responsável pela troca de correspondência; fontes de auxílio: citar o nome da agência financiadora e o tipo de auxílio recebido.

Página dos Resumos deverão ser elaborados dois resumos para os Artigos Originais, Notas de Pesquisa e Artigos de Revisão um resumo em português ou no idioma do texto e outro em inglês, o abstract. Os resumos dos Artigos Originais e Notas de Pesquisa deverão ter no máximo 250 palavras e devem ser estruturados: Objetivos/Objectives, Métodos/Methods, Resultados/Results, Conclusões/Conclusions. Nos Artigos de Revisão o formato narrativo dispensa o uso de resumo estruturado que deverá ter no máximo 150 palavras.

Palavras-chave para identificar o conteúdo dos trabalhos os resumos deverão ser acompanhados de três a 10 palavras-chave em português e inglês. A Revista utiliza os Descritores em Ciências da Saúde (DeCS) da Metodologia LILACS, e o seu correspondente em inglês o Medical Subject Headings (MeSH) do MEDLINE, adequando os termos designados pelos autores a esses vocabulários.

Página das llustrações as tabelas e figuras (gráficos, desenhos, mapas, fotografias) deverão ser inseridas em páginas à parte.

Página da Legenda as legendas das ilustrações deverão seguir a numeração designada pelas tabelas e figuras, e inseridas em folha à parte.

Agradecimentos à colaboração de pessoas, ao auxílio técnico e ao apoio econômico e material, especificando a natureza do apoio.

Referências devem ser organizadas na ordem em que são citadas no texto e numeradas consecutivamente; não devem ultrapassar o número de 30 referências. $\mathrm{A}$ Revista adotou as normas do Committee of Medical Journals Editors (Grupo de Vancouver), com algumas alterações; siga o formato dos exemplos: 


\section{Artigo de revista}

Lopes MCS, Ferreira LOC, Batista Filho M. Uso diário e semanal de sulfato ferroso no tratamento de anemia em mulheres no período reprodutivo. Cad Saúde Pública 1999; 15: 799-808.

\section{Livro}

Alves JGB, Figueira F. Doenças do adulto com raízes na infância. Recife: Bagaço; 1998.

Editor ou Compilador como autor

Norman IJ, Redfern SJ, editors. Mental health care for elderly people. New York: Churchill Livingstone; 1996.

Capítulo de livro

Timmermans PBM. Centrally acting hipotensive drugs. In: Van Zwieten PA, editor. Pharmacology of antiihypertensive drugs. Amsterdam: Elservier; 1984. p. 102-53

Congresso considerado no todo

Proceedings of the 7th World Congress on Medical Informatics; 1992 Sep 6-10; Geneva, Switzerland. Amsterdam: North Holland; 1992.

Trabalho apresentado em eventos

Bengtson S, Solheim BG. Enforcement of data protection, privacy and security in medical informatics. In: Lun KC, Degoulet P, Piemme TE, Rienhoff $O$, editors.

MEDINFO 92. Proceedings of the 7th World Congress on Medical Informatics; 1992

Sep 6-10; Geneva, Switzerland. Amsterdam: North Holland; 1992. p. 1561-5

Dissertação e Tese

Pedrosa JIS. Ação dos autores institucionais na organização da saúde pública no Piaúi: espaço e movimento [dissertação mestrado]. Campinas: Faculdade de Ciências Médicas da Universidade Estadual de Campinas; 1997.

Diniz AS. Aspectos clínicos, subclínicos e epidemiológicos da hipovitaminose A no estado da Paraíba [tese doutorado]. Recife: Departamento de Nutrição, Centro de Ciências da Saúde da Universidade Federal de Pernambuco; 1997.

\section{Documento em formato eletrônico}

Pellegrini Filho A. La BVS y la democratización del conocimiento y la información en salud. 1999. Disponível em URL: Http://www.bireme.br/bvs/reunião/doc/pellegrini.htm [2000 Jan 16]

\section{Envio de manuscritos}

\section{Os trabalhos deverão ser encaminhados para:}

Revista Brasileira de Saúde Materno Infantil Instituto Materno Infantil de Pernambuco, IMIP

Rua dos Coelhos, 300. Boa Vista. Recife, PE, Brasil CEP 50.070-550.

Tel / Fax: + 55 + 812122.4141

E mail: revista@imip.org.br Site: www.imip.org.br 


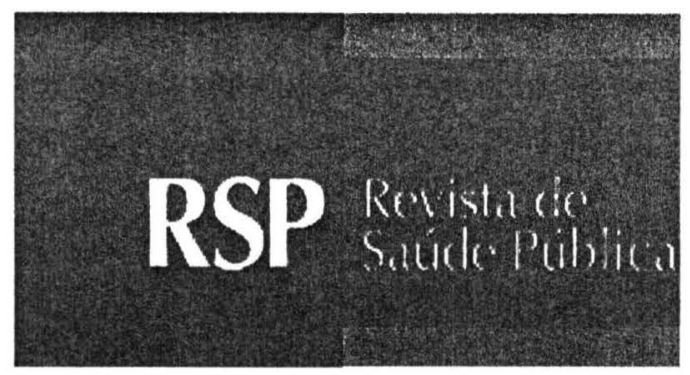

\section{Instruções aos Autores}

Apresentação

A Revista de Saúde Pública é inter e multidisciplinar e arbitrada. Publica prioritariamente pesquisas originais sobre temas relevantes e inéditos sobre o campo da saúde pública, que possam ser replicadas e generalizadas, e também outras contribuições de caráter descritivo e interpretativo, baseadas na literatura recente, bem como artigos sobre temas atuais ou emergentes, comunicações breves e cartas ao editor.

Os manuscritos devem destinar-se exclusivamente à Revista de Saúde Pública, não sendo permitida sua apresentação simultânea a outro periódico, tanto no que se refere ao texto como figuras ou tabelas, quer na integra ou parcialmente, excetuando-se resumos. Os autores devem assinar e encaminhar uma declaração de responsabilidade cujo modelo está disponível no site da Revista.

Os manuscritos submetidos à Revista devem atender à política à sua editorial e às instruções aos autores, que seguem os "Uniform Requirements for Manuscripts Submitted to Biomedical Journals: Writing and Editing for Biomedical Publication" (http://www.icmje.org). No que couber e para efeito de complementação das informações, recomenda-se consultar esse citado documento. Os manuscritos que não atenderem a essas instruções serão devolvidos.

As contribuições destinadas a divulgar resultados de pesquisa original inédita, que possam ser replicados e generalizados, têm prioridade para publicação. Tais contribuições representam não somente pesquisas levadas a efeito no País, mas também na América Latina e em outros países. As contribuições podem ser apresentadas em português, inglês ou espanhol. Os artigos publicados em português são traduzidos para o inglês e divulgados somente no formato eletrônico.

A objetividade é o princípio básico para a elaboração dos manuscritos, resultando em artigos mais curtos de acordo com os limites estabelecidos pela Revista.

Atendidas as condições acima, os manuscritos são encaminhados à Editoria Científica para análise preliminar. Aceitos nesta fase, os manuscritos serão avaliados por relatores externos. Atendidas as condições acima, os manuscritos são 
encaminhados à Editoria Científica para análise preliminar. Aceitos nesta fase, os manuscritos serão avaliados por relatores externos.

Relações que podem estabelecer conflito de interesse, ou mesmo nos casos em que não ocorra, devem ser esclarecidas.

Os critérios éticos da pesquisa devem ser respeitados. Para tanto os autores devem explicitar em Métodos que a pesquisa foi conduzida dentro dos padrões exigidos pela Declaração de Helsink e aprovada pela comissão de ética da instituição onde a pesquisa foi realizada.

Manuscritos não aceitos não serão devolvidos, a menos que sejam solicitados pelos respectivos autores no prazo de até seis meses.

Os manuscritos publicados são de propriedade da Revista, vedada tanto a reprodução, mesmo que parcial em outros periódicos, como a tradução para outro idioma e inclusão de links para artigos da RSP sem a autorização do Editor Científico. Desta forma, os manuscritos submetidos deverão ser acompanhados de documento de transferência de direitos autorais, cujo modelo encontra-se disponível no site da Revista.

Categorias de artigos

Além dos artigos originais, os quais têm prioridade, a Revista de Saúde Pública publica comunicações breves, revisões sistemáticas, comentários, cartas ao editor, editoriais, além de outras.

Artigos originais - São contribuições destinadas a divulgar resultados de pesquisa original inédita, que possam ser replicados e/ou generalizados. Devem ter a objetividade como princípio básico. $\mathrm{O}$ autor deve deixar claro quais as questões que pretende responder.

- Devem ter de 2.000 a 4.000 palavras, excluindo tabelas, figuras e referências. - As tabelas e figuras devem ser limitadas a 5 no conjunto, recomendando incluir apenas os dados imprescindíveis, evitando-se tabelas muito longas, com dados dispersos e de valor não representativo. Quanto às figuras, não são aceitas aquelas que repetem dados de tabelas.

- As referências bibliográficas estão limitadas a um número máximo de 25 , devendo incluir aquelas estritamente pertinentes e relevantes à problemática abordada. Devese evitar a inclusão de número excessivo de referências numa mesma citação.

Referências a documentos não publicados e não indexados na literatura científica (teses, relatórios e outros) devem ser evitadas. Caso não possam ser substituídas por outras, podem ser indicadas nos rodapés das páginas onde estão citadas.

A estrutura dos artigos originais de pesquisa é a convencional: Introdução, Métodos, Resultados e Discussão, embora outros formatos possam ser aceitos. A Introdução deve ser curta, definindo o problema estudado, sintetizando sua importância e destacando as lacunas do conhecimento ("estado da arte") que serão abordadas no 
artigo. Os Métodos empregados, a população estudada, a fonte de dados e critérios de seleção, dentre outros, devem ser descritos de forma compreensiva e completa, mas sem prolixidade. A seção de Resultados deve se limitar a descrever os resultados encontrados sem incluir interpretações/comparações. O texto deve complementar e não repetir o que está descrito em tabelas e figuras. Devem ser separados da Discussão. A Discussão deve começar apreciando as limitações do estudo, seguida da comparação com a literatura e da interpretação dos autores, extraindo as conclusões e indicando os caminhos para novas pesquisas.

Comunicações Breves - São artigos curtos destinados à divulgação de resultados preliminares de pesquisa; de resultados de estudos que envolvem metodologia de pequena complexidade; hipóteses inéditas de relevância a área de saúde pública.

- Devem ter de 800 a 1.600 palavras (excluindo tabelas, figuras e referências) uma tabela/figura e 5 referências.

- Sua apresentação deve acompanhar as mesmas normas exigidas para artigos originais, exceto para resumos, que não são estruturados e devem ter até 150 palavras.

Revisões sistemáticas - Avaliação crítica sistematizada da literatura sobre determinado assunto, devendo conter conclusões. Devem ser descritos os procedimentos adotados, esclarecendo a delimitação e limites do tema. Sua extensão é de 5.000 palavras.

Comentários - São trabalhos descritivos e interpretativos baseados na literatura recente sobre a situação global em que se encontra determinado assunto investigativo, ou artigos opinativos. Sua extensão deve ser de 3.000 palavras.

Cartas ao Editor - Inclui cartas que visam a discutir artigos recentes publicados na Revista ou a relatar pesquisas originais ou achados científicos significativos. Não devem exceder a 600 palavras e a 5 referências.

\section{Autoria}

O conceito de autoria está baseado na contribuição substancial de cada uma das pessoas listadas como autores, no que se refere sobretudo à concepção do projeto de pesquisa, análise e interpretação dos dados, redação e revisão crítica. Manuscritos com mais de 6 autores devem ser acompanhados por declaração certificando explicitamente a contribuição de cada um dos autores elencados (ver modelo). Não se justifica a inclusão de nome de autores cuja contribuição não se enquadre nos critérios acima, podendo, neste caso, figurar na seção "Agradecimentos". A indicação dos nomes dos autores logo abaixo do título do artigo é limitada a 12; acima deste número, os autores são listados no rodapé da página.

Cada manuscrito deve indicar o nome de um autor responsável pela correspondência com a Revista, e seu respectivo endereço, incluindo telefone e e-mail

Preparo dos manuscritos 
- Os manuscritos devem ser preparados de acordo com as "Instruções aos Autores" da Revista.

- Os manuscritos devem ser digitados em extensão .doc, .txt ou .rtf. Deve ser apresentado com letras arial, corpo 12, em folha de papel branco, tamanho A-4, mantendo margens laterais de $3 \mathrm{~cm}$, espaço duplo em todo o texto, incluindo página de identificação, resumos, agradecimentos, referências e tabelas.

- Cada manuscrito deve ser enviado em uma via em papel, por correio e o arquivo do texto para o e-mail da Revista.

- Todas as páginas devem ser numeradas a partir da página de identificação.

Página de identificação - - Deve conter: a) Título do artigo, que deve ser conciso e completo, evitando palavras supérfluas. Recomenda-se começar pelo termo que represente $o$ aspecto mais importante do trabalho, com os demais termos em ordem decrescente de importância. Deve ser apresentada a versão do título para o idioma inglês. O limite de caracteres é 93, incluindo os espaços. b) Indicar no rodapé da página o título abreviado, com até 40 caracteres, para fins de legenda nas páginas impressas. c) Nome e sobrenome de cada autor pelo qual é conhecido na literatura. d) Instituição a que cada autor está afiliado, acompanhado do respectivo endereço. e) Nome do departamento e da instituição no qual o trabalho foi realizado. f) Nome e endereço do autor responsável para troca de correspondência. g) Se foi subvencionado, indicar o tipo de auxílio, o nome da agência financiadora e o respectivo número do processo. h) Se foi baseado em tese, indicar o título, ano e instituição onde foi apresentada. i) Se foi apresentado em reunião científica, indicar o nome do evento, local e data da realização. (Verificação de itens)

Resumos e Descritores - - Os manuscritos para as seções Artigos Originais, Revisões, Comentários e similares devem ser apresentados contendo dois resumos, sendo um em português e outro em inglês. Quando o manuscrito foi escrito em espanhol, deve ser acrescentado resumo nesse idioma. Para os artigos originais os resumos devem ser apresentados no formato estruturado, com até 250 palavras, destacando o principal objetivo e os métodos básicos adotados, informando sinteticamente local, população e amostragem da pesquisa; apresentando os resultados mais relevantes, quantificando-os e destacando sua importância estatística; apontando as conclusões mais importantes, apoiadas nas evidências relatadas, recomendando estudos adicionais quando for o caso. Para as demais seções, o formato dos resumos deve ser o narrativo, com até 150 palavras. Basicamente deve ser destacado o objetivo, os métodos usados para levantamento das fontes de dados, os critérios de seleção dos trabalhos incluídos, os aspectos mais importantes discutidos e as conclusões mais importantes e suas aplicações. Abreviaturas e siglas devem ser evitadas; citações bibliográficas não devem ser incluídas em qualquer um dos dois tipos. Descritores devem ser indicados entre 3 a 10, extraídos do vocabulário "Descritores em Ciências da Saúde" (DeCS), quando acompanharem os resumos em português, e do Medical Subject Headings (MeSH), quando acompanharem os "Abstracts". Se não forem encontrados descritores disponíveis para cobrirem a temática do manuscrito, poderão ser indicados termos ou expressões de uso conhecido. 
Agradecimentos - - Contribuições de pessoas que prestaram colaboração intelectual ao trabalho como assessoria científica, revisão crítica da pesquisa, coleta de dados entre outras, mas que não preencham os requisitos para participar de autoria, devem constar dos "Agradecimentos" desde que haja permissão expressa dos nomeados. Também podem constar desta parte agradecimentos a instituições pelo apoio econômico, material ou outros.

Referências - - As referências devem ser ordenadas alfabeticamente, numeradas e normalizadas de acordo com o estilo Vancouver. Os títulos de periódicos devem ser referidos de forma abreviada, de acordo com o Index Medicus, e grifados.

Publicações com 2 autores até o limite de 6 citam-se todos; acima de 6 autores, citase o primeiro seguido da expressão latina et al.

\section{Exemplos:}

Simões MJS, Farache Filho A. Consumo de medicamentos em região do Estado de São Paulo (Brasil), 1988. Rev. Saúde Pública 1988; 32: 79-83.

Forattini OP. Ecologia, epidemiologia e sociedade. São Paulo: EDUSP; 1992.

Laurenti R. A medida das doenças. In: Forattini, OP. Epidemiologia geral. São Paulo: Artes Médicas; 1996. p. 64-85.

Rocha JSY, Simões BJG, Guedes GLM. Assistência hospitalar como indicador da desigualdade social. Rev Saúde Pública [periódico on line] 1997; 31(5). Disponível em URL: http://www.fsp.usp.br/ rsp [1998 mar 23].

Para outros exemplos recomendamos consultar o documento "Uniform Requirements for Manuscripts Submitted to Biomedical Journals: Writing and Editing for Medical Publication" (http://www.icmje.org).

Referências a comunicação pessoal, trabalhos inéditos ou em andamento e artigos submetidos à publicação não devem constar da listagem de Referências. Quando essenciais, essas citações podem ser feitas no rodapé da página do texto onde foram indicadas. Referências a documento de difícil acesso, em geral de divulgação circunscrita a uma instituição, a um evento e a outros similares, não devem ser citadas; quando imprescindível, podem figurar no rodapé da página que as cita. Da mesma forma, informações citadas no texto, extraídas de monografias ou de artigos eletrônicos, não mantidos permanentemente em sites, não devem fazer parte da lista de referências, mas podem ser citadas no rodapé das páginas que as citam.

A identificação das referências no texto, nas tabelas e figuras deve ser feita por número arábico, correspondendo à respectiva numeração na lista de referências. Esse número deve ser colocado em expoente, podendo ser acrescido do nome(s) do(s) do(s) autor(es) e ano da publicação. Se forem dois autores, citam-se ambos ligados pela conjunção "e"; se forem mais de três, cita-se o primeiro autor seguida da expressão "et al". 


\section{Exemplo:}

Terris et $\mathrm{al}^{8}$ (1992) atualiza a clássica definição de saúde pública elaborada por Winslow.

O fracasso do movimento de saúde comunitária, artificial e distanciado do sistema de saúde predominante parece evidente..$^{9,12,15}$.

\section{A exatidão das referências constantes da listagem e a correta citação no texto} são de responsabilidade do(s) autor(es) do manuscrito.

Tabelas ^ - Devem ser apresentadas separadas do texto, numeradas consecutivamente com algarismos arábicos, na ordem em que foram citadas no texto. A cada uma deve-se atribuir um título breve, não se utilizando traços internos horizontais ou verticais. As notas explicativas devem ser colocadas no rodapé das tabelas e não no cabeçalho ou título. Se houver tabelas extraídas de outros trabalhos, previamente publicados, os autores devem providenciar permissão, por escrito, para a reprodução das mesmas. Esta autorização deve acompanhar os manuscritos submetidos à publicação. Tabelas consideradas adicionais pelo Editor não serão publicadas, mas poderão ser colocadas à disposição dos leitores, pelos respectivos autores, mediante nota explicativa.

Quadros são identificados como Tabelas, seguindo uma única numeração em todo o texto.

Figuras - - As ilustrações (fotografias, desenhos, gráficos etc.), devem ser citadas como figuras. Devem ser numeradas consecutivamente com algarismos arábicos, na ordem em que foram citadas no texto; devem ser identificadas fora do texto, por número e título abreviado do trabalho; as legendas devem ser apresentadas ao final da figura; as ilustrações devem ser suficientemente claras para permitir sua reprodução, com resolução mínima de 300 dpi.. Não se permite que figuras representem os mesmos dados de Tabela. Não se aceitam gráficos apresentados com as linhas de grade, e os elementos (barras, círculos) não podem apresentar colume (3D). Figuras coloridas são publicadas excepcionalmente, e os custos de impressão são de responsabilidade do(s) autor (es) do manuscrito. Nas legendas das figuras, os símbolos, flechas, números, letras e outros sinais devem ser identificados e seu significado esclarecido. Se houver figuras extraídas de outros trabalhos, previamente publicados, os autores devem providenciar permissão, por escrito, para a reprodução das mesmas. Estas autorizações devem acompanhar os manuscritos submetidos à publicação.

Abreviaturas e Siglas - - Deve ser utilizada a forma padrão. Quando não o forem, devem ser precedidas do nome completo quando citadas pela primeira vez; quando aparecem nas tabelas e nas figuras devem ser acompanhadas de explicação quando seu significado não for conhecido. Não devem ser usadas no título e no resumo e seu uso no texto deve ser limitado. 


\title{
Anexo 4 - Normas para publicação no periódico Cadernos de Saúde Pública
}

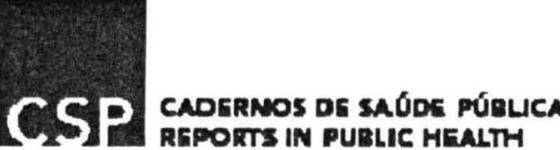

instruções para os autores

Cadernos de Saúde Pública/Reports in Public Health (CSP) publica artigos originais que contribuam ao estudo da saúde pública em geral e disciplinas afins, como epidemiologia, nutrição, parasitologia, ecologia e controle de vetores, saúde ambiental, políticas públicas e planejamento em saúde, ciências sociais aplicadas à saúde, dentre outras.

Serão aceitos trabalhos para as sequintes seções: (1) Revisão - revisão crítica da literatura sobre temas pertinentes à saúde pública (máximo de 8.000 palavras); (2) Artigos - resultado de pesquisa de natureza empírica, experimental ou conceitual (máximo de 6.000 palavras); (3) Notas - nota prévia, relatando resultados parciais ou preliminares de pesquisa (máximo de 1.700 palavras); (4) Resenhas - resenha crítica de livro relacionado ao campo temático de CSP, publicado nos últimos dois anos (máximo de 1.200 palavras); (5) Cartas - crítica a artigo publicado em fascículo anterior de CSP ou nota curta, relatando observações de campo ou laboratório (máximo de 1.200 palavras); (6) Debate - artigo teórico que se faz acompanhar de cartas críticas assinadas por autores de diferentes instituições, convidados pelo Editor, seguidas de resposta do autor do artigo principal (máximo de 6.000 palavras); (7) Fórum - seção destinada à publicação de 2 a 3 artigos coordenados entre si, de diferentes autores, e versando sobre tema de interesse atual (máximo de 12.000 palavras no total).

O limite de palavras inclui texto e referências bibliográficas (folha de rosto, resumos e ilustrações serão considerados à parte).

\section{Apresentação do texto}

Serão aceitas contribuições em português, espanhol ou inglês. O original deve ser apresentado em espaço duplo e submetidos em 1 via, fonte Times New Roman, tamanho 12, com margens de $2,5 \mathrm{~cm}$. Deve ser enviado com uma página de rosto, onde constará título completo (no idioma original e em inglês) e título corrido, nome(s) do(s) autor(es) e da(s) respectiva(s) instituição(ões) por extenso, com endereço completo apenas do autor responsável pela correspondência. Todos os artigos deverão ser encaminhados acompanhados de disquete ou $C D$ contendo o arquivo do trabalho e indicação quanto ao programa e à versão utilizada (somente programas compatíveis com Windows). Notas de rodapé não serão aceitas. É imprescindível o envio de carta informando se o artigo está sendo encaminhado pela primeira vez ou sendo reapresentado à nossa secretaria.

No envio da segunda versão do artigo deverá ser encaminhada uma cópia impressa do mesmo, acompanhadas de disquete.

\section{Colaboradores}

Deverão ser especificadas, ao final do texto, quais foram as contribuições individuais de cada autor na elaboração do artigo.

\section{Ilustrações}

As figuras deverão ser enviadas em impressão de alta qualidade, em preto-e-branco e/ou diferentes tons de cinza e/ou hachuras. Os custos adicionais para publicação de figuras em cores serão de total responsabilidade dos autores.

É necessário o envio dos gráficos, separadamente, em arquivos no formato WMF (Windows Metafile) e no formato do programa em que foram gerados (SPSS, Excel, Harvard Graphics etc.), acompanhados de seus parâmetros quantitativos, em forma de tabela e com nome de todas as variáveis. Também é necessário o envio de mapas no formato WMF, observando que os custos daqueles em cores serão de responsabilidade dos autores. Os mapas que não forem gerados em meio eletrônico devem ser encaminhados em papel branco (não utilizar papel vegetal). As fotografias serão impressas em preto-e-branco e os originais poderão ser igualmente em preto-e-branco ou coloridos, devendo ser enviados em papel fotográfico no formato $12 \times 18 \mathrm{~cm}$.

O número de tabelas e/ou figuras deverá ser mantido ao mínimo (máximo de cinco tabelas e/ou figuras). Os autores deverão arcar com os custos referentes ao material ilustrativo que ultrapasse este limite.

\section{Resumos}

Com exceção das contribuições enviadas às seções Resenha ou Cartas, todos os artigos submetidos em português ou espanhol deverão ter resumo na língua principal e em inglês. Os artigos submetidos em inglês 
deverão vir acompanhados de resumo em português ou em espanhol, além do abstract em inglês. Os resumos não deverão exceder o limite de 180 palavras e deverão ser acompanhados de 3 a 5 palavraschave.

\section{Nomenclatura}

Devem ser observadas rigidamente as regras de nomenclatura zoológica e botânica, assim como abreviaturas e convenções adotadas em disciplinas especializadas.

\section{Pesquisas envolvendo seres humanos}

A publicação de artigos que trazem resultados de pesquisas envolvendo seres humanos está condicionada ao cumprimento dos princípios éticos contidos na Declaração de Helsinki (1964, reformulada em 1975, 1983, 1989, 1996 e 2000), da World Medical Association (http://www.wma. net/e/policy/b3.htm), além do atendimento a legislações específicas (quando houver) do pais no qual a pesquisa foi realizada. Artigos que apresentem resultados de pesquisas envolvendo seres humanos deverão conter uma clara afirmação deste cumprimento (tal afirmação deverá constituir o último parágrafo da seção Metodologia do artigo). Após a aceitação do trabalho para publicação, todos os autores deverão assinar um formulário, a ser fornecido pela Secretaria Editorial de CSP, indicando o cumprimento integral de princípios éticos e legislações específicas.

\section{Referências}

As referências devem ser numeradas de forma consecutiva de acordo com a ordem em que forem sendo citadas no texto. Devem ser identificadas por números arábicos sobrescritos (Ex.: Silva ${ }^{1}$ ). As referências citadas somente em tabelas e figuras devem ser numeradas a partir do número da última referência citada no texto. As referências citadas deverão ser listadas ao final do artigo, em ordem numérica, seguindo as normas gerais dos Requisitos Uniformes para Manuscritos Apresentados a Periódicos Biomédicos (http://www.icmie.org).

Todas as referências devem ser apresentadas de modo correto e completo. A veracidade das informações contidas na lista de referências é de responsabilidade do(s) autor(es).

\section{Exemplos}

\section{Artigos de periódicos}

\section{- Artigo padrão}

Até 6 autores:

Barbosa FS, Pinto R, Souza OA. Control of schistosomiasis mansoni in a small north east Brazilian community. Trans R Soc Trop Med Hyg 1971; 65:206-13.

Mais de 6 autores:

DeJong RJ, Morgan JA, Paraense WL, Pointier JP, Amarista M, Ayeh-Kumi PF, et al. Evolutionary relationships and biogeography of Biomphalaria (Gastropoda: Planorbidae) with implications regarding its role as host of the human bloodfluke, Schistosoma mansoni. Mol Biol Evol 2001; 18:2225-39.

\section{- Instituição como autor}

The Cardiac Society of Australia and New Zealand. Clinical exercise stress testing. Safety and performance guidelines. Med J Aust 1996; 116:41-2.

\section{- Sem indicação de autoria}

Cancer in South Africa [Editorial]. S Afr Med J 1994; 84:15.

\section{- Volume com suplemento}

Deane LM. Simian malaria in Brazil. Mem Inst Oswaldo Cruz 1992; 87 Suppl 3:1-20.

\section{- Fascículo com suplemento}

Lebrão ML, Jorge MHPM, Laurenti R. Hospital morbidity by lesions and poisonings. Rev Saúde Pública 1997; 31 (4 Suppl):26-37.

\section{- Parte de um volume}

Ozben T, Nacitarhan S, Tuncer N. Plasma and urine sialic acid in non-insulin dependent diabetes mellitus. Ann Clin Biochem 1995; 32(Pt 3):303-6.

\section{- Parte de um fascículo}

Poole GH, Mills SM. One hundred consecutive cases of flap lacerations of the leg in aging patients. N Z Med J 1994; 107 (986 Pt 1):377-8.

\section{Livros e outras monografias}

- Indivíduo como autor

Barata RB. Malária e seu controle. São Paulo: Editora Hucitec; 1998.

\section{- Editor ou organizador como autor}


Duarte LFD, Leal OF, organizadores. Doença, sofrimento, perturbação: perspectivas etnográficas. Rio de Janeiro: Editora Fiocruz; 1998.

Denzin NK, Lincoln YS, editors. Handbook of qualitative research. Thousand Oaks: Sage Publications; 1994.

\title{
- Instituição como autor e publicador
}

Institute of Medicine. Looking at the future of the Medicaid programme. Washington DC: Institute of Medicine; 1992.

- Capítulo de livro

Coelho PMZ. Resistência e suscetibilidade à infecção por Schistosoma mansoni em caramujos do gênero Biomphalaria. In: Barbosa FS, organizador. Tópicos em malacologia médica. Rio de Janeiro: Editora Fiocruz; 1995. p. 208-18.

- Eventos (anais de conferências)

Kimura J, Shibasaki H, editors. Recent advances in clinical neurophysiology. Proceedings of the $10^{\text {th }}$ International Congress of EMG and Clinical Neurophysiology; 1995 Oct 15-19; Kyoto; Japan. Amsterdam: Elsevier; 1996

- Trabalho apresentado em evento

Bengtson S, Solheim BG. Enforcement of data protection, privacy and security in medical informatics. In: Lun KC, Degoulet $P$, Piemme TE, Rienhoff O, editors. MEDINFO 92. Proceedings of the $7^{\text {th }}$ World Coangress on Medical Informatics; 1992 Sep 6-10; Geneva, Switzerland. Amsterdam: North Holland; 1992. p. 1561-5.

\section{- Dissertação e tese}

Escobar AL. Malária no sudoeste da Amazônia: uma meta-análise [Dissertação de Mestrado]. Rio de Janeiro: Escola Nacional de Saúde Pública, Fundação Oswaldo Cruz; 1994.

\section{Outros trabalhos publicados}

\section{- Artigo de jornal}

Novas técnicas de reprodução assistida possibilitam a maternidade após os 40 anos. Jornal do Brasil 2004; 31 jan.

Lee G. Hospitalizations tied to ozone pollution: study estimates 50,000 admissions annually. The

Washington Post 1996; 21 jun.

\section{- Documentos legais}

Decreto no. 1.205. Aprova a estrutura regimental do Ministério do Meio Ambiente e da Amazônia Legal, e dá outras providências. Diário Oficial da União 1995; 2 ago.

\section{Material eletrônico}

- CD-ROM

La salud como derecho ciudadano [CD-ROM]. Memoria del VI Congreso Latinoamericano de Ciencias Sociales y Salud. Lima: Universidad Peruana Cayetano Heredia; 2001.

\section{- Internet}

Fundação Instituto Brasileiro de Geografia e Estatística. Estatísticas da saúde: assistência médico-sanitária. http://www.ibge.gov.br (acessado em 05/Fev/2004).

\author{
Cadernos de Saúde Pública \\ Rua Leopoldo Bulhões 1480 \\ Rio de Janeiro RJ 21041-210 Brasil \\ cadernos@enso.flecruzbr \\ (c) 2007 Escola Nacional de Saúde Pública Sergio Arouca, Fundação Oswaldo Cruz.
}


Anexo 5 - Normas para publicação no periódico Saúde e Sociedade

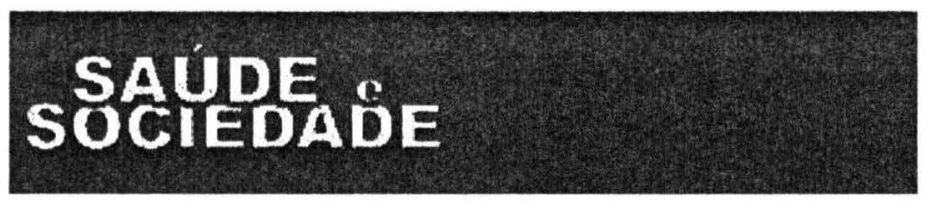

\section{INSTRUÇÕES PARA PUBLICAÇÃO DE TRABALHOS}

Saúde e Sociedade publica matéria inédita de natureza reflexiva, de pesquisa e atualização do conhecimento, sob a forma de: artigos de pesquisa e de atualização; análise de grandes temas; ensaios de natureza teórica metodológica e técnica. Publica, também relatos de experiência; biografias, entrevistas e depoimentos. São particularmente valorizados artigos que façam interface da saúde com a área de humanas.

Os trabalhos devem estar redigidos em português, espanhol, inglês ou francês, ficando os textos sob inteira responsabilidade dos autores, não refletindo obrigatoriamente a opinião do Corpo Editorial.

\section{Do ineditismo do material}

O conteúdo dos artigos enviados para publicação não pode ter sido publicado anteriormente ou encaminhado simultaneamente a outro periódico. Os artigos publicados na Saúde e Sociedade, para serem publicados em outros locais, ainda que parcialmente, necessitam de aprovação por escrito por parte dos Editores.

\section{Da seleção de artigos e revisão por pareceristas}

$\mathrm{Na}$ seleção de artigos para publicação, avalia-se o mérito científico do trabalho e sua adequação às normas editoriais adotadas pela revista. Nos trabalhos de investigação envolvendo seres humanos deve ser explicitada a aprovação do Comitê de Ética em Pesquisa da Instituição onde foi realizada a pesquisa.

Saúde e Sociedade submete todos os originais à apreciação da Comissão Editorial apoiado por consultores ad hoc, que dispõem de autoridade para decidir sobre a conveniência de sua aceitação, podendo inclusive reapresentá-los aos autores, com sugestões de alterações. Cada trabalho será apreciado por no mínimo dois relatores, cujos nomes serão mantidos em sigilo, omitindo-se também o(s) nome(s) do(s) autor(es) perante os relatores.

\section{Carta de apresentação}

Os trabalhos deverão vir acompanhados de uma carta do(s) autor(es), autorizando sua publicação na revista, declarando não haver conflito de interesses. Todos os autores devem assinar a carta enviada aos editores, porém apenas um deve ser identificado como responsável para troca de correspondência, fornecendo o endereço completo (incluir CEP), telefone, fax e correio eletrônico para contato.

\section{Envio do material aos editores}

Os trabalhos deverão ser enviados em disquete ou CD acompanhados de três cópias em papel, para o seguinte endereço: Saúde e Sociedade, Av Dr. Arnaldo 
715 - Prédio da Biblioteca - Espaço Editorial - Sala 2, CEP: 01246 904, São Paulo, SP, Brasil.

\section{Da apresentação dos originais Formato}

Papel tamanho A4, margens de 2,5 cm, espaço 1,5, letra Times New Roman 12. Número máximo de páginas: 20 (incluindo ilustrações e referências bibliográficas).

\section{Estrutura}

Título: Conciso e informativo. Na língua original e em inglês. Incluir como nota de rodapé a fonte de financiamento da pesquisa.

Nome e endereço do(s) autor(es): todos devem informar maior grau acadêmico; cargo; afiliação institucional; endereço completo incluindo rua, cidade, CEP, estado, país, e-mail.

Resumos: Devem refletir os aspectos fundamentais dos trabalhos, com no mínimo 150 palavras e no máximo 250, incluindo metodologia e resultados. Devem preceder o texto e estar na língua do texto e em inglês (abstract).

Palavras-chave: De 3 a 6 , na língua do texto e em inglês, apresentados após 0 resumo. Consulte o DeCS (Descritores em Ciências da Saúde) e/ou o Sociological Abstracts.

Gráficos e tabelas: Os gráficos e tabelas devem ser apresentados em seus programas originais (por exemplo, em Excel: arquivo.xls), devidamente identificados, em escala de cinza.

Imagens: As imagens (figuras e fotografias) devem ser fornecidas em alta resolução ( $300 \mathrm{dpi}$ ), em JPG ou TIF, com no mínimo $8 \mathrm{~cm}$ de largura.

Citações no texto: Devem ser feitas pelo sobrenome do autor (letra minúscula), ano de publicação e número de página quando a citação for literal, correspondendo às respectivas referências bibliográficas. Quando houver mais de dois autores, deve ser citado o primeiro, seguido de "e col".

\section{Referências}

Os autores são responsáveis pela exatidão das referências bibliográficas citadas no texto. As referências deverão seguir as normas da ABNT NBR 6023, serem apresentadas ao final do trabalho e ordenadas alfabeticamente pelo sobrenome do primeiro autor. A seguir alguns exemplos (mais detalhes no site da revista):

\section{- Livro}

MINAYO, M. C. de S.; e DESLANDES, S. F. (Org). Caminhos do pensamento: epistemologia e método. Rio de Janeiro: Fiocruz, 2002.

\section{- Capítulo de Livro}

GOTLIEB, S. L. D.; LAURENTI, R.; MELLO JORGE, M. H. P. Crianças, adolescentes e jovens do Brasil no fim do século XX. In: WESTPHAL, M. F. Violência e criança. São Paulo: EDUSP, 2002. p. 45-72.

\section{- Artigo de Periódico}

TEIXEIRA, J. J. V.; LEFÈVRE, F. A prescrição de medicamentos sob a ótica do paciente idoso. Revista de Saúde Pública, São Paulo, v.35, n.2, p. 207-213, abr. 2001.

\section{- Tese}

LIMA, R. T. Condições de nascimento e desigualdade social. São Paulo, 2001. Tese (Doutorado em Saúde Pública) - Faculdade de Saúde Pública, Universidade de São Paulo, 2001.

\section{- Documentos Eletrônicos}

SALES, A. C. C. L. Conversando sobre educação sexual. Disponível em: <http://www.violenciasexual. org/textos/pdf/conversando ed sexual ana carla.pdf> Acesso em: 13 jan. 2003. 


\title{
Anexo 6 - Termo de consentimento livre e esclarecido TERMO DE CONSENTIMENTO LIVRE E ESCLARECIDO
}

\author{
Carta para obtenção do consentimento livre e esclarecido
}

\section{Cara Senhora}

Eu, Benedito Carlos Cordeiro, (professor universitário), pesquisador da Universidade do Vale do Itajaí, situada à Rua Uruguai, 458 - Itajaí - SC, telefone 47-33417500, RG 422 673, vou desenvolver uma pesquisa cujo título é: "A atenção farmacêutica e o programa de saúde da família: uma associação possível na melhoria do atendimento às gestantes soropositivas no município de Itajaí (SC)", orientado pela Profa. Dra, Nicolina Silvana Romano-Lieber, RG . O objetivo deste estudo é de utilizar o seguimento farmacoterapêutico em gestantes soropositivas atendidas pelo Programa de Saúde da Família de Itajaí (SC) ou no Hospital-Dia de Itajaí e necessito que a Sra. forneça informações à respeito do seu tratamento contra a transmissão do vírus HIV.

Sua participação nesta pesquisa é voluntária, sem sofrer qualquer risco. Ela proporcionará um melhor conhecimento à respeito da utilização da terapia antiretroviral e dos problemas resultantes de sua utilização (PRMs), como adesão e identificação de possíveis eventos adversos, que poderão beneficiar a si mesma ou no futuro outras pessoas. Não existe outra forma de obter dados com relação ao procedimento em questão e que possa ser mais vantajoso.

Informo que a Sra. tem a garantia de acesso, em qualquer etapa do estudo, sobre qualquer esclarecimento de eventuais dúvidas, podendo, caso sinta necessidade, entrar em contato com o Comitê de Ética em Pesquisa (CEP) da Universidade do Vale do Itajar, no endereço e telefone citados acima.

Também é garantida a liberdade da retirada de consentimento a qualquer momento e deixar de participar do estudo, sem qualquer prejuízo.

Garanto que as informaçס̃es obtidas serão analisadas em conjunto com outros pacientes, não sendo divulgada a identificação de nenhum dos participantes.

A Sra. tem o direito de ser mantida atualizada sobre os resultados parciais das pesquisas e caso seja solicitado, darei todas as informações que solicitar.

Não existirá despesas ou compensações financeiras pessoais para o participante em qualquer fase do estudo, incluindo exames e consultas.

Eu me comprometo a utilizar os dados coletados somente para pesquisa e os resultados serão veiculados através de artigos científicos em revistas especializadas e/ou em encontros científicos e congressos, sem nunca tornar possível sua identificação.

Este termo está sendo elaborado em duas vias, sendo que uma via ficará com a Sra. e outra arquivada com os pesquisadores responsáveis.

Abaixo está o consentimento livre e esclarecido para ser assinado caso não tenha ficado qualquer dúvida.

Caso queira, a Sra. poderá tirar outras dúvidas com o Comitê de Ética da Faculdade de Saúde Pública (FSP/USP), no endereço Av. Dr. Arnaldo, 715. CEP: 01246-904. São Paulo - SP, ou pelo telefone: 0 XX 11 30667779, ou ainda pelo e-mail: coep@ fsp.usp.br 


\section{Termo de Consentimento Livre e Esclarecido}

Acredito ter sido suficientemente informada à respeito das informações que li ou que foram lidas para mim, descrevendo o estudo "A atenção farmacêutica e o programa de saúde da família: uma associação possível na melhoria do atendimento às gestantes soropositivas no município de Itajaí (SC)".

Estou ciente de que:

- O serviço prestado é gratuito;

- Este serviço de atenção farmacêutica não inclui: anamnese, diagnóstico ou prognóstico, prescrição, modificação de regimes de dosificação ou de recomendações prescritas pelo médico;

- Este serviço inclui: seguimento dos tratamentos farmacológicos; a busca, encontro e documentação de Problemas Relacionados com Medicamentos (PRMs), informe ao paciente sobre os PRMs, com tentativa de resolução destes e, caso necessário, informe ao prescritor sobre o PRM.

Eu discuti com Benedito Carlos Cordeiro, farmacêutico e professor universitário, sobre a minha decisão em participar nesse estudo. Ficaram claros para mim quais são os propósitos do estudo, os procedimentos a serem realizados, seus desconfortos e riscos, as garantias de confidencialidade e de esclarecimentos permanentes.

Ficou claro também que tenho garantia do acesso aos resultados e de esclarecer minhas dúvidas a qualquer tempo. Concordo voluntariamente em participar deste estudo e poderei retirar 0 meu consentimento a qualquer momento, antes ou durante o mesmo, sem penalidade ou prejuízo ou perda de qualquer benefício que eu possa ter adquirido.

Assinatura da entrevistada

Data

Nome:

Endereço:

RG.

Fone: ( )

Assinatura do(a) pesquisador(a)

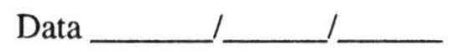




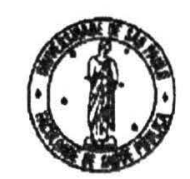

Universidade de São Paulo

Faculdade de Saúde Pública

COMTTE DE ÉTICA - COEP

Av. Dr. Arnaldo, 715 - Assessoria Acadermica . CEP $01246-904$ - São Paulo - Brasil Tclefoncs: (55-11) 3066-7779 - e-mail: coesp@spreusp br

\section{Of.COEP/55/06}

23 de fevereiro de 2006

Pelo presente, informo que o Comité de Ética em Pesquisa da Faculdade de Saúde Pública da Universidade de São Paulo-COEP analisou a aprovou com recomendaçāo, em sua 2.\%/06 Sessāo Extraordinária, realizada em 22.02.06, de acordo com os requisitos da Resoluçáo CNS/196/96 e suas complementares, o Protocolo de Pesquisa n. ${ }^{\circ}$ 1436, intitulado: "A ATENÇÄO FARMACÊUTICA E O PROGRAMA DE SAÚdE DA FAMÍLJA: UMA ASSOCIAÇÄO POSSIVEL NA MELHORIA DO ATENDIMENTO ÀS GESTANTES SOROPOSITIVAS NO MUNICÍPIO DE ITAJAÍ - SC", apresentado pelo pesquisador Benedito Carlos Cordeiro.

O Comitê recomenda que o pesquisador atenda às seguintes recomendaçōes:

a) identificar na Folha de Rosto o cargo do responsável pela Instituiçáo onde a pesquisa será realizada;

b) no Termo de Consentimento Livre e Esclarecido, acrescentar os dados para contato do Comitê de Étlca da Faculdade de Saúde Pública, bem como, o n. ${ }^{\circ}$ do RG do pesquisador e do orientador.

Atenciosamente,

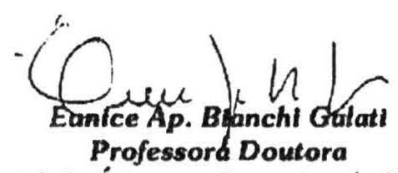

Coordenadora do Comitê de Ética em Pesquitsa da FSP - COEP 
Anexo 8. Cópia do trabalho apresentado no II Congresso de Uso Racional de Medicamentos
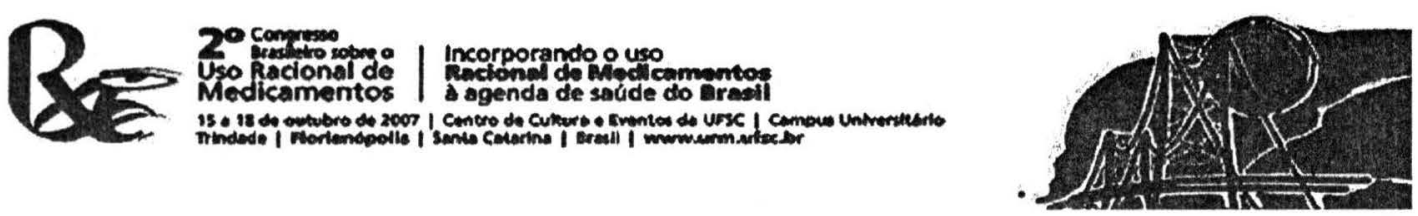

\section{ATENÇÃO FARMACÊUTICA E ADESÃO À TERAPIA ANTI- RETROVIRAL (TARV) DE GESTANTES HIV POSITIVAS (HIV+) EM ITAJAÍ, SC}

Número: 80

Autores: "CORDEIRO, B. C.; ROMANO-LIEBER, N. S.

Instituição: UNIVALI - Universidade do Vale do Itajaí

Localidade: Itajaí - SC

Categoria: Seleção, prescrição e/ou dispensação de medicamentos Idioma: Português

\section{Resumo}

Introdução. A adesão à terapêutica, considerada essencial no uso racional de medicamentos, é ainda mais importante quando do tratamento de doenças infecciosas como a AIDS. Neste caso

em particular, sabe-se que a utilização dos anti-retrovirais (ARV), dentro dos parâmetros adequados, pode reduzir drasticamente a morbi-mortalidade relacionada à esta síndrome e dificultar o aparecimento da resistência viral a estes medicamentos. Especialmente no caso das gestantes HIV + a utilização adequada de ARV é de fundamental importância, pois além de protegerem a si mesmas ainda impedem que aconteça a transmissão vertical do vírus para seus filhos. Objetivo. Avaliar a adesão das gestantes HIV+à TARV antes e depois de seguimento farmacoterapêutico. Método. De um total de 37 gestantes HIV+ que procuraram atendimento no Hospital-Dia de Itajaí, entre julho de 2006 e janeiro de 2007, 32 foram convidadas e aceitaram ser acompanhadas (Método Dáder). Duas não puderam ser contactadas e outras 3 não aceitaram

fazer parte do estudo. Estas 32 gestantes foram seguidas no período de julho de 2006 a julho de 2007, com tempo de acompanhamento variando entre 01 e 27 ou mais semanas. Passado aproximadamente um mês do início da TARV, estas mulheres eram entrevistadas quanto à adesão, usando-se para isso o Simplified Medication Adherence Questionnaire (SMAQ), instrumento derivado daquele proposto por Moriski et al. Passadas aproximadamente 12 semanas, estas mesmas mulheres eram entrevistadas novamente, utilizando o mesmo método. Resultados. Das 32 mulheres, verificou-se que $13(40,63 \%)$ aderiam à TARV na primeira entrevista contra $19(59,37 \%)$ que não aderiam. Seguidas pelo método Dáder, na segunda vez em que responderam o instrumento verificou-se que 18 gestantes $(56,3 \%)$ passaram a aderir à terapia contra $6(18,8 \%)$ que não aderiam (para outras 8 gestantes não foi possível aplicar novamente o questionário, pois tiveram seu filho antes da nova entrevista). Discussão/conclusão.

Verificou-se um aumento na adesão à TARV das gestantes HIV+ pesquisadas, mas,

considerando que o seguimento era feito no próprio Hospital-Dia, não se pode afirmar que o Seguimento Farmacoterapêutico seja o único responsável por esta mudança na atitude das gestantes, uma vez que estas mulheres apresentaram, entre outros fatores, um aumento de préconsultas de enfermagem e consultas médicas. Pode-se afirmar, entretanto, que o Seguimento Farmacoterapêutico, junto com estas outras variáveis, desempenhou um importante papel para a adesão à TARV nestas gestantes, caracterizando a importância do trabalho multiprofissional para a consecução de um objetivo comum. 